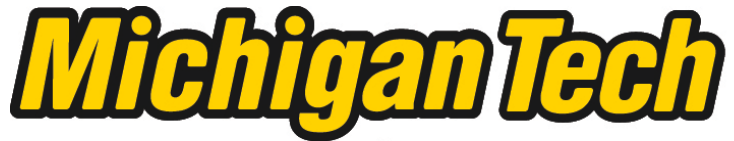 \\ Michigan Technological University Create the Future Digital Commons @ Michigan Tech
}

2009

Decentralized or centralized production : impacts to the environment, industry, and the economy

Abigail R. Clarke-Sather

Michigan Technological University

Follow this and additional works at: https://digitalcommons.mtu.edu/etds

Part of the Mechanical Engineering Commons

Copyright 2009 Abigail R. Clarke-Sather

\section{Recommended Citation}

Clarke-Sather, Abigail R., "Decentralized or centralized production : impacts to the environment, industry, and the economy", Dissertation, Michigan Technological University, 2009.

https://doi.org/10.37099/mtu.dc.etds/355

Follow this and additional works at: https://digitalcommons.mtu.edu/etds

Part of the Mechanical Engineering Commons 


\title{
DECENTRALIZED OR CENTRALIZED PRODUCTION:
}

\section{IMPACTS TO THE ENVIRONMENT, INDUSTRY, AND THE ECONOMY}

\author{
By
}

\section{ABIGAIL R. CLARKE-SATHER}

B.A. Physics, Earlham College, 2004

M.S.M.E., Michigan Technological University, 2006

A DISSERTATION

Submitted in partial fulfillment of the requirements for the degree of

\section{DOCTOR OF PHILOSOPHY}

Mechanical Engineering-Engineering Mechanics

Department of Mechanical Engineering - Engineering Mechanics Michigan Technological University

2009

Copyright (C) Abigail R. Clarke-Sather 2009 



\section{MICHIGAN TECHNOLOGICAL UNIVERSITY \\ DEPARTMENT OF MECHANICAL ENGINEERING - ENGINEERING MECHANICS}

WE HEREBY RECOMMEND THAT THIS DISSERTATION BY Abigail R. Clarke-Sather

ENTITLED

Decentralized or Centralized Production:

Impacts to the Environment, Industry, and the Economy

\begin{tabular}{l} 
BE APPROVED IN PARTIAL FULFILLMENT OF THE \\
REQUIREMENTS \\
FOR THE DEGREE OF \\
Doctor of Philosophy in Mechanical Engineering-Engineering Mechanics \\
\hline
\end{tabular}

\begin{tabular}{lc}
\hline Dissertation Advisor: Dr. John W. Sutherland & Date \\
\hline Dissertation Advisor: Dr. Qiong Zhang & Date \\
& \\
\hline Department Chair: Dr. William W. Predebon & Date
\end{tabular}

\section{Committee on Final Examination}

Dr. John W. Sutherland (Chair, Mech. Eng.-Eng. Mechs.)

Dr. Qiong Zhang (Co-Chair, Civil \& Environmental Engineering)

Dr. David R. Shonnard (Chemical Engineering)

Dr. John K. Gershenson (Mech. Eng.-Eng. Mechs.)

Dr. James Frendeway (School of Technology) 



\title{
Decentralized or Centralized Production: Impacts to the Environment, Industry, and the Economy
}

\author{
Abigail R. Clarke-Sather \\ Department of Mechanical Engineering-Engineering Mechanics \\ Michigan Technological University, 2009
}

\begin{abstract}
Since product take-back is mandated in Europe, and has effects for producers worldwide including the U.S., designing efficient forward and reverse supply chain networks is becoming essential for business viability. Centralizing production facilities may reduce costs but perhaps not environmental impacts. Decentralizing a supply chain may reduce transportation environmental impacts but increase capital costs. Facility location strategies of centralization or decentralization are tested for companies with supply chains that both take back and manufacture products.

Decentralized and centralized production systems have different effects on the environment, industry and the economy. Decentralized production systems cluster suppliers within the geographical market region that the system serves. Centralized production systems have many suppliers spread out that meet all market demand. The point of this research is to help further the understanding of company decision-makers
\end{abstract}


about impacts to the environment and costs when choosing a decentralized or centralized supply chain organizational strategy. This research explores; what degree of centralization for a supply chain makes the most financial and environmental sense for siting facilities; and which factories are in the best location to handle the financial and environmental impacts of particular processing steps needed for product manufacture.

This research considered two examples of facility location for supply chains when products are taken back; the theoretical case involved shoe resoling and a real world case study considered the location of operations for a company that reclaims multiple products for use as material inputs. For the theoretical example a centralized strategy to facility location was optimal: whereas for the case study a decentralized strategy to facility location was best. In conclusion, it is not possible to say that a centralized or decentralized strategy to facility location is in general best for a company that takes back products. Each company's specific concerns, needs, and supply chain details will determine which degree of centralization creates the optimal strategy for siting their facilities. 


\section{Acknowledgements}

I would first like to gratefully acknowledge the constant support of my advisors and mentors, Dr. John W. Sutherland and Dr. Qiong (Jane) Zhang, during my graduate studies. They both have guided and encouraged me, in their own ways, to pursue many opportunities that have enriched both my professional qualifications and personal understanding of this world. This research would not have been possible without the help of Dr. John K. Gershenson, who encouraged me to pursue this research topic as my dissertation and pushed me to follow many opportunities that have helped me develop my intellect and professional skills. Additionally, the valuable input from the other members of my Ph.D. advisory committee - Dr. David R. Shonnard and Dr. James Frendeway - I have greatly appreciated.

Without financial support the completion of this research would not have been possible. I would like to thank the National Science Foundation (under grant no. DGE 0333401), American Association of University Women, Ecologic Designs Inc., and the Michigan Technological University Graduate School for their support of this research.

I would also like to thank my many mentors and colleagues who provided valuable input and support during the completion of my doctoral studies. These individuals include Jim Mihelcic, Hugh Gormann, Shalini Surynarya, Sylvia Matthews, Marilyn Vogler, Nancy Byers-Sprague, Jackie Huntoon, Margot Hutchins, Heather 
Jordan, Valerie Fuchs, Timothy Jenkins, Vishesh Kumar, Julio L. Rivera, Joan Tapani, Michelle Jarvie, Alexis Troschinetz, Xiaoli Ye, Xiaoxia Lai, and Kiran Khadke at Michigan Tech and Robert Bogatin, Davidson Lewis, Devon Ralke, Byron McCann, and Justin Maynes at Ecologic Designs.

I am grateful for my family, whom has supported me, and made it possible for me to pursue my education especially Grammer Jane Stehn, my parents, Sandy and Roger, and my sister, Melanie. So many people have supported my journey to this point, I cannot express enough thanks. I have unending gratitude to my husband, Afton, for his constant encouragement, reassurance, patience, and efforts to make me laugh. 


\section{Table of Contents}

Page

LIST OF TABLES X XI

LIST OF FIGURES T XIV

NOMENCLATURE X XII

1 Introduction 1

$1.1 \quad$ Motivation and Background 1

1.2 Problem Description 5

1.3 Dissertation Objectives 5

2 Literature Review 6

2.1 Introduction 6

$\begin{array}{lll}2.2 & \text { Supply Chains } & 7\end{array}$

2.2.1 Production decentralization and centralization 11

$\begin{array}{ll}\text { 2.2.2 Forward and reverse supply chain networks } & 12\end{array}$

2.2.3 Problems with forward and reverse supply chain analysis $\quad 19$

2.2.4 Supply chains and environmental impact 22

2.3 Environmental Impact Assessment Methods 24

$\begin{array}{lll}2.3 .1 & \text { Life cycle assessment } 24\end{array}$

$\begin{array}{lll}\text { 2.3.2 Spatial considerations } & 27\end{array}$

$\begin{array}{ll}2.3 .3 & \text { Assimilation capacity } \\ 2.30\end{array}$

2.3.4 Allocation 31

$\begin{array}{lll}2.4 & \text { Indicators } & 32\end{array}$

2.4.1 Single Parameter Indicators 34

2.4.2 Multi-Parameter Indicators 36

$\begin{array}{lll}2.4 .3 & \text { Indicator development } & 39\end{array}$

2.4.4 Problems with conventional life cycle assessment and indicators $\quad 40$

2.5 Characterizing Local Environmental Impact 41

2.5.1 Multimedia fate and transport models 45

$\begin{array}{lll}2.6 & \text { Social Sustainability } & 50\end{array}$ 
3 Production Facility Siting Policy: The Role of Companies, Governmental 54 Officials, and the Public

3.1 Business Facility Siting Decision-Making 55

3.2 Governments' Role in where Producers Choose to Locate 59

3.3 The Public's Role in Facility Siting Decisions 62

3.4 Policy Recommendations and Conclusions 66

3.5 Facility location decision-making considered in this research 68

4 Integrating the Spatial Dependence of Environmental Impact into Facility 71 Location Analysis

$\begin{array}{lll}4.1 & \text { Introduction and Background } & 72\end{array}$

4.2 Remanufacturing Facility Location Decision 76

4.3 Formulation of Indicators 81

$\begin{array}{ll}\text { 4.3.1 Global warming potential } & 81\end{array}$

4.3.2 Toxicity potential 83

$\begin{array}{lll}4.3 .3 & \text { Transport cost } & 86\end{array}$

$\begin{array}{lll}\text { 4.3.4 Fixed cost } & 86\end{array}$

4.4 Facility Siting Optimization Method 88

4.4.1 Facility siting optimization by enumeration 89

4.4.2 Facility siting optimization by Lagrangian relaxation 89

$\begin{array}{lll}4.5 & \text { Results and Discussion } & 92\end{array}$

$\begin{array}{lll}\text { 4.5.1 Indicator behavior } & 93\end{array}$

4.5.2 Minimum cost and minimum environmental impact objectives 94

4.5.3 Indicator values for minimum objectives 95

$\begin{array}{ll}\text { 4.5.4 Degree of centralization } & 96\end{array}$

4.5.5 Spatially dependent environmental impact 99

$\begin{array}{ll}\text { 4.5.6 Economies of scale } & 100\end{array}$

$\begin{array}{lll}\text { 4.5.7 Product return rate } & 101\end{array}$

$\begin{array}{ll}\text { 4.5.8 Cost and environmental indicator weights } & 103\end{array}$

4.5.9 Comparison of enumerative and Lagrangian relaxation methods 103

$\begin{array}{lll}4.6 & \text { Summary and Conclusions } & 105\end{array}$

5 Development and Weighting of Social, Environmental, and Economic 108 Indicators for a Sustainable Small/Medium Enterprise

5.1 Introduction 109

$\begin{array}{ll}\text { 5.1.1 Indicators as measure of corporate sustainability performance } & 109\end{array}$

$\begin{array}{ll}\text { 5.1.2 Methods for measuring corporate sustainability performance } & 110\end{array}$

5.1.3 Development and weighting of indicators for this research 113

$\begin{array}{lll}5.2 & \text { Weighting of Indicators } & 114\end{array}$ 
$\begin{array}{lll}\text { 5.2.1 Create PC matrices } & 115\end{array}$

$\begin{array}{lll}\text { 5.2.2 Resolve PC matrix inconsistency } & 117\end{array}$

5.2.3 Combine PC matrices of multiple decision-makers 120

$\begin{array}{ll}5.2 .4 & \text { Calculate weights } \\ 5.2 .5 & 122\end{array}$

$\begin{array}{ll}\text { 5.2.5 Review and finalize weights } & 123\end{array}$

$\begin{array}{ll}\text { 5.2.6 Summary of weighting method } & 123\end{array}$

$\begin{array}{lll}5.3 & \text { Application } & 124\end{array}$

$\begin{array}{ll}\text { 5.3.1 Indicator development } & 125\end{array}$

$\begin{array}{lll}5.4 & \text { Results } & 127\end{array}$

$\begin{array}{lll}\text { 5.4.1 Economic indicators } & 127\end{array}$

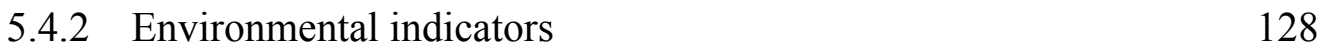

$\begin{array}{lll}5.4 .3 & \text { Social indicators } & 129\end{array}$

$\begin{array}{lll}5.4 .4 & \text { Weights } & 131\end{array}$

$\begin{array}{lll}5.5 & \text { Discussion } & 136\end{array}$

$\begin{array}{ll}5.6 & 139\end{array}$

$\begin{array}{lll}5.7 & \text { Appendix } & 141\end{array}$

6 Using Indicators of Sustainability to Find Locations to Expand Operations 144

$\begin{array}{lll}6.1 & \text { Introduction } & 144\end{array}$

$\begin{array}{ll}6.2 \text { Background } & 146\end{array}$

$\begin{array}{lll}\text { 6.2.1 } & \text { Market demand } & 147\end{array}$

$\begin{array}{ll}\text { 6.2.2 Potential new locations } & 150\end{array}$

$\begin{array}{lll}6.3 & \text { Approach } & 151\end{array}$

$\begin{array}{lll}\text { 6.3.1 Growth scenario } & 152\end{array}$

6.3.2 Formulation of indicators 153

$\begin{array}{ll}\text { 6.3.3 Calculation of indicators } & 156\end{array}$

$\begin{array}{lll}\text { 6.3.4 Problem details } & 161\end{array}$

$\begin{array}{ll}\text { 6.3.5 Solution method } & 163\end{array}$

$\begin{array}{lll}6.4 & \text { Results } & 170\end{array}$

$\begin{array}{lll}\text { 6.4.1 Dependence on scale } & 173\end{array}$

$\begin{array}{ll}\text { 6.4.2 Level of operations } & 175\end{array}$

$\begin{array}{ll}\text { 6.4.3 Building or renting facilities } & 179\end{array}$

6.4.4 Spatial dependence of environmental impact 179

$\begin{array}{ll}6.5 \text { Discussion } & 180\end{array}$

$\begin{array}{lll}6.6 & \text { Conclusions } & 183\end{array}$

7 Summary and Conclusions $\quad 184$

$\begin{array}{lll}7.1 & \text { Summary of the Dissertation } & 184\end{array}$

7.2 Conclusions from this Research 188

$\begin{array}{lll}\text { 7.2.1 Centralization and decentralization } & 190\end{array}$

\begin{tabular}{ll}
7.3 & Recommendations for Future Work \\
\hline 7.4 & 191
\end{tabular}

\begin{tabular}{ll}
7.4 & Broader Impacts of this Work \\
\hline
\end{tabular} 
REFERENCES

193

VITA

216 


\section{List of Tables}

Page

Table 2.1: Differences among forward and reverse supply chain network models

Table 2.2: $\quad$ Supply chain network models' objective functions

Table 2.3: $\quad$ Product retirement options used in various supply chain network models

Table 2.4: Variables and concepts included in supply chain network models

Table 2.5: $\quad$ Potential environmental disturbances to inventory for LCA (Brezet and van Hemel, 1997; Graedel, 1998; Guinée, 2002)

Table 2.6: $\quad$ Single parameter indicators - adapted from (Clarke and Gershenson, 2007)

Table 2.7: $\quad$ Multi-parameter indicators - adapted from (Clarke and Gershenson, 2007)

Table 2.8: $\quad$ Comparison of multimedia fate and transport models - mass transfer processes include advection (A), chemical reaction (C), diffusion $(\mathrm{D})$, non-diffusive processes $(\mathrm{N})$, and partitioning $(\mathrm{P})$

Table 3.1: $\quad$ Factors influencing producer location decisions (Chavda, 2004; Conner, 2007; Gambale et al., 2007; Seid, 2007)

Table 4.1: Average percent difference between best approximate and optimal solutions, as well as the number of iterations and CPU time for the Lagrangian Relaxation method under the different cost weight, $c w$, scenarios

Table 5.1: $\quad$ Manager d's pairwise comparison of environmental indicators 
Table 5.2: $\quad$ Corresponding $\lambda_{\max }, C R, \delta$, and $\sigma$ for environmental indicator matrices

Table 5.3: Combined responses for environmental indicators and calculated weights (in bold) $\left(\lambda_{\max }=3.0056, C R=.0054\right)$

Table 5.4: $\quad$ Combined responses for indicator categories and calculated Weights (in bold) $\left(\lambda_{\max }=3.0056, C R=.0489\right)$

Table 5.5: Calculated and revised weights for all indicators and indicator categories

Table 5.6: Consistency indices of randomly generated matrices, $R I$, by size $n \times n$ (Saaty, 1980)

Table 5.7: $\quad$ Principal eigenvalue, $\lambda_{\max }$, and consistency ratio, $C R$, for $A$ and $A$ '

Table 6.1: $\quad$ Potential metro areas for expanding Ecologic's operations

Table 6.2: Weights for economic indicators and index category, adapted from (Clarke-Sather et al., 2009a)

Table 6.3: Weights for economic indicators and index category, adapted from (Clarke-Sather et al., 2009a)

Table 6.4: $\quad$ Original and revised weights for environmental indicators and index category weights, adapted from (Clarke-Sather et al., 2009a)

Table 6.5: Allocation of markets' demand (rows) to locations (columns) for minimum solution for 6 facilities $(p=6)$ where 1 denotes allocation of demand

Table 6.6: Level of operation decision when HOU satisfies CN market demand

Table 6.7: $\quad$ Normalized environmental indicator values when HOU satisfies $\mathrm{CN}$ market demand

Table 6.8: $\quad$ Index values for HOU meeting demand from Central Market

Table 6.9: $\quad$ Sustainability index values for all locations, $p=6$ minimum solution 
Table 6.10: Level of operation by number of facilities sited, $p$, and location selected, when spatially dependent and invariant solutions differ, solutions with spatial dependence in light grey and without in black

Table 6.11: The locations that satisfies all markets' demands by number of facilities sited, $p$, when spatially dependent and invariant environmental impact solutions differ, solutions with spatial dependence in light grey and without in black 


\section{List of Figures}

Page

Figure 2.1: Traditional model of supply chain actors - material flows in black, information flows in grey, adapted from (Beamon, 1998)

Figure 2.2: Closed-loop supply chain - forward material flow solid, reverse material flow dotted, adapted from (Beamon, 1998)

Figure 2.3: Material, energy, waste, and emissions flows for a supply chain member

Figure 2.4: $\quad$ Seven echelon supply chain

Figure 2.5: Interaction between supply chain and environmental effects

adapted from (Bloemhof-Ruwaard et al., 1995; Bras, 1997; ClarkeSather et al., 2010)

Figure 2.6: $\quad$ System boundary around cradle to grave life-cycle stages

Figure 2.7: Responsible parties along the product life-cycle adapted from

(Graedel, 1998)

Figure 2.8: Comparison of indicators (single parameter or broad indicators in grey, multi-parameter or impact indicators in white) for insight gained from effort exerted - adapted from (Clarke and Gershenson, 2007)

Figure 4.1: Annual demand in pairs of shoes for each demand location (American Apparel \& Footwear Association (AAfA), 2006; U.S. Census Bureau, 2007b)

Figure 4.2: $\quad$ The 9 demand locations and potential facility sites (white circles) located within CHEMGL's 9 ecoregions (Wright et al., 2008) 
Figure 4.3: Facility sites (white) satisfying demand from demand locations (grey) for the minimum cost objective amongst all product return rates

Figure 4.4: $\quad$ Normalized indicator values (a) and indicator values as a percentage of total objective (b) as cost indicator weight decreases (for $r_{R}=100 \%$ )

Figure 4.5: Numbers of facilities sited for (a) different cost weights, $r_{R}=100 \%$ and (b) different product return rates, $c w=20 \%$ and

Figure 4.6: Allocation of demand from locations (white) to facilities (grey) for $r_{R}=50 \%$ at (a) $c w=30 \%$ and (b) $c w=20 \%$

Figure 4.7: Fixed cost and number of facilities sited as a function of product return rate for $c w=25 \%$

Figure 4.8: Objective values for different cost weights and product return rates

Figure 4.9: Number of facilities sited for the minimum objectives of the Lagrangian relaxation method by product return rate and cost weight

Figure 4.10: Objective calculated by Lagrangian relaxation method for all product return rates and cost weights

Figure 5.1: Flow chart of steps to weight indicators using pairwise comparison analysis

Figure 5.2: $\quad$ Flow chart of steps to develop indicators

Figure 5.3: Original environmental indicator matrices for all managers

Figure 5.4: Revised environmental indicator matrices for all managers

Figure 6.1: Overall structure of Ecologic's business and operations

Figure 6.2: $\quad$ Ecologic's U.S. market regions and potential facility locations (grey circles)

Figure 6.3: Distribution of demand for every 100 products sold by market -

Pacific Northwest (PW), Great Lakes (GL), Southeast (SE), Central (CN), Northeast (NE), West Coast (WC), and Rocky Mountains $(\mathrm{RM})$ - and by product line 
Figure 6.4: $\quad$ For every 100 products sold within U.S. market (as shown in Figure 6.3), reclaimed material needs in kilograms

Figure 6.5: The potential locations of operations shown relative to the 158 CHEMGL ecoregions

Figure 6.6: Minimum objective function values for spatially dependent and spatially invariant environmental impact by number of facilities sited, $p$

Figure 6.7: Locations and level of operation for minimum objective $(p=6)$ solution considering the spatial dependence of environmental impact

Figure 6.8: $\quad$ Flows of materials and product for minimum objective $(p=6)$ solution considering the spatial dependence of environmental impact

Figure 6.9: Weighted and normalized environmental indicators by $p$ for (a) spatially invariant (b) and spatially dependent toxicity potential 


\title{
Nomenclature
}

\author{
$r_{R}$ and $r_{D} \quad$ fraction of total annual demand for resoled shoes and discarded (and \\ replaced with newly manufactured) shoes respectively such that \\ $r_{D}=1-r_{R}$

$\circ \quad$ Hadamard product \\ $\lambda_{i}^{z}$ \\ $L B^{z}$ \\ $A^{\prime}$ \\ $D^{\prime}$ \\ $\alpha^{z}$ \\ $t^{z}$ \\ $a_{i j_{m}}$ \\ $\hat{I}$ \\ $\wedge$ \\ $\left(a_{i j}\right)_{\text {grouped }}$ \\ $\left(a_{i j}\right)_{k}$ \\ $a$ \\ A \\ $A_{\text {grouped }}$ \\ AIJ \\ $a_{i j}$ \\ AIP \\ $B$ \\ C \\ chem \\ $\mathrm{CN}$ \\ cw \\ $D$ \\ $d_{i j}$ \\ $e c$ \\ Lagrange multiplier for iteration $i$ \\ lower bound for objective function for iteration $\mathrm{z}$ \\ pairwise comparison matrix revised by multiplying all entries with $\gamma$ \\ revised deviation matrix with entries $D_{i j}^{\prime}$ \\ scaling factor for the $t^{z}\left(\alpha^{1}=2\right)$ \\ step decrease for changing Lagrange multiplier value \\ modified matrix entry \\ normalized indicator value \\ denotes a normalized indicator \\ grouped matrix entry in $A_{\text {grouped }}$ \\ matrix entry in pairwise comparison matrix $A$ from decision-maker $k$ \\ air boundary layer environmental compartment \\ pairwise comparison matrix \\ pairwise comparison matrices from several decision-makers grouped \\ together \\ aggregating individual judgments \\ matrix entry in pairwise comparison matrix $A$ \\ aggregating individual priorities \\ Deviation matrix with entries $B_{i j}$ \\ concentration of chemical \\ chemical of interest \\ Central \\ cost indicator weight \\ discarded \\ travel distance between a demand location $\mathrm{i}$ and a facility $\mathrm{j}$ \\ environmental compartment, where chemicals concentrate$$
\text { xix }
$$ 


\begin{tabular}{|c|c|}
\hline$E_{\text {chem }}$ & $\begin{array}{l}\text { chemical emissions rate in } \mathrm{kg} \text { of chemical emitted per } \mathrm{km} \text { traveled } \\
\text { and per kg of truckload hauled }\end{array}$ \\
\hline Econ & composite economic sustainability index \\
\hline$E F_{e c}$ & $\begin{array}{l}\text { exposure factor for a particular environmental compartment, e.g. } \\
\text { how much water on average a person ingests per day }\end{array}$ \\
\hline Env & composite environmental sustainability index \\
\hline env & subscript denotes an individual environmental indicator \\
\hline$e w$ & environmental indicator weight \\
\hline$f$ & cost of hauling a truckload of shoes one kilometer \\
\hline$F C$ & $\begin{array}{l}\text { fixed cost of producing and resoling a shoe pair for demand } \\
\text { locations at the facilities specified in } X_{i j}\end{array}$ \\
\hline FT & Fish toxicity \\
\hline$g$ & number of decision-makers \\
\hline GL & Great Lakes \\
\hline$G W P_{\text {chem }}$ & $\begin{array}{l}\text { global warming potential of chemical c per kilogram }(\mathrm{kg}) \text { chemical } \mathrm{c} \\
\text { emitted }\end{array}$ \\
\hline$G W P_{i j}$ & $\begin{array}{l}\text { global warming potential for transporting shoes demanded by } \\
\text { location } i \text { to or from facility } j \text { per year of shoe-life }\end{array}$ \\
\hline$h_{i}$ & total annual demand for shoes (in pairs) at location $\mathrm{i}$ \\
\hline$I$ & indicator value \\
\hline$i$ & demand location, i.e. market \\
\hline$I_{F T, m f r}, I_{F T, r e s}$ & $\begin{array}{l}\text { fish toxicity per shoe pair for the manufacture or resoling of a shoe } \\
\text { pair respectively }\end{array}$ \\
\hline$I_{I N G, m f r}, I_{I N G, r e s}$ & $\begin{array}{l}\text { human ingestion toxicity for the manufacture or resoling of a shoe } \\
\text { pair respectively }\end{array}$ \\
\hline$I_{I N H, m f r}, I_{I N H, r e s}$ & $\begin{array}{l}\text { human inhalation toxicity for the manufacture or resoling of a shoe } \\
\text { pair respectively }\end{array}$ \\
\hline$I_{\max }$ & maximum indicator value \\
\hline$I N G$ & Ingestion \\
\hline$I N H$ & Inhalation \\
\hline$j$ & facility site, metro area \\
\hline$k$ & a specific decision-maker \\
\hline$L C_{50}$ & lethal concentration were $50 \%$ of population of fish exposed die \\
\hline$L_{R}, L_{D}$ & lifetimes (in years) of resoled shoes and discarded shoes respectively \\
\hline & weight (mass) of truckload in $\mathrm{kg}$ \\
\hline$m f r$ & manufacturing \\
\hline$n$ & number of indicators \\
\hline $\mathrm{NE}$ & Northeast \\
\hline$N_{M}$ & number of shoe pairs per truckload \\
\hline$P C$ & pairwise comparison \\
\hline PW & Pacific Northwest \\
\hline$R$ & resoled \\
\hline
\end{tabular}




\begin{tabular}{|c|c|}
\hline $\begin{array}{l}\text { Reference } \\
\text { res }\end{array}$ & $\begin{array}{l}\text { release compartment, environmental compartment where chemicals } \\
\text { were released } \\
\text { reference chemical } \\
\text { resoling }\end{array}$ \\
\hline$R f C$ & $\begin{array}{l}\text { reference concentration, amount of chemical that can be inhaled } \\
\text { constantly without harmful effects per day }\end{array}$ \\
\hline$R f D$ & $\begin{array}{l}\text { reference dose, amount of chemical that can be ingested per day } \\
\text { without harmful effects per kilogram body weight }\end{array}$ \\
\hline $\mathrm{RM}$ & Rocky Mountains \\
\hline SE & Southeast \\
\hline SME & Small/medium enterprise \\
\hline Soc & composite social sustainability index \\
\hline Sust & the composite sustainability index \\
\hline$s w$ & surface water environmental compartment \\
\hline$T C_{i j}$ & $\begin{array}{l}\text { cost of transporting shoe pairs demanded by location } \mathrm{i} \text { to facility } \mathrm{j} \\
\text { per year of shoe-life }\end{array}$ \\
\hline$T P_{i j}$ & $\begin{array}{l}\text { toxicity indicator for production of shoe pairs demanded by location } \\
\text { i at facility } j \text { per year of shoe-life }\end{array}$ \\
\hline$U B$ & lowest upper bound for objective function over all iterations \\
\hline$V_{i j}$ & ratios of the weights, $w$, for the $(i, j)$ entry in matrix $V$ \\
\hline$w$ & column vector of weights composed of entries $w_{i}$ \\
\hline$W$ & weight \\
\hline WC & West Coast \\
\hline$W_{F T}, W_{I N G}, W_{I N H}$ & $\begin{array}{l}\text { the weights for fish toxicity, ingestion toxicity, and inhalation } \\
\text { toxicity respectively }\end{array}$ \\
\hline$X_{i j}$ & $\begin{array}{l}\text { allocation of demand from location } i \text { to facility } j \text {, if value is } 1 \text { that } \\
\text { location's demand is serviced by the facility, otherwise value is zero }\end{array}$ \\
\hline$Y_{j}$ & $\begin{array}{l}\text { existence of a facility at } j \text {, if value is } 1 \text { a facility is located at that site, } \\
\text { otherwise value is zero }\end{array}$ \\
\hline$z$ & iteration number \\
\hline$\gamma$ & $\begin{array}{l}\text { pairwise comparison matrix revision factor, valued between zero and } \\
\text { one }\end{array}$ \\
\hline$\delta$ & $\begin{array}{l}\text { maximum absolute difference between an original and revised } \\
\text { element }\end{array}$ \\
\hline$\lambda_{i}$ & Lagrange multiplier \\
\hline$\lambda$ & maximum or principal Lagrange multiplier \\
\hline 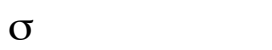 & standard deviation over all matrix elements \\
\hline
\end{tabular}





\section{Chapter 1}

\section{Introduction}

\subsection{Motivation and Background}

Manufacturers increasingly must address recovery of products at end-of-life as pressure from legislation and consumers mount. Specifically,

[t]he Waste Electrical and Electronic Equipment (WEEE) Directive makes electronic product manufacturers and retailers (including foreign producers and internet retailers) financially responsible for electronic waste motivating companies outside of the European Union to make product design changes and other countries to shun polluting practices by improving environmental legislation. (Clarke and Gershenson, 2006)

Remanufacturing is currently commercially viable for plane, train, and car engines, heavy equipment (e.g., machine tools), medical equipment, and computers (Thierry et al., 1995). Manufacturers are beginning to recognize that creating environmentally responsible products and processes decreases spending on operations and overhead, as well as prospective financial liability for environmental and human health damages (Jayaraman et al., 1999). However, certain industries have tried remanufacturing and met both success and failure. Office furniture remanufacturing had been financially successful in the past led by Herman Miller, Steelcase, and Haworth. Moving from independently owned decentralized remanufacturing facilities with low 
production volumes to centralized high production volume facilities met with far less success, perhaps due to high transportation costs and returned product management troubles (Gunter, 2004). Transportation costs and logistics have great bearing on the success of remanufacturing operations. Hence restructuring of facility locations and distribution routing strategies can make or break the economics of remanufacturing. As more industries consider remanufacturing as an attractive choice to meeting existing or looming legislative requirements, concrete strategies for facility location and distribution must be chosen in order to achieve financial viability for remanufacturing. One important consideration that motivates used product recovery is environmental impact.

Engineering ethics (and ethics guidelines) require that environmental impact become integrated into supply chain modeling and environmental excellence strived for in supply chain operations (Beamon, 2005). The effectiveness of creating many decentralized clusters of facilities is being considered because of the recognition that local customer differences between markets are important to satisfy. Retailers in part may make demographic clusters (sometimes based on geographic similarities) to better reach customers in particular markets (Rigby and Vishwanath, 2006). Co-location of manufacturing or processing facilities is also important for reaching goals of Industrial Ecology such as eco-industrial park development where facilities share (trade) wastes for use as feedstocks to other processes (Ehrenfeld and Gertler, 1997).

Corporations are perpetually choosing which approaches to processing, logistics, and product design will best meet company goals. Creating models of different potential operational scenarios can aid in business and environmental decision-making. "Models 
provide a framework for comparing the toxicity potential of industrial activities in lifecycle impact assessments comparing two or more alternative processes and their associated chemical emission scenarios (MacLeod et al., 2004)." Many different models of reverse supply chain networks consider different types of specific products and forward and reverse supply chain networks. A few models consider environmental impacts. However, the author has found no quantitatively verifiable conclusions about when to create centralized or decentralized supply chain networks for companies that take back and manufacture products. Others have identified similar needs:

Quantitative results on, e.g. combination of collection and distribution in closed-loop networks or integration of facilities would be helpful for a better understanding of product recovery networks. Guidelines as to which activities to combine or to separate and an assessment of the transportation impact of product recovery would be valuable contributions. (Fleischmann et al., 2000)

Many researchers have investigated supply chain design in order to minimize cost by suggesting changes in locations of production systems. This research will evaluate the impact of "closed-loop" production systems on environmental impact and costs. These methods will aid company decision-making to minimize negative environmental, industrial, and economic impacts to particular locations.

Local environmental impacts have a different character than impacts on other scales, for example global or regional scales. For this reason, this research will characterize the environmental damages incurred immediately by actions during production and over time on the wellbeing of future ecosystem carrying capacity. Multimedia fate and transport models have been used in assessing the environmental impact of chemicals at local, regional, or global scales. Differences in transportation 
required and process scale will influence the environmental impact of production strategies.

Localizing production has impacts on product design choices such as processing and remanufacturing limitations based on the capabilities of supply chain members. However, a local supply chain also has the advantage of easier communication and therefore ability to initiate concurrent engineering approaches between supply chain members. Containing production within a physical area affects costs (such as reducing transportation requirements). "[M] uch more work needs to be done on the issue of transportation costs, economies of scale, and location (Lyons, 2007)." Transportation costs can plummet in a localized approach to manufacturing but other manufacturing related costs (e.g., capital costs, energy use, materials cost) could rise.

Environmental impact needs to be considered when siting facilities in a supply chain due to both legislative and consumer pressures. Additionally, need for models that can represent both the supply chain that recovers products and spatially differentiated environmental impact are needed. "More complicated and adapted models (and methods) are necessary to cope with recovery management in the supply chain approach and with regional problems in the environmental chain approach (Bloemhof-Ruwaard et al., 1995)." Combining environmental impact assessment with facility location analysis for the optimization of supply chains can characterize impacts and provide decision-makers with information on how to reduce the environmental damages caused by industrial systems (Bloemhof-Ruwaard et al., 1995). 


\subsection{Problem Description}

Supply chains that both recover and manufacture products are simultaneously pushed to centralize facilities, because of capital costs, and to decentralize facilities, due to transportation costs. Exploring the optimal degree of centralization for locating facilities in a combined forward and reverse supply chain is needed. Environmental impact is often overlooked in industrial decision-making, especially for facility location decisions. Answering which strategy to use to site facilities for supply chains that operate in both a forward and reverse direction in terms of costs and environmental impact is essential in a world of rapid industrial development to create new and to upgrade old infrastructure. Advantages and disadvantages exist to centralized and decentralized facility location strategies. The trade-offs in terms of cost and environmental impact of supply chains have not been systematically investigated and are not well understood.

\subsection{Dissertation Objectives}

This dissertation explores two strategies for locating production facilities centralization and decentralization when considering costs and environmental impact. These strategies are further explored for costs, environmental impact, and social sustainability concerns. The objectives of this dissertation are to:

- Combine costs with economies of scale and spatially dependent environmental impact to compare differences between centralized and decentralized strategies for locating facilities in a forward and reverse supply chain

- Develop sustainability indicators and weights for use in comparing facility location strategies for a company that manufactures and takes back products

- Incorporate social sustainability concerns along with costs and environmental impact for comparing facility location strategies

- Compare the sustainability of facility location strategies for a company that manufactures and takes back products 


\section{Chapter 2}

\section{Literature Review}

\subsection{Introduction}

There are two relevant areas of background research for the problem of weighting financial and environmental impacts between decentralized or centralized facility location strategies, supply chain modeling and environmental impact assessment. Current efforts at environmental impact assessment of supply chains are explored. Distinctions between forward and reverse supply chain networks, including a comparison of supply chain models, are discussed. In particular the differences between production decentralization and centralization are defined.

Understanding environmental impact assessment methods is important when deciding whether to follow a decentralized or centralized strategy for facility siting. Environmental impact assessment methods include such approaches as life cycle assessment and multimedia fate and transport analysis. The specifics of life cycle assessment such as spatial considerations, assimilation capacity, allocation and indicators are all discussed. Social sustainability concerns are mentioned as well. 


\subsection{Supply Chains}

A supply chain (Figure 2.1) is the combined effort of suppliers, manufacturers, distributors, and retailers to turn materials into products and transport these goods to users (Beamon, 1998). In order to design a supply chain, decisions about the following must be made: site location, replenishment policies, manufacturing policies, transportation policies, stocking levels, lead times, customer service, location, production, inventory, and transportation.

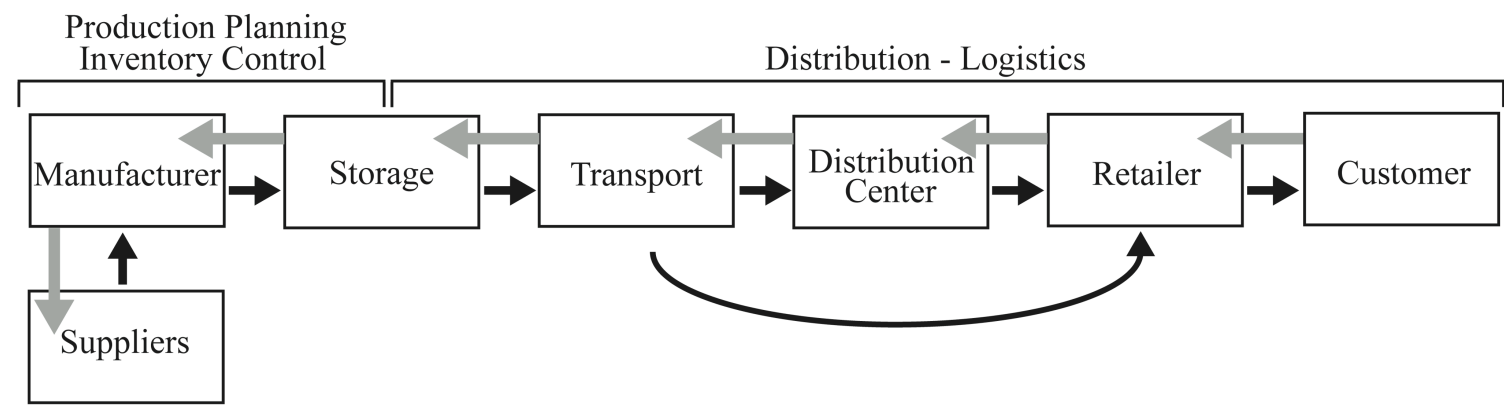

\section{Figure 2.1: Traditional model of supply chain actors - material flows in black, information flows in grey, adapted from (Beamon, 1998)}

Forward supply chains have different costs and procedures for distribution and storage of products than returned products in reverse supply chains. Manufacturers approach collecting products for remanufacturing in several ways - direct return to manufacturers, return to retailers, or return to a third party collector (Savaskan et al., 2004). Often firms do not have closed-loop logistics established. Many firms instead rely on logistics organizations that specialize in reverse distribution of parts (Jayaraman et al., 1999). 


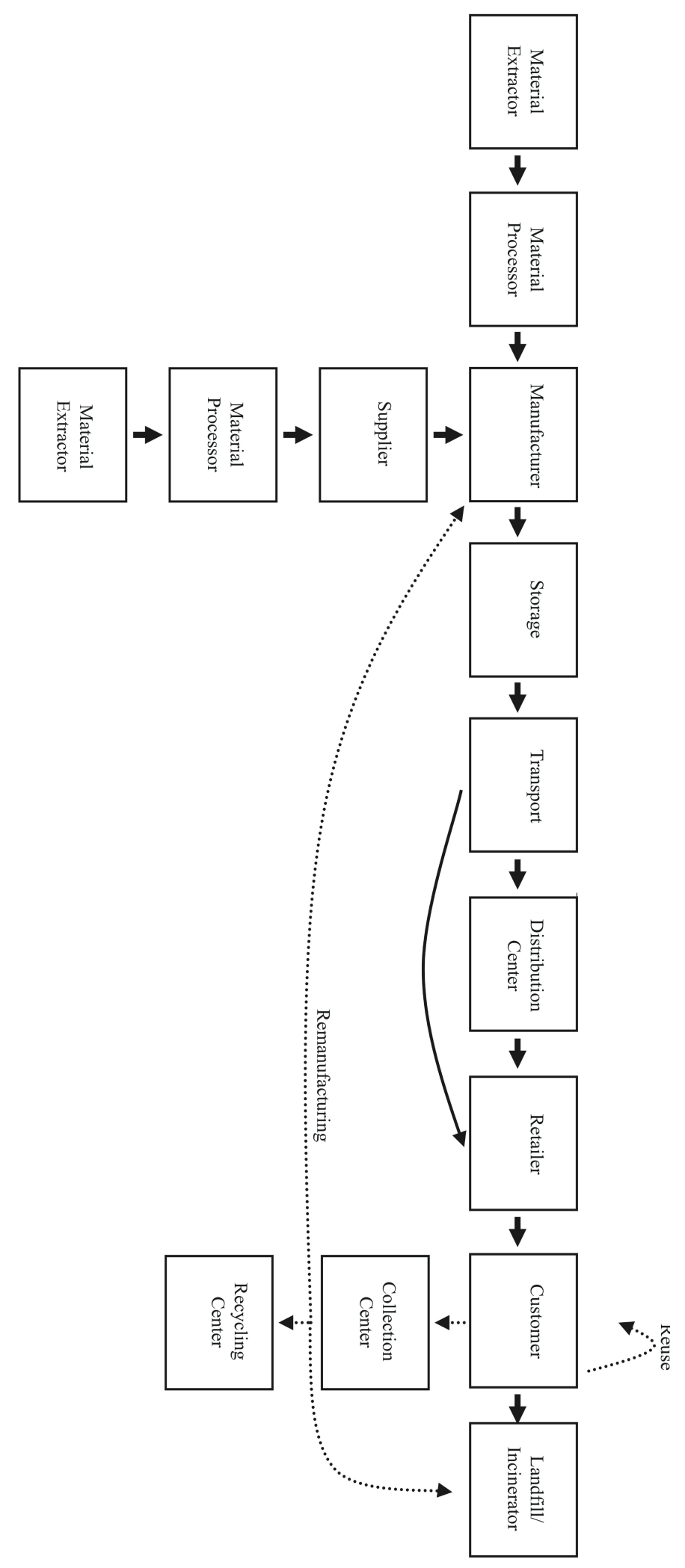

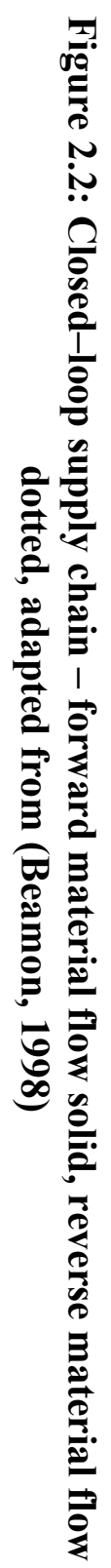


Closed-loop supply chains (Figure 2.2) involve the transportation of products in a forward and reverse direction to the same company (Blumberg, 2005). An open-loop supply chain never returns products back to the original manufacturer. Every member of the supply chain is responsible for the materials and energy used as well as the creation of products (material), waste and emissions. Figure 2.3 describes the flows to and from a member of the supply chain. These flows to and from supply chain members have repercussions for the environment and human health.

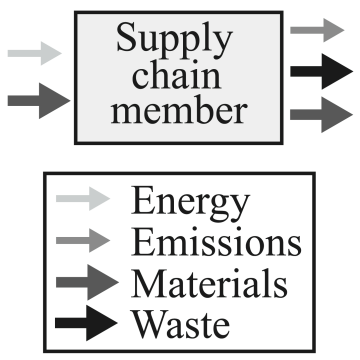

Figure 2.3: Material, energy, waste, and emissions flows for a supply chain member

Reverse logistics is the flow of used products from customers back to all actors in the reutilization chain from material recyclers to product remanufacturers. This flow of goods is driven by the amount of used goods available (supply). The supply of returned products is not often well known; uncertainties abound in the quantities and quality of returned products (Fleischmann et al., 2000; Jayaraman et al., 1999). Establishing the network layout and material flows is essential to achieve efficient reverse logistics (Jayaraman et al., 1999). Others describe reverse logistics as only turning around the direction of flow of unwanted products and redistributing refurbished/remanufactured products through the same channels as the forward network (Fleischmann et al., 2000). However, this assumption simplifies the complexity of the reverse distribution network. 
The reverse distribution network is complicated since returned products come from a multitude of places. Hence, product collectors must work against entropy by taking small amounts of unwanted products in many places and conglomerating these products in one location (Fleischmann et al., 2000). The difficulty in bringing together products has significant financial and environmental impacts. Accordingly, logistics make up a substantial portion of costs for a reverse supply chain network (Krikke et al., 1999). Because of differences in transportation costs between networks, the reverse network design is key to economic feasibility of product remanufacturing (Fleischmann et al., 2001).

Once all of the returned products are brought back together, different product recovery options are possible: Reuse consists of finding another user to use the product in its existing condition. Recycling involves the breakdown of a product into different materials which then get processed into material feedstocks (Thierry et al., 1995). Cannibalization removes a few particular components for reuse but discards the rest (Thierry et al., 1995). Repair fixes a product to a level where it will still function (Thierry et al., 1995). Refurbishing fixes production functioning and improves its condition (Thierry et al., 1995). Remanufacturing takes previously utilized product components and repairs and refurbishes these components to the same standards for new product components (Jayaraman et al., 1999).

When optimizing the reverse supply chain network, companies must choose a strategy for implementation. Companies must decide when to use pre-existing facilities and distribution routes from the forward network or when to create a new network of added facilities and distinct distribution patterns just for the reverse network. Original 
equipment manufacturers that take back products often utilize parts of pre-existing networks (Fleischmann et al., 2001).

Forward production has distinct issues from reverse production. Hence, optimizing for both forward and reverse supply chain networks can differ significantly from optimizing for either forward or reverse supply chains alone. In order to summarize, a discussion of the problems with current supply chain network analysis will be mentioned. Finally, environmental impact is an important, but often forgotten, factor to consider when evaluating any supply chain.

\subsubsection{Production decentralization and centralization}

Since companies must come up with a unique strategy when establishing and refining forward and reverse networks, exploring different strategic options is useful. The key component of this dissertation is to examine when centralization or decentralization facility siting strategies make sense for a company to employ. The intricacy of steps to a product's assembly, as well as potential recovery alternatives, can affect the degree to centralization or decentralization a company chooses for network design (Fleischmann et al., 2000).

Centralisation refers to the number of locations at which similar activities are carried out. In a centralised network each activity is installed at a few locations only, whereas in a [decentralised] network the same operation is carried out at several different locations in parallel. (Fleischmann et al., 2000)

One factor in siting decisions is whether to place distribution and remanufacturing facilities near where products are returned or demand for remanufactured products exists (Jayaraman et al., 1999). When products can be reused many times with little need for changes to the product made, transportation becomes a very important part of total cost 
which can result in decentralized network locations close to customers (Fleischmann et al., 2000). On the other hand, "[f]acilities with high fixed costs generally require centralised operations, while other activities may be decentralised to reduce transportation costs (Fleischmann et al., 2000)." Additionally, collecting low value products relies on economies of scale which is met through a centralization of the network structure (Fleischmann et al., 2000). Realff et al. note that as difficulty of manufacturing increases - reuse, remanufacturing, and refurbishing will be favored recovery strategies. For products with high value materials and little production complexity - materials recycling will be preferred (Realff et al., 1999,2000). Since increases in manufacturing complexity makes reuse, remanufacturing, and refurbishing of products more popular options, decentralized production networks for these more complex products may make more economic and environmental sense to pursue. In summary, there are reasons to choose a centralized or decentralized strategy for facility location - but these reasons have not been systematically investigated.

\subsubsection{Forward and reverse supply chain networks}

Fleischmann et al. developed several different factors that distinguish product recovery networks (Fleischmann et al., 2000). These factors include:

- Legally obligated or commercially warranted product take-back;

- Facility operation costs relative to facility set-up costs;

- Whether third party collectors or original producer act as remanufacturers;

- Weight, volume, fragility, toxicity, perishability, and product life (Fleischmann et al., 2000);

- And quality, constancy, and quantity of returned product supply. 
Many models of forward and reverse supply chain networks have been created to realistically assess the benefits of different networks structures for particular products and take-back situations. These models are not uniform in their approaches to helping decision-makers choose how best to configure a network. Differences arise between models because of:

- Optimization objective functions;

- Scenarios explored;

- Origin of returned product supply;

- Sensitivity analysis;

- And types of products investigated.

Table 2.1 highlights some of the similarities and differences between forward and reverse supply chain network models (Barros et al., 1998; Beamon and Fernandes, 2004; Bloemhof-Ruwaard et al., 1996a; Bloemhof-Ruwaard et al., 1996b; Cohen and Moon, 1991; Fleischmann et al., 2001; Gottinger, 1988; Jayaraman et al., 1999; Krikke et al., 2003; Krikke et al., 1999; Louwers et al., 1999; Nema and Gupta, 2003; Realff et al., 1999,2000; Savaskan et al., 2004; Spengler et al., 1997). Each of the differences between the models warrants more explanation. 
Table 2.1: Differences among forward and reverse supply chain network models

\begin{tabular}{|c|c|c|c|}
\hline Model Name & Levels & Facilities Considered & Capacitated \\
\hline Barros et al., 1998 & 2 & Sand cleaners, warehouses & Yes \\
\hline $\begin{array}{c}\text { Beamon and } \\
\text { Fernandes, } 2004\end{array}$ & 4 & $\begin{array}{c}\text { Collection centers, manufacturers, } \\
\text { retailers, warehouses }\end{array}$ & Yes \\
\hline $\begin{array}{l}\text { Bloemhof- } \\
\text { Ruwaard et al., } \\
1996 \mathrm{a}\end{array}$ & 2 & Producers, waste processors & Yes \\
\hline $\begin{array}{c}\text { Bloemhof- } \\
\text { Ruwaard et al., } \\
\text { 1996b }\end{array}$ & 3 & $\begin{array}{c}\text { Collection centers, paper } \\
\text { producers, virgin or recycled pulp } \\
\text { producers }\end{array}$ & No \\
\hline $\begin{array}{l}\text { Cohen and Moon, } \\
1991\end{array}$ & 3 & $\begin{array}{l}\text { Distributors, material suppliers, } \\
\text { producers }\end{array}$ & Yes \\
\hline $\begin{array}{l}\text { Fleischmann et } \\
\text { al., } 2001\end{array}$ & 3 & $\begin{array}{l}\text { Collection centers, distributors, } \\
\text { manufacturers }\end{array}$ & No \\
\hline Gottinger, 1988 & 3 & $\begin{array}{l}\text { Landfills, producers, waste } \\
\text { processors }\end{array}$ & Yes \\
\hline $\begin{array}{c}\text { Jayaraman et al., } \\
1999\end{array}$ & 3 & $\begin{array}{l}\text { Collection centers, } \\
\text { remanufacturers, retailers }\end{array}$ & Yes \\
\hline Krikke et al., 1999 & 2 & $\begin{array}{l}\text { Collection centers, } \\
\text { remanufacturers }\end{array}$ & No \\
\hline Krikke et al., 2003 & 3 & Producers, recoverers, warehouses & Yes \\
\hline $\begin{array}{c}\text { Louwers et al., } \\
1999\end{array}$ & 3 & $\begin{array}{l}\text { Collection centers, pre-processors, } \\
\text { recyclers }\end{array}$ & Yes \\
\hline $\begin{array}{l}\text { Nema and Gupta, } \\
2003\end{array}$ & 4 & $\begin{array}{l}\text { Incinerators, landfills, transfer } \\
\text { stations, waste sources }\end{array}$ & Yes \\
\hline $\begin{array}{l}\text { Realff et al., } 1999 \\
\text { and } 2000\end{array}$ & 3 & $\begin{array}{l}\text { Mechanical or chemical recyclers, } \\
\text { shoddy producers, warehouses }\end{array}$ & Yes \\
\hline $\begin{array}{l}\text { Savaskan et al., } \\
2004\end{array}$ & 2 & Manufacturers, retailers & No \\
\hline $\begin{array}{c}\text { Spengler et al., } \\
1997\end{array}$ & 3 & Producers, retailers, warehouses & Yes \\
\hline
\end{tabular}

Each model has its own objective function (Table 2.2). The most common objective function for a supply chain network model is to minimize cost (Nema and Gupta, 2003). However, minimization of cost can be used in conjunction with other objective functions. For example, Nema and Gupta minimize for both cost and risk and conclude that these two goals are at odds with each other (Nema and Gupta, 2003). For 
more than one optimization goal, the individual goals will compete with each other. The objective function sets the goal of the scenario considered by the model.

Table 2.2: Supply chain network models' objective functions

\begin{tabular}{|c|c|}
\hline Model Name & Objective Function \\
\hline Barros et al., 1998 & Minimize cost \\
\hline Beamon and Fernandes, 2004 & Minimize present loss* \\
\hline Bloemhof-Ruwaard et al., 1996a & Minimize cost \\
\hline Bloemhof-Ruwaard et al., 1996b & Minimize cost and environmental impact \\
\hline Cohen and Moon, 1991 & Minimize cost \\
\hline Fleischmann et al., 2001 & Minimize cost \\
\hline Gottinger, 1988 & Minimize cost \\
\hline Jayaraman et al., 1999 & Minimize cost \\
\hline Krikke et al., 1999 & Minimize cost \\
\hline Krikke et al., 2003 & Minimize cost \\
\hline Louwers et al., 1999 & Minimize cost, waste, and energy use \\
\hline Nema and Gupta, 2003 & Maximize profit \\
\hline Realff et al., 1999 and 2000 & Maximize profit \\
\hline Savaskan et al., 2004 & Minimize cost and maximize recycling rate \\
\hline Spengler et al., 1997
\end{tabular}

*present loss is defined as the sum of investment and operational costs

Supply chain network models investigate different scenarios. The number of supply chain echelons or levels is just one factor that gives a picture of the scenario considered. A supply chain echelon encompasses the entire list of processes necessary for the product to come to a completion point. From this completion point, the product will move to the next echelon for more processing or enter into the supply chain for distribution, retail sale, or use. Figure 2.4 illustrates a generic seven echelon (level) supply chain. 


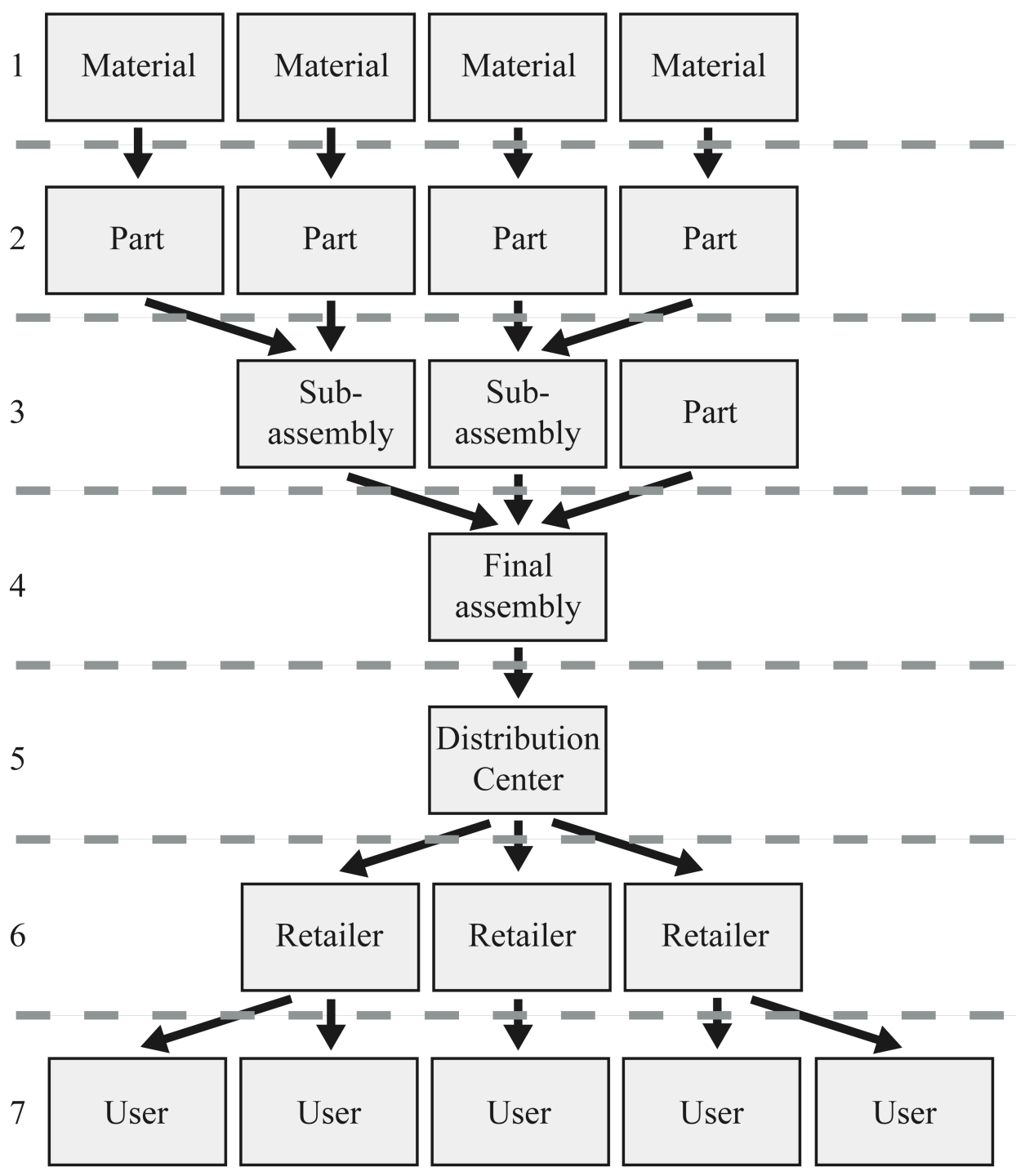

Figure 2.4: Seven echelon supply chain

Other parts of the scenario that a supply chain model considers are the geographic locations of the supply chain network. Some models are purely theoretical and hence do not correspond to a particular geographic area or supply chain network. Many other models are based in parts of Europe.

Each model considers different types of facilities that are most relevant to the problem under investigation. Many models just look at the forward supply chain (e.g., production and distribution to customers), while other models just characterize the 
reverse supply chain (e.g., product collection, recycling, and waste disposal). Very few researchers consider both the forward and reverse supply chain of specific products. Fleischmann et al. present an exception with their model of forward and reverse network design for photocopiers and paper (Fleischmann et al., 2001).

Other parts of the scenario a model builds involve capacity and facility location decisions. Capacitated models of supply chains consider the quantity of goods that each facility can store. Uncapacitated models of supply chains assume that each facility can hold any number of goods (ignoring any capacity constraints). Including capacity constraints increases the complexity, yet accuracy, of the computational side of a model.

How locations are selected also sets the scene for a model. Many of the models start out with predetermined or a fixed set of locations or nodes on a network where a facility can be sited. Open models are the exact opposite, in these models a facility can be sited anywhere in the selected region. Fixing locations is mathematically easier to calculate in a model, since choice is limited and distances between two locations are then always known. Computational ease is most likely the reason that most models use fixed locations. However, depending on how locations are fixed, more freedom exists in how the facility siting choices are made. Some fixed locations are pre-existing, which often means that the locations are already associated with a real world location for a facility. This reduces freedom in choice but likely reflects more accurately, i.e. the kind of choices that are available for the particular problem. Some locations may still be fixed but not known beforehand. For this case, the model may determine fixed locations, e.g. randomly generating locations. 
To take best advantage of fixed locations, it seems that starting with a network of possible locations and successively eliminating or choosing between candidate locations makes the most sense. Several others have followed this approach, and the candidate locations they have chosen are all political or population centers for a region (e.g., (Fleischmann et al., 2001) and (Realff et al., 1999)). This approach effectively eliminates the possibility of locating factories in less populous areas such as rural areas; This concern is relevant because of its potential to reduce the effects of environmental impact by redeveloping areas in cities instead of developed previously undeveloped green space. The following factors establish the scenario of a model: the number of echelons, geographical area, facility types, capacity, and location choice.

Table 2.3: Product retirement options used in various supply chain network models

\begin{tabular}{|c|c|c|c|c|c|c|c|c|}
\hline Model Name & 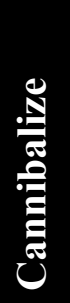 & 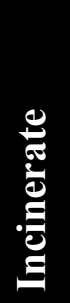 & $\begin{array}{l}\text { 晋 } \\
\text { 恶 }\end{array}$ & 䢘 & 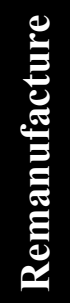 & 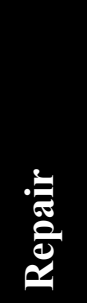 & 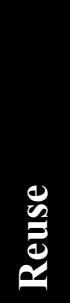 & 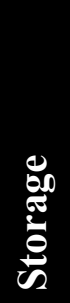 \\
\hline Barros et al., 1998 & & & & & & & $\mathrm{X}$ & $\mathrm{X}$ \\
\hline Beamon and Fernandes, 2004 & & & & & & & & $\mathrm{X}$ \\
\hline Bloemhof-Ruwaard et al., 1996a & & & $\mathrm{X}$ & & & & & \\
\hline Bloemhof-Ruwaard et al., 1996b & & $\mathrm{X}$ & $\mathrm{X}$ & $\mathrm{X}$ & & & & $\mathrm{X}$ \\
\hline Cohen and Moon, 1991 & & & & & & & & \\
\hline Fleischmann et al., 2001 & & $\mathrm{X}$ & $\mathrm{X}$ & $\mathrm{X}$ & $\mathrm{X}$ & & $\mathrm{X}$ & $\mathrm{X}$ \\
\hline Gottinger, 1988 & & $\mathrm{X}$ & $\mathrm{X}$ & & & & & \\
\hline Jayaraman et al., 1999 & & & & $\mathrm{X}$ & $\mathrm{X}$ & $\mathrm{X}$ & & \\
\hline Krikke et al., 1999 & $\mathrm{X}$ & $\mathrm{X}$ & $\mathrm{X}$ & $\mathrm{X}$ & $\mathrm{X}$ & $\mathrm{X}$ & $\mathrm{X}$ & $\mathrm{X}$ \\
\hline Krikke et al., 2003 & $\mathrm{X}$ & & & & $\mathrm{X}$ & $\mathrm{X}$ & & \\
\hline Louwers et al., 1999 & & $\mathrm{X}$ & $\mathrm{X}$ & $\mathrm{X}$ & & & & $\mathrm{X}$ \\
\hline Nema and Gupta, 2003 & & $\mathrm{X}$ & $\mathrm{X}$ & & & & & \\
\hline Realff et al., 1999 and 2000 & & $\mathrm{X}$ & $\mathrm{X}$ & $\mathrm{X}$ & & & & $\mathrm{X}$ \\
\hline Savaskan et al., 2004 & $\mathrm{X}$ & & $\mathrm{X}$ & & $\mathrm{X}$ & & & \\
\hline Spengler et al., 1997 & & $\mathrm{X}$ & $\mathrm{X}$ & $\mathrm{X}$ & & & $\mathrm{X}$ & \\
\hline
\end{tabular}


Most models relevant to this dissertation research involve product take back. As mentioned before, most models only consider the product take-back part of the production network. Each of the models in turn only considered particular product takeback options (Table 2.3).

\subsubsection{Problems with forward and reverse supply chain analysis}

As mentioned previously, most researchers investigate either the forward or reverse supply chain but not both together. Fleischmann et al. provide an exception by looking at whether it is beneficial to optimize the forward and reverse directions of a supply chain sequentially or at the same time. The researchers find that optimizing forward and reverse supply chain networks at the same time produces networks with similar costs or significant cost savings as compared to considering the forward and reverse directions separately (Fleischmann et al., 2001). Hence looking at both the forward and reverse supply chain together is important in order to optimize a supply chain network fully.

Most supply chain network models currently optimize solely for cost (Nema and Gupta, 2003). Only a few models consider aspects besides costs such as; risk, environmental impact, economies of scale, facility location strategies, or realistic (nonuniform) assessment of returned product quality. Further discussion of several of these models that include factors besides costs follows (Table 2.4).

Nema and Gupta characterize the risk in transporting hazardous waste. The risk considered is proportional to: travel distance, potential hazard based on the material properties, quantity of the waste, and the susceptibility of the surroundings to harm (which is solely based on human exposure and does not include ecosystem differences). 
Table 2.4: Variables and concepts included in supply chain network models

\begin{tabular}{|c|c|c|c|c|c|c|c|c|c|}
\hline Model Name & $\frac{1}{2}$ & ڤั & 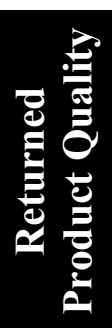 & 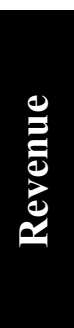 & 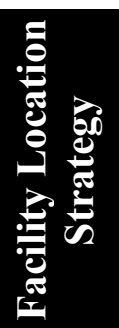 & 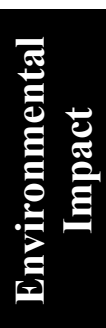 & 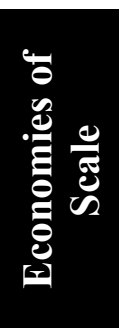 & 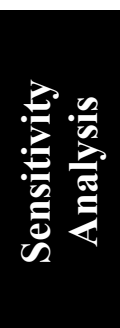 & 递 \\
\hline Barros et al., 1998 & & $\mathrm{X}$ & $\mathrm{X}$ & & & & & & $\mathrm{X}$ \\
\hline $\begin{array}{c}\text { Beamon and } \\
\text { Fernandes, 2004 }\end{array}$ & & $\mathrm{X}$ & $\mathrm{X}$ & & & & & $\mathrm{X}$ & $\mathrm{X}$ \\
\hline $\begin{array}{c}\text { Bloemhof-Ruwaard } \\
\text { et al., 1996a }\end{array}$ & & $\mathrm{X}$ & & & & & & & $\mathrm{n} / \mathrm{a}$ \\
\hline $\begin{array}{c}\text { Bloemhof-Ruwaard } \\
\text { et al., 1996b }\end{array}$ & & $\mathrm{X}$ & $\mathrm{X}$ & & & $\mathrm{X}$ & & $\mathrm{X}$ & $\mathrm{X}$ \\
\hline $\begin{array}{c}\text { Cohen and Moon, } \\
1991\end{array}$ & & $\mathrm{X}$ & $\mathrm{n} / \mathrm{a}$ & & $\mathrm{X}$ & & $\mathrm{X}$ & $\mathrm{X}$ & $\mathrm{n} / \mathrm{a}$ \\
\hline $\begin{array}{c}\text { Fleischmann et al., } \\
2001\end{array}$ & & $\mathrm{X}$ & & & & & & $\mathrm{X}$ & $\mathrm{X}$ \\
\hline Gottinger, 1988 & & & $\mathrm{X} 1$ & & & & & & $\mathrm{n} / \mathrm{a}$ \\
\hline $\begin{array}{c}\text { Jayaraman et al., } \\
1999\end{array}$ & & $\begin{array}{l}\mathrm{X} \\
2 \\
\end{array}$ & & & & & & $\mathrm{X}$ & $\mathrm{X}$ \\
\hline Krikke et al., 1999 & & $\mathrm{X}$ & $\mathrm{X} 2$ & & $\mathrm{X}$ & & & & $\mathrm{X}$ \\
\hline Krikke et al., 2003 & & $\mathrm{X}$ & & & $\mathrm{X}$ & $\mathrm{X}$ & & $\mathrm{X}$ & $\mathrm{X}$ \\
\hline Louwers et al., 1999 & & $\mathrm{X}$ & & & & & & $X$ & $\mathrm{X}$ \\
\hline $\begin{array}{l}\text { Nema and Gupta, } \\
2003\end{array}$ & $\mathrm{X}$ & & $\mathrm{X}^{1}$ & & & $\mathrm{X}$ & & $\mathrm{X}$ & $\mathrm{X}$ \\
\hline $\begin{array}{l}\text { Realff et al., } 1999 \\
\text { and } 2000\end{array}$ & & $\mathrm{X}$ & $\mathrm{X}^{1}$ & $\mathrm{X}$ & $\mathrm{X}$ & & $\mathrm{X}$ & $\mathrm{X}$ & $\mathrm{X}$ \\
\hline $\begin{array}{c}\text { Savaskan et al., } \\
2004\end{array}$ & & $\mathrm{X}$ & $\mathrm{X}^{2}$ & $\mathrm{X}$ & & & & & $\mathrm{X}$ \\
\hline Spengler et al., 1997 & & & $\mathrm{X}^{1}$ & $\mathrm{X}$ & & & & & $\mathrm{X}$ \\
\hline
\end{tabular}

Additionally, Nema and Gupta calculate risk differently for the processing of waste and transportation (Nema and Gupta, 2003).

Realff et al. consider economies of scale, but assume that tripling the capacity of plants will only double the expenses. The authors admit this assumption is not based on 
the data collected and does not necessarily accurately reflect realistic conditions (Realff et al., 1999,2000). Researchers need to incorporate factors such as economies of scale in as realistic a manner as possible.

Savaskan et al. consider economies of scale when comparing different remanufacturing situations where the manufacturer, retailer, or third party respectively is responsible for returned product collection. The authors find that the retailer collection system results in maximum profit for all because of the retailer locations close to customers. "[T]he closer an agent is to the market, the more efficient is the collection of used products for all parties involved in the channel (Savaskan et al., 2004)." Furthermore the authors predict that creating a remanufacturing supply chain for the first time would reinforce the profitability of the retailer as the collection agent since forward distribution systems are already operating. This model shows that third party collection results in greater costs for remanufacturers and hence decreases the incentive to remanufacture products. These authors identify the need to consider both economies of scale and facility locations to the costs of remanufacturing in particular for collection. "An extension of this research could consider the case of unequal costs of collection because of economies of scale (we conjecture that this would favor third-party collection), proximity to the consumer (this would favor retailer collection), and other possible reasons (Savaskan et al., 2004)." 


\subsubsection{Supply chains and environmental impact}

The emerging modern view of environmental responsibility is much broader than has historically been the case. It envisions an approach in which one looks not to the past, but to the future, and has as the goal the design and manufacture of products, the operation of processes, and the management of facilities so that environmental factors are recognized and their impacts minimized. Such actions are increasingly viewed as sound business practice in a competitive world concerned both with the perceptions of customers and with the planet on which we live. (Graedel, 1998)

Evaluating a supply chain's performance depends upon the long-term approach of a company regarding production (Beamon, 1999). Oftentimes cost is used as the only performance indicator (Beamon, 1999; Nema and Gupta, 2003). Indicators of supply chain operation miss many of the important identifiers of supply chain functioning. Incorporating other aspects of sustainability, including environmental impact in addition to cost, can create indicators of performance that are more useful and relevant to specific questions about supply chains (Swisher et al., 2006). Considering only cost will neglect other parts of a corporation's strategic vision, such as environmental performance.

Supply chain modeling must consider more than costs since supply chain decisions have significant effects on the environment. Supply chain modeling at present, by and large, does not deal with environmental impacts found through life cycle assessment (Krikke et al., 2003). However, the supply chain has many specific effects on the environment including releasing emissions, creating waste, and needs for materials and energy (Figure 2.5). 
Environment

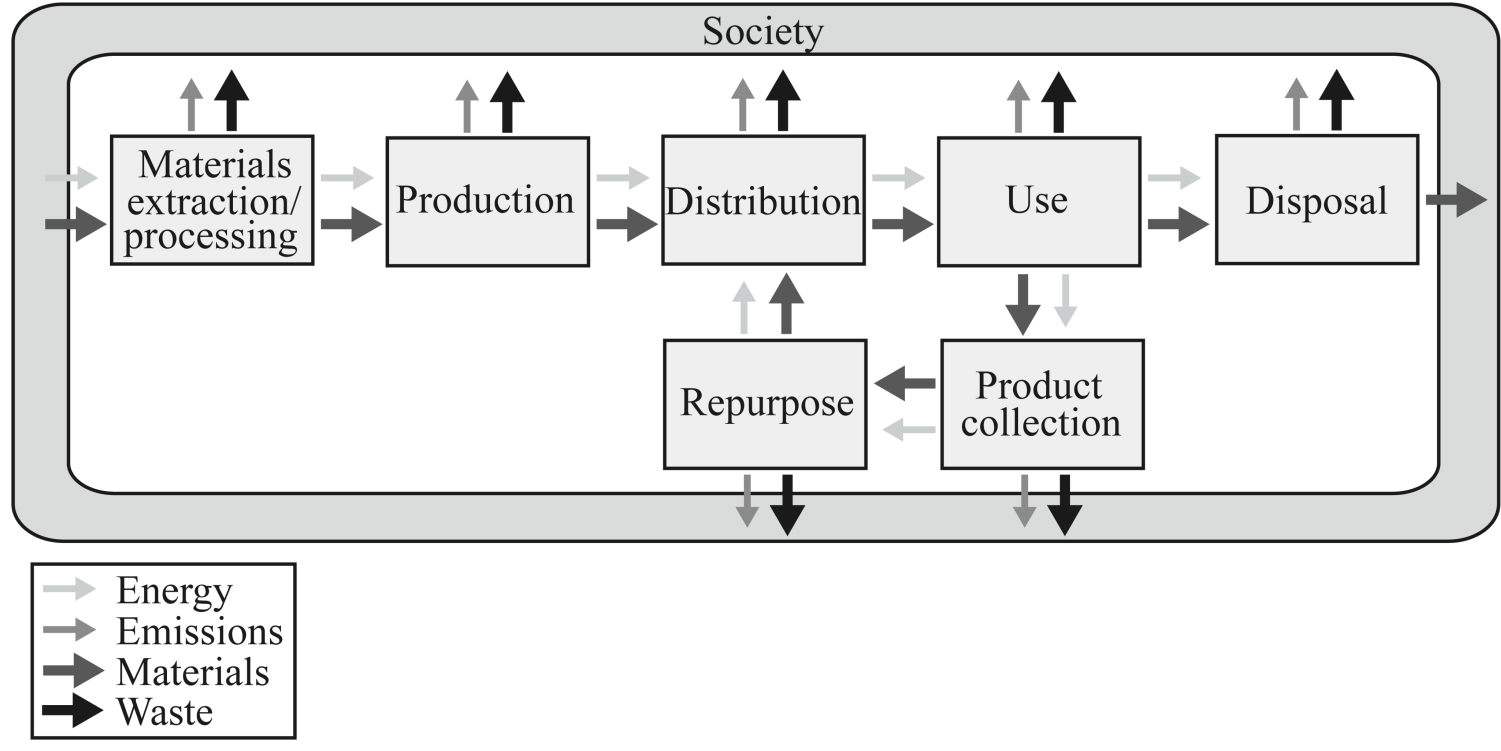

Figure 2.5: Interaction between supply chain and environmental effects adapted from (Bloemhof-Ruwaard et al., 1995; Bras, 1997; Clarke-Sather et al., 2010)

Researchers today are adequately able to quantify potential costs for particular supply chain designs. Life cycle assessment can adequately assess the environmental impacts of supply chains. However, life cycle thinking and environmental impact assessment has rarely been included in the modeling and analysis of supply chains (Bloemhof-Ruwaard et al., 1995). Environmental impact has rarely been used alone or with costs to forecast the impacts of different configurations of supply chains. When environmental impact is considered in the analysis of supply chains, it is often considered without regards to cost (Bloemhof-Ruwaard et al., 1996b). Rarely the effects of environmental impact and costs on supply chains are considered together (Krikke et al., 2003; Quariguasi Frota Neto et al., 2007a,b). When cost and environmental impacts are considered together, environmental impacts may only be considered as an inventory of quantities, e.g. (Krikke et al., 2003) measures energy and waste but does not express the effects that these quantities have on human and environmental health. Additionally, these 
approaches may be able to consider both environmental impacts and costs, e.g. (Quariguasi Frota Neto et al., 2007a,b), but may not be easily able to include a third factor such as social sustainability. Additionally these methods do not consider the spatial dependence of environmental impact. Including the spatial differences in environmental impact is important when deciding between different locations for siting facilities in the supply chain.

\subsection{Environmental Impact Assessment Methods}

Life cycle assessment is a widely used tool for quantifying environmental effects and suggesting improvements. Indicators are specific tools that are used for environmental impact assessment, which is then often incorporated into larger life cycle assessment analyses. Multimedia fate and transport models characterize local environmental impacts through the geographic movement of emissions. All of these tools have a place in illustrating the effects that forward and reverse supply chain designs have on the environment.

\subsubsection{Life cycle assessment}

The outcome of life cycle assessment (LCA) informs designers on how to alter design choices to improve product environmental performance. Life cycle assessments are often performed to compare multiple product or process design options for environmental impact. Life cycle assessment (LCA) is generally described as consisting of four different steps by the widely accepted ISO 14040 standards: goal and scope definition, inventory analysis, impact analysis and interpretation of results (also called improvement analysis) (International Organization for Standardization (ISO), 1998,2000a,b,2006a,b). Because of limitations due to data, time, and cost, achieving the 
goal of an LCA must be feasible within these and other constraints. Defining the scope of an LCA involves creating a system boundary or in other words deciding which life-cycle stages will be included in the analysis. In general the stages from materials extraction to product disposal also called from cradle to grave, are included (Figure 2.6).

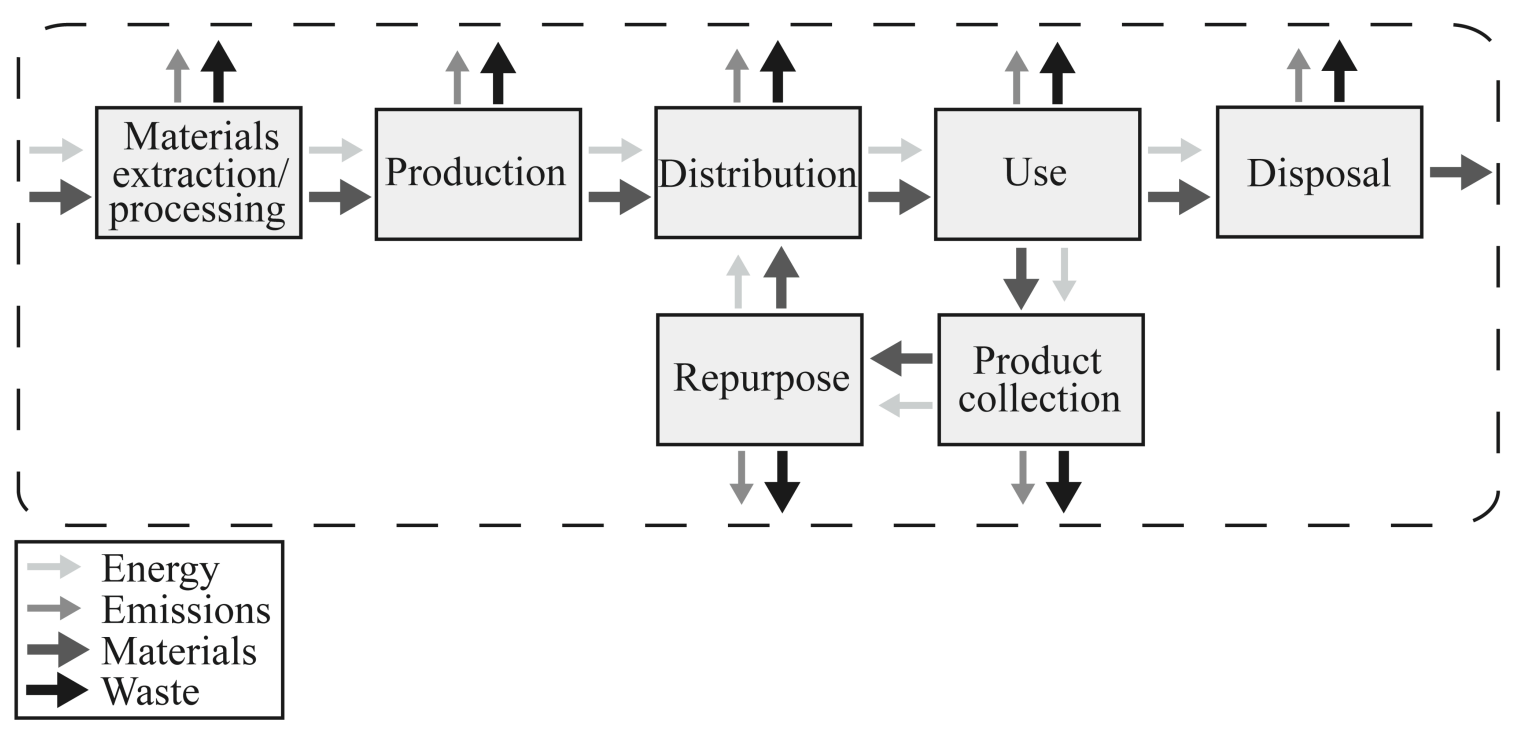

Figure 2.6: System boundary around cradle to grave life-cycle stages

When comparing multiple products or process designs to choose the best option one can redefine the system boundary to only include those life cycle stages that differ between the products or processes of interest. Additionally the "functional unit" or a chosen standard quantity of performance for a particular product must be decided before starting an LCA.

Inventory analysis involves a careful determination of material and energy flows during different life-cycle stages (Figure 2.5). In addition to all inputs to each stage, the following outputs should be included; the desired finished product, byproducts, effluent, air releases, solid waste and other environmental disturbances (Brezet and van Hemel, 1997; Graedel, 1998; Guinée, 2002) (Table 2.5). 
Table 2.5: Potential environmental disturbances to inventory for LCA (Brezet and van Hemel, 1997; Graedel, 1998; Guinée, 2002)

\begin{tabular}{|c|}
\hline Potential Environmental Disturbances \\
\hline Acid rain \\
\hline Biodiversity loss \\
Climate change \\
\hline Depletion of mineral resources \\
\hline Depletion of renewable resources \\
\hline Eutrophication \\
\hline Heat \\
\hline Land use \\
\hline Loss of life supporting services \\
\hline Noise \\
\hline Ozone \\
\hline Radiation - including light \\
\hline Smells in air or water \\
\hline Smog formation \\
\hline Toxicity to people, soil, or water \\
\hline Water overuse \\
\hline
\end{tabular}

Impact analysis entails figuring out what effects that the emissions, wastes and resource use outlined in the life-cycle inventory will have for the environment and people (Guinée, 2002). In order to perform an impact analysis several steps must be followed:

1. Selection of relevant impact categories for the product life-cycle considered

2. Classification of inventory elements into impact categories

3. Selection of methods to characterize or measure impact categories

4. Characterize environmental and human health impacts through use of impact potentials for midpoint indicators and through human health effects for endpoint indicators (Graedel, 1998; Guinée, 2002; UNEP DTIE Production and Consumption Unit, 2003)

5. Create a common assessment for different parts of the life-cycle inventory that affect the same impact, i.e. normalize impacts within a impact category for comparison

6. Note all impacts that were not quantified or measured

7. Weight the importance of impact categories 
8. Perform any sensitivity analysis necessary (Graedel, 1998; Guinée, 2002;

Sonnemann et al., 2002)

The above outlines a typical approach to LCA. There are many specific aspects to life cycle assessment such as considering spatial differences, assimilation capacities, and allocating impacts. Performing an LCA entails the incorporation of a lot of information into a careful analysis involving many steps. Despite the organization and large amounts of data, current approaches to life cycle assessment often fail to address aspects of reality including the spatial and time-dependent nature of environmental impact (Guinée, 2002).

\subsubsection{Spatial considerations}

Often spatial considerations are ignored in LCA simply because the extent of the problem under consideration is global as different processes undertaken by one company are made all over the world (Burgess and Brennan, 2001). For chemicals that are released diffusely over a region, using non-spatial analysis provides an adequate assessment of risk estimates to people in different areas (Pennington et al., 2005). However, this practice is not justifiable for many cases since ecological damage can affect a range of spatial scales from local to worldwide. Gases such as carbon dioxide cause climate change, which has effects globally. Sulfur oxides $\left(\mathrm{SO}_{\mathrm{x}}\right)$ are instrumental in creating acid rain on a regional scale. Toxic releases such as lead can have very localized effects depending upon the form of the release (air, water, or soil release; chemical form of lead). Considering effects at all spatial scales is essential for a realistic appraisal of potential impact to specific locations. "Although the life-cycle impact assessment (LCIA) process within an LCA is a systematic framework in which emissions are evaluated and interpreted with regard to potential life-cycle health and environmental impacts, the 
scope of LCIA does not allow full-scale, site-specific risk assessments (McKone and Small, 2007).”

The need for incorporating spatial concerns or evaluating spatial impacts has been recognized but many solutions have not come forth. Some suggest creating a sort of equivalence for damage level between different ecosystem types (e.g., a water use impact relation between forest and desert climates) based on average factors that describe a particular ecosystem type. Still others propose dividing the inventory by location of emission by rough type such as city or rural and then performing separate analyses (Burgess and Brennan, 2001). Multimedia fate and transport models provide more detailed and realistic spatial analyses of emissions.

The extent to which industrial releases affect people are determined by several factors: chemical properties, fate and persistence of chemicals in the environment, distance between chemicals and populations, as well as food production (MacLeod et al., 2004). It is not obvious how to best include spatial concerns in impact analysis. The optimal choice would be to have a model of appropriate scale, i.e., the expected travel distance of the chemical (MacLeod et al., 2004). When evaluating the variety of chemicals that may be released by one industrial process, meeting this requirement becomes difficult without including spatial specificity on a variety of scales. Huijberts et al. investigated the fate of 375 substances using the USES-LCA (Uniform System for the Evaluation of Substances - Life cycle assessment) method and found that near $90 \%$ of these substances encompass a spatial range (mean distance the substance covers after emission) smaller than the continental scale used by the USES model (Huijbregts et al., 
2003). Hence for many of those 375 substances a more localized spatial resolution would have produced more accurate results.

Industrial chemical releases between separate locations result in populations that are exposed to different concentrations of compounds. Due to spatial differences, these populations have distinct toxicological effects and ultimately dissimilar levels of risk. "Neglecting spatial heterogeneity introduces uncertainty into the assessment because certain characteristics of the real system are not captured (MacLeod et al., 2004)." Incorporating spatial uniqueness into supply chain decision-making "is more credible and informative" than analyses that ignore geographic differences (MacLeod et al., 2004).

At the same time spatially explicit models are more data and time intensive (MacLeod et al., 2004). The accuracy of models relates to the uncertainty in data inputs. For long range transport, uncertainties in mass-transfer values and environmental halflives are great enough to make less spatially refined (simpler) models as accurate as the more complex spatially resolved models (Bennett et al., 2001).

Many life cycle assessments neglect the spatial dependence of impacts despite the fact that for certain situations, spatial analysis is necessary. Zhang et al. found that comprehensive fate and transport assessment is needed when toxicity is low or moderate and similar among the substances considered. Toxicity will differ among substances due to travel distance and the locations or environmental compartments substances end up in along the way (Zhang et al., 2001). Additionally, "a spatially explicit assessment is necessary to evaluate the relative contribution to population intake in a remote region as a result of a small local source versus a larger source in a distant location (MacLeod et al., 
2004)." In terms of the specific problem considered in this dissertation, whether to pursue a centralized or decentralized facility location strategy, considering spatial impacts is essential for accurate assessment of environmental impact. Because the difference in effects from smaller local point sources and distant larger sources are considered, spatially specific analysis must be used.

\subsubsection{Assimilation capacity}

The assimilation capacity of a particular location for certain releases must be considered. Spatial scale again plays a very important role for assimilation capacity. Local, regional, and global assimilation capacities differ for particular compounds. In particular, forests and seas have very different abilities to handle acidification. Hence, distinctions must be made between different types of ecosystems' assimilation capacities (Burgess and Brennan, 2001). The assimilation capacity should be based upon the particularities of the ecosystems that make up the region of consideration. Accounting for how releases from a particular product relate to the total quantity of a compound released by society, gives a better picture of how the particular product's release affects the assimilation capacity of a specific location.

The assimilation capacity of a location is directly correlated with the severity of the ecological damage to that location. Hence, the ecosystem well-being indicators utilized for environmental remediation will differ from location to location. Since ecosystems are not static but always changing in response to a variety of parameters (e.g., seasonal differences in temperature and light), ecological damage will also have varying degrees of severity with time (Graedel, 1998). Releases of multiple compounds can 
converge and worsen a particular environmental effect. This convergence makes quantification of multiple compounds' effects difficult.

\subsubsection{Allocation}

Allocation of impacts can be difficult for LCA. Consensus about how to perform allocation has not been reached (Burgess and Brennan, 2001). A manufacturing facility may create several products, making it difficult to decide which impacts are due to which product. In order to decide, a particular factor that presumably is proportional to the impact is compared between the several products. Many allocation strategies use product weight for comparison. Product volume, embedded energy, or value (especially monetary value) are other allocation strategies employed. The choice of allocation factor may not be rigorously defendable. Yet the allocation factor has many effects for the outcomes of the overall life cycle assessment including recommendations. Another approach involves considering the specifics of processing in order to deduce which types of equipment are used to create specific products and to only assign responsibility for the environmental impact caused by the specific processes to the responsible products. Also, enlarging the system boundary provides a way to avoid some allocation problems, meanwhile further complicating data gathering and analysis (Burgess and Brennan, 2001). Sensitivity analysis can be employed to illuminate the repercussions of allocating impacts in a particular way (Graedel, 1998).

Yet, still more problems with allocation exist. Allocation can be especially difficult when considering impact to users. Every person comes in contact with a variety of harmful compounds: deciding how much various products, activities, or events lead to different human health impact levels is complicated. Additionally, different responsible 
parties control different parts of a product life-cycle's environmental impact (Figure 2.6). Each responsible party differs from each other in their actions and susceptibilities and often as not, location. Therefore, recommendations for different parts of the life-cycle can have disparate ramifications for the parties involved.

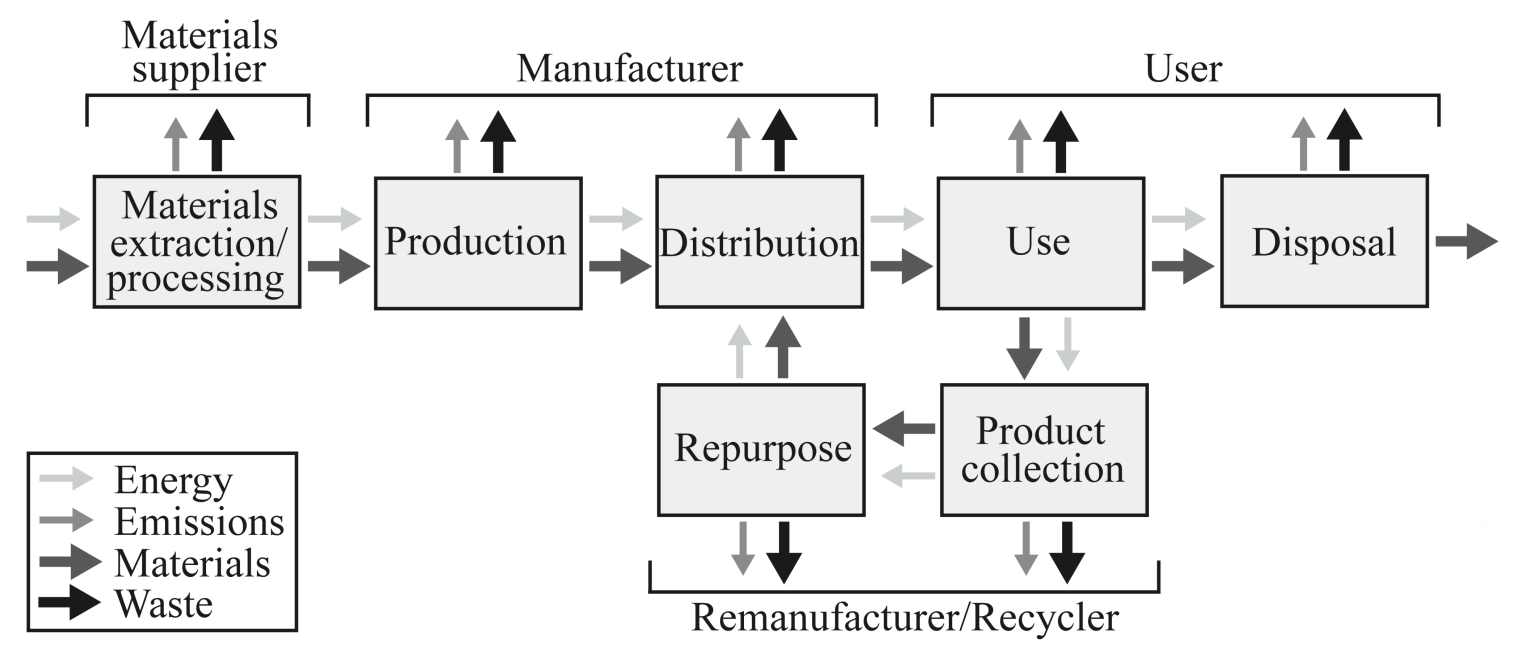

Figure 2.7: Responsible parties along the product life-cycle adapted from (Graedel, 1998)

\subsection{Indicators}

Indicators assess environmental impact. This assessment is then used to establish the impact and weighting for life cycle assessment or similar tools. Indicators quantify particular categories of impact, resulting in a predicted environmental damage (Borland and Wallace, 1999). In general, indicators provide a single impact score by evaluating a single parameter or assessing many impact parameters and combining their values. The science used to measure environmental impacts is incomplete and complex. Hence, indicators can be inaccurate impact assessors (Lewis and Gertsakis, 2001). Each indicator is a balance between the effort extended to achieve the indicator score and the knowledge provided from that result (Figure 2.8). Different indicators take more time and thought to 
complete while presenting more or less to aid the designer when choosing between options.

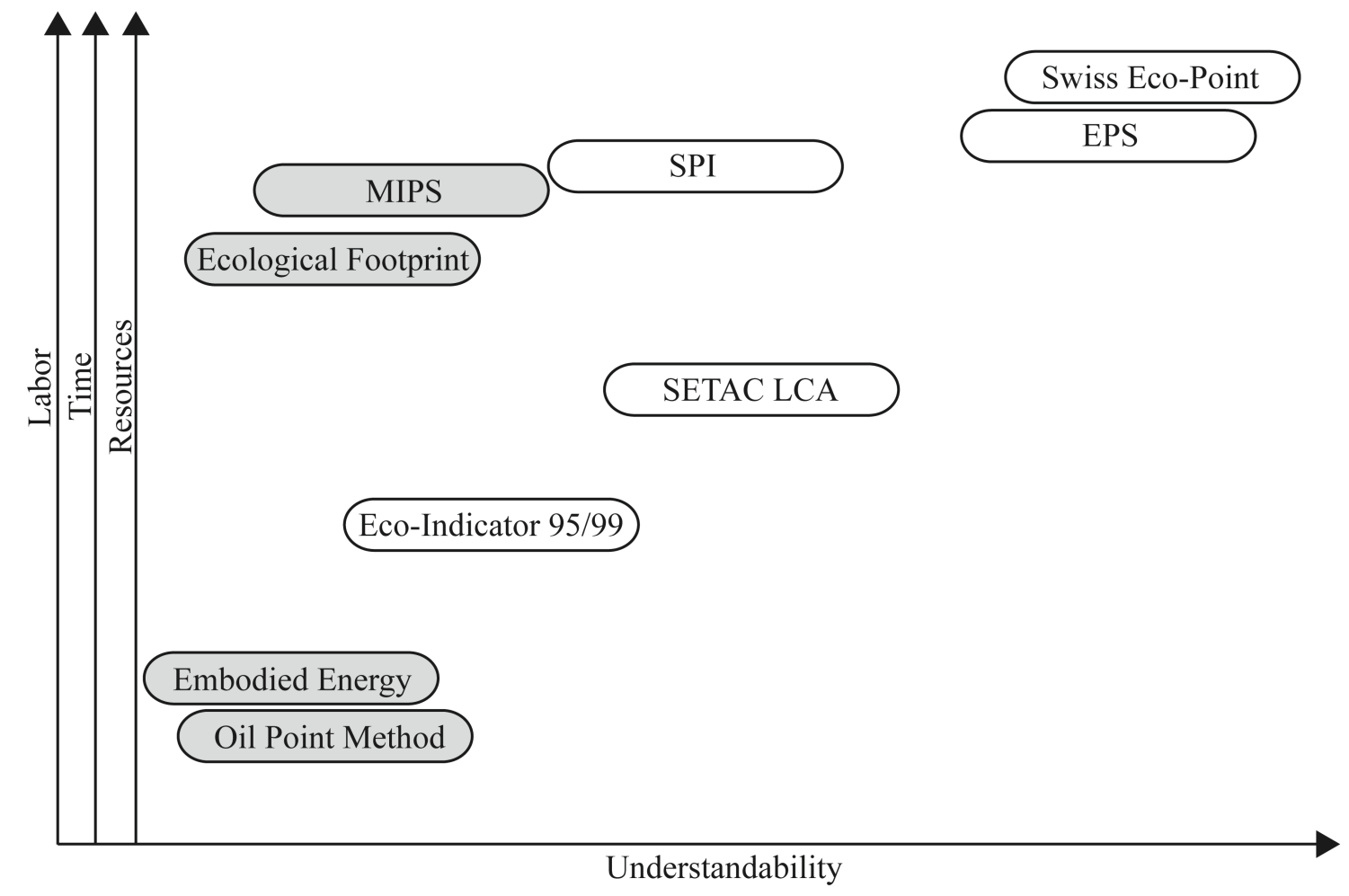

Figure 2.8: Comparison of indicators (single parameter or broad indicators in grey, multi-parameter or impact indicators in white) for insight gained from effort exerted - adapted from (Clarke and Gershenson, 2006)

Indicators can be characterized by focus. Some indicators focus on single categories of impact while others consider multiple categories. Single parameter indicators, also called broad indicators, generally quantify an amount of a particular waste created (Burgess and Brennan, 2001) or resource used. Single parameter indicators may be simpler to execute, but the results may miss crucial areas of environmental impact that have no direct quantitative relationship to resource use (Burgess and Brennan, 2001). Additionally, the single parameter indicators lack any sort of ranking of importance of the parameter under scrutiny (often called weighting) (Burgess and 
Brennan, 2001). Multi-parameter indicators, also known as impact indicators, involve complex assessment of a variety of different issues, which then receive weights by how important each issue is deemed. These different issues are weighted and then aggregated into a single score which then may be difficult to interpret since individual environmental concerns are not easy to tease out of a single number (Burgess and Brennan, 2001). Some of the issues under consideration may not be obviously quantifiable (e.g., the worth of aesthetics) (Burgess and Brennan, 2001).

Additionally, how specific environmental concerns are weighted relative to each other can be contested. Using experts to determine weightings may change by the experts involved in the decision (Burgess and Brennan, 2001). Despite the problems mentioned, both types of parameters can portray environmental impacts in a way that furthers some understanding of product design choices.

\subsubsection{Single parameter indicators}

Single parameter indicators have the potential to provide results that are more meaningful, since all impacts are rated by the effect to one unit of measure such as mass flow in kilograms for Material Input Per Service Unit (MIPS). However, these indicators also have the disadvantage of overlooking environmental impacts not well characterized by that unit of measure. For MIPS the differences in materials due to toxicity are ignored (Lewis and Gertsakis, 2001). Table 2.6 shows how single parameter indicators differ by units, environmental impact categories considered, and data requirements. 
Table 2.6: Single parameter indicators - adapted from (Clarke and Gershenson, 2006)

\begin{tabular}{|c|c|c|c|c|}
\hline \multicolumn{2}{|c}{$\begin{array}{c}\text { Unit of } \\
\text { Comparison }\end{array}$} & $\begin{array}{c}\text { Impact } \\
\text { Categories } \\
\text { Characterized }\end{array}$ & $\begin{array}{c}\text { Data } \\
\text { Requirements }\end{array}$ & $\begin{array}{c}\text { Advantages or } \\
\text { Disadvantages }\end{array}$ \\
\hline $\begin{array}{c}\text { Ecological } \\
\text { Footprint }\end{array}$ & $\begin{array}{c}\text { Hectares of } \\
\text { land }\end{array}$ & Land use & $\begin{array}{c}\text { Product life- } \\
\text { cycle } \\
\text { inventory }\end{array}$ & $\begin{array}{c}\text { Lacks data } \\
\text { needed for } \\
\text { analysis and only } \\
\text { focuses on effects } \\
\text { to land }\end{array}$ \\
\hline $\begin{array}{c}\text { Embodied } \\
\text { energy }\end{array}$ & Energy & Energy use & $\begin{array}{c}\text { Product life- } \\
\text { cycle } \\
\text { inventory }\end{array}$ & $\begin{array}{c}\text { Simple measure } \\
\text { allows easy } \\
\text { comparison } \\
\text { between products }\end{array}$ \\
\hline $\begin{array}{c}\text { Material } \\
\text { Input Per } \\
\text { Service } \\
\text { Unit } \\
\text { (MIPS) }\end{array}$ & $\begin{array}{c}\text { Mass flow in } \\
\text { kilograms }\end{array}$ & Resource use & $\begin{array}{c}\text { Extensive } \\
\text { data with } \\
\text { high } \\
\text { accuracy }\end{array}$ & $\begin{array}{c}\text { Neglects } \\
\text { differences } \\
\text { between materials }\end{array}$ \\
\hline $\begin{array}{c}\text { Oil Point } \\
\text { Method }\end{array}$ & $\begin{array}{c}\text { Energy content } \\
\text { of one } \\
\text { kilogram of } \\
\text { crude oil } \\
\text { called an Oil } \\
\text { Point (OP) }\end{array}$ & Resource use & $\begin{array}{c}\text { Product life- } \\
\text { cycle } \\
\text { inventory }\end{array}$ & $\begin{array}{c}\text { Gives qualitative } \\
\text { results that needs } \\
\text { careful holistic } \\
\text { interpretation }\end{array}$ \\
\hline
\end{tabular}

The Ecological Footprint (Wackernagel, 1994) assesses environmental impact by calculating the total area of land "bioproductivity" or productive capacity used to support an activity. Factors relate different types of resource extraction (such as fossil fuel use) into areas of land productive capacity required for that activity. All effects can be represented by a single number with the unit hectares of land required (Chambers et al., 2000; Lewis and Gertsakis, 2001). Embodied Energy is a concept that comes from input/output analysis, which assesses the total amount of energy required for the product life-cycle (Lewis and Gertsakis, 2001). The Material Input Per Service Unit (MIPS) (Schmidt-Bleek and Klüting, 1994) indicator accounts for specific material and energy 
flows throughout a product life-cycle to reduce material throughput (Hertwich et al., 1997; Lewis and Gertsakis, 2001). The Oil Point Method (OPM) quantifies environmental impact by the energy content of one kilogram of crude oil called an "Oil

Point." LCA methodology is used to uncover the energy used in each part of the product life-cycle and conversion information from energy into oil point indicators is provided (Berner et al., 2005).

\subsubsection{Multi-parameter indicators}

Multi-parameter indicators combine designated values of environment impact in several areas into a single score. The implication of the individual indicator can be buried in the combined score because of the tradeoffs among the different effects of each environmental impact category. For that reason, multi-parameter indicators can also be more difficult to assess than single indicator values. However, multi-parameter assessments have the potential to account for a larger variety of environmental impacts. Table 2.7 shows how multi-parameter indicators differ by units, environmental impact categories considered, and data requirements. 
Table 2.7: Multi-parameter indicators adapted from (Clarke and Gershenson, 2006)

\begin{tabular}{|c|c|c|c|c|}
\hline & Units & Impact Categories & Data Needs & Pros and Cons \\
\hline $\begin{array}{l}\text { Swiss Eco- } \\
\text { point (SEP) }\end{array}$ & $\begin{array}{l}\text { Eco- } \\
\text { point }\end{array}$ & $\begin{array}{l}\text { Waste reduction, } \\
\text { toxicity, } \\
\text { climate change, } \\
\text { ozone generation, } \\
\text { resource depletion, } \\
\text { etc. (14 } \\
\text { categories) }\end{array}$ & $\begin{array}{l}\text { Location } \\
\text { specific data } \\
\text { with a fair } \\
\text { amount of } \\
\text { accuracy }\end{array}$ & $\begin{array}{c}\text { Ignores } \\
\text { emissions } \\
\text { outside of } \\
\text { Switzerland }\end{array}$ \\
\hline $\begin{array}{c}\text { Environmental } \\
\text { Priority } \\
\text { System (EPS) }\end{array}$ & $\begin{array}{c}\text { Environ } \\
\text { mental } \\
\text { load unit } \\
\text { per } \\
\text { kilogram }\end{array}$ & $\begin{array}{l}\text { Human health, } \\
\text { biological } \\
\text { diversity, } \\
\text { manufacturing, } \\
\text { waste reduction, } \\
\text { and aesthetics } \\
\end{array}$ & $\begin{array}{l}\text { Little data } \\
\text { needed but high } \\
\text { accuracy } \\
\text { required }\end{array}$ & $\begin{array}{l}\text { Errors in input } \\
\text { information } \\
\text { strongly affect } \\
\text { analysis }\end{array}$ \\
\hline $\begin{array}{l}\text { Sustainable } \\
\text { Process Index } \\
\text { (SPI) }\end{array}$ & $\begin{array}{l}\text { Meter } \\
\text { squared }\end{array}$ & $\begin{array}{l}\text { Waste reduction, } \\
\text { toxicity, } \\
\text { climate change, } \\
\text { ozone generation, } \\
\text { depletion, etc. }\end{array}$ & $\begin{array}{l}\text { Location } \\
\text { specific data } \\
\text { with a fair } \\
\text { amount of } \\
\text { accuracy }\end{array}$ & $\begin{array}{l}\text { Robust to some } \\
\text { errors in input } \\
\text { information }\end{array}$ \\
\hline $\begin{array}{l}\text { SETAC's life- } \\
\text { cycle impact } \\
\text { assessment } \\
\text { (SETAC } \\
\text { LCA) }\end{array}$ & $\begin{array}{c}\text { Relative } \\
\text { scale }\end{array}$ & $\begin{array}{c}\text { Climate change, } \\
\text { ozone generation, } \\
\text { toxicity, } \\
\text { acidification, } \\
\text { eutrophication, } \\
\text { etc. }\end{array}$ & $\begin{array}{l}\text { Little data input } \\
\text { needed }\end{array}$ & $\begin{array}{l}\text { Gives consistent } \\
\text { results }\end{array}$ \\
\hline $\begin{array}{l}\text { Eco-indicator } \\
95 \text { and } 99\end{array}$ & $\begin{array}{c}\text { Numeric } \\
\text { value }\end{array}$ & $\begin{array}{l}\text { Human health, } \\
\text { ecosystem health, } \\
\text { and resources }\end{array}$ & $\begin{array}{l}\text { Product life- } \\
\text { cycle inventory }\end{array}$ & $\begin{array}{c}\text { Incorporates } \\
\text { chemical fate } \\
\text { and differences } \\
\text { between } \\
\text { receiving } \\
\text { ecosystems, } \\
\text { overemphasizes } \\
\text { acidification, } \\
\text { deemphasizes } \\
\text { land use and } \\
\text { biodiversity } \\
\text { concerns }\end{array}$ \\
\hline
\end{tabular}


The Swiss Eco-point (SEP) measures location specific impacts by a relative comparison measure, eco-point, derived from ecosystem health quality levels. Fourteen categories of impact are evaluated for relative distance from a target for the impact category such that values that lie further from the target value for a category are given higher weightings (Hertwich et al., 1997; Lewis and Gertsakis, 2001). The Environmental Priority System (EPS) was created by Volvo, the Federation of Swedish Industries, and the Swedish Environmental Research Institute to combine factors from several impact categories; willingness to pay measures are used to quantify the importance of particular impacts (Ashley, 1993; Hertwich et al., 1997; Lewis and Gertsakis, 2001). Very little input information is required to perform this analysis, but errors in input information can affect the analysis strongly (Hertwich et al., 1997). Ecoindicator 95 was created by Pré Consultants and the Dutch Government in 1995 and improved in 1999 as Eco-indicator 99 (Pré Consultants, 2006a). For the Ecoindicator 95 method, the weights for indicators are measured by the distance from an impact category target, similar to the Swiss Eco-point. Only a few impact categories are used, hence certain impacts like acidification are overemphasized by the Eco-indicator (Jansen and Vercalsteren, 2001; Lewis and Gertsakis, 2001). The Sustainable Process Index sets out to quantify pollution taxation on the environment using land or area as the measure similar to the ecological footprint except looking at several impact areas. Data must be fairly accurate to beget a pertinent outcome. The Society of Environmental Toxicology and Chemistry's Life-cycle Impact Assessment (SETAC LCA) characterizes impacts by assigning each a relative score in particular impact categories. Not much information is needed to perform this analysis (Hertwich et al., 1997). 
Through the interpretation of an LCA, an advised course of action to lessen detrimental environmental effects is proposed. This proposal comes from synthesizing information from each of the previous LCA steps (Graedel, 1998). The LCA recommendations can be used to improve all aspects of design, production, and what happens to products after use, so called product retirement.

\subsubsection{Indicator Development}

Methods to develop indicators are differentiated by who participates or, so-called, top-down and bottom-up approaches. The top-down approach to creating indicators (Azapagic, 2004; Esty et al., 2005; Goedkoop and Spriensma, 2000; United Nations Division for Sustainable Development (UN DSD), 2009) involves only experts such as company decision-makers, politicians, policy-makers, or scientists (Bell and Morse, 2008; Singh et al., 2009). A purely bottom-up approach is less common, but hybrids of top-down and bottom-up approaches are used more often. There are several ways hybrid approaches provide guidance in the development of sustainability indicators (Alliance for Sustainability, 2006): (1) decision-makers can solicit opinions from stakeholders (e.g., local community residents including indigenous tribes, non-governmental organizations, and industrial groups) (Chamaret et al., 2007; Fraser et al., 2006; Global Reporting Initiative, 2008), (2) stakeholders (such as communities) can seek out experts, or (3) stakeholders can leverage their own collective expertise (AtKisson, 1996).

Once the decision about who will be involved in developing and weighting indicators is made, there are numerous processes to develop sustainability indicators (World Bank, 1996). In any indicator development process, participants may be given background material or participate via meetings, workshops, group activities with like or 
unlike-minded individuals, open-forums, interviews, or surveys. In general, increased participation of stakeholder groups lengthens the time required to develop a set of indicators.

\subsubsection{Problems with conventional life cycle assessment and indicators}

Local scale spatial impacts are generally neglected in LCA (Burgess and Brennan, 2001; Graedel and Allenby, 2003; Guinée, 2002). Ignoring the spatial effects (i.e. location) of environmental damage is an approach taken to simplify environmental impact characterization. However, the results from this type of approach fall short of a full analysis of environmental impact (Burgess and Brennan, 2001), especially risk.

Additionally, the impact analysis step in Life-cycle Impact Assessment neglects: transport and specific location of emissions, ambient emissions present, and environmental effects that are difficult to characterize (Reap et al., 2003). LCA is an important tool for evaluating the environmental impact of product designs. However, impact analysis in LCA lacks consideration of the particular sensitivities and initial conditions of the places where impacts occur along a product's life-cycle. "LCA does not provide the framework for a full-fledged local risk assessment study, indentifying which impacts can be expected due to the functioning of a facility in a specific locality (Guinée, 2002)." For example, water usage requirements in dry and wet climates have different severities of effects (Reap et al., 2004).

Also, LCA neglect the changing interaction of a product's effect on the environment with time (Guinée, 2002). Considering the effect of time is necessary for forecasting into the future (Graedel, 1998). Impacts that are difficult to characterize with indicators and difficult to evaluate with LCA are ignored altogether. 
Reap et al. connect ecosystem models to a simplified LCA to address the missing spatial and dynamic dimensions while still using the current capabilities of LCA (Reap et al., 2003). However, Reap et al.'s approach can only be applied to the local scale because of the complexity and details of parameters involved. All scales of environmental impact, from local to global, should be considered in order to make a full analysis. The greatest difficulty in assessment lies in characterizing local environmental impact.

\subsection{Characterizing Local Environmental Impact}

Looking at local environmental impacts gives a different perspective than considering regional or global environmental impacts. Depending on the compounds released and the scale of release, (local, regional, and global) impacts can have different short-term or long-term impacts to people and the environment. In terms of risk perception, local environmental impacts can be more easily perceived when directly seen by people. Direct interaction influences people's perception of risk from local environmental impacts, since buying and using certain products is based upon their own sensory experience of the effects instead of an abstract idea like global climate change. In areas where glaciers are receding in a visible manner, local impacts of climate change can be easily seen and acknowledged. But in many other locales, it is difficult to perceive or notice climate change effects directly because the effects do not occur regularly or are subtle instead of as visibly obvious as receding glaciers. For example, increased average temperature (shifts in seasons) is difficult for a person to feel, looking at data can be more convincing. Increased intensity of storms or weather is hard to perceive because comparisons must be made between storms now and in the past. Human memory is 
faulty. All in all, over and underestimation of environmental impact results when local spatial considerations are neglected (Pennington et al., 2005).

Where substances move - or the chemical fate - occurs because of the substance's chemical characteristics such as solubility in water and the characteristics of the environs where the particular substances are released such as air flows and temperature. Chemical characteristics are the same everywhere but different environments have vastly different characteristics (Mackay et al., 1992). Hence, the specific location where substances are released effects how much of a substance is in what parts of an environment. The quantities of substances in particular locations have much greater risk for human and environmental health than other locations - which has a great effect on the total risk created by release of those substances.

Multimedia fate and transport models consider the movement of substances simultaneously through a variety of media (e.g., air, water, and biological organisms). This approach considers all potential emission locations of a particular substance, follows mass-balance relations, incorporates environmental fate and persistence, and tracks the substance from emission sources to sinks. Assessing the sinks includes evaluating organism exposure and formulating risk characterizations for human and environmental health (McKone and MacLeod, 2003b). Risk is the potential of harmful results coming from contact with an agent capable of causing negative change (Zhang et al., 2001). Multimedia fate and transport analysis has been used to pinpoint for a particular substance when and along what part of the substance's transport remediation endeavors have the most potential for success (McKone and MacLeod, 2003b). 
The output of multimedia fate and transport models is a quantity of a particular substance in a specific media (sometimes called an environmental compartment) based upon conservation of mass. These models characterize compounds emitted on a regular basis (Renner, 1995). Spatially explicit models take into account the proportion and location of different compartments relative to a particular geographical area of interest. Hence, a spatially explicit multimedia fate and transport model outputs a quantity of a particular type of substance in a specific compartment at a distinct location within a geographical region.

Two types of information are required to enter into a multimedia fate and transport analysis - information about emitted compounds such as physical/chemical properties and information about the environment which the compounds are emitted to such as landscape properties (e.g., meteorological data that influences chemical reaction and transformation between phases or media) (Renner, 1995). The life-cycle inventory of a product will give the concentrations of outputs of specific categories of compounds. The physical and chemical properties of these released compounds can be found from experimental databases or estimated by EPA EPISuite ${ }^{\mathrm{TM}}$ software (U.S. Environmental Protection Agency (EPA), 2009)by knowing the CAS Registry number (Chemical Abstracts Service a division of the American Chemical Society) or the structure of compounds.

The information about the released compounds' physical and chemical properties as well as background concentrations in the environment can be put into a multimedia fate and transport model and the output will be concentrations of these particular compounds in particular compartments of the environment (e.g. plant foliage, sediment, 
surface water and the stratosphere). These concentrations in particular environmental compartments are based on the compounds' chemical properties and the environmental properties of the location, e.g. ambient temperature.

After obtaining the concentrations of compounds in various domains, an assessment of exposure can be done. Exposure occurs by the intake of compounds through several routes - inhalation, ingestion, and dermal contact. Exposure is usually evaluated through average daily intake (intake rate) of a compound or by the concentration taken in during a particular period of time of contact with the compound (McKone and MacLeod, 2003b). Using standard exposure information to assess total intake by uptake rates for inhalation, ingestion, and dermal contact can allow the assessment of exposure to humans or the environment. The data for how much of a particular compound will be taken in by people and other organisms through these routes can be found from several resources (National Center for Environmental Assessment, 1989; U.S. Environmental Protection Agency, 2009b). The environmental exposure can be assessed by considering intake by key species that act as indicator species for a particular type of ecosystem. Biologists have identified many of these indicator species that are symbols of eco-region health (e.g., fish in the Great Lakes).

After the concentration of compounds in humans, other organisms, and the environment is estimated using the concentration and exposure information, the toxicity of these compounds to these bodies must be considered. The toxicity data for particular compounds can be found from the EPA IRIS (Integrated Risk Information System) database (U.S. Environmental Protection Agency, 2009b) or TOXNET (U.S. National Library of Medicine, 2009). Reference toxicity levels for humans often come from 
studies on rats. This toxicity data and exposure concentration is then used to calculate relative risk of release of the specific compound in the particular concentration to a standard known problem causing compound (e.g., benzene, a known carcinogen) through a ratio (Shonnard and Hiew, 2000). Relative risk is the typical comparison for toxicity of compounds.

\subsubsection{Multimedia fate and transport models}

Most multimedia fate and transport models are based on Mackay's approach which includes conservation of mass and dividing the environment into compartments (e.g., the CHEMGL model includes such compartments as surface water, sediment, vadose soil, and plant foliage (Zhang et al., 2003)) which are best applied to low level diffuse emissions over long periods of time and large distances (McKone and MacLeod, 2003b).

MacLeod and Mackay utilize the following general approach to multimedia fate and transport problems:

- Gather chemical information

- Locate emissions data

- Assess chemical fate without regard to geographic differences

- Assess chemical fate regionally

- Assess chemical fate locally (MacLeod and Mackay, 1999)

Many of the models are fugacity type models, where fugacity has the units of pressure (Pascal) and corresponds to a likelihood of a compound changing to another chemical phase (e.g., liquid to gas) or to another compartment (e.g., from sediment to surface water) (McKone, 1994). Fugacity based models makes computations easier for 
transport between media and phases because at small concentrations of compounds of interest, fugacity is proportional to concentration (McKone, 1994).

The accuracy and consistency of multimedia fate and transport models depends upon the problem set-up or scenarios considered, conceptualization of influences in the model, computational approach, approximations made for parameter values, and uncertainty analysis (McKone, 1994). Models can be described as screening level, which are used during the beginning of the design process to highlight potential ecological issues, or assessment level, which can make more accurate judgments. However, the quality of data significantly impacts the accuracy for either screening level or assessment level models (Whelan et al., 1992). The screening level of models cannot be validated because so many parameters are incorporated into a model's structure and each parameter carries with it uncertainty. Verification of the models can highlight how realistic or useful characterizations of compound transport can be made with a particular multimedia fate and transport model (Zhang et al., 2003). Most of the models in Table 2.8 are screening level models.

Multimedia fate and transport models can be distinguished by several criteria:

- Geographic specificity

- Number of compartments

- Closed or open systems

- Mass transfer/exchange processes

- Steady-state or dynamic

- Compartment mixing

- Spatial specificity
- Target or transport focus

- Model outputs

- Timescale of model

- Chemical category focus

- Verification

- Uncertainty characterization

- Risk characterization 
Table 2.8 illustrates some of the differences between these models (Bakker et al., 2003; Fenner et al., 2005; Huijbregts et al., 2005; Huijbregts et al., 2003; Jolliet et al., 2003; Life Cycle Systems Group, 2005; Mackay et al., 1996; MacLeod et al., 2004; MacLeod and Mackay, 1999; MacLeod and MacKay, 2004; Matthies et al., 2004; McKone, 1993a,b,c; Pennington et al., 2005; Prevedouros et al., 2004; Rosenbaum and Margni, 2004; Struijs and Peijnenburg, 2002; Su and Wania, 2005; ten Berge, 1994; Toose et al., 2004; van de Meent, 1993; Woodfine et al., 2002; Zhang et al., 2003).

The models, which are generic, have geographic parameters that describe a region of a particular size. These parameters can be tailored for a specific geographic area. However, the generic models lack the detail in environmental parameters (or landscape parameters) that the location specific models possess. Additionally, the larger the spatial resolution scale (regional to global) the less specificity about geographic and climatic differences is incorporated into a model. Even within the regional and continental spatial resolution scales, certain models have better geographical specificity in parameters than others. In part these differences in specificity have to do with how many different compartments (and how representative those compartments are of the environment) model possesses. Greater specificity in geographic detail is necessary in order to adequately compare differences between more distant and larger emission sources and smaller more localized emission sources.

Chemicals can move through the environment by a variety of mass transfer processes, advection, diffusion, chemical reaction, and others. Some models only consider a few of these processes for simplicity. Including more mass transfer processes provides a better picture of where compounds move and concentrations arrive. 
Table 2.8: Comparison of multimedia fate and transport models - mass transfer processes include advection (A), chemical reaction (C), diffusion (D), non-diffusive processes $(\mathrm{N})$, and partitioning $(\mathrm{P})$

\begin{tabular}{|c|c|c|c|c|c|c|}
\hline Model Name & 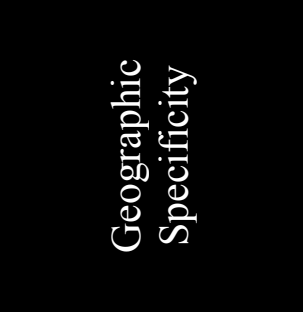 & 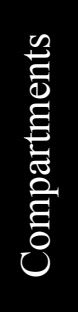 & 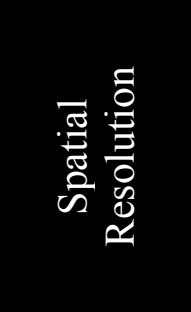 & 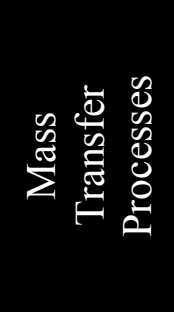 & 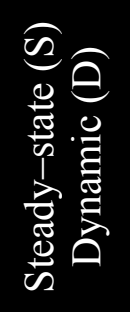 & 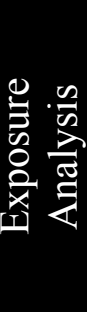 \\
\hline $\begin{array}{l}\text { BETR North } \\
\text { America }\end{array}$ & $\begin{array}{c}24 \text { watershed } \\
\text { regions }\end{array}$ & 7 & Continent & A C D & $\mathrm{S}$ & \\
\hline BETR Europe & 50 regions & 7 & Continent & A C D & $S \& D$ & \\
\hline BETR-World & $\begin{array}{l}25 \text { global } \\
\text { regions }\end{array}$ & 7 & Globe & A C D & $S \& D$ & \\
\hline CAirTOX & Generic & 7 & Region & $\mathrm{ACD}$ & S or D & $\mathrm{X}$ \\
\hline CalTOX & Generic & 7 & Region & A C D N & S or D & $\mathrm{X}$ \\
\hline ChemCAN & $\begin{array}{c}24 \text { zones in } \\
\text { Southern } \\
\text { Ontario }\end{array}$ & 5 & Region & A C D & $S \& D$ & $\mathrm{X}$ \\
\hline CHEMGL & $\begin{array}{c}\text { Great Lakes } \\
\text { watershed }\end{array}$ & 10 & Region & A C D N & $S \& D$ & $\mathrm{X}$ \\
\hline CHEMGL (U.S.) & 9 U.S. regions & 11 & Region & $\mathrm{ACDN}$ & S \& D & $\mathrm{X}$ \\
\hline $\mathrm{EQC}$ & $\begin{array}{c}\text { Generic } 100,000 \\
\text { sq. km region }\end{array}$ & 6 & Region & A C & $\mathrm{S}$ & \\
\hline GEOTOX & Inland W. U.S. & 8 & Region & A D & $\mathrm{S}$ & $\mathrm{X}$ \\
\hline Globo-POP & $\begin{array}{l}10 \text { latitudinal } \\
\text { global zones }\end{array}$ & 9 & Globe & A C D & $\mathrm{D}$ & \\
\hline HAZCHEM & $\begin{array}{l}\text { European soil } \\
\text { characteristics }\end{array}$ & 5 & Region & A C & $\mathrm{S}$ & $\mathrm{X}$ \\
\hline Impact 2002 & W. Europe & 12 & Continent & $\mathrm{ACD}$ & S\&D & $\mathrm{X}$ \\
\hline Impact 2002 & $\begin{array}{c}42 \text { global } \\
\text { regions }\end{array}$ & 12 & Global & A C D & $S \& D$ & $\mathrm{X}$ \\
\hline Mackay Level I & Generic region & 6 & Region & $\mathrm{P}$ & $\mathrm{S}$ & \\
\hline Mackay Level II & Generic region & 6 & Region & $\mathrm{AC}$ & $\mathrm{S}$ & \\
\hline Mackay Level III & Generic region & 4 & Region & A C D & $\mathrm{S}$ & \\
\hline SimpleBox & Generic & 8 & Region & $\mathrm{ACD}$ & $\mathrm{S}$ & \\
\hline USES-LCA & W. Europe & 6 & Continent & $\mathrm{AC}$ & $\mathrm{S}$ & $\mathrm{X}$ \\
\hline USES-LCA & N. Hemisphere & 6 & $\begin{array}{l}\text { Continent } \\
\text { hemi- } \\
\text { sphere } \\
\end{array}$ & A C & $\mathrm{S}$ & $\mathrm{X}$ \\
\hline
\end{tabular}


Also, assuming that the model is operating at steady-state is a simplifying assumption for models because in the real world the environment changes with time and is dynamic. However, dynamic models are much more computationally intensive. For a compound released to air, by the time steady state is achieved the chemical has traveled regionally from its emission source.

After comparing these available multimedia fate and transport models, several models work well for this research. CHEMGL possesses the greatest geographic detail. Hence, CHEMGL provides the greatest accuracy for assessing local environmental impacts. Changing the CHEMGL model parameters to become more spatially localized is possible. Properties such as humidity and temperature are already based upon averages and will likely stay the same on a local or regional scale. The properties that will change are landscape parameters that will be altered in relation to the physical size of the local region characterized. Other continental scale models include BETR North America (for North America) and IMPACT 2002 (for Europe). However, IMPACT 2002 seems to have more geographically specific parameters and overall provide a more accurate picture than BETR North America. Outside of North America and Europe, different models have been altered for other locations (e.g., ChemCAN adapted for Japan (Kawamoto et al., 2001), USES-LCA adapted for Australia (Huijbregts et al., 2003)).

Often researchers utilize multimedia fate and transport analysis for only specific chemical compounds. This is useful for predicting where particular compounds will end up over time. However, this analysis does not help industries prevent the spread of many different compounds. In order to be effective at reducing damage to people and the environment, multimedia fate and transport analysis must be applied to the design of 
industrial systems. Multimedia fate and transport analysis is less commonly used to predict and hence prevent the spread of chemicals before an industrial system is in place.

\subsection{Social Sustainability}

Many organizations have incorporated sustainability into their mission, vision, and strategic goals (Kates et al., 2005). Traditionally, businesses consider the economic effects of their actions. Over the past several decades, many businesses have taken actions to minimize their environmental impact. Businesses are now beginning to consider social sustainability in conjunction with economic and environmental aspects. Social sustainability for companies include a wide range of concerns from labor practices to responsibility for products, customers, and society as a whole (Global Reporting Initiative, 2008). Some of these concerns are regulated legally (Occupational Safety \& Health Administration (OSHA), 2009) while other concerns are completely voluntary for companies to address (AccountAbility, 2008; Fairtrade Labelling Organizations International (FLO), 2009; International Labour Organization (ILO), 2009; Social Accountability International, 2001; United Nations (UN), 1948). Some companies are expanding their consideration of social impacts to include how the business affects consumers and stakeholders within both local and regional communities (Global Reporting Initiative, 2008).

\subsection{Summary}

Today, researchers focus on the forward end of production or the reverse but not both. Since product take-back has a legal mandate for compliance in Europe (and legislation is spreading to other countries as well) (Clarke and Gershenson, 2006) a switch in research focus is needed. Attention must be given to the optimization of 
forward and reverse production together. Fleischmann et al. have already found that optimizing forward and reverse supply chain networks at the same time can have significant cost savings over considering only one direction for particular products versus considering only a single direction (Fleischmann et al., 2001). Hence, researchers today must look at forward and reverse production as integrated systems to make better recommendations for their design.

Strategic supply chain research has focused on quantifying costs for decades. However, cost is not the only important factor to businesses, governments, or the public. Environmental impact is emerging as an important concern to all three groups, as well as social sustainability. Hence, the consideration of other aspects of facilities such as environmental impact, specifically the risks of chemical releases, and economies of scale must all be brought into the analysis. Existing research considers these elements separately in conjunction with cost. In order to better reflect reality and provide better guidance for actual facility location decisions all of these factors must be considered as part of the analysis.

Additionally, many researchers have focused on the effects of changing the location of one or two facilities in a particular product's supply chain network. Since avoiding environmental impact and risk are important to society, a more comprehensive strategy must be considered. Strategic decision-making about facility location is needed in order to reduce total costs and environmental impact to businesses and society. Cost and environmental impact are dependent on the character of the supply chain network, so only considering where one or two new facilities should be sited does not answer what 
places will give the best future positioning for a company in terms of reduced cost and environmental impact.

Some researchers have considered environmental damage caused by supply chain decision-making. However, the tools used did not include any analysis of the spatial damages associated with the environmental impact. Where damages occur, someone likely suffers. Who suffers affects potential liability and hence a company's license to operate in society. Clearly companies need to obey existing laws but they also must anticipate the risks they create for the communities they operate in. Failing to anticipate these risks may motivate community members to seek legal means, protest, or boycott to attempt to revoke a company's license to operate in society. As society's and specific communities' awareness of environmental impacts increase companies are less likely to be able to ignore potential problems. Although not required for companies to operate now, knowing which places and how people and the affected ecosystems will react to the damages caused by operations could be essential for remaining in business in the future.

Facilities have very specific impacts because of their locations and who is affected. For certain types of chemical releases (i.e. toxins) that will cause great local spatial scale damage (e.g. emissions released from a point source that travels slowly instead of diffusely over a region) the inclusion of spatial dependence of environmental impact and its associated risk is warranted to include in a comparison of facility locations (Pennington et al., 2005). In these cases, if spatial dependence is ignored the risk calculated may miss the key differences among facility location options. Ignoring the differences in impact between locations could hinder a business' ability to make the most 
prudent decision to avoid future issues with liability or with their license to operate in society.

Multimedia fate and transport analysis can characterize the spatial dependence of environmental impact. The current usage of multimedia fate and transport analysis too often focuses on chemicals after release, the damage caused by past industrial decisionmaking. Instead of focusing on the symptoms, this type of analysis needs to be used to diagnose the potential problems of industrial decisions. The spirit of the legislation in Europe is to reduce the environmental damage caused by industry. Multimedia fate and transport analysis is the screening tool needed to illustrate what harm is caused by placing facilities in specific places. 


\section{Chapter 3}

\section{A Literature Review of Production Facility Siting Policy: The Role of Companies, Governmental Officials, and the Public}

Choosing the site of a production facility is an important task for business, government and the public. Typically, businesses are offered a variety of financial incentives by state governments and local communities to locate their production facilities and bring jobs to residents. But, too often governments offer the wrong incentives and end up giving away benefits that are of no direct interest to business. Both the government and the public need to reform their reactions to facility siting in their communities, in the case of government by being more informed about the needs of specific businesses and offering more relevant incentives, and in the case of the public to raise objections and take action to prevent the construction of facilities that may adversely affect their communities. The public must realize that a new facility may be a mixed blessing that once built is very difficult to remove.

Companies make facility siting decisions based on a variety of factors encompassing politics, economics, legalities, the environment, culture, and social considerations (Dolan and Aldous, 1993; Kodali and Routroy, 2006). State and local 
governments seek out business development due to high pressure to improve the lives of their citizens through employment opportunities and to increase the tax base. Some of the pressure on government officials to bring companies into their constituencies comes from the trend by companies to move operations offshore (Whitehouse, 2007). Locating a manufacturing facility in a community can mean economic improvements and growth; altering the landscape of a place can change local people's sense of identity, way of life, and connection to the past (Boholm and Löfstedt, 2005). The public may benefit economically from the siting of a production facility while be harmed by negative effects due to pollution. These negative effects may incite communities to organize opposition to the siting of certain facilities within their boundaries.

Companies, government officials, and the public all play a role in influencing the siting of production facilities. Companies create their own private policies for choosing particular places to site facilities, while governments have public policies to both attract business and protect citizens. The public has opportunities to enter the decision-making legitimately or illegitimately, as will be seen shortly. Through courting and opposition, policies are created that aid the decision-making of where real facilities are built and operate to the benefit and detriment of all parties.

\subsection{Business Facility Siting Decision-Making}

Producers of goods and services choose to create new facilities and expand as business increases. Businesses prospering catalyze the need for policy approaches to production facility location. Companies look for many factors when choosing a facility location. Recently more U.S. manufacturers have moved their production operations overseas for several cost-related reasons. The decision-making process utilized by 
businesses is internally driven but influenced by external inputs and actions from government officials and the public.

Building new infrastructure is expensive and risky, so many companies now contract with other suppliers to make certain parts or to do some aspect of product assembly. But, despite initially higher costs there are several reasons to construct facilities instead of contracting out to suppliers: (a) Companies can have greater control over production processes in their facilities, which can ensure that product quality remains high; (b) Suppliers and subcontractors are juggling the demands of many business customers; and (c) shortcuts, compromises, or delays in delivery from a supplier can be avoided when a company produces its own parts (Conner, 2007).

Once the decision to create a new facility is made, companies begin the facility decision-making process. Buss' framework for facility siting decision-making states that the following eight actions are taken once a company decides to construct or enlarge an existing building.

- Configure a facility siting decision-making team

- Note important features needed for the particular site

- Identify requirements desired for a new location (including non-economic concerns)

- Research potential locations and compare site qualities to listed requirements

- Sequentially remove potential locations due to suitability

- Focus on a few sites, start dialogues with governmental officials in these locations

- Estimate building construction and set up costs

- Analyze the feasibility of each site (Buss, 2001)

The business site selection process is unique because each company looks for different amenities. Every business has its own policy for what perspectives, values and 
people need to be part of facility decision-making; government officials must employ facility siting policies to accommodate businesses that are flexible enough to change on a case-by-case basis.

Labor costs (Gambale et al., 2007), union bargaining power and labor productivity are all cited as reasons companies choose to move or increase operations (Jelavich, 2001). Both corporations and government decision-makers acknowledge that tax policy and available public infrastructure influences where corporations locate (Jarrell et al., 2006). Differences between areas can uncover what amenities are important. "In smaller geographical areas, factors of production (e.g., labor costs, services, transportation, and markets) are likely to be more similar, so differences in tax levels across communities are more likely to drive the business decision" (Jarrell et al., 2006). Table 3.1 lists several factors that influence where producers choose to locate facilities. 


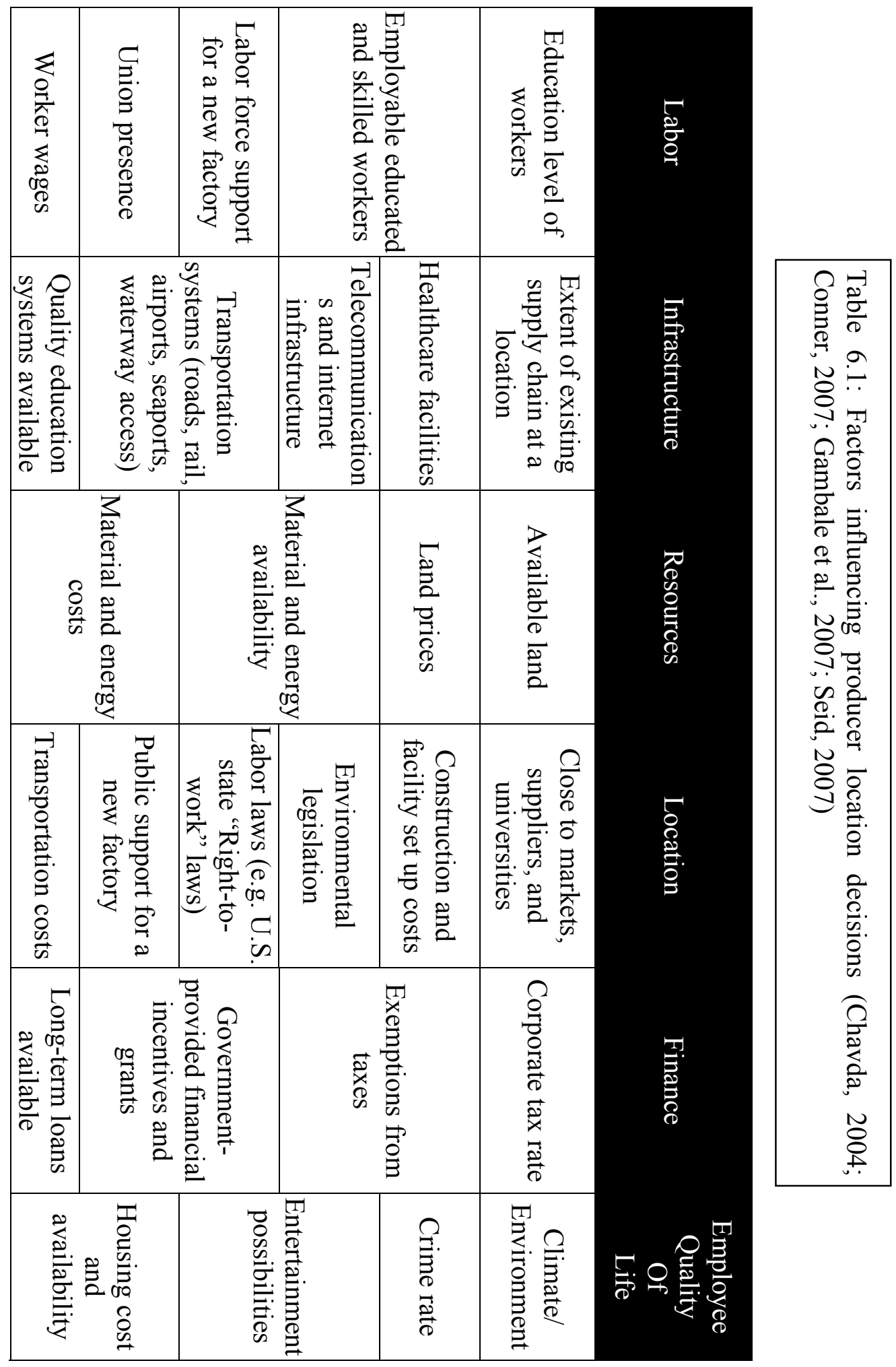


Chavda found through surveying manufacturing, high technology and financial service companies that different businesses are influenced to locate by different factors. The factors manufacturers are most concerned with are property tax reductions, industrial development bonds, unskilled labor availability, capital grants, affordable energy prices and housing and low crime rates. These preferences point to a manufacturer's interest in government assistance which helps cut costs (Chavda, 2004).

Many U.S. manufacturing operations have moved overseas in the past 20 years in search of cheaper inputs (e.g., labor). Nearly $90 \%$ of audiovisual products, $44 \%$ of appliances and $38 \%$ of computers are imported into the U.S.; manufacturing has dropped from 20 to $12 \%$ of the U.S. gross domestic product since 1980 . Manufacturing of particular types of products has remained on U.S. soil - products that are modified locally, fragile, or very big. Also, manufacturing that involves little labor or that increases productivity faster than labor needs stay in the U.S. instead of outsourcing (Whitehouse, 2007).

\subsection{Governments' Role in where Producers Choose to Locate}

Government officials are charged with preserving employment within their districts, which is no easy feat as other states and nations compete to win companies' facilities and jobs. Manufacturing has been the mainstay of many states' job markets. As manufacturing ships overseas, the duty to preserve employment propels government officials to court business to locate in their districts. For example, Toyota recently agreed to create a new automobile assembly factory in Tupelo, Mississippi, and Governor Haley Barbour acted as a salesperson for Tupelo and Mississippi. The Governor invited Toyota 
officials to see the potential industrial site, toured with officials around the site, and even made trips to Japan to sell the project (Seid, 2007).

Government officials persuade manufacturers to create facilities in their districts in part by offering financial packages called economic development incentive. These incentives take a variety of forms including tax credits (e.g. investment, expansion, increasing employment, corporate or personal income, research and development, property or sales and site preparation), reduced rates for financing, and grants and free land (Jarrell et al., 2006). In the case of the Toyota plant in Tupelo, Mississippi, \$328 million enticed Toyota to locate there in addition to the Governor's persuasiveness. States, like Kansas, even advertise the incentives given to companies building facilities in trade journals (Gambale et al., 2007).

States and communities also offer retention incentives to keep companies in their state; other states and communities may offer enticements for relocating. In the last decade, several counties within North Carolina offered up a variety of financial economic development incentives in efforts to lure Dell to their area over others. State and local officials are willing to give these incentives in order to keep businesses from leaving, shore up floundering businesses, bring in or grow new business and to help businesses survive tough times (Jarrell et al., 2006).

Courting companies through tax breaks and promised infrastructure development has a long history in the United States starting in the colonial period. Incrementally, providing tax breaks became an expected policy. Certain innovations such as tax-free bonds (in 1936), state business development corporations (in 1949), and development finance authorities (in 1955) quickly spread amongst many states. The policy of 
promoting growth through economic development incentives has escalated to the point where states offer nearly all possible tax incentives to companies seeking to relocate (Buss, 2001), in addition to other enticements. North Carolina coaxed Dell to locate a new facility there with $\$ 242$ million, which comes to " $\$ 10,756$ annually in incentives for each \$28,000-per-year job (Jarrell et al., 2006).” Sometimes governmental bodies are even willing to bend zoning rules in place in order to allow companies to locate at particular sites (Abram, 2005). In other instances officials will find ways to circumvent or relent regulations such as established rates for corporate tax or workers' wages to entice companies (Jarrell et al., 2006).

Some of the ways government officials offer economic development incentives causes tension within the current U.S. legal framework. The Commerce Clause in the U.S. Constitution prohibits any actions that inhibit the free flow of commerce between states including preventing competition. Two recent rulings by the Supreme Court and Sixth Circuit Court of Appeals respectively, Granholm v. Heald and Cuno v. DaimlerChrysler, confirm the upholding of the commerce clause. The rulings established that giving preferential treatment to in-state business is not allowed, either through access to markets or preferential tax reductions for the expansion of local operations. Providing property tax incentives are allowed, but a company's business prospects generally are unaffected by particular property tax reductions. Other states could offer the same property tax advantages, nullifying the effect of the incentive on relocating commerce to one particular area. These court decisions prompted the introduction of the Economic Development Act of 2005 in both the Senate and House to ensure a state's ability to provide economic development incentives in all forms to encourage companies 
to remain. Currently, litigants in other cases are seeking to show that economic development incentives violate the commerce clause and therefore should be illegal (Jarrell et al., 2006).

Increases in employment and economic prosperity often do not materialize until after the political lifetime of the particular politician pushing those incentives. If employment gains are not achieved, politicians can indict businesses, the economy or consumer behavior to explain lackluster business performance (Buss, 2001). Politicians increase their popularity by pushing these initiatives, but usually are not penalized by voters if the incentives do not work as promised. States rarely evaluate the policy measure of economic development incentives in detail (Buss, 2001; Jarrell et al., 2006). Hence the effectiveness of using economic development incentives to increase job growth and local economies are largely unknown. Spending on developing public infrastructure can attract businesses to set up shop. Yet these governmental efforts are by no means a guarantee that companies will come or that the local economy will reap the benefits of the investment (Chavda, 2004; Jarrell et al., 2006).

\subsection{The Public's Role In Facility Siting Decisions}

Citizens have concerns about factories locating nearby because of potential decreases in property values and pollution from noises, sounds and smells (Abram, 2005). A company or governmental body may not include feedback from the public because of perceived lack of interest, but the intrusion of industry can tarnish or negate the local character and sense of place either through pollution or intangible threats such as potential industrial accidents (Simmons and Walker, 2005). The values that people hold about places can change with time; hence companies and government officials may 
have difficulty assessing and incorporating these values into decision-making. The involvement of citizens in land use decisions through public participation is a key to ensuring that the public's values are recognized, acknowledged and reflected in land use decisions.

Companies and governmental agencies often include public comment and feedback in the facility siting process through public participation programs. Public participation is the process "by which public concerns, needs, and values are incorporated into governmental and corporate decision-making. It is two-way communication and interaction, with the overall goal of better decisions that are supported by the public (Creighton, 2005)." Incorporation of public participation and comments in governmental agencies' and companies' decision-making processes is an essential part of maintaining a democracy, as every democracy relies on citizen involvement to ensure the public's opinions are reflected in decisions.

Several federally legislated mechanisms exist to inform the public of potential damages from production facilities and new facilities or projects. The Emergency Planning and Community Right-to-Know Act of 1986 (EPCRA) and Pollution Prevention Act of 1990 compel companies to publicly report toxic emissions through a toxics release inventory (TRI). TRI reports are created annually (U.S. Environmental Protection Agency, 2007a).

The National Environmental Policy Act of 1969 (NEPA) requires that federal agencies must assess environmental impacts of new projects. Private companies subcontracted or funded to do work for a federal agency also are subject to NEPA legislation. Through NEPA, a federal agency must analyze a project to see if it will create 
substantial environmental impacts through an environmental assessment (EA). If substantial impact is not created a finding of no significant impact (FONSI) is written; otherwise an environmental impact statement (EIS) detailing potential damages is prepared. Public participation is brought in through public meetings as well as through comments to the federal agency on environmental impacts concerned. Regulations, permits, and the media inform the public of land use changes but often without enough time to prevent unwanted change. Davies found that citizens generally did not believe that their opinions were sought out and brought into the land use planning process despite public participation initiatives (Davies, 1999).

If communities decide they do not want the nuisance a facility will create, they will push for NIMBY (Not in My Backyard) and LULU (Locally Unwanted Land Uses) restrictions to keep out unwanted types of facilities (e.g., factories, group homes, prisons, hospitals, landfills, incinerators and hazardous waste facilities). Socio-economic differences influence the effectiveness of community facility siting restrictions; less favorable facilities often are sited in poorer neighborhoods due to lack of community organization or clout with politicians and business (Beatley, 1994). Environmental racism leads to the higher concentration of polluting industries and undesirable facilities in areas with many ethnic or racial minorities (Cole and Foster, 2001).

Despite the existence of public participation programs for land use planning purposes, the public's opinions may be disregarded in policies or implementation. Davies found through many focus group interviews in two regions in the U.K. that even though public participation programs were in place, “the public's intangible, qualitative and intrinsic environmental values that were justified on moral, spiritual or intuitive grounds 
were consistently marginalized or excluded from plans and policies" (Davies, 1999). Most people lack knowledge of the planning process and where they can participate, and this knowledge deficit exacerbates the gap between the public's values and the land use decisions made.

The perceived influence of the public's input on decisions affects the utility of participation programs. Research has shown that citizens view decision-makers' ideas as holding much more power than their own (Davies, 1999). If the public perceives that their opinions will have minor impact on the end decision, participation is likely to be low. Lack of participation reinforces this viewpoint by the continued dearth of public opinion incorporated into land use decisions. Many of these factors converge to make the public feel that even if their opinions reach decision-makers' ears, no concessions for their values will be made.

Opposition to a company locating a factory arises due to differing values and levels of trust between industry or government officials, the public, the technologically literate, the environmentally aware and other private landholders (Boholm and Löfstedt, 2005). Tracking declines in property values is a common approach to assessing the negative effects of living near a factory, but this measure does not capture all of the damages to affected parties (Simmons and Walker, 2005). The sense of place, personal wellness and quality of life are also important.

Past actions between governmental bodies and citizenry reaffirm or break down trust (Abram, 2005). People are concerned about the risk or environmental and health impacts of siting facilities based on the context in which decision-makers and local actors' present these potential impacts. The public is less likely to be swayed by scientific 
assessment of risks, and more so by emotion, even when efforts at educating about risks have been exercised (Boholm and Löfstedt, 2005).

\subsection{Policy Recommendations and Conclusions}

State officials' approach to courting industry needs revamping, and the proper documentation of the existing economic development incentive efforts is a first step. Evaluation of these policies coupled with the cutting off of poorly performing incentive programs needs to occur regularly. One suggested approach is to fine companies for not meeting stated goals (Buss, 2001). But this approach seems self-defeating as businesses generally cannot predict their performance and might prefer to locate where incentives come without restrictions.

New policies should seek to deter bidding wars between communities that increase the value of incentive offers to companies. Chavda found through surveying governmental officials, manufacturers, high technology and financial service companies, the financial incentives government officials thought businesses preferred differed from what the companies actually wanted. Therefore, increasing the selectivity of incentives is both advisable and important. Particular types of companies and industries respond more to different types of incentives, financial or otherwise, yet any business will always accept financial incentives from government officials (Chavda, 2004).

The focus of economic development incentives should change from trying to attract businesses to "growing" business leaders and start-up companies. Educating business leaders who are rooted in a community can encourage the creation of jobs without the threat of businesses eventually moving on. This approach works at improving 
existing social capitol instead of competing with other communities for the scarce resource of successful companies (Shuman, 1998).

Simmons and Walker suggest that more control in land use planning be given to the local level (Simmons and Walker, 2005). At this level more of the public has a chance to become decision-makers, in effect increasing public participation. Another local solution is to create land use institutions that reserve certain uses for land (e.g., districts for recreation, preservation or agricultural purposes). Local land use institutions have been effective at preventing unwanted damage at a community planning scale (Ostrom, 1990), and more public participation will only increase that trend.

Facility siting policy is catalyzed by businesses but influenced by government and citizen actions. Manufacturers have particular needs from facility sites such as available industrial development bonds and unskilled labor, affordable energy prices and low crime rates (Chavda, 2004). Government officials try to lure companies to their districts with economic development incentive packages that cause bidding wars for companies between communities. Evaluating the effectiveness of using economic development incentives as a policy to encourage economic prosperity for states and locales is needed. The public plays an important role in facility siting through participation measures, voluntary or required, when federal agencies are involved and environmental damage is caused. Moving land use decision-making to a more local level is one way to increase public participation and public influence in production facility siting decisions. Producers, government officials, and the public each have important roles that affect how private business policy and public governmental policy shape where facilities will locate and operate. 
In summary, the role of business in facility siting is that of a rational actor, seeking to maximize benefits. But in cost-benefit analysis one might easily overlook intangibles that are nevertheless important to both business and employees, such as quality of life, enjoyable climate, welcoming communities, and other factors that influence morale and productivity. These intangibles may defy a simple bottom line perspective. The role of government in facility siting needs to be more rational; the winat-any-cost philosophy results in giving too much to business in some cases. Government needs to be wiser about the desires of specific businesses and offer more provisions that meet identified company needs and lessen the conferring of more generic tax incentives. Finally, the public must have more confidence in its role in encouraging or preventing facility siting in communities, as the public is the final authority on the subject. The public, when mobilized by groups or utilizing media to express concerns, must act decisively and quickly or the established facility will be there to stay.

\subsection{Facility location decision-making considered in this research}

There are many concerns involved when siting facilities that encompass a variety of actors including businesses, government officials, and the public. It would be difficult to create specific decision-aids for siting facilities that encompass the concerns of all of these actors. The research in this dissertation focuses on how U.S. businesses make decisions to site facilities. This focus is justified, because in the U.S. currently businesses are able to freely decide where to locate facilities.

Specifically, zoning laws set by certain government officials restrict where and what type of business may be sited in an area. However concerning major U.S. metropolitan areas, in general a business will be able to find a place with appropriate 
zoning for siting a facility. Thus government officials generally can only influence a business' decision for example through offering incentives. The greater health and safety hazard a business' operations pose to a community the more restricted a business will be in its siting choices. Many businesses do not pose the level of hazard that would restrict their choices beyond areas zoned as appropriate for industrial use.

Similarly, only in the cases where a business' operations pose a significant health and safety hazard is public feedback formally required, such as during environmental impact assessment. More often, when facilities do not pose great health risks, the public's opinion is not formally assessed when a business wants to site a facility. Thus the public, like government officials, can only influence where a company locates facilities.

In addition to a focus on company decision-making, this research considers the specific concerns of businesses that take back products. A focus is made on utilizing quantitative methods for finding the best facility locations. Not all concerns of businesses are considered in this research that would be time prohibitive. This research does incorporate facility siting concerns that are overlooked by existing quantitative methods for siting facilities. In particular, these concerns relate to sustainability.

This research seeks to aid companies that take back products to find the optimal locations for facilities. To that end, many aspects of facility siting that are generally ignored in facility location analysis are considered in this research, such as:

- comparison of strategies to site facilities, e.g. decentralization and centralization,

- optimization of forward and reverse supply chains simultaneously except (Fleischmann et al., 2001),

- the spatial dependence of environmental impact,

- $\quad$ economies of scale except (Cohen and Moon, 1991; Realff et al., 1999,2000), 
- optimization for costs and environmental impacts together except (Krikke et al., 2003; Quariguasi Frota Neto et al., 2007a,b), and

- incorporation of social sustainability concerns, especially for SMEs (Luetkenhorst, 2004). 


\section{Chapter 4}

\section{Integrating the Spatial Dependence of Environmental Impact into Facility Location Analysis ${ }^{*}$}

Most facility location optimization problems consider costs but not environmental impacts. When environmental impacts and costs are addressed jointly in facility location problems, often key aspects of costs or environmental impacts are neglected. This paper includes two key aspects - the spatial dependence of environmental impact and the economies of scale of costs - that rarely receive consideration. Including the spatial dependence of environmental impact creates a new perspective on the formulation of facility location problems. This new perspective is applied to investigate the best strategy for siting production facilities that both manufacture and remanufacture products in a closed-loop supply chain. The siting strategy of centralization, or conversely decentralization, for locating production facilities is examined by comparing the objectives for different numbers of facilities sited. An objective function minimizing combined costs and environmental impacts is considered, since these factors currently motivate corporations to recover products at end-of-use. The facility location problem is represented as a discrete $p$-median formulation and solved by two methods, enumeration

\footnotetext{
${ }^{*}$ This chapter was submitted as a journal publication to the International Journal of Production Research
} 
and Lagrangian relaxation. A theoretical example considering the production and resoling of shoes is investigated. This paper applies this new perspective on facility location analysis - including spatially dependent environmental impact - to optimize the number and location of production facilities in a closed-loop supply chain for combined costs and environmental impacts.

Keywords: environmental impact assessment; facility location; multimedia fate and transport models

\subsection{Introduction and Background}

The goal of facility location analysis is to site facilities and route demands to optimize a particular objective, with cost minimization as a common objective (Krikke $e t$ al., 2003). As concerns have grown about humanity's impacts on the environment ((World Commission on Environment and Development, 1987), facility location research began to consider the environmental impact of siting decisions singularly (BloemhofRuwaard et al., 1996b) or in addition to cost (Krikke et al., 2003; Quariguasi Frota Neto et al., 2007a,b).

Despite the inclusion of environmental impact into facility location analysis, a key component is missing from this type of research: the incorporation of spatial dependence in environmental impact. The spatial dependence of environmental impact matters because particular environmental impacts vary spatially across local, regional, and global scales. For chemicals that persist in the environment and transport on a global scale, ignoring the spatial dependence can still adequately describe impacts to people and the 
environment (Burgess and Brennan, 2001; Pennington et al., 2005). But many chemicals have more regional and local effects; sulfur oxides (SOx) create acid rain regionally, whereas lead $(\mathrm{Pb})$ has very localized effects. Depending on the type of chemical release, different spatial scales have relevance.

Similarly, different locations have distinct ecosystems that possess varying abilities to assimilate certain pollutants, e.g., forests and seas differ in sensitivity to acidification. Hence, locations with distinct ecosystems possess different assimilation capacities for specific chemicals (Burgess and Brennan, 2001). "Neglecting spatial heterogeneity introduces uncertainty into the [environmental impact] assessment because certain characteristics of the real system are not captured (MacLeod et al., 2004)." Ecosystem characteristics determine a region's assimilation capacity and therefore the severity of environmental impact for releasing particular chemicals to that region. Industrial chemical releases, even of the same type and magnitude, to ecologically distinct regions expose humans and other organisms to different levels of compounds; resulting in different severity of effects to people and the environment.

Operations research techniques can be employed to make recommendations for facility locations that minimize environmental impact. Considering spatial dependence is essential to realistically consider environmental impacts of potential facility locations. This paper contributes a new perspective to operations research by presenting a method to include spatially dependent environmental impact when optimizing facility locations.

Increased concerns about costs and environmental impacts over the product lifecycle have led industries to consider how to best recover value from products at end-ofuse (Kumar et al., 2007). Remanufacturing can improve cost effectiveness (Sutherland et 
al., 2002) and reduce environmental impact (Dowlatshahi, 2005; Guide et al., 2000; Thierry et al., 1995) such as energy intensity of processing (Sutherland et al., 2008). For remanufacturing, a reverse supply chain (including collection of products from customers, transportation to company facilities, remanufacturing, and distribution to customers again) has to be set up to take back products in addition to the forward supply chain (including manufacturing, distribution to customers, and product end-of-use). Setting up operations to handle both a forward and reverse supply chain creates additional costs for transportation, infrastructure, and operation of different manufacturing (or remanufacturing) lines. Considering how many facilities to locate for a supply chain, in other words whether to pursue a strategy of centralizing or decentralizing facilities, can in part determine financial success of a remanufacturing business. For example, office furniture remanufacturing in the U.S. was financially successful in the past at companies such as Herman Miller, Steelcase, and Haworth when these companies employed independently owned decentralized remanufacturing facilities with low production volumes to remanufacture furniture. However, when these facilities were reorganized to form centralized high production volume facilities, remanufacturing soon was largely abandoned. It seems likely the centralization of facilities resulted in high transportation costs and problems in managing large volumes of returned products that negatively impacted the ability of the companies to remanufacture (Gunter, 2004).

Thus, including accurate costs, such as the economies of scale related to operating and infrastructure costs, can help businesses decide on the optimal strategy for siting facilities and allocating demand. A few discrete facility location problems (Holmberg and Ling, 1997; Snyder et al., 2007; Sun and Gu, 2002) consider nonlinear cost terms 
associated with economies of scale. However, the authors are unaware of research that optimizes for discrete facility locations with an objective including costs with economies of scale and environmental impact.

This paper discusses the application of a new perspective for facility location analysis that minimizes combined spatially dependent environmental impacts and costs with economies of scale to select the optimal degree of centralization for siting facilities that both manufacture and remanufacture a single type of product. Highly centralized supply chains have few production facilities that service an entire market; wholly decentralized supply chains use many production facilities to meet the demands of multiple market regions (Fleischmann et al., 2000). Indicators of environmental impact and cost were formulated for the life cycle stages that differed between a newly manufactured and remanufactured product, production and distribution. The indicators of environmental impact and cost were normalized and weighted before being combined into the objective function.

The optimal solution to this facility location-allocation problem, represented as a discrete $p$-median problem, was calculated through enumeration. The theoretical example explored in this paper considers a small number of potential facility sites $(n=9)$ and demand locations $(m=9)$, which allows this problem to be solved by enumeration. In addition, this facility location problem was solved by Lagrangian relaxation to accommodate real-world facility location-allocation problems that have more potential facility sites and demand locations, which would be too computationally time-consuming to solve by enumeration. This facility location problem could be represented by other formulations, e.g., $p$-center, $p$-hub, or the ordered median problem (Nickel and Puerto, 
2005 ) with different restrictions related to; capacity, cost or objective functions, (e.g., convex, concave (Sun and Gu, 2002), stochastic with a probability distribution (Tadei et al., 2009), type of solutions space (e.g., continuous, network), and/or number of products or facilities considered. Other techniques could be used to solve the representative facility location problem of interest. The contribution of this paper is not the application of a particular solution technique to a particular type of facility location problem. Rather this paper demonstrates how considering the spatial dependence of environmental impacts and economies of scale of costs affects the optimization outcomes for facility location. Considering both environmental impact and cost together creates different minimal objectives, sited facilities, and numbers of facilities sited (i.e., the degree of centralization of facilities) than when these indicators are considered singly. In general, this paper presents further evidence that both environmental impacts and costs need consideration in facility location decision-making.

\subsection{Remanufacturing Facility Location Decision}

The new perspective presented in this paper, considering spatially dependent environmental impact and costs with economies of scale, was applied to a theoretical shoe manufacturing/remanufacturing facility location decision. One challenge of recovering and reutilizing durable fashion products, such as footwear, comes from highly uncertain product return rates (Morana and Seuring, 2007; Staikos and Rahimifard, 2007). Two large U.S. footwear manufacturers have overcome the difficulties of recovering footwear by employing radically different strategies for the facility location of shoe resoling operations; one employs a centralized approach by co-locating resoling operations with some manufacturing operations, while the other employs a decentralized 
approach by authorizing stores to resole their shoes across the entire U.S. market (Birkenstock USA, 2008; Chaco Inc., 2007). Both strategies are financially viable, but the environmental impacts of each strategy are unknown.

It was assumed that the largest markets for footwear in the U.S. are the 9 most populous U.S. metropolitan areas, as defined by the U.S. Census, encompassing both the locations of demand for shoes and potential facility sites (Figure 4.1). Annual demand for shoes was based on data regarding the population of a metro area (U.S. Census Bureau, 2007b) and national demand for footwear (American Apparel \& Footwear Association (AAfA), 2006).

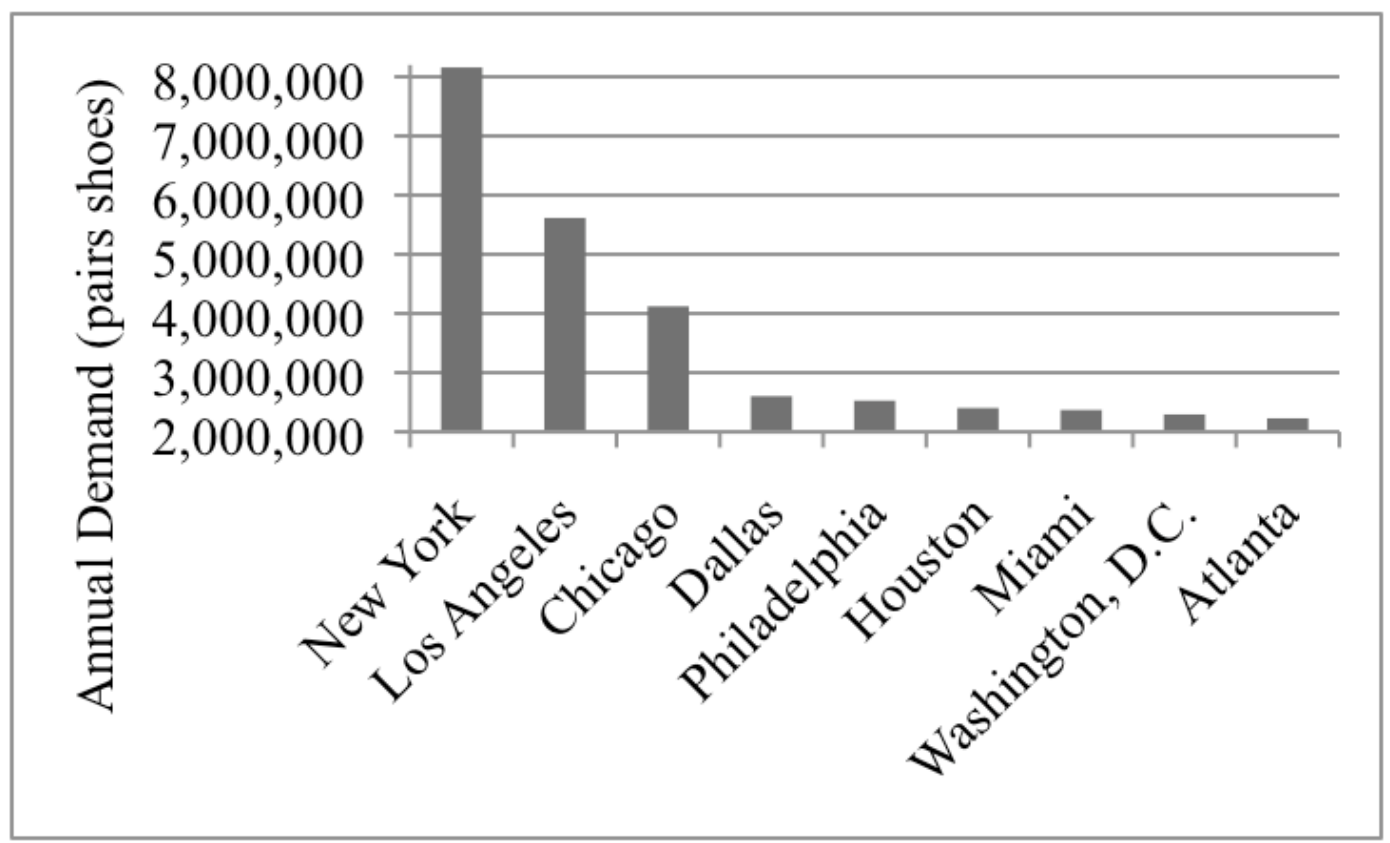

Figure 4.1: Annual demand in pairs of shoes for each demand location (American Apparel \& Footwear Association (AAfA), 2006; U.S. Census Bureau, 2007b)

Spatially dependent environmental impact was assessed with the toxicity potential indicator. This indicator calculates the effects of certain amounts of toxic chemicals from industrial processes in different environmental compartments (e.g. air, water, and soil). A 
multimedia fate and transport model, the CHEMGL national model (Wright et al., 2008; Zhang et al., 2003), was used to determine the spatial dependence of environmental impact by calculating the amounts of chemicals that accumulate in different environmental compartments within specific geographical regions. CHEMGL breaks the continental U.S. into 9 ecoregions (Figure 4.2).

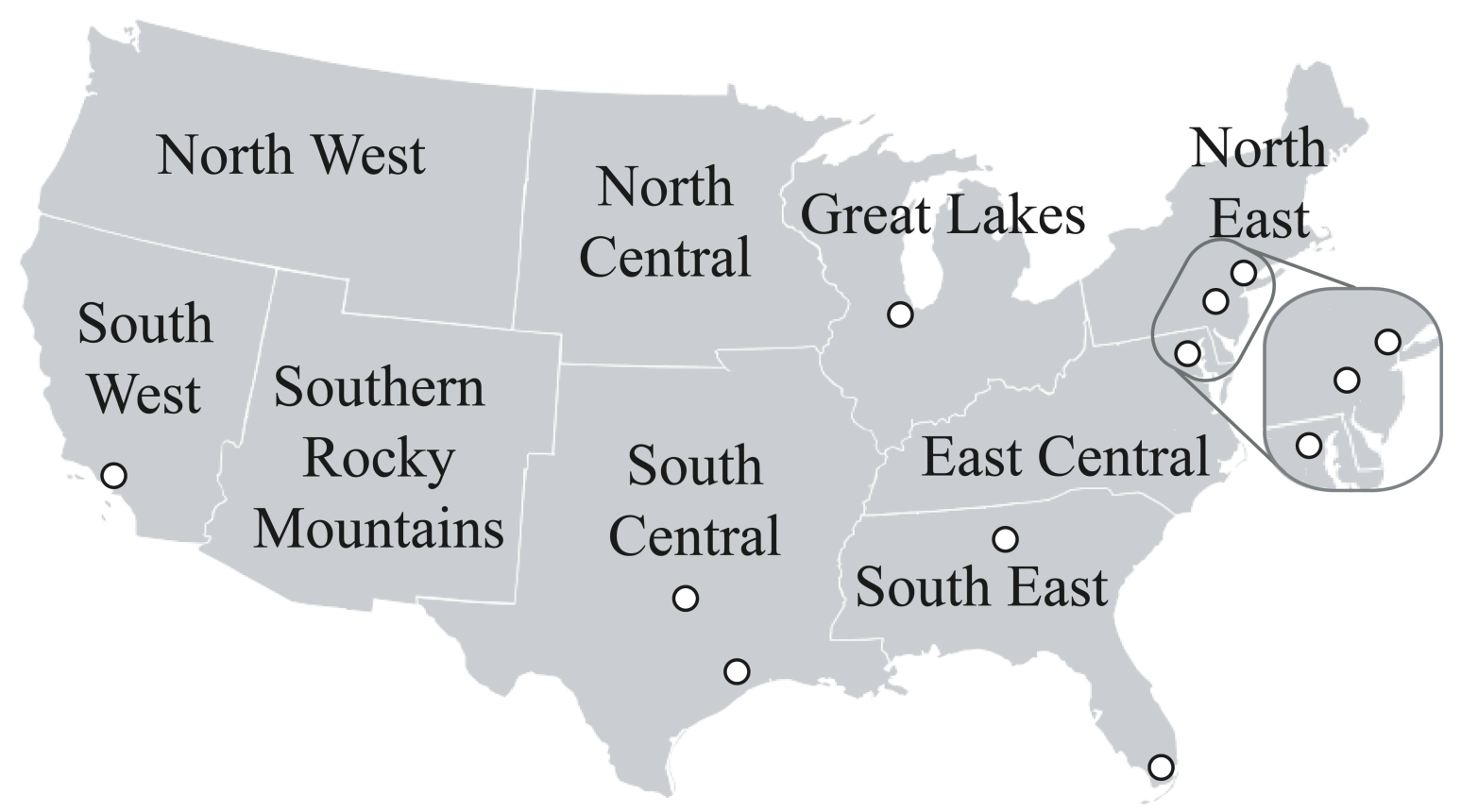

Figure 4.2: The 9 demand locations and potential facility sites (white circles) located within CHEMGL's 9 ecoregions (Wright et al., 2008)

Part of the challenge in finding a cost effective and environmentally sound siting strategy for a remanufacturing business concerns uncertainty in product recovery rates. Product recovery rates affect the amount of transportation needed. Transportation of recovered products make up a substantial portion of costs for supply chains that take back products (Krikke et al., 1999). Thus, where and how facilities are sited affects the economic feasibility of product remanufacturing (Fleischmann et al., 2001). 
The fraction of shoes recovered for resoling was characterized by $r_{R}$, with the fraction of shoes discarded rather than resoled given as $r_{D}=1-r_{R}$. The portion of discarded products that enter the reverse supply chain is zero, since discarded shoes are either landfilled or incinerated at end-of-use. The total annual demand for shoes at each location was assumed constant. It is assumed that a resoled shoe will have a longer product lifetime than a shoe that is discarded at end-of-use.

When a pair of shoes wears out, they may either be resoled or discarded, and it is assumed that resoled shoes are resoled only once. When a new pair of shoes is manufactured it is assumed to have a use lifetime, $L D$, of three years; resoled shoes last an additional two years. In order to make fair comparisons between resoled or discarded shoes, because of their different use lifetimes, the same unit of measurement must be used. This unit is called a functional unit (Graedel, 1998), and is widely employed during life cycle assessment. For this application, the functional unit chosen was the use of a pair of shoes for a year.

First, let us consider a situation in which a pair of shoes is manufactured, used for three years, and then discarded and replaced with new shoes. Thus, for shoes discarded and then replaced with new shoes (termed discarded shoes), 1 new pair of shoes is needed every three years; this translates into the functional unit receiving $\frac{1}{L_{D}}$ of the environment impact and cost of shoe manufacturing. For a second case in which new shoes are resoled after 3 years and then last 2 more years before being replaced with new shoes (these are termed resoled shoes), the total use lifetime is 5 years, LR, before disposal. Thus, newly 
manufactured shoes are needed every five years; $\frac{1}{L_{R}}$ of the environmental impact and cost of manufacturing and the environmental impact and cost of resoling is allocated to every functional unit.

All indicator values were calculated for the entire shoe or sole lifetime and allocated to the functional unit, a year of shoe use, by dividing by the use lifetime, either LD or LR. Equation 4.1 shows the numbers of shoes manufactured and resoled each year to meet annual shoe demand given the different use lifetimes of resoled and newly manufactured shoes.

$$
\left(\begin{array}{c}
\text { shoes } \\
\text { manufactured } \\
\text { per year }
\end{array}\right)=\left(\frac{r_{R}}{L_{R}}+\frac{r_{D}}{L_{D}}\right) h_{i} \quad\left(\begin{array}{c}
\text { shoes } \\
\text { resoled } \\
\text { per year }
\end{array}\right)=\frac{r_{R}}{L_{R}} h_{i}
$$

\section{Indices}

$\begin{array}{ll}R & \text { resoled } \\ D & \text { discarded } \\ i & \text { demand location } \\ j & \text { facility site }\end{array}$

\section{Variables}

$r_{R}$ and $r_{D}$

fraction of total annual demand for resoled shoes and discarded (and replaced with newly manufactured) shoes respectively such that $r_{D}=1-r_{R}$

$h_{i} \quad$ total annual demand for shoes (in pairs) at location $\mathrm{i}$

$L_{R}, L_{D} \quad$ lifetimes (in years) of resoled shoes and discarded shoes respectively

The goal of this paper is to find the optimal strategy, based on degree of centralization, to site production facilities that manufacture and resole shoes such that 
combined costs and environmental impacts are minimized. To evaluate the optimal siting strategy, 4 indicators were selected.

\subsection{Formulation of Indicators}

The specific environmental impact and cost indicators chosen represent the life cycle stages relevant to this application. The life cycle stages that differ for resoled and discarded shoes are manufacturing, remanufacturing, and the associated transportation required for distribution; hence transportation and production environmental impacts and costs in the objective function were considered in the forward and reverse directions. The composition of materials and subassemblies as well as the use of either type of shoe are assumed to be the same. The end-of-use life cycle stage was ignored since the focus of this paper is to find the optimal siting strategy.

The global warming potential assesses transportation environmental impact while neglecting spatial dependence. The toxicity potential evaluates production environmental impact with spatial dependence. Transportation cost is solely affected by the location of a facility and the amount of products transported. Fixed cost, including facility setup and operation costs, depends upon the size of the facility and responds to economies of scale. Indicators were normalized by their absolute maximum value over all combinations of facilities.

\subsubsection{Global warming potential}

The Intergovernmental Panel on Climate Change (IPCC) created the global warming potential to measure a particular chemical's propensity to cause global climate change. The IPCC reports global warming potentials of relevant chemicals in carbon 
dioxide $\left(\mathrm{CO}_{2}\right)$ equivalents by weight for different time horizons (Houghton et al., 2001). For this application, a time horizon of 100 years was used.

Industrial activities, such as transporting products, can release hundreds of distinct chemicals. In this application, it is assumed that trucks transport footwear between a demand location $i$ and facility site $j$ ignoring the small travel distances within metropolitan areas. Equation 4.2 provides an overview of the global warming potential $(G W P)$ relation for transportation.

$\left(\begin{array}{c}G W P \\ \text { from } \\ \text { transport }\end{array}\right)=\left(\begin{array}{c}\text { truck } \\ \text { weight }\end{array}\right) \sum_{\text {chemicals }}\left(\right.$ truckloads $\left(\sum_{m f r}\right.$ distance $+\sum_{\text {res }}$ distance $\left.)\left(\begin{array}{c}\text { Chemical } \\ \text { Emission } \\ \text { Rate }\end{array}\right)\left(\begin{array}{c}G W P \\ \text { of } \\ \text { Chemical }\end{array}\right)\left(\begin{array}{c}\text { Allocation } \\ \text { of } \\ \text { Demand }\end{array}\right)\right)$

\section{Indices}

$m f r \quad$ manufacturing

res resoling

In Equation 4.2, the only variables that differ for shoes that are resoled or discarded at end-of-use are the distance and number of truckloads. Both resoled (subscript res) and newly manufactured shoes (subscript $\mathrm{mfr}$ ) are transported to customers. At end-of-use, resoled shoes are transported back to the production facility for resoling and then to customers again; shoes that are manufactured and then subsequently resoled before ultimately being discarded require twice the travel distance of shoes that are manufactured and then discarded as shown in Equation 4.3. The number of truckloads in Equation 4.4 depends upon the number of shoes manufactured or resoled per year, as expressed in Equation 4.1, and the number of shoes per truckload NM. Equation 4.5 shows the final global warming potential for a particular demand location, $i$, 
and facility location, $j$. Released chemical types and emissions rates were based on a 16ton diesel truck in the SimaPro 7.1 database (Pré Consultants, 2006b).

$$
\begin{aligned}
& \text { distance }_{m f r}=\mathrm{d}_{i j} \quad \text { distance }_{r e s}=2 \mathrm{~d}_{i j} \\
& \left.(\# \text { of truckloads) })_{m f r}=\left(\frac{r_{R}}{L_{R}}+\frac{r_{D}}{L_{D}}\right) \frac{h_{i}}{N_{M}} \text { (\# of truckloads }\right)_{r e s}=\frac{r_{R} h_{i}}{L_{R} N_{M}} \\
& G W P_{i j}=M \sum_{\text {chem }} E_{\text {chem }} G W P_{\text {chem }}\left(3 d_{i j} \frac{r_{R} h_{i}}{L_{R} N_{M}}+d_{i j} \frac{r_{D} h_{i}}{L_{D} N_{M}}\right) X_{i j}
\end{aligned}
$$

\section{Indices}

chem chemical species

\section{Variables}

$d_{i j}$

$N_{M}$

$G W P_{i j}$

$G W P_{\text {chem }}$

$M$

$E_{\text {chem }}$ travel distance between a demand location $i$ and a facility $\mathrm{j}$

number of shoe pairs per truckload

global warming potential for transporting shoes demanded by location $i$ to or from facility $j$ per year of shoe-life

global warming potential of a chemical per kilogram $(\mathrm{kg})$ chemical emitted

weight (mass) of truckload in $\mathrm{kg}$

chemical emissions rate in $\mathrm{kg}$ of chemical $c$ emitted per $\mathrm{km}$ traveled and per kg of truckload hauled

\section{Decision Variables}

$X_{i j}$

allocation of demand from location $i$ to facility $j$, if value is one demand is routed to that facility, otherwise value is zero

\subsubsection{Toxicity potential}

The impact associated with the release of a chemical depends on the potential exposure to the chemical and the intrinsic adverse effects of the chemical. The potential exposure is determined by concentrations of a chemical and an exposure factor. A person 
can be exposed to a chemical through three pathways: inhalation, ingestion, and dermal contact (Zhang et al., 2001). The exposure pathways and intake rate of a substance, also called the exposure factor, will determine the amount of a substance a person takes in. The exposure factor conveys how much, on average, a person is expected to intake from a particular environmental compartment, e.g. 2 liters for water or 20.1 grams of fish daily. Standard intake rates from different exposure pathways have been determined for people in order to understand the effects of chemical releases into different environmental compartments (National Center for Environmental Assessment, 1989). A spatially explicit multimedia fate and transport model, CHEMGL in this application, calculates the concentrations of chemicals in specific environmental compartments within an ecoregion based on the principle of conservation of mass (McKone and MacLeod, 2003a).

The chemical releases for shoe manufacturing and resoling used to calculate the toxicity potential were obtained from Toxic Release Inventories data (U.S. Environmental Protection Agency, 2007b). Most of the chemical releases related to shoe manufacturing and resoling are related to producing the sole. However, some additional operations release chemicals during the manufacture of shoes that are unnecessary when simply resoling shoes, which accounts for the difference in chemical releases for manufacturing and resoling.

After the concentrations of chemicals in different environmental compartments are estimated, the toxicity potential can be calculated. The toxicity potential is an aggregate of three indicators; fish toxicity, human ingestion toxicity, and human inhalation toxicity. Fish toxicity represents toxicity effects to the environment because fish are often a keystone (i.e. representative) species for measuring the health of a 
particular ecosystem. Combining these indicators into a potential expresses more about toxicity effects of the released chemicals than a single indicator. Each indicator compares the toxicity, and exposure, of the chemical of interest with a reference chemical allowing for understanding of the severity of effects expected from the chemical of interest (Shonnard and Hiew, 2000).

Each indicator in the toxicity potential was calculated for all ecoregions where a potential facility location $j$ resides, using CHEMGL (Wright et al., 2008). A particular indicator was normalized, dividing by the highest indicator value for manufacturing, resoling and all ecoregions, and then multiplied with a weighting factor; all weights for toxicity indicators were assumed to be equal for this research. These normalized and weighted toxicity indicators were aggregated into the toxicity potential $T P_{i j}$, Equation 4.6.

$$
\begin{aligned}
& T P_{i j}=h_{i}\left(\frac{r_{R}}{L_{R}}+\frac{r_{D}}{L_{D}}\right) \sum_{j}\left(W_{F T} \hat{I}_{F T, m f r}+W_{I N H} \hat{I}_{I N H, m f r}+W_{I N G} \hat{I}_{I N G, m f r}\right) X_{i j} \\
& +h_{i} \frac{r_{R}}{L_{R}} \sum_{j}\left(W_{F T} \hat{I}_{F T, r e s}+W_{I N H} \hat{I}_{I N H, r e s}+W_{I N G} \hat{I}_{I N G, r e s}\right) X_{i j}
\end{aligned}
$$

\section{Indices}

$\wedge$

\section{Variables}

$T P_{i j}$

$I_{F T, m f r}, I_{F T, r e s}$

$I_{I N H, m f r}, I_{I N H, r e s}$ denotes a normalized indicator

toxicity indicator for production of shoe pairs demanded by location $i$ at facility $j$ per year of shoe-life

fish toxicity per shoe pair for the manufacture or resoling of a shoe pair respectively

human inhalation toxicity for the manufacture or resoling of a shoe pair respectively 
$I_{I N G, m f r}, I_{I N G, r e s} \quad$ human ingestion toxicity for the manufacture or resoling of a shoe pair respectively

$W_{F T}, W_{I N H}, W_{I N G} \quad$ weights for the respective normalized indicators

\subsubsection{Transportation cost}

The transportation cost of trucks delivering loads of shoes between demand location $i$ and potential facility site $j$ per year of shoe-life is given in Equation 4.7. $f$ denotes the cost of transporting a load one kilometer by truck (Barnes and Langworthy, 2003). Travel distances are defined in the same manner as for the GWP.

$$
T C_{i j}=\left(\frac{3 r}{L_{R}}+\frac{r_{D}}{L_{D}}\right) \frac{f d_{j} h_{i}}{N_{M}} X_{i j}
$$

\section{Variables}

$T C_{i j}$

cost of transporting shoe pairs demanded by location $i$ to facility $j$ per year of shoe-life

$f$ cost of hauling a truckload of shoes one kilometer

\subsubsection{Fixed cost}

Costs for setup and operation are combined into one indicator of fixed cost, $\mathrm{FC}$, in Equation 4.8 based on economies of scale. Therefore fixed cost depends on the specific combination of demand locations $i$ that a potential facility site $j$ services. The first half of the indicator equation considers the fixed costs associated with setting up and running manufacturing operations, the second half concerns only remanufacturing operations. All of the demands that are met by one facility are summed before applying the economies of scale equation to obtain the fixed cost of that facility. Fixed cost for manufacturing or remanufacturing is divided by the lifetime (or multiplied by the percentage of shoes 
resoled or discarded divided by the respective lifetime) to obtain the fixed cost per year of shoe-life. Fixed costs for manufacturing and remanufacturing are then summed together.

$$
F C=a \sum_{1}^{i}\left(\left(\frac{r_{R}}{L_{R}}+\frac{r_{D}}{L_{D}}\right) \sum_{1}^{j}\left(\left(r_{R}+r_{D}\right) h_{i} X_{i j}\right)^{b}+\sum_{1}^{j} \frac{\left(r_{R} h_{i} X_{i j}\right)^{b}}{L_{R}}\right)
$$

\section{Variables}

$F C$

fixed cost of producing and resoling a shoe pair for demand locations at the facilities specified in $\mathrm{X}_{i j}$

When applying the Lagrangian relaxation method, the fixed cost indicator needed to vary by both facility, $j$, and demand location, $i$ (Equation 4.9) in order to affect the Lagrange multipliers. Fixed cost already depends upon the facility sited, $j$. Thus for the Lagrangian relaxation, fixed cost for manufacturing or remanufacturing was allocated to a specific demand location, $i$, through multiplying the fixed cost of a sited facility, $j$, by the ratio of the demand for that location $i$ with respect to the sum of all demand the particular facility $j$ serviced.

$$
F C_{i j}=\frac{h_{i}}{\sum_{1}^{j} h_{i} X_{i j}} a\left(\sum_{1}^{j}\left(\frac{r_{R}}{L_{R}}+\frac{r_{D}}{L_{D}}\right)\left(\left(r_{R}+r_{D}\right) h_{i} X_{i j}\right)^{b}+\sum_{1}^{j} \frac{\left(r_{R} h_{i} X_{i j}\right)^{b}}{L_{R}}\right)
$$




\subsection{Facility Siting Optimization Method}

The formulated indicators were incorporated into the objective function to compare facility locations for environmental impact, including spatial dependence, and costs, including economies of scale. The theoretical facility location decision for remanufacturing was represented as a $p$-median problem, where $p$ is the total number of facilities to site. The $p$-median objective, to minimize the weighted distance between facilities and demand locations, often employs demand as the weight (Daskin, 1995); in this case, a sum of normalized and weighted costs and environmental impacts formed the objective function (Equation 4.10). The number of facilities, $p$, was varied from 1 to 9 to find the optimal degree of centralization. An exact solution method, enumeration (Section 4.4.1), and an approximate solution method, Lagrangian relaxation (Section 4.4.2), were employed to solve the theoretical remanufacturing facility location decision considered.

$$
\text { Minimize } \sum_{i} \sum_{j}\left(e w \hat{T} P_{i j}+c w \hat{F} C_{i j}+e w G \hat{W} P_{i j}+c w \hat{T} C_{i j}\right)
$$

\section{Variables}

$c w, e w$

cost weight and environmental indicator weights respectively

Since the percentage of products taken back for remanufacturing, or product return rate, is often not known a priori, the product return rate was varied between $0 \%$ and $100 \%$ in $10 \%$ intervals to test the robustness of the optimal solution to that variation. Finally, how important decision-makers deem certain indicators can also affect the minimal objective. Therefore, all 4 indicators were weighted such that the weights for both costs were the same, with $\mathrm{cw}$ denoting a single cost weight, and the weights for both 
environmental indicators were the same, with the weight of each environmental indicator denoted by ew. All 4 indicators added up to $100 \%$, so $c w+e w=50 \%$. The cost indicator weight, $\mathrm{cw}$, was varied from $50 \%$ to $0 \%$ (thus the single environmental indicator weight, ew, was varied through the same range in reverse order). How decision-makers choose weights for a specific facility location decision is a sufficiently involved topic that it was explored by the authors in another paper (Clarke-Sather et al., 2009b).

\subsubsection{Facility siting optimization by enumeration}

Enumerating solutions is time consuming but allows the comparison of all possible solutions to find the absolute minimum objective (Equation 4.10). The exact solution was enumerated for all possible combinations of demand allocations and facilities. The minimum objective was found as a function of $p$, the number of facilities

sited, $r_{R}$, product return rate, and $c w$, cost weight (or environmental impact weight). All indicators and thus the minimum objectives were calculated for every facility/demand allocation set. The minimum objectives amongst $r_{R}$ and $c w$ are discussed in the next section.

\subsubsection{Facility siting optimization by Lagrangian relaxation}

Since solving the $p$-median problem is NP hard (nondeterministic polynomialtime hard), computational time increases exponentially with the addition of potential facilities or demand locations. Thus, as the number of potential facility sites considered increases,. a less time-consuming method is needed to secure a solution that approaches the optimal objective. Therefore, the authors present a heuristic that could be employed to handle larger problem instances and hence optimize real world strategic facility location problems. This algorithm is tested on the same theoretical example as was evaluated 
using enumeration. The acceptable closeness to the optimal results and reduced computational time suggest that it could be easily scaled to larger problem instances. Lagrangian relaxation has long been used to solve $p$-median problems with success (Canavate-Bernal et al., 2000; Cornuejols et al., 1977; Daskin, 1995; Narula et al., 1977; Teitz and Bart, 1968). The purpose of presenting this approximate method is to show that spatially dependent environmental impact and costs including economies of scale can be incorporated into an objective function and facility location problem that can be solved by a method capable of handling greater numbers of facilities.

Lagrangian relaxation (Equation 4.11) loosens constraints through multiplying by the Lagrange multiplier $\lambda_{i}$. The loosened constraint is then added to the objective function. For this case, Equation 4.12 was relaxed, allowing the demand at location $i$ to be met by more than one facility $j$. Equations 4.13-4.16 ensure that: (1) no more than $p$ facilities are sited, (2) all demands are filled by a facility, and (3) either none or all of demand is serviced by a facility.

$$
\operatorname{Minimize} \sum_{i} \sum_{j} h_{i} d_{i j} X_{i j}+\sum_{i} \lambda_{i}\left(1-\sum_{j} X_{i j}\right)
$$

\section{Constraints}

$$
\begin{aligned}
& \sum_{j} X_{i j}=1 \quad \forall i \quad \sum_{i} \lambda_{i}\left(1-\sum_{j} X_{i j}\right) \quad \text { (relaxed) } \\
& \sum_{j} Y_{j}=p \\
& X_{i j}-Y_{j} \leq 0 \quad \forall i, j \\
& Y_{j}=0,1 \quad \forall j \\
& X_{i j}=0,1 \quad \forall i, j
\end{aligned}
$$




\section{Decision Variables}

$X_{i j}$

$Y_{j}$ allocation of demand from location $i$ to facility $j$, if value is 1 that location's demand is serviced by the facility, otherwise value is zero

existence of a facility at $j$, if value is 1 a facility is located at that site, otherwise value is zero

The algorithm iterates until the values for the minimal upper bound and lower bound for that iteration are equivalent within a certain tolerance $\left(10^{-4}\right.$ in this case $)$; hence a solution is found (Daskin, 1995). After the $z$ th iteration, denoted by a superscript, a heuristic is used to update the Lagrange multiplier to reduce the gap in meeting the constraint, Equations 4.17-4.18. $t^{z}$ is the factor by which the current Lagrange multiplier decreases when the minimal upper bound UB found over successive iterations comes closer to the value of the iteration's lower bound $L B^{z} . \alpha^{z}$ is the scaling factor for $t^{z} ; \alpha^{z}$ doubled in value after every 10 iterations when the lower and minimal upper bounds remain the same values. If the particular instance fails to resolve after 1000 iterations the starting value of the Lagrange multipliers is stepwise decreased until resolution occurs.

$$
\begin{aligned}
& \lambda_{i}^{z+1}=\max \left\{0, \lambda_{i}^{z}-t^{z}\left[\sum_{j} X_{i j}^{z}-1\right]\right\} \\
& t^{z}=\frac{\alpha^{z}\left(U B-L B^{z}\right)}{\sum_{i}\left[\sum_{j} X_{i j}^{z}-1\right]^{2}}
\end{aligned}
$$

\section{Indices}

$z$

iteration number

\section{Variables}

$\lambda_{i}$

$\lambda_{i}^{z}$

$t^{z}$

$\alpha^{z}$

\section{Lagrange multiplier}

Lagrange multiplier for iteration $i$

step decrease for changing Lagrange multiplier value scaling factor for the $t^{z}\left(\alpha^{1}=2\right)$ 
$\begin{array}{ll}L B^{z} & \text { lower bound for objective function for iteration } z \\ U B & \text { lowest upper bound for objective function over all iterations }\end{array}$

The modified objective function for this application incorporates the Lagrangian relaxation formulation as shown in Equation 4.19. Equations 4.5-4.7 and 4.9 define the elemental values for the cost and environmental indicators, e.g., $F C_{i j}$ is the elemental value of fixed cost for servicing demand from location $i$ at facility $j$. Elemental indicator values are summed over all $i$ and $j$ to calculate the entire indicator value. These values must be normalized and weighted to put all indicators in the same dimensionless units before inclusion in the objective function. Changes in $r_{R}$ and weights, $c w$ and $e w$, affect the indicator values, so each indicator was divided by the highest indicator value (across all values of $r_{R}$ and $c w$ or $e w$ ) to normalize the indicator.

$$
\text { Minimize } \sum_{i} \sum_{j}\left(e w \hat{T} P_{i j}+c w \hat{F} C_{i j}+e w G \hat{W} P_{i j}+c w \hat{T} C_{i j}\right)+\sum_{i} \lambda_{i}\left(1-\sum_{j} X_{i j}\right)
$$

\subsection{Results and Discussion}

Minimum objective values were calculated as a function of different product return rates and weights for cost and environmental indicators for various numbers of facilities sited (ranging from 1 to 9). The minimum objective values for this theoretical example were affected by the behavior of the particular indicators selected, degree of centralization, spatial dependence of environmental impact, economies of scale, product return rate, and weights for cost and environmental indicators. Minimum objective values were calculated using the enumeration method. These values were then compared with the minimum objectives calculated with the Lagrangian relaxation method. 


\subsubsection{Indicator behavior}

The indicators used in this theoretical example were chosen because they are driven to either decentralize or centralize facilities. The global warming potential $(G W P)$ and transportation costs (TC) are both strongly affected by distance. Hence, either indicator favors decentralized facility locations that minimize distance traveled. When only minimizing for a single indicator, for both $G W P$ and $\mathrm{TC}$ the optimal degree of centralization of facilities was the facility sites where the least distance was travelled, i.e. a facility sited at each demand location. Since transportation within a metropolitan area is neglected, the minimum solution was the same no matter how many products were taken back for both indicators.

Conversely, economies of scale push the fixed cost indicator to favor centralized solutions. The minimum solution when only considering fixed costs occurred when only one facility is sited and no products are taken back. Similarly, seeking to reduce the overall toxicity results in centralizing facilities in regions where they will cause the least impact. The minimum solution when only considering the toxicity potential occurred when no products are taken back and all demand is met by one facility in Dallas (DA) or Houston (HO). DA and $\mathrm{HO}$ are in the South Central CHEMGL region, which has the lowest toxicity potential of all CHEMGL regions.

Optimizing for an individual indicator, at least for the indicators selected for this theoretical example, tends to drive the degree of centralization to one extreme or the other. However, when collectively considering these indicators, it will be seen that a balance will be struck among the indicators that balances their competing effects on degree of centralization. 


\subsubsection{Minimum cost and minimum environmental impact objectives}

The minimum cost objective (considering both fixed costs and transportation costs) occurred when only two facilities were sited, a standalone facility at LA and a facility at DC that met all other locations' demand (Figure 4.3). This absolute minimum objective for the cost indicators occurred when no products were taken back $\left(r_{R}=0 \%\right)$. The sited facilities and allocation of demand were the same for all product return rates. Thus, the fixed cost indicator dominated the degree of centralization for the minimum objective.

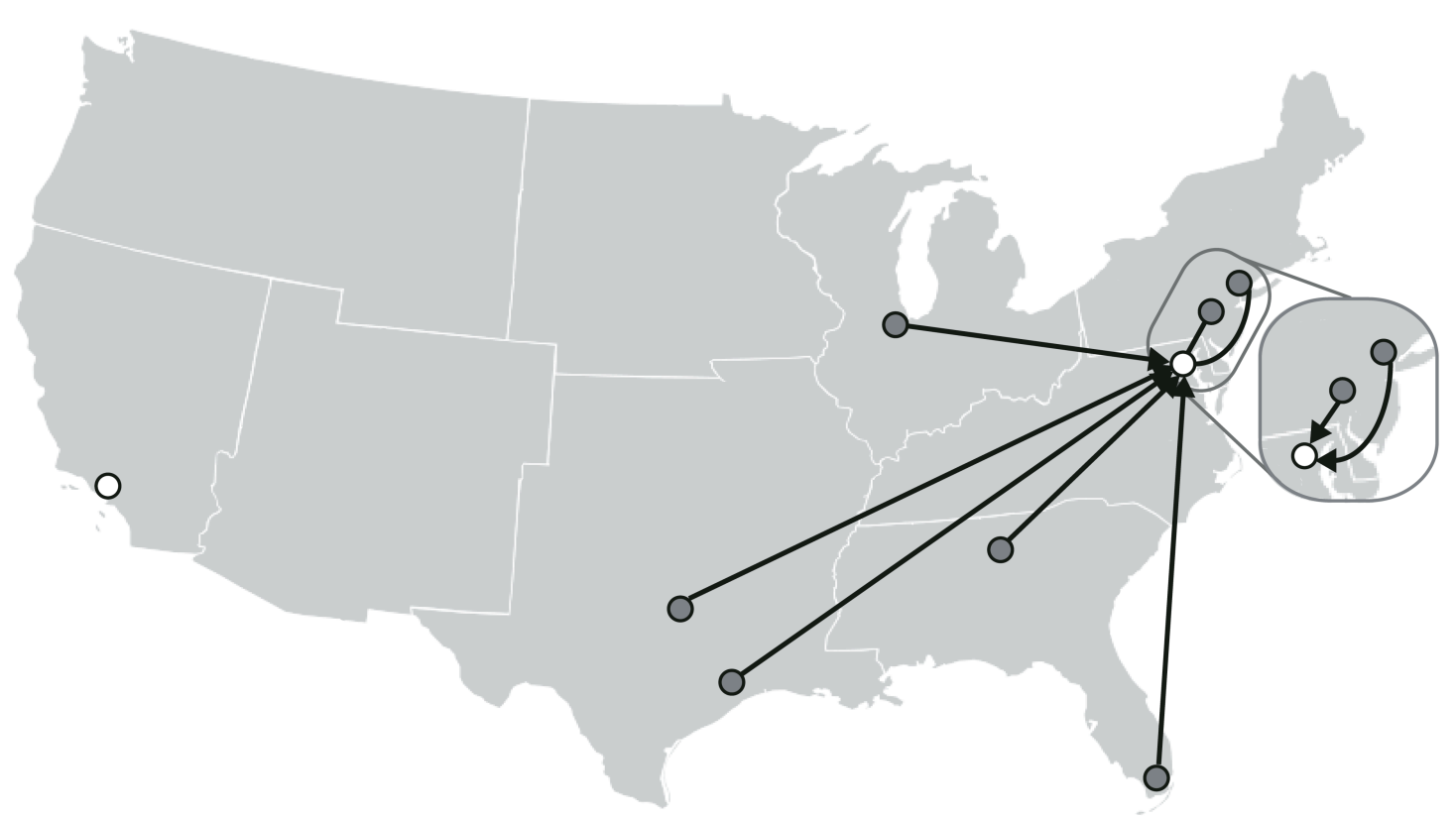

Figure 4.3: Facility sites (white) satisfying demand from demand locations (grey) for the minimum cost objective amongst all product return rates

In contrast, the minimum environmental impact objective (which considers both toxicity potential of production and GWP of transportation) occurred, regardless of product return rate, when facilities were sited at each demand location. This minimal objective makes sense since $G W P$ will be the smallest when products travel the least 
distance. The low GWP value compensates for higher toxicity potential values. The minimum objective over all product return rates when considering only environmental impact occurred when no products were returned $\left(r_{R}=0 \%\right)$. When no products are taken back less infrastructure and transportation of products is needed, lowering the financial and environmental impacts.

Of course, to keep this theoretical example simple, only the impact concerned with an increased product lifetime for resoled shoes versus newly manufactured shoes was considered. The actual costs and environmental impacts of material extraction and materials production for shoes or shoe disposal through landfilling or incineration were neglected. Including impacts from the entire shoe life cycle could have changed which product return rate created the least financial or environmental impact.

\subsubsection{Indicator values for minimum objectives}

Each indicator makes up a certain portion of the minimum objective values obtained for the various cases considered. Figure 4.4 shows how the composition (with respect to the four indicators) of the minimum objective changes as the weight on the cost indicators changes. As is evident, the fixed cost and toxicity potential are consistently a much greater percentage of the minimum objective than their companion indicators: transportation cost and GWP due to transportation. Fixed cost represents the largest percentage of the optimal objective for cost weights ranging from 50 to $30 \%$; the toxicity potential has the greatest percentage of the minimum solution for cost weights from 20 to $0 \%$. The GWP contributes the least to the objective because its total range in value was much less than other indicators amongst different cost and environmental indicator weights. 


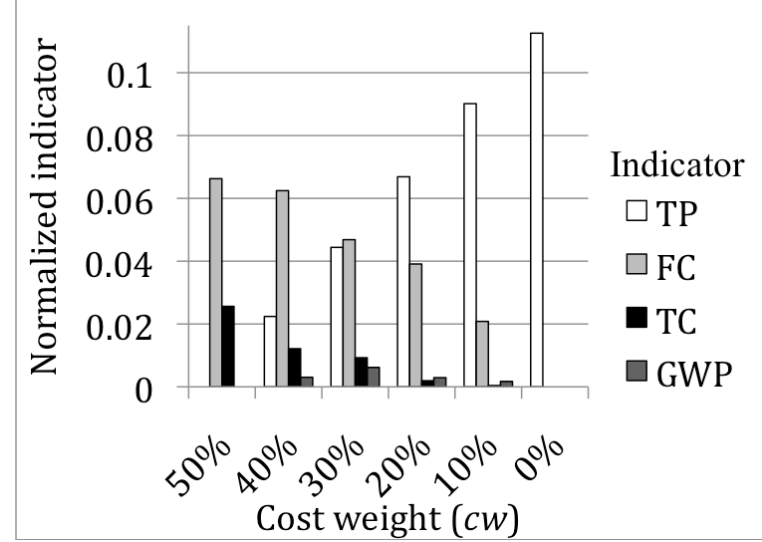

(a)

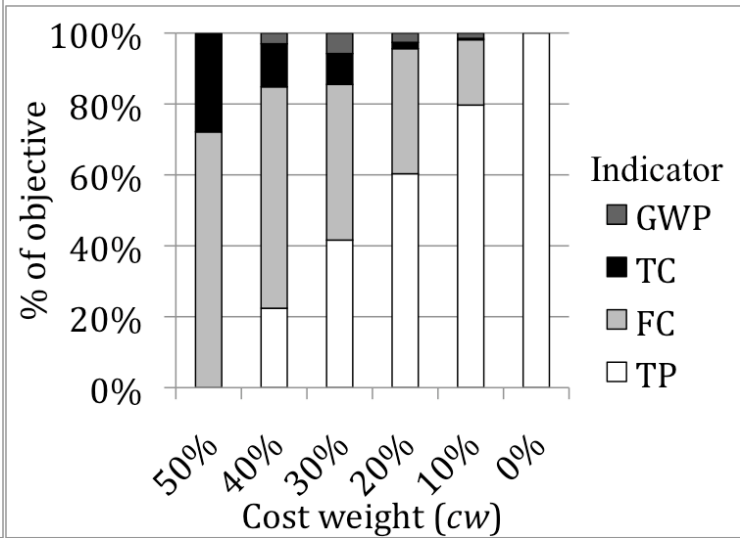

(b)

Figure 4.4: Normalized indicator values (a) and indicator values as a percentage of total objective (b) as cost indicator weight decreases (for $r_{R}=100 \%$ )

\subsubsection{Degree of centralization}

There are two ways in which the degree of centralization affects the minimum objective, the number of facilities sited and which facilities are sited. Two trends emerged for the numbers of facilities sited as the various conditions were examined for this theoretical example. As the product return rate increased the number of facilities sited was increased (Figure 4.5b). At lower product return rates a higher degree of centralization (centralized facility location) created the minimum objective, whereas at higher product return rates a lower degree of centralization was optimal (decentralized facility location). Secondly, as the cost weight decreased and environmental indicators weight increased more facilities were sited for the minimum objective (Figure 4.5a). Therefore at higher cost weights and lower environmental indicator weights a higher degree of centralization (centralized facility location) creates the minimal objective; whereas at lower cost weights and higher environmental indicator weights a lower degree of centralization (decentralized facility location) creates the optimal objective. 


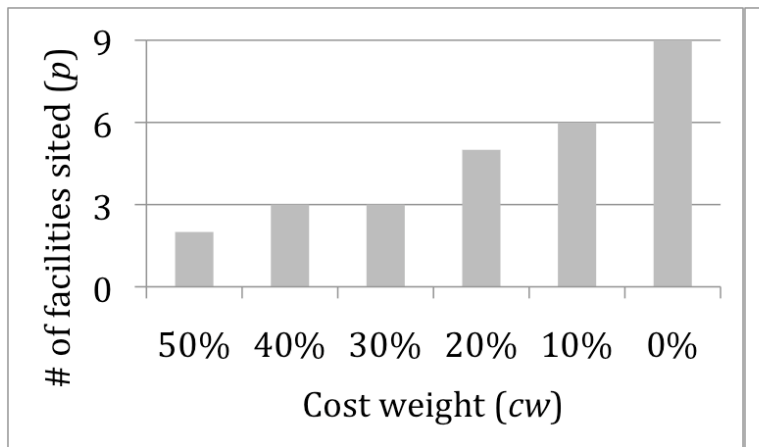

(a)

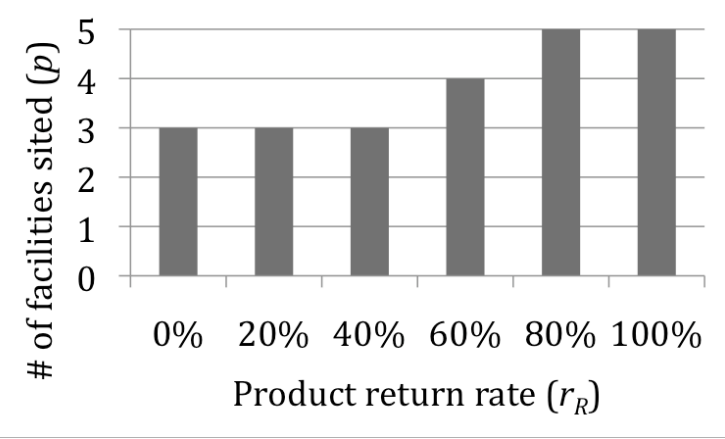

(b)

Figure 4.5: Numbers of facilities sited for (a) different cost weights, $r_{R}=100 \%$ and (b) different product return rates, $c w=20 \%$

In terms of which facilities were sited for the minimum objective solutions for this theoretical example, there were two major trends: all the minimum objective solutions included a standalone facility for Los Angeles (LA); and clusters of facilities tended to form around nearby cities, specifically between New York (NY) and Washington D.C. (DC), and Dallas (DA) and Houston (HO).

Siting a facility at LA makes sense for this problem because LA has the second largest demand and is the farthest away from the majority of other demand locations. Thus transportation cost and GWP would increase greatly if LA's demand were met by a facility in another city. Also the South West CHEMGL region where LA is located has the second least toxicity potential per shoe pair. Hence toxicity potential will be relatively low for a facility sited in LA.

As the cost weight decreased and product return rate increased more facilities were sited. Specifically demand from Miami (MI) tended to move from a (DA/HO) cluster to a standalone MI facility. Chicago $(\mathrm{CH})$ was the next to get a standalone facility by leaving the NY/DC cluster. Atlanta (AT) followed by leaving the DA/HO cluster. 
The specific indicator values, product return rates, and cost or environmental indicator weights affected whether a cluster would be sited in DC instead of NY or HO instead of DA. With regards to the NY/DC cluster, DC resides in the East Central CHEMGL region, which has a lower toxicity potential per shoe pair than NY in the North East CHEMGL region. DC is also the closest city to Atlanta (AT), Chicago $(\mathrm{CH})$, and Miami (MI) in the NY/DC cluster. Siting a facility in DC to satisfy the demand of several other facilities lowers transportation cost and global warming potential. However as the product return rate increases more transportation of products is required, especially for the locations with the greatest demand. Hence transportation costs and environmental impacts are reduced when facilities are sited at the locations with highest demand, favoring siting a cluster at NY. As the cost weight decreases and environmental indicator weight increases, the portion of the overall minimum objective value associated with the toxicity potential increases. The savings in the toxicity potential achieved by locating in DC instead of NY were outweighed by the increase in transportation cost and GWP; thus, NY created a lower objective than DC as cost weight decreased and environmental indicator weight increased (Figure 4.6). 


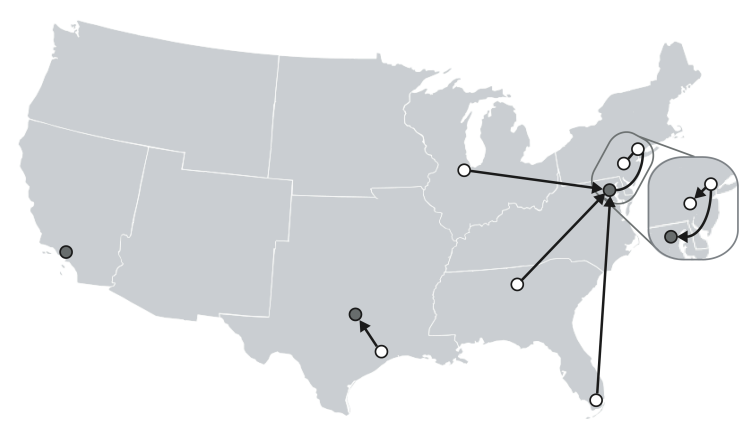

(a)

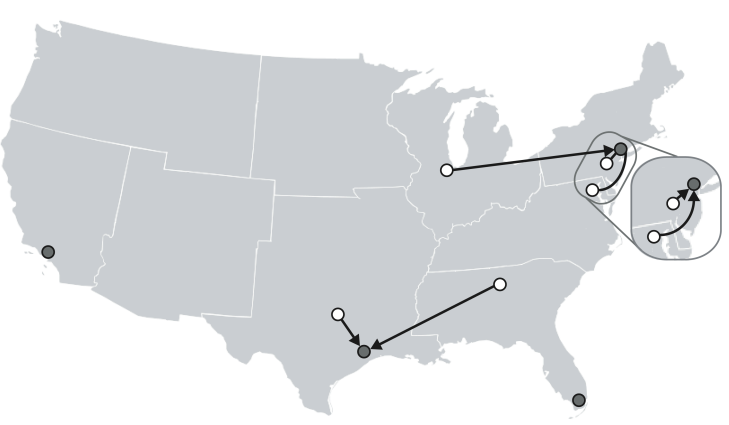

(b)

Figure 4.6: Allocation of demand from locations (white) to facilities (grey) for $\boldsymbol{r}_{\boldsymbol{R}}=$ $50 \%$ at (a) $c w=30 \%$ and (b) $c w=20 \%$

Considering the DA/HO cluster, both $\mathrm{HO}$ and DA are located in the South Central

CHEMGL region - the least sensitive region for the toxicity potential. The only way to distinguish objectives between DA and $\mathrm{HO}$ were the transportation cost and GWP since both toxicity potential and fixed costs were the same for the same allocation of demand. At higher cost weights, DA and $\mathrm{HO}$ were the only facilities in the cluster; AT, $\mathrm{CH}$, and MI were allocated to the DC cluster. Since DA has greater demand than HO (and thus more transportation would be required if the facility is not in DA ) siting a facility at DA created the lowest transportation and GWP. As cost weight decreased (and the environmental indicator weight rose) more facilities were clustered together at AT, DA, HO, and sometimes MI. HO is located closer to both AT and MI than DA. Thus when the cost weight decreased or environmental indicator weight rose, a facility cluster was sited at $\mathrm{HO}$ because of lower transportation costs and GWP (Figure 4.6).

\subsubsection{Spatially dependent environmental impact}

Spatially dependent environmental impact, included in this theoretical example through the toxicity potential indicator, affected the minimum objective and the facilities sited. As the cost weight decreased and environmental indicator weight increased the 
toxicity potential became the greatest contributor to the minimum objective (Figure 4.4b); hence the minimum values of the toxicity potential greatly influenced where facilities were sited. Without considering spatial dependence, there would be no difference in toxicity potential by location only by the type and volume of manufacturing operations. Thus the spatial dependence of environmental impact influenced both the minimum objective and the facility sited. Neglecting the spatial dependence of environmental impact when choosing between different locations to site facilities would have resulted in a different, and less appropriate, solution for the real world siting problem.

\subsubsection{Economies of scale}

The economies of scale for fixed cost in the optimal solution changed with product return rate and the weighting of costs and environmental impact. At higher cost weights and lower environmental impact weights, fixed cost was the indicator that contributed the most to the minimum objective. As product return rate decreased, and consequently the fixed cost decreased for the minimum objective. Fixed cost, being based on economies of scale, decreased when fewer facilities were sited especially for lower levels of demand. Thus as product return rate decreased, fixed costs lowered and so did the number of facilities sited (Figure 4.7). Therefore the fact that the fixed cost reflected economies of scale affected the total number of facilities sited and thus the degree of centralization. Considering a simple linear relationship between product demand and fixed cost would have missed changes to the degree of centralization. 


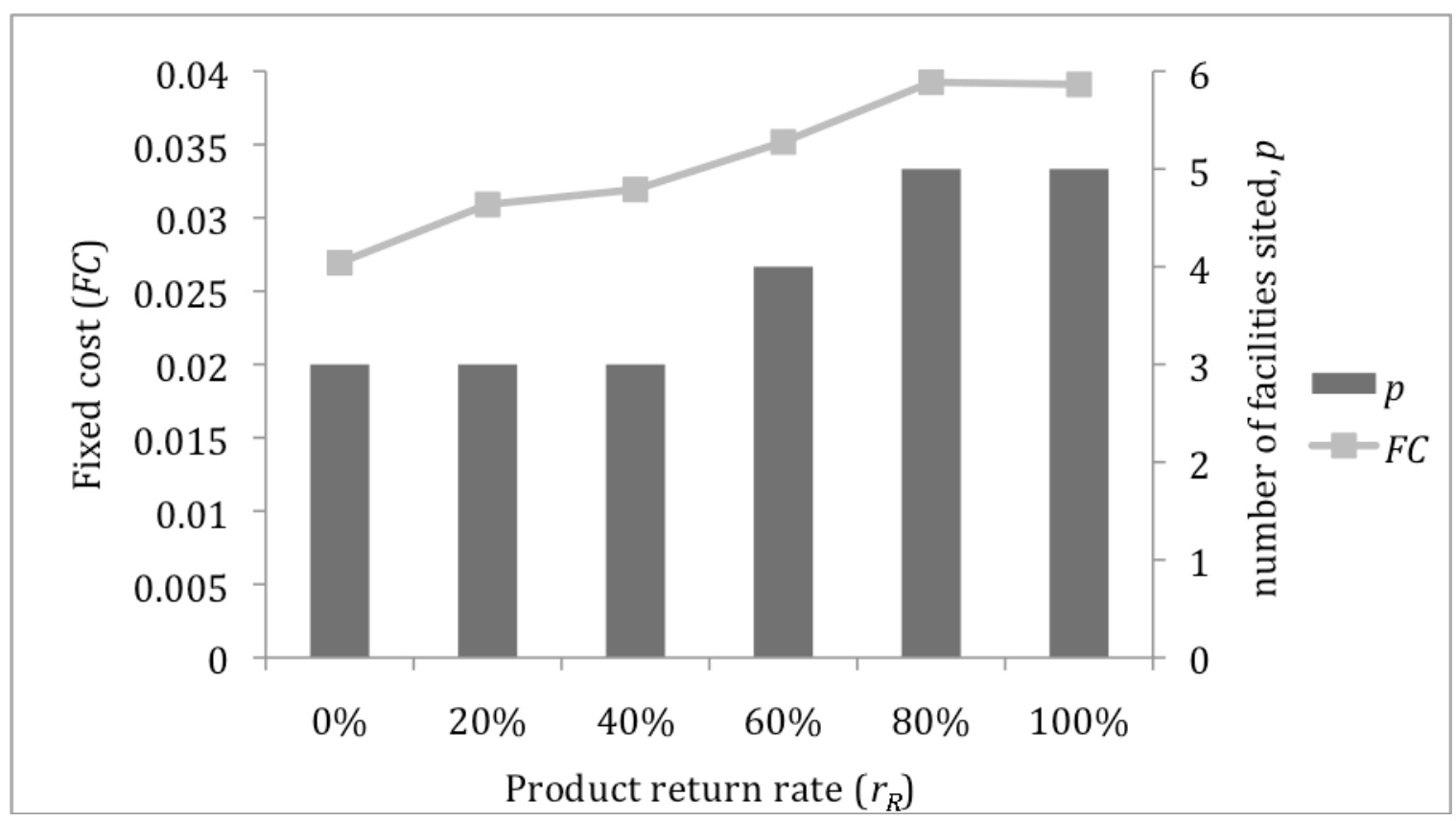

Figure 4.7: Fixed cost and number of facilities sited as a function of product return rate for $c w=25 \%$

\subsubsection{Product return rate}

As product return rate increases, the minimum objective value increases (Figure 4.8); when no shoes are resoled the objective is at its minimum $\left(r_{R}=0 \%\right)$. As the cost weight decreases, and thus environmental indicator weight increases, the minimum objective value increases. The lowest of all objective function values occurs when costs are the only objective considered $(c w=50 \%)$. 


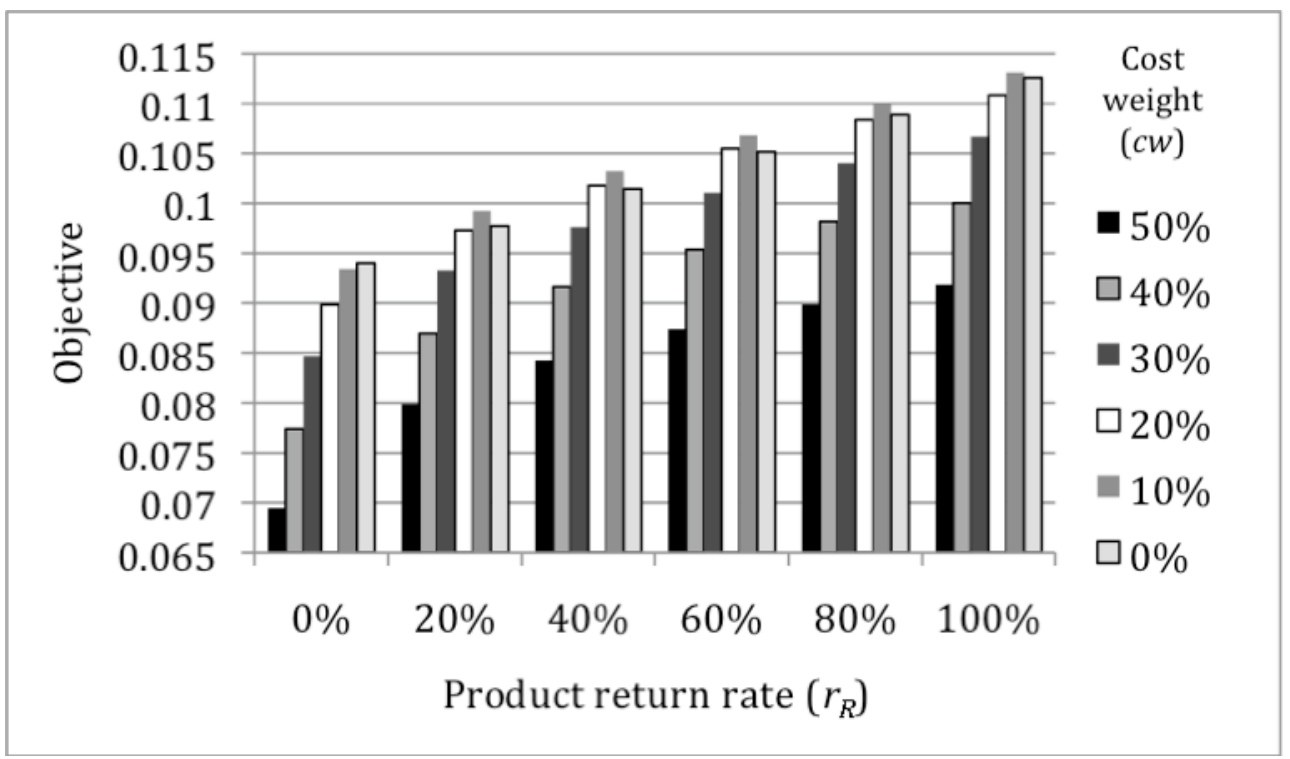

Figure 4.8: Objective values for different cost weights and product return rates

The minimum objective increased as a function of product return rate because as more products are returned, more infrastructure and transportation of products are needed. In general, the number of facilities sited increased as the product return rate increased; this served to decrease transportation cost and GWP. Thus as product return rate increased a lower degree of centralization (decentralized facilities) created the minimum objective for the return rate of interest (Figure 4.7). Which facilities satisfied the demand from certain locations did not change significantly as new facilities were added. Generally, a new facility would involve replacing a demand location in either the $\mathrm{NY} / \mathrm{DC}$ or DA/HO cluster with a standalone facility at that location (Figure 4.8). The same facility locations and demand allocations to facilities were sited for nearly all product return rates. Product return rates are quite variable and difficult to predict before product take back begins (Fleischmann et al., 1997). The analysis for this theoretical example provided a set of facility locations and demand locations for near optimum cost 
and or environmental impact solution that are similar even when the product return rate changes.

\subsubsection{Cost and environmental indicator weights}

It is important that weights reflect decision-makers' actual preferences (Bell et al., 2001); weighting of indicators always plays a role in the outcome of an analysis. For this theoretical example, as the cost weight decreased and the environmental indicator weight increased the minimum objective increased (Figure 4.8). Specifically the fixed cost indicator influenced the minimum objective at higher cost weights, whereas toxicity potential had more influence at lower cost weights (Figure 4.6a). Additionally, more facilities were sited as the cost weight decreased and the environmental indicator weight increased. In this case, lower cost weights and higher environmental indicator weights tend to promote decentralized facility siting.

\subsubsection{Comparison of enumerative and Lagrangian relaxation methods}

The Lagrangian relaxation method was able to reasonably approximate the true optimal objective obtained via the enumeration method (Table 4.1). From Table 4.1, the average percent difference for the minimal objective calculated with the Lagrangian relaxation method is within an acceptable range of the enumeration method's minimal objective. In fact, the Lagrangian relaxation method found the same optimal objective as the enumeration method when $c w=0 \%$ for all cases. The worst case, $c w=40 \%$ and $r_{R}=$ $100 \%$, had a difference of $12.5 \%$ between the Lagrangian and enumerative minimum objectives. 
Table 4.1: Average percent difference between best approximate and optimal solutions, as well as the number of iterations and CPU time for the Lagrangian Relaxation method under the different cost weight, $c w$, scenarios

\begin{tabular}{|c|c|c|c|}
\hline$c w$ & $\begin{array}{c}\text { \% difference } \\
\text { best solution } \\
\text { from optimal }\end{array}$ & $\begin{array}{c}\text { \# of } \\
\text { iterations }\end{array}$ & $\begin{array}{c}\text { CPU time } \\
\text { (seconds) }\end{array}$ \\
\hline $50 \%$ & $3.47 \%$ & 99 & 0.0212 \\
\hline $40 \%$ & $6.29 \%$ & 101 & 0.0838 \\
\hline $30 \%$ & $6.01 \%$ & 109 & 0.1327 \\
\hline $20 \%$ & $3.34 \%$ & 102 & 0.7226 \\
\hline $10 \%$ & $1.80 \%$ & 124 & 1.5515 \\
\hline $0 \%$ & $0.00 \%$ & 279 & 1.8777 \\
\hline
\end{tabular}

The facilities sited and allocations of demand were not always the same between the approximate and the exact solutions. However, the trends that as product return rate increased and cost weight decreased the number of facilities sited increased held in general (Figure 4.9). The objective function also follows the same trends as the enumerated minimum objective, increasing as product return rate increases and cost weight decreases (Figure 4.10). The minimum objectives between the methods were in complete agreement, occurring at the $r_{R}=0 \%, c w=50 \%$ case. Due to the similarities between the results for the Lagrangian relaxation and enumeration methods, for this theoretical example an approximation method can be used to guide decision-makers to make appropriate decisions about the degree of centralization when the objective includes spatially dependent environmental impacts and fixed costs with economies of scale. 


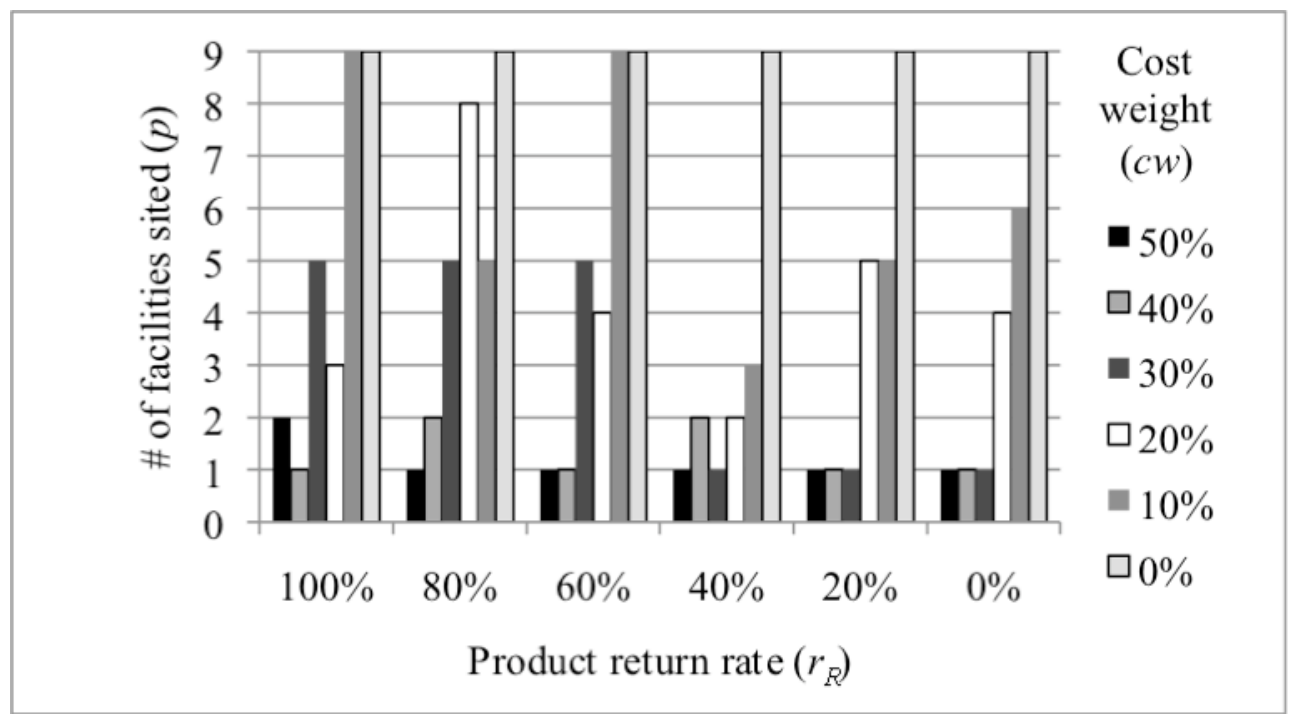

Figure 4.9: Number of facilities sited for the minimum objectives of the Lagrangian relaxation method by product return rate and cost weight

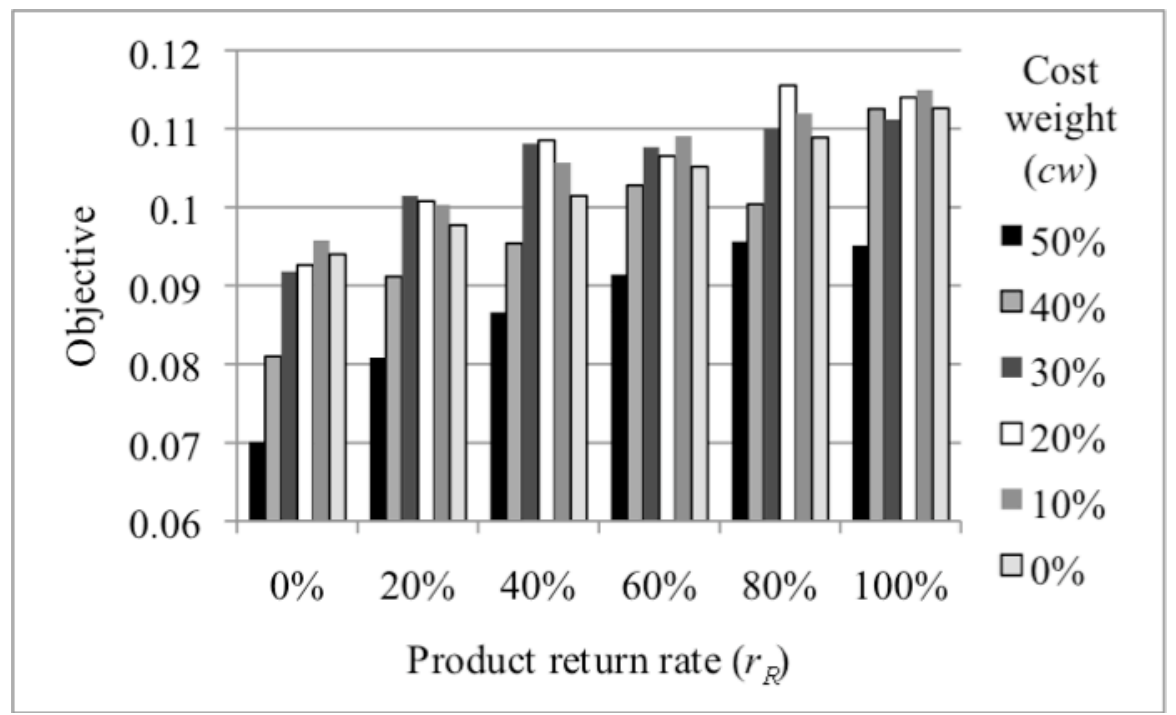

Figure 4.10: Objective calculated by Lagrangian relaxation method for all product return rates and cost weights

\subsection{Summary and Conclusions}

This paper has presented a new perspective on the facility location problem. It has incorporated cost and environmental indicators in the objective. One of the environmental indicators is toxicity potential which is spatially dependent on the geographic location of 
the facility to be sited. The paper has also addressed an issue of growing importance; the siting of facilities that may be undertaking both manufacturing and remanufacturing; moreover it has considered both the forward and reverse supply chains associated with such a situation for a theoretical example. The siting strategy "degree of centralization," (or conversely, degree of decentralization) was examined by solving the facility location problem for a range of sited facilities (1-9). Specifically, the number and locations of facilities that produce and resole shoes were optimized for combined costs and environmental impacts and solved as a $p$-median problem. This $p$-median problem was solved using two methods, enumeration and Lagrangian relaxation. Product return rates for remanufacturing were varied from no products taken back to all products taken back. Each indicator was weighted, and the weights for cost or environmental impact indicators were varied from costs being the only indicators considered by the objective to the opposite situation with environmental impacts the only indicators considered by the objective.

Some of the insights gained through the analysis performed for this theoretical shoe manufacturing example include:

- Environmental impact is spatially dependent and affects optimal facility locations. Including the spatial dependence of environmental impact is important to reflect the realities of a facility location decision.

- Economies of scale for fixed cost affects the number of facilities sited. Including economies of scale allows decision-makers to understand how the degree of centralization is affected for a specific facility location decision.

- Degree of centralization, whether to site facilities in a centralized or decentralized manner, is affected by product return rate and indicator weights. Lower product return rates tend to centralize facilities, whereas higher product return rates tend to decentralize facilities due to increased product volumes to transport. 
- For companies that have highly variable product return rates, the optimal number of facilities to site may change, but it is likely that the optimal number of facilities to site will be similar, and their locations will at least be within a nearby cluster of facilities.

- Certain indicators will tend to dominate the minimum objective found because the values of the indicators vary more greatly for different indicator weights.

- Approximation methods can be used to approach the true optimal objectives with acceptable accuracy allowing this type of analysis to be applied to greater numbers of demand locations and facility sites.

- Considering both environmental impact and costs together results in different minimal objectives, sited facilities, and degrees of centralization than simply considering environmental impact or cost alone. Certain factors, such as spatially dependent environmental impact and costs with economies of scale, affect the outcomes of facility location analysis when considering remanufacturing in terms of the minimal objective and sited facilities. 


\section{Chapter 5}

\section{Development and Weighting of Social, Environmental, and Economic Indicators for a Sustainable Small/Medium Enterprise ${ }^{\dagger}$}

A growing number of companies are interested in measuring the social, environmental, and economic performance of their businesses. Some companies are moving beyond measurement of impacts to incorporating an assessment of sustainability impacts into their decision-making processes. Formulating relevant indicators of sustainability performance is a difficult task for any organization, but especially for small/medium enterprises (SMEs) that lack financial, knowledge, and labor resources for this task. This paper creates a method for developing and weighting sustainability indicators for a strategic planning decision - where to locate operations and facilities in an SME's growing supply chain. For specific types of decision-making, such as for the strategic planning of supply chains, sustainability impacts can vary dramatically among different geographic locations. This approach was applied to a sustainable SME that manufactures consumer products from reclaimed materials. The SME's managers applied

\footnotetext{
${ }^{\dagger}$ This chapter is under review as a journal publication for the Journal of Environmental Management
} 
the method to develop sustainability indicators encompassing three categories- the economic, environmental, and social concerns of their business. The managers weighted the indicators utilizing pairwise comparison analysis then revised the weights for individual indicators and indicator categories. This paper considers several overlooked perspectives within sustainability assessment; the concerns of SMEs, strategic planning decisions for businesses, and effect of location on impacts.

Keywords: sustainability; indicators; pairwise comparison analysis

\subsection{Introduction}

International concern for environmental degradation, population growth, and economic inequities has given rise to the concept of sustainable development, commonly defined as "meeting the needs of the present without compromising the ability of future generations to meet their own needs (Bruntland Commission, 1987)." The Johannesburg Declaration on Sustainable Development described three pillars of sustainability: economic, environmental, and social (UN, 2003), often referred to in the business world as the triple bottom line (Elkington, 1994). There is increasing pressure from a multitude of sources, e.g., international organizations, governments, stakeholders, and markets, for businesses to address this triple bottom line in a holistic way.

\subsubsection{Indicators as measure of corporate sustainability performance}

As businesses incorporate sustainability into their visions and missions, they often develop quantitative indicators to measure performance. As with other performance measures, care must be taken to balance what can be measured with what should be 
measured (McCool and Stankey, 2004). Specifically, companies utilize quantitative indicators to:

- establish the current level of organizational performance (McCool and Stankey, 2004);

- allow external parties to monitor performance (CorporateRegister.com, 2009);

- measure internal progress toward (a) goal(s) (McCool and Stankey, 2004); and

- predict the impact of proposed changes relative to performance goals (Kates et al., 2001; Spangenberg and Bonniot, 1998).

The development of indicators involves not only deciding what is important and relevant to track, but also what is meaningful to quantify (McCool and Stankey, 2004). Companies utilize economic and environmental indicators more often, which are better established, than social sustainability indicators (Veleva and Ellenbecker, 2001). The need for composite indices of two or all three dimensions of sustainability has been recognized (Sikdar, 2003) and indices have been created (Krajnc and Glavic, 2005; Singh et al., 2007,2009; Zhou et al., 2007).

Companies may include many different stakeholder groups in the indicator development process. These stakeholder groups may include: employees, shareholders, suppliers, or community organizations in the region where the business is located (GRI, 2008). Companies may also limit involvement to those deemed "experts," such as company decision-makers, policy-makers, or scientists (Azapagic, 2004; Bell and Morse, 2008; Esty et al., 2005; Goedkoop and Spriensma, 2000; Singh et al., 2009; UN DSD, 2009).

\subsubsection{Methods for measuring corporate sustainability performance}

Many methods for measuring corporate sustainability performance, either company specific or standardized, exist (see Singh et al. (2009) for an extensive review). 
Existing methods have several shortcomings: extensive time, knowledge, labor, and thus financial requirements; neglect of variation in sustainability impact by location; reliance on outside experts to define relevant sustainability concerns; lack applicability to strategic decision-making; and are unable to incorporate multiple decision-makers' inputs during weighting.

Timberland's "code of conduct" and corporate responsibility reporting (The Timberland Company, 2007) and BASF's Eco-efficiency analysis and SEEBalance ${ }^{\mathrm{TM}}$ (Kolsch et al., 2008; Shonnard et al., 2003) can assess the sustainability impacts of their global supply chains in 35 countries and 300 factories (The Timberland Company, 2007) and nearly 330 operations around the world (BASF, 2009) respectively. The operations of SMEs are not as complex as those of large-scale companies. Very few SMEs apply sustainability assessment methods because of the time, knowledge, labor, and financial resources required (Tsai and Chou, 2009). Global companies have largely defined what corporate sustainability means despite the existence of many more SMEs than multinational corporations (Luetkenhorst, 2004). Several corporate indicator development and weighting methods more appropriate for smaller companies are timeintensive (Krajnc and Glavic, 2005; Singh et al., 2007) taking from a year to several years to complete development and weighting of indicators into a composite index. Due to the barriers to sustainability assessment, SME perspectives on what constitutes sustainability are largely unknown and missing from business and academic discourses (Redmond et al., 2008).

Few methods are able to consider how sustainability impacts vary by location, except (Ugwu and Haupt, 2007; Ugwu et al., 2006; Zhou et al., 2007). Geographic 
location affects financial (U.S. Census Bureau, 2007a), environmental (MacLeod et al., 2004) and social impacts (Vanclay, 2006). Sustainability assessment, including indicators, often ignores how the impact varies for the same operations in different geographic locations (Graedel, 1998) due to inherent economic, environmental, and social differences between places. The authors are not aware of research that estimates potential sustainability impact variation so that decision-makers who oversee location decisions have the ability to choose the site where less impact is created.

Other approaches are not applicable to strategic decision-making. Muñoz et al. created a fuzzy logic approach, which evaluates company sustainability performance (Muñoz et al., 2008) but cannot guide companies during decision-making. Certain methods utilize sustainability indicators for the strategic planning of urban or regional development (Kowalski et al., 2009; Li et al., 2009); companies' development concerns differ from governments.

Many methods depend upon experts to define what are the important aspects of sustainability and thus relevant sustainability indicators for all companies (GRI, 2008; UNCSD, 2001) or performance standards and goals (Ugwu and Haupt, 2007; Ugwu et al., 2006). Standardized systems of sustainability indicators, such as GRI (GRI, 2008), are useful for external comparison, but may lack measures relevant to a company or particular decision (O'Connor and Spangenberg, 2008; Singh et al., 2007; Veleva and Ellenbecker, 2001). Ecologic reported on standardized sustainability metrics using the GRI G3 guidelines (Bogatin and Clarke, 2008); the information collected for those metrics did not pertain to the strategic decision of where to grow operations. Sustainability indicators must be pertinent and useful to the decision-makers and 
decision (Ugwu et al., 2006). Some methods neglect input from corporate decisionmakers in the development of indicators (Jung et al., 2001) though corporate decisionmakers enact the changes based on sustainability assessment findings. Many company decision-makers, as the experts of their own businesses, have created indicators of sustainability performance tailored for their own decision-making needs.

Some methods have no way of handling input on weights from multiple decisionmakers (Ugwu and Haupt, 2007; Ugwu et al., 2006); in general, several company decision-makers will be involved in sustainable strategic planning. Zhou et al. (2007) consider multiple decision-makers and use data envelopment analysis to calculate weights by finding an optimal weight while only starting with a lower and upper bound for each indicator determined by decision-makers. Their process works well for finding compromises between decision-makers who will not come to agreement on their own, but would work poorly for the management of a company who have to act in concert upon recommendations stemming from the decisions made using weighted indicators. Zhou et al.'s method removes some of the influence decision-makers have over the weighting process. A company is more likely to use weights they agree upon (Forman and Peniwati, 1998). Bell et al. found that regardless of the method chosen to calculate weights, decision-makers trust the outcomes more when they were able to review and revise weights after applying a calculation method (Bell et al., 2001).

\subsubsection{Development and weighting of indicators for this research}

This paper explores one company's perspective on an appropriate composite sustainability index for strategic decision-making as well as social sustainability concerns affecting their business. This company used the weighted indicators to answer 
the question of where to expand its operations. The authors developed this approach and an analyst (the first author) facilitated application of this method as an observer. The four managers that oversee the company were the decision-makers involved in developing indicators both collectively and individually.

The method presented in this paper uses pairwise comparison analysis (PCA) to weight the developed indicators. PCA determines weights by soliciting a decisionmaker's opinion on how much more or less important one indicator is than another indicator for a particular decision, i.e., a pairwise comparison, for all pairings of indicators (e.g., indicator A is three times as important as indicator B). PCA assumes that there exists a global (or intrinsic) importance, i.e. weight, associated with each indicator that can be calculated from the pairwise comparisons (Saaty, 1980).

This research investigates several overlooked concerns, including; (1) opinions on sustainability from small/medium enterprises (SMEs) (Redmond et al., 2008) specifically their thoughts on social sustainability, (2) the development of indicators to consider how sustainability impacts vary by location - spatial differences are often ignored in assessment of environmental impacts (Graedel, 1998) and thus sustainability, and (3) utilizing sustainability assessment in business strategic planning.

\subsection{Weighting of Indicators}

Pairwise comparison analysis (PCA) was the calculation method chosen to weight indicators for the following four reasons. The method: shows how each indicator measures up to every other indicator, which elucidates more about the importance of an indicator relative to other indicators than rankings; clarifies the global importance among several decision-makers incorporating each person's comparisons of indicator pairs 
before grouping comparisons to create indicator weights; preserves more of each decision-maker's opinions for indicator weights than averaging multiple indicator weights; and evaluates by requiring a certain level of consistency amongst a decisionmaker's pairwise comparisons. Additionally company decision-makers can apply this technique without extensive financial resources, knowledge, or time, and expert opinions to create indicator weights.

\subsubsection{Create PC matrices}

The first step of weighting indicators (Figure 5.1) involves decision-makers defining the relative importance of each indicator compared to every other indicator for a particular decision in a pairwise comparison (PC) matrix and then calculating the weights from the PC matrix (Table 5.1). The relative importance between indicator pairs was measured with the Saaty scale (Saaty, 1980) where 9 denotes the absolute importance of one indicator over another, 1 states equal importance of indicators, and 1/9 denotes absolute unimportance of one indicator relative to another (Saaty, 1980). The ratio structure of the scale allows for the calculation of weights using this method. Often it is assumed that decision-makers are supplying verbal instead of numerical feedback, i.e. indicator $\mathrm{A}$ is absolutely more important than indicator $\mathrm{B}$ versus $\mathrm{A}$ is 9 times as important as B, which is then translated into a ratio scale value by an analyst or tool. However, time and resources are saved if ratio values are entered at the outset. Other ratio-based scales, e.g. the geometric, Ma-Zheng, and Salo scales, improve upon certain performance aspects of the Saaty scale (Dong et al., 2008). Arguably, with the Saaty scale it is easier for decision-makers to understand the connection between verbal and 
numerical feedback because no external parameters need to be selected and the mathematics are simple, which only involves taking the reciprocal of a number.

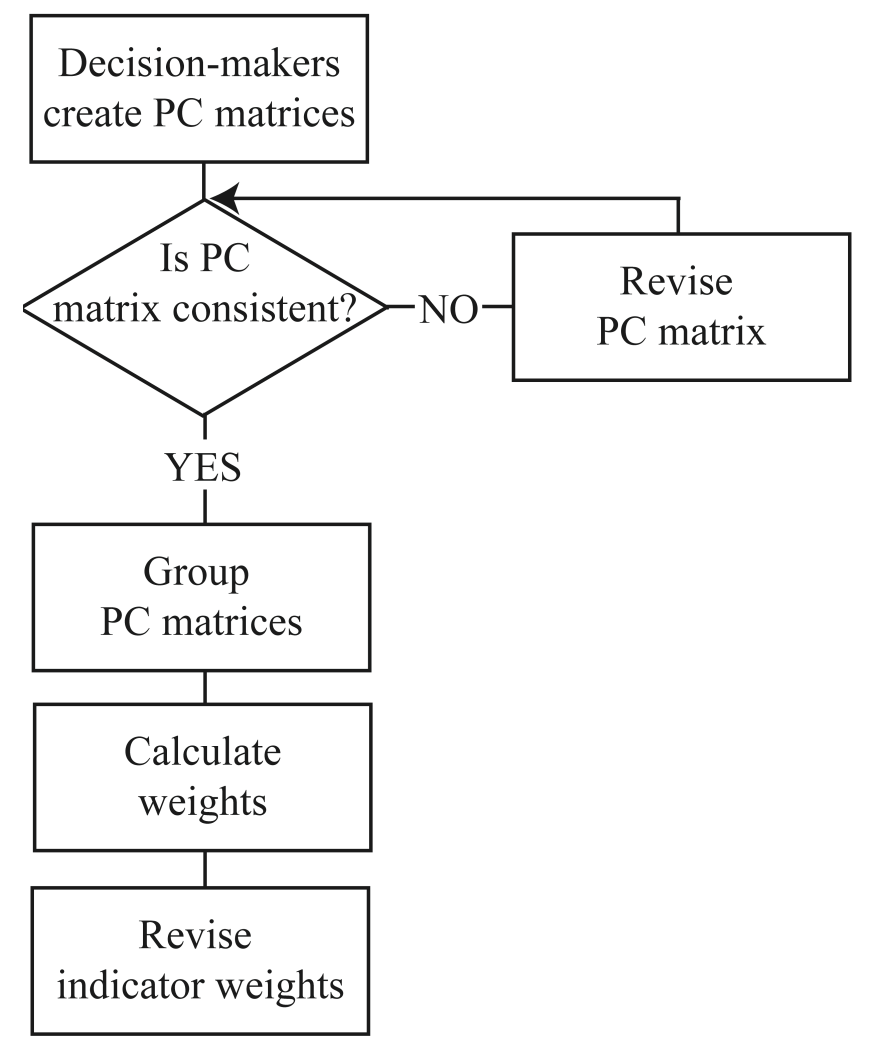

Figure 5.1: Flow chart of steps to weight indicators using pairwise comparison analysis 
Table 5.1: Manager d's pairwise comparison of environmental indicators

\begin{tabular}{|c|c|c|c|}
\hline & $\begin{array}{c}\text { 1. Number of } \\
\text { reclamation } \\
\text { partners }\end{array}$ & $\begin{array}{c}\text { 2. Amount of } \\
\text { reclaimed } \\
\text { materials }\end{array}$ & $\begin{array}{c}\text { 3. Density of } \\
\text { competitors for } \\
\text { reclaimed } \\
\text { materials }\end{array}$ \\
\hline $\begin{array}{c}\text { 1. Number of } \\
\text { reclamation partners }\end{array}$ & 1 & 6 & 1 \\
\hline $\begin{array}{c}\text { 2. Amount of } \\
\text { reclaimed materials }\end{array}$ & $1 / 6$ & 1 & $1 / 2$ \\
\hline $\begin{array}{c}\text { 3. Density of } \\
\text { competitors for } \\
\text { reclaimed materials }\end{array}$ & 1 & 2 & 1 \\
\hline
\end{tabular}

A pair of indicators, $i$ and $j$, have a relative importance with respect to each other, $a_{i j}$, that is stored in a square PC matrix, $A$. The matrix $A$ contains comparisons between all indicator pairs; if indicator $i$ is assessed as four times more important than indicator $j$, then matrix entry $a_{i j}=4$. Due to the reciprocal symmetry of this type of comparison, indicator $j$ is one fourth as important as indicator $i$ and hence matrix entry $a_{j i}=1 / 4$ or $a_{i j}=$ $1 / a_{j i}$. A decision-maker's PC matrix of the relative importance of all of the indicators relative to one another can be used to calculate the global importance of the indicators, or weights. The global importance is termed $\alpha_{i}$, and the relative importance of indicators $i$ and $j, a_{i j}$, is the ratio of two global importances $\alpha_{i} / \alpha_{j}$.

\subsubsection{Resolve PC matrix inconsistency}

The second step in weighting indicators involves determining whether the PC matrices filled out by decision-makers are consistent and revising PC matrices with unacceptable levels of inconsistency. To be absolutely consistent, a PC matrix must be symmetrically reciprocal and transitive, i.e., $a_{i j} a_{j k}=a_{i k}$ for all values of $i, j$, and $k$. Attaining perfect consistency is unlikely. Often, decision-makers make pairwise 
comparisons that are inconsistent (Crawford and Williams, 1985; Xu and Wei, 1999), due to difficulties in comparing multiple items (Saaty, 1980). A PC matrix with an acceptable level of inconsistency will produce usable results. Extremely inconsistent matrices have conflicting orders of importance for indicators, which makes creating meaningful weights from the decision-maker's PC matrix difficult (Saaty, 2003; Saaty and Hu, 1998). Saaty created the consistency ratio $(C R)$ to set a threshold for acceptable inconsistency and to measure the consistency of matrices (Equation 5.1). For a matrix to be defined as consistent (i.e., consistent enough to produce usable results), the consistency index $(C I)$ of the matrix must be less than or equal to $10 \%$ of the mean $C I$ of a randomly generated PC matrix $(R I)$ of the same size ( $\underline{n}$ rows by $n$ columns, where $n$ is the number of indicators) (Saaty, 1980). The value for $R I$ (Table 5.6 in the appendix) is calculated by averaging the $C I$ of 500 randomly generated square PC matrices for each $n$ (Saaty, 1980). This rule has been revised for $3 \times 3$ and $4 \times 4$ matrices to $5 \%$ and $8 \%$ respectively (Saaty, 1994a) to reduce the number of random matrices that are deemed consistent (Lane and Verdini, 1989).

$$
C R=\frac{C I}{C R} \leq .1(10 \%) \text { and } C I=\frac{\lambda_{\max }-n}{n-1}
$$

The method for calculating indicator weights, also called the prioritization method, defines which measure of consistency is appropriate and hence which methods for resolving inconsistency apply. Several approaches exist for revising inconsistent matrices to make them nearly consistent, including, the decision-maker revising their PC matrix (Forman and Peniwati, 1998; Saaty, 1980), modifying single PC matrix entries (Harker, 1987; Saaty, 2003), and modifying all PC matrix entries (Cao et al., 2008; 
González-Pachón and Romero, 2004; Lin et al., 2008; Xu and Wei, 1999). Certain drawbacks exist for each of these approaches to revise inconsistent matrices. Decisionmakers revising their own PC matrix entries to be more consistent requires considerable time and effort (Xu and Wei, 1999). Concern that the revised PC matrix will not represent the original intent of the decision-makers arises when modifying single or all matrix entries. To address the latter concern, $\mathrm{Xu}$ and Wei created two measures of difference between the original and revised matrix (Xu and Wei, 1999), $\delta$ and $\sigma$ (Equations 5.2 and 5.3). $\delta$ measures the maximum absolute difference between an original and revised element while $\sigma$ characterizes the standard deviation over all matrix elements (assuming the complete population of judgments is known therefore the denominator is $n$ instead of $n-1$ ). The lower the values of these measures the better (Cao et al., 2008; Xu and Wei, 1999), $\delta<2$ and $\sigma<1$ denote acceptable similarity between the original and revised PC matrix (Xu and Wei, 1999).

$$
\begin{aligned}
& \delta=\max \left\{\left|a_{i j_{m}}-a_{i j}\right|\right\} \quad \forall i, j=1, \ldots, n \text { where } a_{i j_{m}} \text { is the modified matrix entry } \\
& \sigma=\frac{\sqrt{\sum_{i=1}^{n} \sum_{j=1}^{n}\left(a_{i j_{m}}-a_{i j}\right)^{2}}}{n}
\end{aligned}
$$

The method to revise inconsistent PC matrices created by Cao et al. (Equations 5.4-5.7) was used because of its ability to maintain the greatest measure of similarity to the original inconsistent PC matrix after revising matrix entries, i.e., the lowest values of $\delta$ and $\sigma$ (Cao et al., 2008). This revision method alters the values of every entry in a PC matrix slightly by a factor, $\gamma$, until acceptable consistency is achieved. Specifically, the weights, $w_{i}$, in column vector $w$ are calculated using the right eigenvector method 
(Equation 5.9). Ratios of the weights create $V_{i j}$, the $(i, j)$ entry in matrix $V$ (Equation 5.4). From $V$ and $A$, the deviation matrix, $B$, is calculated (Equation 5.5) with entries, $B_{i j}$. A PC matrix is consistent if all $B_{i j}$ entries equal one.

Next a new deviation matrix altered by $\gamma$ is calculated, creating $B^{\prime}$ (Equation 5.6). $B^{\prime}$ and $W$ create a revised PC matrix, $A^{\prime}$ (Equation 5.7). $\gamma$ is valued between zero and one; values of $\gamma$ closest to one maintain the most similarity to the judgments contained within the original PC matrix as measured by $\delta$ and $\sigma$ (Cao et al., 2008). Cao et al. found $\gamma=.98$ to produce the best results, so that value for $\gamma$ was used in this paper. If the revised PC matrix, $A^{\prime}$, is inconsistent then it replaces $A$ and the process continues by recalculating - the weights $w$ with the right eigenvector method, $V$ (Equation 5.4), $B$ (Equation 5.5), $B^{\prime}$ (Equation 5.6), and $A^{\prime}$ (Equation 5.7) until $A^{\prime}$ has acceptable consistency.

$$
\begin{aligned}
& V_{i j}=w_{i} / w_{j} \text { for all } i \text { and } j \\
& A=V \circ B \text { where the Hadamard product, } \circ \text {, is defined as } a_{i j}=V_{i j} B_{i j} \quad \forall i \text { and } j \\
& B^{\prime}=\left[\begin{array}{ccc}
B_{i j}{ }^{\prime} & \ldots & \ldots \\
\ldots & \ldots & \ldots \\
\ldots & \ldots & \ldots
\end{array}\right] \text { where } B_{i j}{ }^{\prime}=\gamma B_{i j}+(1-\gamma) \text { for } B_{i j} \geq 1 \text { or } B_{i j}{ }^{\prime}=1 / B_{j i}{ }^{\prime} \text { for } B_{i j}<1 \\
& A^{\prime}=V \circ B^{\prime}
\end{aligned}
$$

\subsubsection{Combine PC matrices of multiple decision-makers}

The third step in calculating indicator weights combines the PC matrices of multiple decision-makers. Approaches for grouping decision-makers' judgments can occur at different steps in the PCA process (Escobar and Moreno-jiménez, 2007; Forman 
and Peniwati, 1998; Gass and Rapcsák, 1998; Mikhailov, 2004; Ramanathan and Ganesh, 1994; Van Den Honert and Lootsma, 1996).

One such approach seeks to have decision-makers group comparisons into a single PC matrix by reaching consensus on their pairwise comparisons of indicators (Moreno-Jiménez et al., 2008; Saaty, 1980), which occurs during the first step - creating PC matrices. Other ways of combining judgments include aggregating individual judgments (AIJ) - grouping matrices together - which occurs after PC matrices are created or aggregating individual priorities (AIP) - grouping weights together which occurs after weights are calculated (Forman and Peniwati, 1998). Forman and Peniwati state that AIJ should be used when individuals are expected to act in concert (e.g., fulfilling a corporate mission), whereas AIP should be used when individuals have differing goals (e.g., parties developing legislation) (Forman and Peniwati, 1998). In the context of this application, a company weighting indicators to choose between growth strategies and future facility locations, the AIJ approach is appropriate.

There are two main approaches used to group multiple PC matrices by aggregating individual judgments (AIJ), the geometric mean method (Barzilai and Golany, 1994) and the weighted arithmetic mean method (Ramanathan and Ganesh, 1994); there are differing views on which method is best (Mikhailov, 2004). The geometric mean method for group aggregation was used in this paper because of cited concerns regarding the importance of preserving the reciprocal nature of comparisons, which is important for consistency; the arithmetic mean method does not preserve reciprocity when combining group judgments (Aczèl and Saaty, 1983; Barzilai and Golany, 1994; Forman and Peniwati, 1998). Additionally, grouping with the arithmetic 
mean method can result in rank reversal (where the order of importances in the group matrix differs from the original matrices), while grouping with the geometric mean method does not (Leskinen and Kangas, 2005). The geometric mean method multiplies each entry, $a_{i j}$, in every PC matrix by one over the number of decision-makers, $g$. Next the single entry for one decision-maker, $\left(a_{i j}\right)_{k}$, is multiplied by the entries in the same position for all other decision-makers and then placed in that same position in the new grouped matrix, $\left(a_{i j}\right)_{\text {grouped }}$ (Equation 5.8).

$$
\left(a_{i j}\right)_{\text {grouped }}=\prod_{k=1}^{g}\left(a_{i j}\right)_{k}^{1 / g} \text { for all } i \text { and } j \text { where } A_{\text {grouped }}=\left[\begin{array}{ccc}
\left(a_{i j}\right)_{\text {grouped }} & \ldots & \ldots \\
\ldots & \ldots & \ldots \\
\ldots & \ldots & \ldots
\end{array}\right]
$$

where $g$ is the number of decision-makers and $k$ denotes the $k^{\text {th }}$ decision-maker

\subsubsection{Calculate weights}

The second to last step in the weighting method is to calculate weights. The most common methods for calculating indicator weights are: the right eigenvector method (Saaty, 1980) - which defines the weights as the eigenvector associated with the principle (maximal) eigenvalue of the PC matrix; and the row geometric mean (Crawford and Williams, 1985) (also called logarithmic least squares) method - which defines the weights as the product of all elements in a row of the PC matrix raised to the power of one over the number of indicators. Several researchers found that these methods perform similarly (Dong et al., 2008; Herman and Koczkodaj, 1996; Ishizaka and Lusti, 2006). While researchers do not agree about which methods for calculating weights perform better for specific applications (Srdjevic, 2005), the right eigenvector method is widely used in practice (Choo and Wedley, 2004; Mikhailov, 2004; Xu and Wei, 1999) and 
yields valid weights when used correctly (Harker and Vargas, 1987; Saaty, 1986,1990,1994b; Saaty, 1996; Saaty and Hu, 1998; Vargas, 1990; Vargas, 1994). $\lambda_{\max }$, the principle eigenvalue of a PC matrix is calculated by finding the maximum value that satisfies Equation 5.9.

$$
A w=\lambda_{\max } w \text { and } e^{T} w=1 \text { or } \sum_{i=1}^{n} w_{i}=1
$$

where $n$ is the number of indicators, $A$ is the $n \times n$ PC matrix, $w$ is the $n \times 1$

column vector of resulting weights $w_{i}, \lambda_{\max }$ is the principal eigenvalue, and $e^{T}=(1,1, \ldots, 1)$ such that $e$ is $1 \times n$

\subsubsection{Review and finalize weights}

After calculating the weights with PCA, the decision-makers must ensure that the calculated weights reflect their judgment. Through the process of weighting indicators individually and discussing the calculated group weights a new understandings of the inter-relatedness and thus the importance of these indicators to each other may come to decision-makers. If the calculated weights do not reflect the full extent of their judgment, the decision-makers are given the opportunity to revise weights collectively to better reflect their intent. Bell et al. found that decision-makers prefer methods where they can revise indicator weights after the weights are calculated (Bell et al., 2001).

\subsubsection{Summary of weighting method}

In summary, the method employed in this paper consists of the following five steps:

1. Decision-makers create PC matrices by comparing all indicators in pairs (Saaty, 1980).

2. Resolve any inconsistency in decision-makers' PC matrices using Cao et al.'s method (Cao et al., 2008). 
3. Combine decision-makers' PC matrices by applying the geometric mean method (Barzilai and Golany, 1994).

4. Calculate the weights of the indicators from the combined PC matrices using the right eigenvector method (Saaty, 1980).

5. Review the calculated weights and make revisions to the weights to better reflect decision-makers' judgment of indicator importance (Bell et al., 2001).

\subsection{Application}

The application of this indicator development and weighting method was a case study with Ecologic Designs, Inc. a manufacturer committed to both sustainability and local production that started operations in July 2006 (Bogatin and Clarke, 2008). Ecologic recycles polymeric materials (e.g., billboard vinyl, tire inner tubes, wetsuits, and climbing rope) into bags and accessories. An integral part of their business consists of reclaiming materials, clearly demonstrating Ecologic's commitment to the environment. In addition, Ecologic relies upon individuals and community partners (e.g., governmental agencies, non-profits, and other businesses) to help collect the reclaimed material stream. For Ecologic to achieve its goals, it must value the people that help it fulfill its mission by supplying reclaimed materials, promoting its reclamation services, buying its products, and promoting the outdoor activities and lifestyle of its customers.

This company markets its products to web and traditional retail customers in addition to business-to-business (B2B) clients through a reclamation service and private labeling. Currently, Ecologic reclaims materials and manufactures products in the U.S. and is committed to staying in the U.S. for additional business growth. The company sells most of its products within the U.S., but has an increasing international market presence. 
Ecologic has a fairly simple organizational structure; four managers oversee all aspects of the business. These aspects include, managing employees that perform general labor tasks such as processing of reclaimed materials, design and prototype construction, sewing, product assembly, as well as marketing. The management team also oversees interactions with contracted facilities and contract employees (i.e., garment workers) and brokers relationships with retail, wholesale, and B2B clients.

Ecologic needed to decide how to grow the company's operations in a way that meets its sustainable mission. This sentiment is outlined in Ecologic's 2007 Sustainability report, "[a]s we grow, our goal is to invest in sustainable technologies and efficient processes to increase the overall positive impact we have on local and global communities (Bogatin and Clarke, 2008)." Thus Ecologic's goal was to create indicators to evaluate growth strategies for expanding operations. As demand for certain Ecologic products increased in particular markets, Ecologic wanted the capability to compare the suitability of various locations for expanding operations through either contracting, renting, or purchasing facilities. Ecologic used the indicators and weights developed in this paper to find the best locations for the expansion of their supply chain and satisfy their economic, environmental, and social sustainability priorities outlined in the indicators.

\subsubsection{Indicator development}

Who develops indicators is just as important as how indicators are created (GRI, 2008). Regarding strategic planning for where to expand operations, managers are most capable to define performance indicators. Managers have expertise about a company's operations and values and are responsible for implementing strategic decisions. 


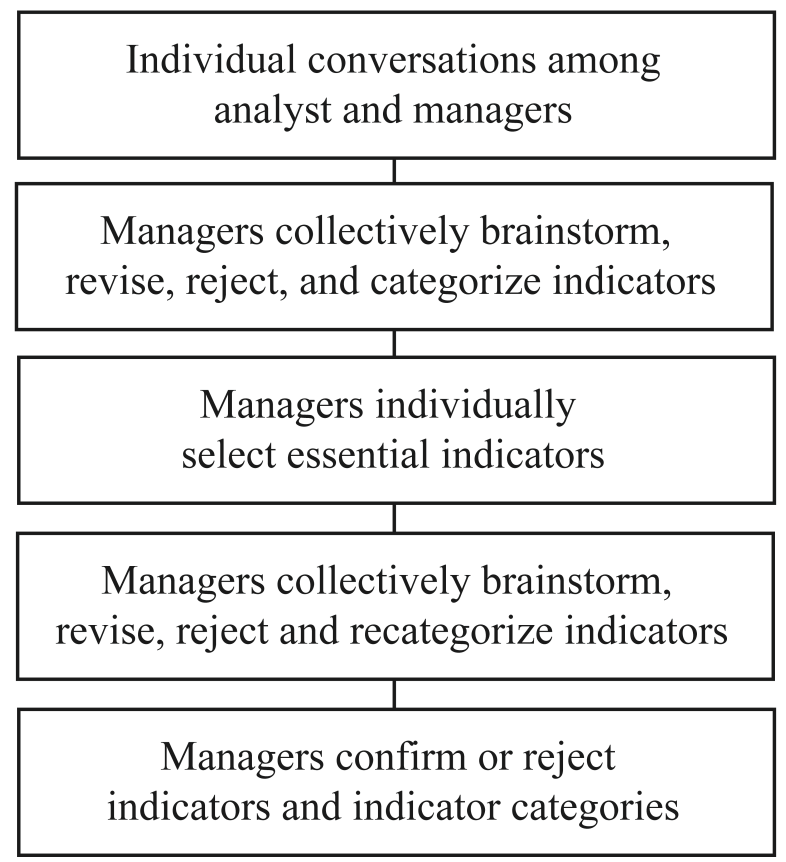

\section{Figure 5.2: Flow chart of steps to develop indicators}

The indicator development process (Figure 5.2) was employed by the managers and concurrently adapted as it was applied at Ecologic. The process started with individual conversations with the managers (step 1) from which a list of indicators was generated to start group discussion. During the first of two meetings (step 2) the managers brainstormed, categorized, and revised indicators during the meeting to create a new list of potential indicators. During the discussion, the managers developed two criteria for indicators: (1) indicators must pertain to day-to-day business operations; and (2) indicators must vary by location. Next managers individually approved and added to the potential indicator list (step 3), from which an approval rating for each indicator and list of new suggestions for indicators was created. These items started off the second discussion among managers (step 4) where the managers considered the new indicators, 
rejecting and re-categorizing indicators to create a final list. Each manager approved the final list of indicators and categories (step 5).

\subsection{Results}

The application of this approach includes the development of indicators, discussed first, and weightings for those indicators, which follow second. Many indicators of economic, environmental, and social performance were considered to help make the decision of how and where to expand Ecologic's operations. The Ecologic management team wanted to ensure that operations in new locations would have the least possible negative effect on sustainability and no more adverse local impacts than their existing Denver metro-based operations. All of the sustainability indicators are measured such that minimizing the indicator values minimizes the negative effects to sustainability.

\subsubsection{Economic indicators}

Seven economic indicators were formulated with units as shown in brackets.

1. Operating costs $[\$ /$ product $]$

2. Labor costs $[\$ /$ product $]$

3. Facility setup costs [\$/product]

4. Land and construction costs [\$/product]

5. Warehouse/factory rental costs [\$/product]

6. Transportation costs [\$/product]

7. Proximity to reclaimed materials [distance]

Several economic indicators are composites of a few costs, e.g., 'Operating costs' includes materials, labor, energy, and administrative costs. However, labor costs were deemed important enough by the managers to warrant a separate indicator. Sustainability indicators compiled together for a single purpose, e.g. creating an index of sustainability, 
are often inter-related or dependent (Singh et al., 2009). Interdependence of sustainability indicators in part arises from the increased utility and relevance of indicators that incorporate multiple, often overlapping, aspects of sustainability economic, environmental, and social (Swisher et al., 2006). Similarly, 'Land and construction costs' and 'Warehouse/factory rental costs' combined with capital costs and location-specific job creation tax credits comprise 'Facility setup costs.' 'Transportation costs' includes fuel and maintenance costs; in Ecologic's case, part of transportation costs are labor for the collection and processing of waste vegetable oil. Primarily, Ecologic uses transportation to collect reclaimed materials. For this reason, the distance traveled and time to collect reclaimed materials strongly affects transportation costs, which is why 'Proximity to reclaimed materials' is an economic indicator.

\subsubsection{Environmental indicators}

Three environmental indicators were developed.

1. Number of reclamation partners by location [square area/partner]

2. Amount of reclaimed materials in an area [square area/material]

3. Density of competitors for other reclaimed materials [\# competitors/square area]

The environmental indicators that Ecologic created focus on resource use, specifically Ecologic's use of reclaimed materials. Ecologic has many other environmental concerns. However, these three indicators relate directly to Ecologic's environmental goals and meet the criteria that indicators should affect day-to-day business operations and vary by location. 'Number of reclamation partners by location' measures the number of reclamation partners (e.g., bicycle shops for bicycle inner tubes or climbing gyms for climbing rope) by type of reclaimed material found in a given 
location. A greater number of reclamation partners for a particular material will likely increase the diversity of material (e.g., many colors of climbing rope) and also interface with a greater number of potential customers. 'Amount of reclaimed materials in an area' measures the quantity of material available, by type, at specific locations. 'Density of competitors for other reclaimed materials' becomes important when considering access to the material supply that constitutes Ecologic's products and brand promise. Competitors for materials are other organizations that are trying to reclaim the same waste materials. Right now, competition is a particular concern in many cities for businesses collecting waste vegetable oil (which Ecologic uses to fuel its vehicles) for use as a fuel directly or conversion into biodiesel (Hutton, 2008).

\subsubsection{Social indicators}

Seven indicators were created to characterize social sustainability impacts.

1. Average employee commute [time]

2. Availability of alternative transportation systems [area/\# systems]

3. Public health [SustainLain ${ }^{\text {TM }}$ City Ranking (SustainLane, 2009)]

4. Availability of manufacturing facilities (for contracting sewing and other processing operations) [area/\# facilities]

5. Availability of skilled labor [area/\# skilled laborers]

6. Availability of warehouse facilities [area/\# facilities]

7. Proximity to transportation hubs (e.g., ports, UPS, FedEx, airports) [distance]

The social indicators that Ecologic created span the internal and external relationships that the company must build and maintain, reflecting how Ecologic interacts with its employees and its business partners. 'Average employee commuting distance,' 
'Availability of alternative transportation systems,' and 'Public health' represent Ecologic's concern for internal relationships, i.e., employee health and well-being. Concerns about reducing total employee commuting times and providing alternative transportation options (e.g., biking or busing) reflect Ecologic's commitment to reducing environmental impact and, more importantly, attracting employees that value the same commitment. Ecologic's concern for public health came from the managers' sense of equity - only wanting operations in locations where they would want to live and work. Ecologic looked at public health holistically as a measure of access to a clean environment and low incidence of disease relating to both the condition of the local environment and local culture; the analyst determined that the SustainLain ${ }^{\mathrm{TM}}$ city rankings (SustainLane, 2009) best fit Ecologic's definition of public health.

The availability of manufacturing facilities, skilled labor, and warehouse facilities, as well as 'Proximity to transportation hubs' represent Ecologic's concern for external relationships, i.e., the interactions and relationships essential to maintaining business health and well-being. Ecologic cooperates with other manufacturers and external parties on a variety of levels beyond the traditional supplier/client relationship including sharing techniques, equipment, and best practices. 'Availability of manufacturing facilities' reveals the importance Ecologic places on relationships with contract manufacturers. The extent of Ecologic's relationships with manufacturers allows Ecologic to expand not only the scale, but also scope of projects, because of the skills, knowledge, and extra capacity that contract manufacturers provide. 'Availability of skilled labor' reflects the value Ecologic places on a community that educates and supports a skilled workforce. Ecologic needs skilled industrial garment sewers to train to 
work with reclaimed materials. A community that fosters a skilled workforce enables Ecologic to respond to increases in demand for its products. 'Availability of warehouse facilities' shows Ecologic's need for space. This indicator indirectly reflects the density of commerce and thus the potential for Ecologic to partner with businesses and reclaim their wastes adding environmental benefit. 'Proximity to transportation hubs' is important to any business, but especially for Ecologic, which both ships products out and reclaimed materials in. Locating close to a transportation hub improves how Ecologic relates to customers, reclamation partners, and the environment, as well as reducing costs. Ecologic and other supply chain members, from customers to suppliers, enhances their resilience of their business and operations, which primarily benefits the social health of the company, but may also have secondary economic and environmental benefits.

\subsubsection{Weights}

The analyst provided a tool for the managers to assess the importance of the economic, environmental, and social indicators using PCA. During the first step of the method - create PC matrices - each manager filled out four PC matrices. A PC matrix was constructed for each of the three categories of indicators (economic, environmental, and social). The final matrix compared the indicator categories with each other. The environmental indicators PC matrices created by one manager and all managers are shown in Table 5.1 and Figure 5.3 respectively. Since the PC matrix is reciprocal and all diagonal entries are equal to one, each manager only filled out the top portion (shaded in Table 5.1) of the matrix; all other values were automatically calculated by taking the reciprocal of the corresponding entry, $a_{j i}$. For the PC matrix in Table 5.1, the manager 
deemed 'Number of reclamation partners by location' 6 times as important as 'Amount of reclaimed materials in an area.'

After the managers filled out the PC matrices came the second step of the weighting method - resolve PC matrix inconsistency. Each manager's PC matrix (Figure 5.3) was checked for consistency (Table 5.2), i.e., $C R \leq 5 \%$ for $n=3,8 \%$ for $n=4$ (Lane and Verdini, 1989), or $10 \%$ for $n>4$ (Saaty, 1980). Equation 5.1 calculated the consistency ratio $(C R)$ for each PC matrix (see the appendix for calculation details). $\lambda_{\max }$, the principal eigenvalue, was calculated by taking the maximum value of the 'eig' function of a PC matrix in Matlab 7.4.0.

Table 5.2: Corresponding $\lambda_{\max }, C R, \delta$, and $\sigma$ for environmental indicator matrices

\begin{tabular}{|c|c|c|c|c|}
\hline \multirow{2}{*}{} & \multicolumn{4}{|c|}{ Managers } \\
\cline { 2 - 5 } & $\mathrm{A}$ & $\mathrm{b}$ & $\mathrm{c}$ & $\mathrm{d}$ \\
\hline$\lambda_{\max }$ & 3.0055 & 3.1356 & 3.094 & 3.1356 \\
\hline Revised $\lambda_{\max }$ & $\mathrm{n} / \mathrm{a}$ & 3.0504 & 3.0512 & 3.0504 \\
\hline $\mathrm{CR}$ & $.53 \%$ & $13.04 \%$ & $9.04 \%$ & $13.04 \%$ \\
\hline Revised $C R$ & $\mathrm{n} / \mathrm{a}$ & $4.85 \%$ & $4.93 \%$ & $4.85 \%$ \\
\hline$\delta<2$ & $\mathrm{n} / \mathrm{a}$ & .4581 & .6627 & .7949 \\
\hline$\sigma<1$ & $\mathrm{n} / \mathrm{a}$ & .2433 & .2749 & .2927 \\
\hline
\end{tabular}

$$
\left[\begin{array}{ccc}
1 & 2 & 5 \\
1 / 2 & 1 & 2 \\
1 / 5 & 1 / 2 & 1
\end{array}\right]\left[\begin{array}{ccc}
1 & 1 / 3 & 3 \\
3 & 1 & 3 \\
1 / 3 & 1 / 3 & 1
\end{array}\right]\left[\begin{array}{ccc}
1 & 1 / 5 & 4 \\
5 & 1 & 8 \\
1 / 4 & 1 / 8 & 1
\end{array}\right]\left[\begin{array}{ccc}
1 & 6 & 1 \\
1 / 6 & 1 & 1 / 2 \\
1 & 2 & 1
\end{array}\right]
$$

(a)

(b) (c)

(d)

Figure 5.3: Original environmental indicator matrices for all managers 


$$
\left[\begin{array}{lll}
1 & 2 & 5 \\
.5 & 1 & 2 \\
.2 & .5 & 1
\end{array}\right]\left[\begin{array}{ccc}
1 & .384 & 2.603 \\
2.603 & 1 & 3.458 \\
.384 & .289 & 1
\end{array}\right]\left[\begin{array}{ccc}
1 & .216 & 3.694 \\
4.618 & 1 & 8.663 \\
.271 & .115 & 1
\end{array}\right]\left[\begin{array}{ccc}
1 & 5.205 & 1.153 \\
.192 & 1 & .434 \\
.868 & 2.305 & 1
\end{array}\right]
$$

(b)

(c)

Figure 5.4: Revised environmental indicator matrices for all managers

The matrices for managers $\mathrm{b}, \mathrm{c}$, and $\mathrm{d}$ in Figure 5.3 were not consistent $(C R=$ $13.04 \%>5 \%$ ), so the matrices were revised (Figure 5.4) using Cao et al.'s method (Equations 5.4-5.7) (Cao et al., 2008). When a matrix is revised the measures of similarity between the original and revised PC matrices should be calculated, $\delta$ and $\sigma$ (see the appendix for calculation details); values of $\delta<2$ and $\sigma<1$ are acceptable, with smaller values denoting more similarity between the original and revised matrix. All revised matrices have acceptable $C R, \delta$, and $\sigma$ (Table 5.2).

For the third step of the weighting method - combine PC matrices of multiple decision-makers - each manager's revised PC matrix for individual indicators, e.g. environmental indicators (Table 5.3), and for the categories of indicators (Table 5.4) were combined using the aggregating individual judgments (AIJ) approach (Forman and Peniwati, 1998) and geometric mean method (Barzilai and Golany, 1994) (see the appendix for calculation details). In the fourth step - calculate weights - the weights for the grouped individual indicators, e.g. environmental indicators (Table 5.3) and for the categories of indicators (Table 5.4) were calculated with the right eigenvector method (Saaty, 1980). 
Table 5.3: Combined responses for environmental indicators and calculated weights (in bold) $(\lambda \max =\mathbf{3 . 0 0 5 6}, \mathrm{CR}=\mathbf{. 0 0 5 4})$

\begin{tabular}{|c|c|c|c|c|}
\hline & $\begin{array}{c}\text { 1. Number of } \\
\text { reclamation } \\
\text { partners }\end{array}$ & $\begin{array}{c}\text { 2. Amount of } \\
\text { reclaimed } \\
\text { materials }\end{array}$ & $\begin{array}{c}\text { 3. Density of } \\
\text { competitors for } \\
\text { reclaimed materials }\end{array}$ & \\
\hline $\begin{array}{c}\text { 1. Number of } \\
\text { reclamation partners }\end{array}$ & 1 & .9647 & 2.7283 & $\begin{array}{c}\mathbf{4 2 . 4} \\
\mathbf{\%}\end{array}$ \\
\hline $\begin{array}{c}\text { 2. Amount of } \\
\text { reclaimed materials }\end{array}$ & 1.0365 & 1 & 2.2578 & $\begin{array}{c}\mathbf{4 0 . 8} \\
\mathbf{\%}\end{array}$ \\
\hline $\begin{array}{c}\text { 3. Density of } \\
\text { competitors for } \\
\text { reclaimed materials }\end{array}$ & .3665 & .4429 & 1 & $\begin{array}{c}\mathbf{1 6 . 7} \\
\mathbf{\%}\end{array}$ \\
\hline
\end{tabular}

Table 5.4: Combined responses for indicator category and calculated weights (in bold $)\left(\lambda_{\max }=3.0056, C R=.0489\right)$

\begin{tabular}{|c|c|c|c|c|}
\hline & $\begin{array}{c}\text { 1. Economic } \\
\text { indicators }\end{array}$ & $\begin{array}{c}\text { 2.Environmental } \\
\text { indicators }\end{array}$ & $\begin{array}{c}\text { 3.Social } \\
\text { indicators }\end{array}$ & \\
\hline $\begin{array}{c}\text { 1. Economic } \\
\text { indicators }\end{array}$ & 1 & 1.3674 & 1.832 & $\mathbf{4 2 . 5 2 \%}$ \\
\hline $\begin{array}{c}\text { 2. Environmental } \\
\text { indicators }\end{array}$ & .7313 & 1 & 2.6313 & $\mathbf{3 8 . 9 4 \%}$ \\
\hline $\begin{array}{c}\text { 3. Social } \\
\text { indicators }\end{array}$ & .5459 & .38 & 1 & $\mathbf{1 8 . 5 4 \%}$ \\
\hline
\end{tabular}

In the final step - revise and finalize weights - the decision-makers reviewed and made any changes to the weights that were needed to reflect their best understanding of the indicators' importance (Bell et al., 2001). Table 5.5 summarizes the weights calculated by the first four steps of the method and the revisions to those weights after the final step. 
Table 5.5: Calculated and revised weights for all indicators and indicator categories

\begin{tabular}{|l|c|c|}
\hline Indicator categories & Calculated & Revised \\
\hline Economic indicators & $43 \%$ & $35 \%$ \\
\hline Environmental indicators & $39 \%$ & $25 \%$ \\
\hline Social indicators & $19 \%$ & $40 \%$ \\
\hline Economic indicators & $25 \%$ & $25 \%$ \\
\hline Proximity to reclaimed materials & $20 \%$ & $14 \%$ \\
\hline Transportation costs & $17 \%$ & $14 \%$ \\
\hline Labor costs & $13 \%$ & $14 \%$ \\
\hline Operating costs & $12 \%$ & $20 \%$ \\
\hline Warehouse/ factory rental costs & $8 \%$ & $5 \%$ \\
\hline Land and construction costs & $5 \%$ & $8 \%$ \\
\hline Facility setup costs & & \\
\hline Environmental indicators & $42 \%$ & $38 \%$ \\
\hline Number of reclamation partners & $41 \%$ & $37 \%$ \\
\hline Amount of reclaimed materials in an area & $17 \%$ & $25 \%$ \\
\hline Density of competitors for reclaimed materials & & \\
\hline Social indicators & $12 \%$ & $20 \%$ \\
\hline Public health & $18 \%$ & $10 \%$ \\
\hline Availability of skilled labor & $17 \%$ & $10 \%$ \\
\hline Proximity to transportation hubs & $8 \%$ & $6.5 \%$ \\
\hline Average employee commuting distance & $7 \%$ & $6.5 \%$ \\
\hline Availability of alternative transportation systems & $26 \%$ & $45 \%$ \\
\hline Availability of manufacturing facilities & $2 \%$ \\
\hline Availability of warehouse facilities & & \\
\hline
\end{tabular}

The weighted indicator categories were combined into one composite index, which measured sustainability performance for the strategic decision about supply chain expansion. Indicators were normalized by dividing by the indicator's highest value. First indicators were multiplied by their corresponding weights and summed by category to create a single composite indicator, e.g. the composite environmental indicator. Then all three indicators were summed to become the composite sustainability index (Equation $5.11)$. 
Sust $=W_{E c o n} E c o n+W_{E n v} E n v+W_{S o c}$ Soc such that Env $=\sum_{1}^{n} W_{e n v} \hat{I}_{e n v}$ and $\hat{I}=\frac{I}{I_{\max }}$

\section{Variables}

Sust

the composite sustainability index

Econ, Env, and Soc the composite economic, environmental, and social sustainability indices respectively

$\begin{array}{ll}e n v & \text { subscript denotes an individ } \\ W & \text { weight } \\ n & \text { number of indicators } \\ I & \text { indicator value } \\ I_{\max } & \text { maximum indicator value } \\ \hat{I} & \text { normalized indicator value }\end{array}$

\subsection{Discussion}

While reviewing the calculated weights for all the indicators, the managers reached a greater understanding of the importance of the indicators to the decision at hand as well as the relationships between the indicators. What motivated the revisions to the weights for the indicators and indicator categories follows.

The economic indicators reflect the costs of any business as well as costs that affect Ecologic more strongly because of its reliance on a reclaimed material supply, such as transportation and labor costs necessary to utilize that supply. The managers' weights of economic indicators were not in total agreement. 'Proximity to reclaimed materials' was calculated as the most important economic indicator, which reflected all but one manager's opinion. Transportation costs were the next highest weighted, with all managers weighting the indicator similarly. Labor costs were weighted third highest with an even split among the managers as to that indicator's importance. The top three weighted indicators fit the two criteria Ecologic developed, i.e., these indicators are 
essential for day-to-day operations such as picking up and transporting reclaimed materials and will vary among different locations.

The importance of the economic indicators was revised during the discussion of calculated weights. Managers became more concerned about the availability of facilities for contracting or renting. A consensus emerged that the first expansion of operations was likely to involve contracting or renting facilities instead of building new facilities. This reasoning motivated all of the revisions to the weightings, specifically the increased weight of 'Warehouse/factory rental costs' and the decreased weight of 'Land and construction costs'. The weights for transportation, labor, and operating costs were revised because these indicators were seen as equal among themselves but less important than the cost associated with renting a facility.

The three environmental indicators developed highlight Ecologic's main environmental concern and their main contribution as a business - reclaiming and repurposing waste. Managers split evenly in weighting higher ' Number of reclamation partners' or 'Amount of reclaimed materials.' No managers weighted most highly the 'Density of competitors for reclaimed materials.' During the review process, the managers agreed that the weights for these indicators should be much closer in value, as the revised weights reflect.

The seven social indicators developed highlight several concerns; the traditional need for workspace and sustainability motivated concerns - increasing efficiency, reducing impacts, and working within a healthy community. The most important social indicator, 'Availability of manufacturing facilities,' was weighted highly in all PC matrices. Similar to the economic indicators, the managers differed in their opinions of 
indicator importance as reflected in the PC matrices; 'Public health' and 'Availability of warehouse facilities' indicators were weighted from most to least important by different managers. The indicator weights (e.g., availability of manufacturing facilities, labor, and transportation hubs) reflect the first criteria for selecting indicators that Ecologic developed - the ability to run their business. Revisions of the social indicator weights increased emphasis on the importance of manufacturing facilities, while deemphasizing labor and transportation concerns. Additionally, managers agreed that, where manufacturing facilities were available, warehouse facilities could be found. This understanding further deemphasized the importance of warehouse facilities because of its interdependence with 'Availability of manufacturing facilities.' 'Public health' was weighted more highly as a manager was able to convince others of the increased importance of that through the conversation. Ecologic's top two social indicators, after revision, reflect a commitment to creating and maintaining good relationships with other businesses and the surrounding community.

Regarding the indicator categories, half of the managers weighted the economic, environmental, and social indicators as equally important; whereas the other two managers weighted economic or environmental indicators more highly. The method truly yielded a compromise between the decision-makers' judgments, when calculating importance as economic, environmental, then social indicators. When the managers discussed the weightings, new priorities emerged from the consensus that without a network of contract manufacturers (and the skills, knowledge and capacity those facilities offer) expanding operations would not be possible. Thus, the social indicators category was weighted most highly. The managers surmised that where there is industry, as 
represented by the existence or availability of manufacturing facilities or warehouses, there are materials to reclaim. Thus, the weighting of the environmental indicators category was lowered. The differences between the weights for the indicator categories lessened because of the managers' agreement that the importance of economic, environmental, and social indicators are more similar than not.

Other methods to develop and weight indicators require extensive time and knowledge (GRI, 2008; Kolsch et al., 2008; Shonnard et al., 2003; Spangenberg, 2008; The Timberland Company, 2007). Extensive requirements increase the costs of sustainability assessment, creating a financial barrier most SMEs cannot overcome because they have fewer resources than larger companies (Hillary, 2004; Tsai and Chou, 2009). Krajnc and Glavic (Krajnc and Glavic, 2005) and Singh et al. (Singh et al., 2007) created similar methods to this approach, developing 38 indicators into an index over six years (Krajnc and Glavic, 2005) and creating 71 indicators from seven stakeholder groups (from shareholders to community members) over a year-long period (Singh et al., 2007). The entire process of indicator development and weighting for Ecologic was spread out over a six month period from September 2008 through February 2009, with only intermittent activity by managers involving four meetings and a survey, for no more than 40 hours total spent by all managers. Only indicators specific to the strategic planning decision were developed and weighted, saving time and aiding company decision-makers to choose between specific options.

\subsection{Summary and Conclusions}

In this paper, sustainability indicators were developed and weighted by an SME's managers to help make a decision about how and where to expand operations. Out of this 
process, three categories of indicators were created - economic, environmental, and social indicators. PCA was used to weight (1) the importance of individual indicators within the economic, environmental, or social categories and (2) these categories relative to one another.

The contribution to knowledge from this paper is a demonstrable method an SME can apply for creating and weighting sustainability indicators that vary by location for use in strategic decision-making. This work contributes an SME perspective about the potential uses of sustainability assessment as well as what sustainability concerns, specifically social sustainability, affect their business. Other methods apply sustainability indicators for strategic planning (Kowalski et al., 2009; Li et al., 2009), but this paper creates a method appropriate for the concerns and needs of company decision-makers.

In general, the indicators developed by Ecologic varied greatly from standardized systems of indicators such as the Global Reporting Initiative (GRI, 2008). Assumptions and omissions are present in any set of sustainability indicators, including standardized systems. However common assumptions present in standardized sustainability indicators, such as that a level of antagonism exists between businesses and employees or their surrounding community may not be true for an SME; for Ecologic and many other SMEs, the strength of their relationships with other businesses, employees, and the surrounding community are what makes their business possible and successful. Common omissions such as neglecting how sustainability impacts vary by location may overlook important aspects of a strategic company decision; Ecologic considered how locations may differ by potential business partnerships, ease in transporting products, quality of life for 
employees and the surrounding community, and costs. Most businesses have these same concerns when considering where to locate operations or facilities.

Sustainability indicators specific to company concerns and the decisions a company needs to make are more likely to influence company decision-making than standardized indicators. Sometimes it is unclear which changes a company should pursue from the information provided by standardized sustainability indicators. The method in this paper allows indicators to be developed for a clearly defined purpose - to provide information for a decision about where to locate operations and facilities. The intended use of the indicators for a strategic planning decision allowed company decision-makers to develop fewer and more poignant indicators with little effort and time.

The method presented in this paper can be applied to other companies, especially SMEs, to address the unique concerns of their businesses in a relevant manner. This approach has several advantages over existing sustainability indicator development and weighting methods, because this method:

- can be used for the strategic planning purposes of SMEs;

- considers variation of sustainability impacts by location, which is often overlooked;

- takes less time, knowledge, and financial resources; and

- allows decision-makers to revise weights.

\subsection{Appendix}

Table 5.6: Consistency indices of randomly generated matrices, $R I$, by $\operatorname{size} n \times n$ (Saaty, 1980)

\begin{tabular}{|c|c|c|c|c|c|c|c|c|}
\hline$n$ & 1 & 2 & 3 & 4 & 5 & 6 & 7 & 8 \\
\hline$R I$ & 0 & 0 & .52 & .9 & 1.12 & 1.24 & 1.32 & 1.41 \\
\hline
\end{tabular}


For the matrix in Table 5.1, $\lambda_{\max }=3.136$ and $n=3$ so $R I=.52$ (Table 5.6) and from Equation $5.1 C I=\frac{3.136-3}{2}=.068$ so $C R=\frac{.069}{.52}=.13(13 \%)$. Thus $C R>5 \%$ and hence the PC matrix is inconsistent and in need of revision. Cao et al.'s method consists of several iterations. Below is the first iteration of that method, $\gamma=.98$, as applied to the matrix in Table 5.1.

$$
\begin{aligned}
& w=\left[\begin{array}{lll}
.517 & .124 & .359
\end{array}\right]^{\mathrm{T}} \\
& W=\left[\begin{array}{ccc}
1 & 4.16 & 1.442 \\
.24 & 1 & .347 \\
.693 & 2.885 & 1
\end{array}\right] \text { and } D=\left[\begin{array}{ccc}
1 & 1.442 & .693 \\
.693 & 1 & 1.442 \\
1.442 & .693 & 1
\end{array}\right] \\
& D^{\prime}=\left[\begin{array}{ccc}
1 & 1.433 & .698 \\
.698 & 1 & 1.433 \\
1.433 & .698 & 1
\end{array}\right] \text { and } \quad A^{\prime}=\left[\begin{array}{ccc}
1 & 5.963 & 1.006 \\
.168 & 1 & .497 \\
.994 & 2.012 & 1
\end{array}\right]
\end{aligned}
$$

Table 5.7: Principal eigenvalue, $\lambda_{\max }$, and consistency ratio, $C R$, for $A$ and $A$,

\begin{tabular}{|c|c|c|}
\hline & $\lambda_{\max }$ & CR \\
\hline $\mathrm{A}$ & 3.136 & .13 \\
\hline $\mathrm{A}^{\prime}$ & 3.131 & .126 \\
\hline
\end{tabular}

Whenever a matrix is revised the measures of similarity between the revision and the original matrix, $\delta$ (Equation 5.2) and $\sigma$ (Equation 5.3), are calculated such as for Table 5.4.

$$
\begin{aligned}
& \left|a_{i j_{m}}-a_{i j}\right|=\left[\begin{array}{ccc}
0 & .795 & .153 \\
.026 & 0 & .066 \\
.133 & .305 & 0
\end{array}\right] \text { so the maximum values is } \delta=.795 \\
& \sigma=\frac{\sqrt{\sum_{i=1}^{n} \sum_{j=1}^{n}\left[\begin{array}{ccc}
0 & .632 & .023 \\
.001 & 0 & .004 \\
.018 & .093 & 0
\end{array}\right]}}{3} \text { therefore } \sigma=.293
\end{aligned}
$$




\section{Chapter 6}

\section{Utilizing Sustainability Indicators to Find Locations to Expand Operations for a Small/Medium Enterprise*}

Business operations affect the economy, environment, and society, i.e. sustainability. These affects are meted out through facilities, and their operations, that make up a supply chain. Hence the locations of facilities within the supply chain affect sustainability. Yet, most often the locations of facilities are optimized only for costs; rarely, costs and environmental impacts have both been considered to optimize facilities within a supply chain. Businesses need a more holistic view of the factors, beyond simply cost, that affect their supply chain and their success. Including social, as well as financial and environmental, impacts creates a more holistic picture of facility location optimization by adding overlooked, relevant information to the business decision. Fortunately, interest in sustainability is growing among the business community including small/medium enterprises (SMEs). So far very few SMEs have established sustainability indicators for use within strategic decision-making such as deciding how to

\footnotetext{
This chapter will be submitted as a journal publication to the Journal of Cleaner Production
} 143 
expand operations. This research presents a real world application of utilizing sustainability indicators to evaluate potential facility locations for one SME.

Keywords: sustainability indicators, facility location, small/medium enterprises

\subsection{Introduction}

Many have shown that the success of a business is affected by more than just costs (Chavda, 2004; Conner, 2007; Gambale et al., 2007; Hawken et al., 1999; McDonough and Braungart, 2002; Seid, 2007). More people are recognizing the importance of social and environmental sustainability, but are businesses? It is heartening to note that the number of businesses undertaking some form of sustainability reporting continues to grow. Since 2005, twice as many businesses in the U.S. are releasing sustainability information (Anonymous, 2008). But the question remains: is the sustainability information gathered by companies for reports being applied to the decisions that affect a company's business?

Strategic planning decisions, and specifically where to locate operations and facilities, represents an important opportunity for businesses to incorporate sustainability into a decision-making process. For products, the analogous decisions occur during the design of products, where most of the sustainability impact is decided (Clarke and Gershenson, 2007; Keoleian and Menery, 1993). For a business, many of the sustainability impacts will be set with the design of supply chains that comes with strategic planning. Setting up facilities and operations in a particular location is not a short-term decision; especially for SMEs (small/medium enterprises), relationships with suppliers and contractors are maintained over long periods of time. Additionally, facility 
location decisions can be very difficult for a business to change. The sustainability impacts for siting operations at specific locations will stay with a company for a long time. Thus, it is very important that businesses do more than catalog their current sustainability impacts; businesses need to consider the potential social, environmental, and economic impacts of strategic plans in order to select solutions that produce the least impact.

This research concerns one relatively new manufacturer that wants to address social and environmental concerns in addition to costs for a strategic decision - how to expand its current supply chain as demand for its products grows. This SME formulated and weighted sustainability indicators (Table 6.2) to answer three specific questions: (1) which operations to move to potential locations? (2) which of the potential locations are optimal for expansion? and (3) how many new locations to open?

At its core, this research aims to make recommendations for the best strategy this SME should take for locating operations as demand for its products increases. In addition, there are two very interesting ramifications of this work that contribute to general knowledge in this area. First, this work aims to show that the sustainability impacts for this real-world facility location decision vary by the number of facilities sited; thus economic, environmental, and social sustainability are all affected by the scale of operations. Additionally, this research investigates whether considering or ignoring the spatial dependence of environmental effects results in different optimal facility locations and thus recommendations to company decision-makers. This research shows that neither the scale of operations nor the spatial dependence of environmental impact can be 
ignored when trying to find the most sustainable option for facility locations in the real world.

\subsection{Background}

This research engaged the four managers of Ecologic Designs, Inc., a start-up manufacturer of bags and accessories from reclaimed materials. Ecologic started its business in 2006 by making a variety of products from reclaimed bicycle inner tubes, billboard vinyl, climbing rope, and tractor tire inner tubes. All of the analysis is based upon products made from these materials. Since then, the company has developed and marketed products made from reclaimed wetsuits and coffee bags. Ecologic works with a variety of different organizations from climbing gyms to bicycle shops to help collect the materials the company needs to make products. Besides overseeing materials collection, Ecologic managers supervise materials processing, production, and how products reach customers (Figure 6.1).

Currently all of Ecologic's materials processing and production and nearly all of its reclaimed material acquisition occurs in the Denver metropolitan area. Ecologic is committed to localized production, or in other words manufacturing products as close as possible to the users of those products. The company plans on all manufacturing remaining in the U.S. as demand grows. Ecologic's commitment to localized production stems from their commitment to sustainability. Because of these commitments, Ecologic wants to make the most sensible decision for expanding operations within the U.S., a decision that will consider economic, environmental, and social factors. 


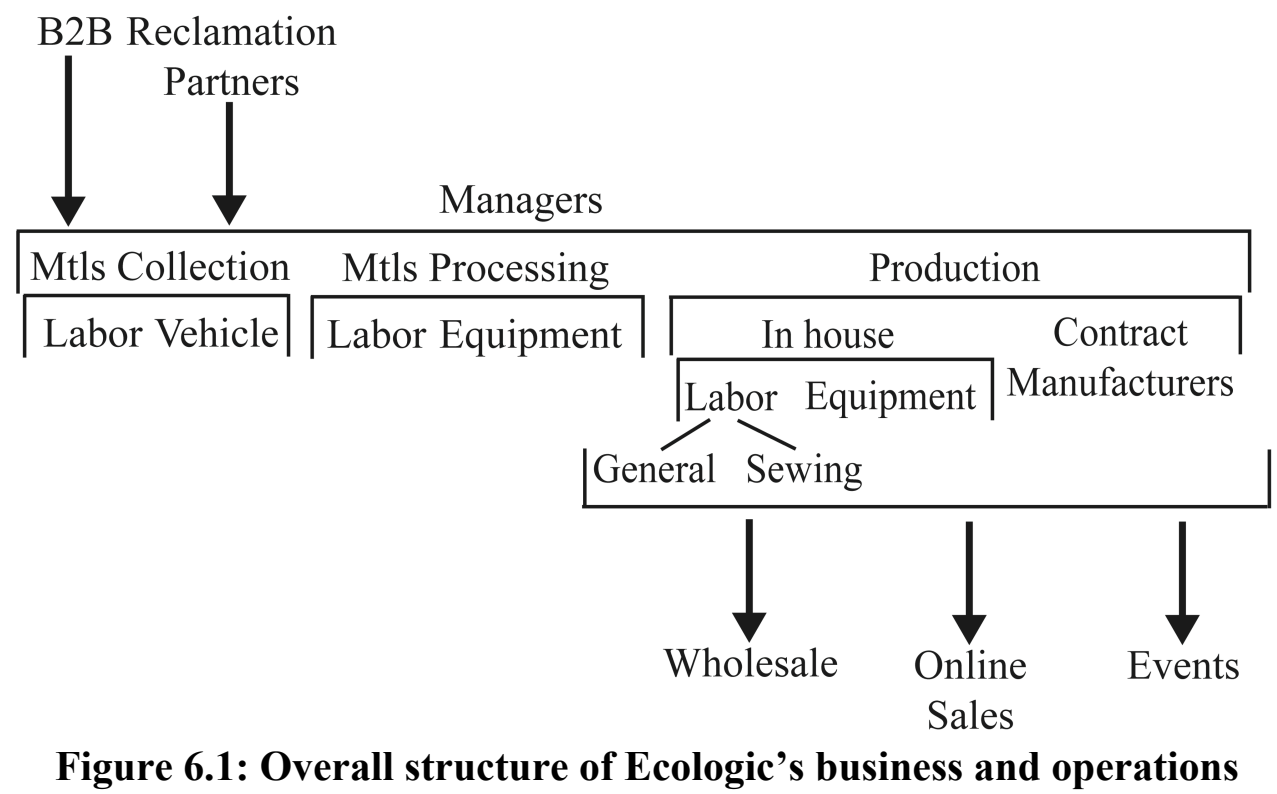

Ecologic sells products to several types of clients; retail, wholesale, and businessto-business (B2B), through several mediums (product fairs, in-store, online, and through catalogs). It sells directly to customers online and at events and festivals. Ecologic has ongoing relationships with retailers all across the U.S. of various sizes. Additionally, Ecologic sells products through several catalogs that are marketed in North America and Asia. Finally, Ecologic has many B2B customers of various sizes; Ecologic typically reclaims materials from B2B customers and then crafts customized products for these customers from their provided materials. Though Ecologic has clients in all parts of the world, most of Ecologic's sales are within the U.S.

\subsubsection{Market demand}

Ecologic has divided its largest market, the U.S., into 7 unique geographic markets (Figure 6.2). Much of Ecologic's current business occurs within the Rocky Mountains market (labeled as 'Rocky Mtns' in Figure 6.2). 


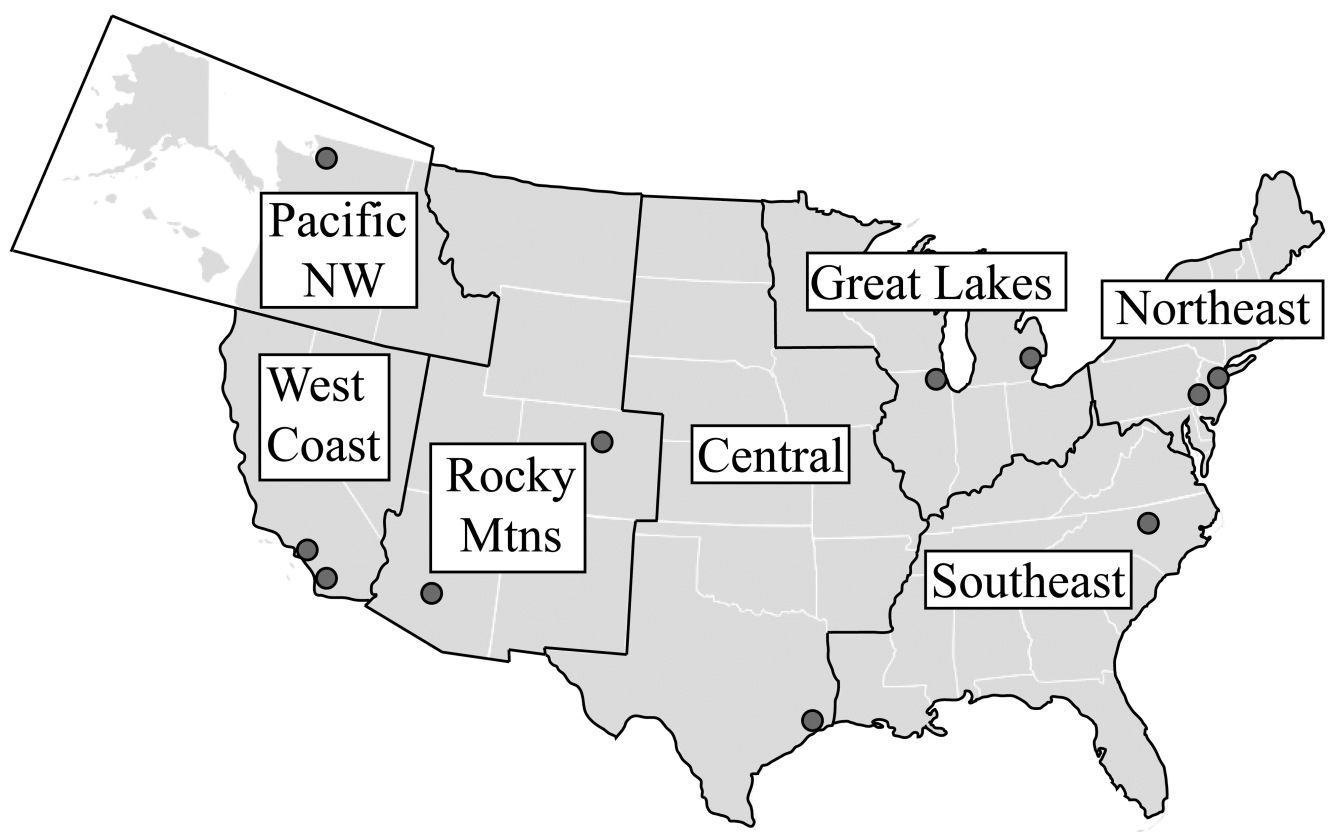

Figure 6.2: Ecologic's U.S. market regions and potential facility locations (grey circles)

The Rocky Mountains market is presently responsible for consuming the majority of the products (Figure 6.3). Ecologic has three main product lines, which are named for the reclaimed materials used in the products. However, the figure reveals that Ecologic does possess a presence in the other markets; furthermore, the types of products demanded by these markets vary. Moreover, discussions with the managers revealed that there exists untapped demand in all the markets.

Each market has different levels of demand for materials owing to the fact that product demand varies from market-to-market (Figure 6.4). All of the reclaimed materials are currently supplied from the Denver metro area. Thus as demand for the three product lines grows the demand for materials will grow. At a certain point the demand for products, and thus materials, will outstrip the availability of reclaimed materials in the Denver metro area. Once Ecologic has greater need for materials than the 
Denver metro can supply, it will be forced to expand its current supply chain to satisfy demand for its products. An increase in demand to that level necessitates that Ecologic at least acquire reclaimed materials from another location, which leads to the questions of where to expand and which level of operations to move to new locations.

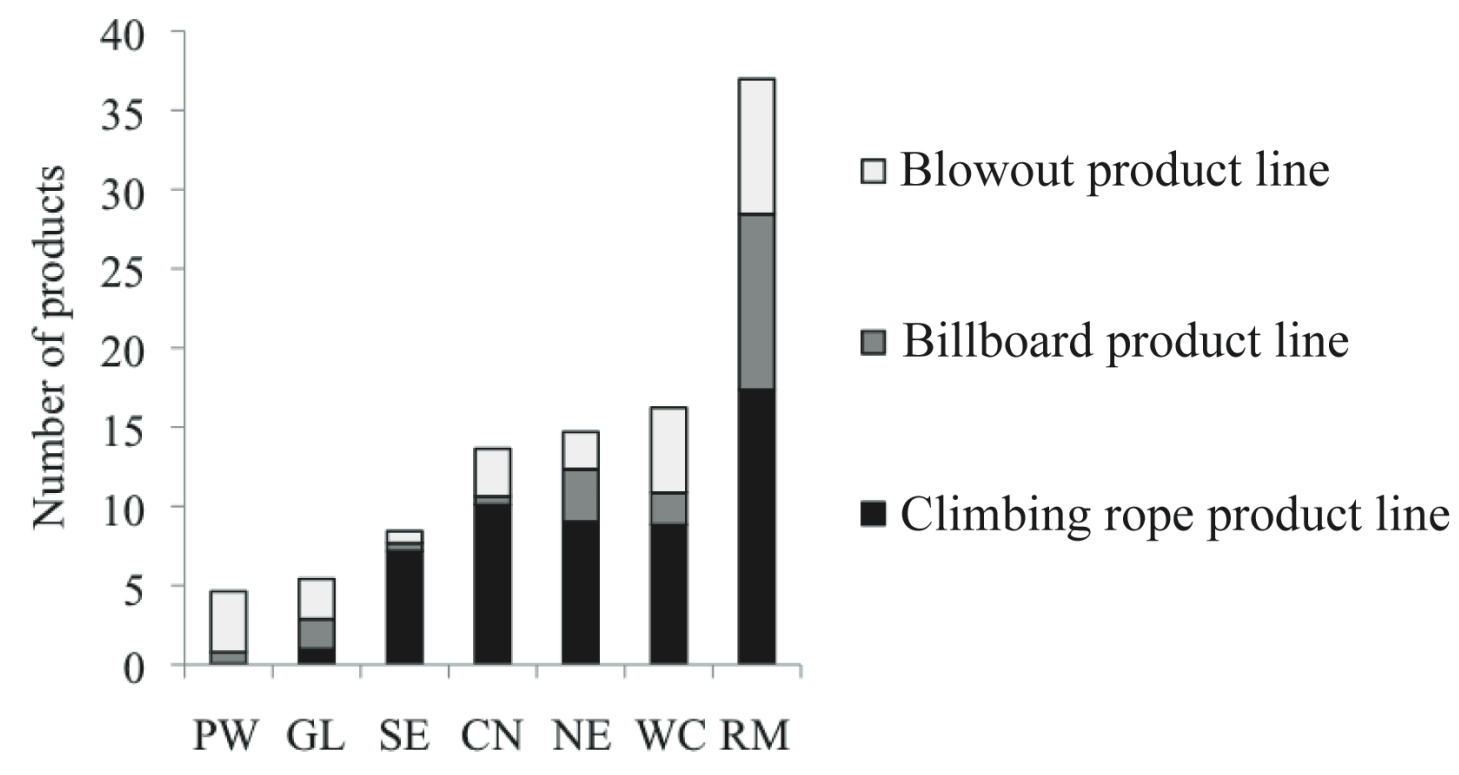

Figure 6.3: Distribution of demand for every 100 products sold by market - Pacific Northwest (PW), Great Lakes (GL), Southeast (SE), Central (CN), Northeast (NE), West Coast (WC), and Rocky Mountains (RM) - and by product line 


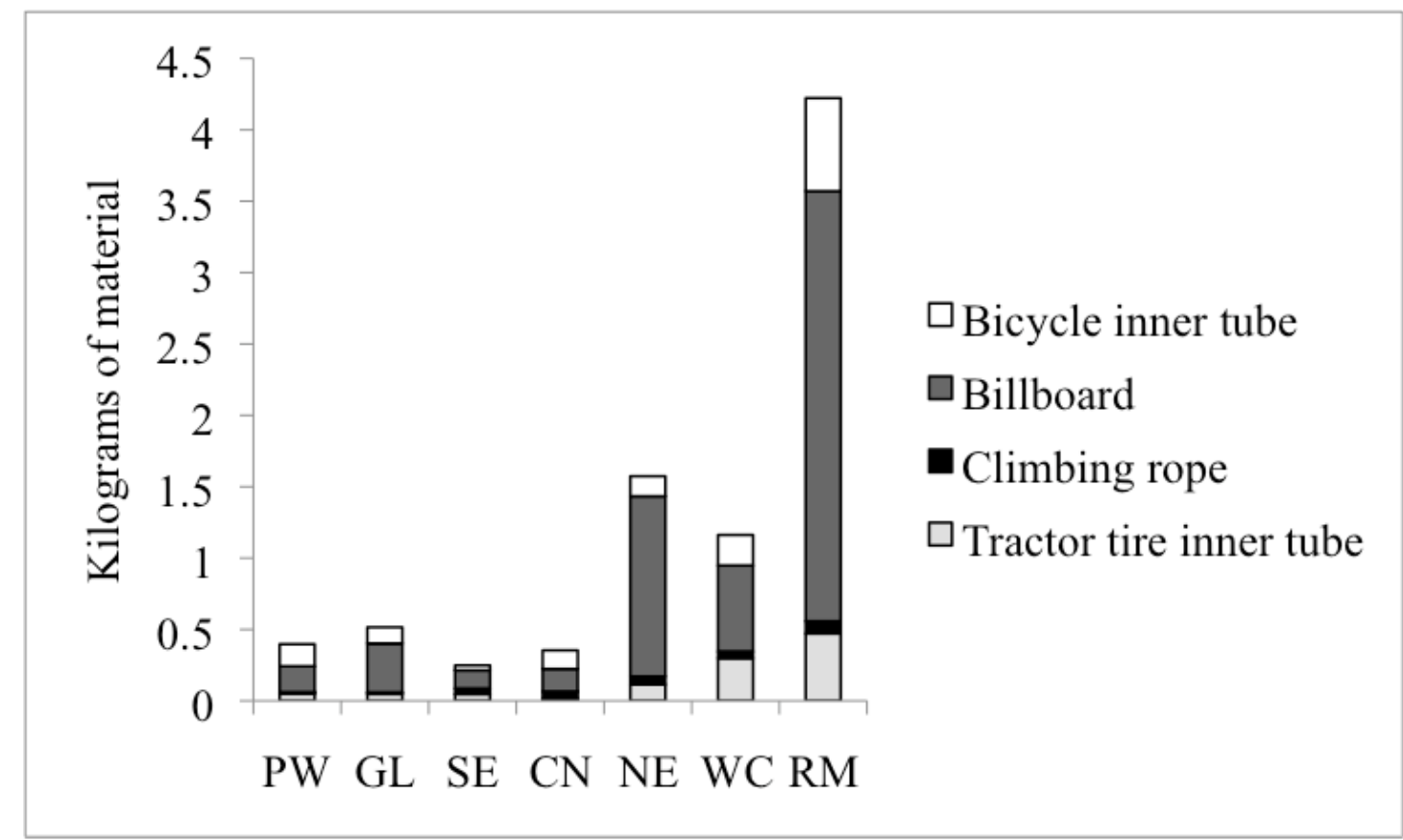

Figure 6.4: For every 100 products sold within U.S. market (as shown in Figure 6.3), reclaimed material needs in kilograms

\subsubsection{Potential facility locations}

In the face of potential increases in demand for their products, much discussion about which growth scenarios to consider came from Ecologic's managers. Ecologic determined 10 metro areas that would be good candidate locations for expanding operations (in addition to the existing location in the Denver metro area) (Table 6.1). These 10 metro areas were chosen by Ecologic because of their existing relationships or links with contract manufacturers, reclamation partners, and retailers in those cities. Figure 6.2 showed the locations of all of these metro areas. In order to test whether decentralizing (localizing) or centralizing its operations was the most sustainable option Ecologic selected enough facilities so that there would be at least 1 potential location for each of the 7 market regions. These potential locations are located in many different types of ecosystems as noted that the 10 potential locations reside in 7 of the 9 ecoregions 
in the national CHEMGL multimedia fate and transport model (Wright et al., 2008; Zhang et al., 2003), which is discussed in greater detail in Section 5.3.3.

Table 6.1: Potential metro areas for expanding Ecologic's operations

\begin{tabular}{|c|c|c|c|}
$\begin{array}{c}\text { Current Metro } \\
\text { Area }\end{array}$ & Abbreviation & Corresponding Market & $\begin{array}{c}\text { CHEMGL } \\
\text { ecoregion }\end{array}$ \\
\hline Denver & DEN & Rocky Mountains (RM) & $\begin{array}{c}\text { Southern } \\
\text { Rocky } \\
\text { Mountains }\end{array}$ \\
\hline Metro Area & Abbreviation & Corresponding Market & $\begin{array}{c}\text { CHEMGL } \\
\text { ecoregion }\end{array}$ \\
\hline Chicago & CHI & Great Lakes (GL) & Great Lakes \\
\hline Detroit & DTT & Great Lakes (GL) & Great Lakes \\
\hline Greensboro & GSO & South East (SE) & East Central \\
\hline Houston & HOU & Central (CN) & South Central \\
\hline Jersey City & JRC & Northeast (NE) & North East \\
\hline Los Angeles & LAX & West Coast (WC) & South West \\
\hline Philadelphia & PHL & Northeast (NE) & North East \\
\hline Phoenix & PHX & Rocky Mountains (RM) & $\begin{array}{c}\text { Southern } \\
\text { Rocky } \\
\text { Mountains }\end{array}$ \\
\hline San Diego & SAN & West Coast (WC) & South West \\
\hline Seattle & SEA & Pacific Northwest (PW) & North West \\
\hline
\end{tabular}

Currently Ecologic manufactures products and collects reclaimed materials within the Denver metro area. If demand for products grows as forecasted, Ecologic will need to expand its operations. The company plans to keep its headquarters and current level of operations in the Denver metro area. However, how and where growth occurs affects whether Ecologic expands current operations in Denver or opens other level of operations in new metro areas.

\subsection{Approach}

The approach to solve this facility location question consisted of several steps. First of all the problem was defined, in other words the specific decision about where to 
locate facilities or the growth scenario was outlined. Secondly, indicators of sustainability were developed and weighted by Ecologic's managers (Table 6.2) based on the factors they valued in expanding the supply chain. In particular, Ecologic selected indicators that were important to every day running of their business and that differed between potential metro areas. The indicators were calculated, normalized, weighted, and then combined into a category indicator (with one category indicator for each dimension of sustainability: economic, environmental, and social). These category indicators were then weighted and combined together to form an objective function (Clarke-Sather et al., 2009a). Finally, a solution method was adapted from (Clarke-Sather et al., 2009c) and then employed to solve this specific problem.

\subsubsection{Growth scenario}

Predicting the future is never easy, especially when trying to consider how demand for products will grow. Through brainstorming sessions with the managers at Ecologic, individually and as a group, the important aspects of potential supply chain expansion began to emerge. Through these sessions the importance of material supply concerns arose. Even just one large-scale nation-wide client could outstrip the current reclaimed material supply available in the Denver metro area. This situation would force Ecologic to consider how to obtain the required material supply and thus how to reconfigure their supply chain. An increase in total product demand is what would push Ecologic to make a location decision. If the existing total annual demand across all markets for Ecologic's products were to increase by 400 times, both the used bike inner tube and climbing rope supply in Denver would be outstripped. Ecologic has a wide variety of customers located in all corners of the U.S. Thus it does not seem likely that 
demand will only grow in 1 or 2 regions at a time. It was assumed that the current demand levels in all U.S. markets increased by multiplying current demand levels by 400 .

The growth scenario developed for this facility location problem considers that current demand levels increase by 400 times in each of the 7 markets (Figure 6.2) such that there is not enough reclaimed materials supply in the Denver metro to meet the increased demand levels. 10 potential new locations were identified for metropolitan areas located so that at least 1 location was specified for each of the 7 U.S. market regions. The Denver metro area, where Ecologic's current operations are located, was considered as an additional location site. Ecologic wanted to maintain headquarters and existing operations in the Denver metro, but was open to the possibility of operations moving to other locations or expanding operations in Denver.

\subsubsection{Formulation of indicators}

As has been noted, Ecologic previously formulated and weighted sustainability indicators for use in making their decision about how and where to expand operations (Clarke-Sather et al., 2009a) (Table 6.2). During this process the managers of Ecologic developed three environmental indicators. However, since one of the core emphases of this research is to test assess the difference between environmental indicators that include or neglect spatial dependence, toxicity potential was added as a fourth environmental indicator (Table 6.3). The weights for the environmental indicators were kept as similar as possible to the original intentions of Ecologic's managers; these weights preserved the ratios of weights between the 3 indicators Ecologic developed. 
Table 6.2: Weights for economic indicators and index category, adapted from (Clarke-Sather et al., 2009a)

\begin{tabular}{|c|c|c|c|}
\hline $\begin{array}{l}\text { Indicator or } \\
\text { Index category }\end{array}$ & Weight & Varies by & Data Sources \\
\hline Economic indicators & $35 \%$ & & \\
\hline $\begin{array}{l}\text { Proximity to } \\
\text { reclaimed materials }\end{array}$ & $25 \%$ & $\begin{array}{l}\text { Market, } \\
\text { Location }\end{array}$ & $\begin{array}{c}\text { Distances-(Google Inc., } \\
2009 a)\end{array}$ \\
\hline $\begin{array}{l}\text { Warehouse/factory } \\
\text { rental costs }\end{array}$ & $20 \%$ & $\begin{array}{l}\text { Location, } \\
\text { Demand } \\
\text { satisfied }\end{array}$ & $\begin{array}{c}\text { Cost of rent-(LoopNet, } \\
2009) \\
\text { Square footage- } \\
\text { Ecologic } \\
\end{array}$ \\
\hline Transportation costs & $14 \%$ & $\begin{array}{l}\text { Location, } \\
\text { Demand } \\
\text { satisfied } \\
\end{array}$ & Ecologic \\
\hline Labor costs & $14 \%$ & $\begin{array}{l}\text { Location, } \\
\text { Demand } \\
\text { satisfied }\end{array}$ & Ecologic \\
\hline Operating costs & $14 \%$ & $\begin{array}{l}\text { Location, } \\
\text { Demand } \\
\text { satisfied } \\
\end{array}$ & Ecologic \\
\hline Facility setup costs & $8 \%$ & $\begin{array}{l}\text { Location, } \\
\text { Demand } \\
\text { satisfied }\end{array}$ & $\begin{array}{l}\text { Capital costs-Ecologic } \\
\text { Tax credits-State } \\
\text { Economic Development } \\
\text { Agencies, } \\
\text { e.g. (NJ Business, 2009) }\end{array}$ \\
\hline $\begin{array}{l}\text { Land and } \\
\text { construction costs }\end{array}$ & $5 \%$ & $\begin{array}{l}\text { Location, } \\
\text { Demand } \\
\text { satisfied }\end{array}$ & $\begin{array}{c}\text { Construction costs- } \\
\text { (RSMeans, 2009) } \\
\text { Land costs-(LoopNet, } \\
\text { 2009) } \\
\text { Square footage-- } \\
\text { Ecologic }\end{array}$ \\
\hline
\end{tabular}


Table 6.3: Weights for social indicators and index category, adapted from (ClarkeSather et al., 2009a)

\begin{tabular}{|c|c|c|c|}
\hline $\begin{array}{l}\text { Indicator or } \\
\text { Index category }\end{array}$ & Weight & Varies by & Data Sources \\
\hline Social indicators & $40 \%$ & & \\
\hline $\begin{array}{l}\text { Availability of } \\
\text { manufacturers }\end{array}$ & $45 \%$ & Location & $\begin{array}{c}\text { (U.S. Census Bureau, } \\
\text { 2009) }\end{array}$ \\
\hline Public health & $20 \%$ & Location & (SustainLane, 2009) \\
\hline $\begin{array}{l}\text { Availability of } \\
\text { skilled labor }\end{array}$ & $10 \%$ & Location & $\begin{array}{l}\text { (U.S. Bureau of Labor } \\
\text { Statistics, 2009) }\end{array}$ \\
\hline $\begin{array}{l}\text { Proximity to transit } \\
\text { hubs }\end{array}$ & $10 \%$ & Location & $\begin{array}{l}\text { Distances-(Google Inc., } \\
\text { 2009a) } \\
\text { Transit hubs-(Anonymous, } \\
\text { 2006; Association of } \\
\text { American Port Authorities, } \\
\text { 2009; FedEx, 2009; United } \\
\text { Parcel Service of America, } \\
\text { 2009) }\end{array}$ \\
\hline $\begin{array}{c}\text { Average employee } \\
\text { commute }\end{array}$ & $6.5 \%$ & Location & $\begin{array}{c}\text { (U.S. Census Bureau, } \\
\text { 2008) }\end{array}$ \\
\hline $\begin{array}{c}\text { Availability of } \\
\text { alternative transit }\end{array}$ & $6.5 \%$ & Location & $\begin{array}{c}\text { (Federal Transit } \\
\text { Administration, 2009) }\end{array}$ \\
\hline $\begin{array}{c}\text { Availability of } \\
\text { warehouses }\end{array}$ & $2 \%$ & Location & $\begin{array}{c}\text { (U.S. Census Bureau, } \\
\text { 2009) }\end{array}$ \\
\hline
\end{tabular}


Table 6.4: Original and revised weights for environmental indicators and index category, adapted from (Clarke-Sather et al., 2009a)

\begin{tabular}{|c|c|c|c|c|}
\hline $\begin{array}{c}\text { Indicator/Index } \\
\text { category }\end{array}$ & $\begin{array}{l}\text { Original } \\
\text { weights }\end{array}$ & $\begin{array}{l}\text { Revised } \\
\text { weights }\end{array}$ & Varies by & Data Sources \\
\hline $\begin{array}{c}\text { Environmental } \\
\text { indicators }\end{array}$ & $25 \%$ & $25 \%$ & & \\
\hline $\begin{array}{l}\text { Number of } \\
\text { reclamation partners }\end{array}$ & $38 \%$ & $31 \%$ & Location & $\begin{array}{l}\text { (Google Inc., } 2009 \mathrm{~b}, \mathrm{c}, \mathrm{d} ; \\
\text { U.S. Economic Census, } \\
\text { 2009a,b) }\end{array}$ \\
\hline $\begin{array}{c}\text { Amount of reclaimed } \\
\text { materials }\end{array}$ & $37 \%$ & $30 \%$ & Location & Ecologic \\
\hline $\begin{array}{c}\text { Density of } \\
\text { competitors for } \\
\text { reclaimed materials }\end{array}$ & $25 \%$ & $20 \%$ & Location & Ecologic \\
\hline Toxicity potential & $\mathrm{n} / \mathrm{a}$ & $19 \%$ & $\begin{array}{l}\text { Location, } \\
\text { Demand } \\
\text { satisfied }\end{array}$ & $\begin{array}{l}\text { Emissions-Ecologic } \\
\text { Toxicity information- } \\
\text { (U.S. Environmental } \\
\text { Protection Agency, 2009b; } \\
\text { U.S. National Library of } \\
\text { Medicine, 2009) }\end{array}$ \\
\hline
\end{tabular}

\subsubsection{Calculation of indicators}

Values for the indicators in Tables 6.2, 6.3, and 6.4 were calculated on an annual and per product basis. Indicator values were calculated for every combination of demand and possible location to satisfy that demand (11 locations total including the existing location in Denver). These individual indicator values were normalized, weighted and combined into the three category indices: economic, environmental, and social. Each category index was normalized by its highest indicator value and weighted.

Several of these indicators required the use of involved calculation procedures. A few procedures are highlighted below, specifically for the toxicity potential (environmental indicator), availability of alternative transportation systems (social indicator), and proximity to reclaimed materials (economic indicator). 
The toxicity potential was calculated for production emissions only. All of the production emissions result from processing climbing rope. Climbing rope is primarily made of Nylon 6 (also known as polyamide 6) and like many webbing products is cut by heating the polymer beyond the melting point. Part of the process considered is proprietary, and thus specific processing details are not discussed here. At this time, no emissions data are available for this process, so an estimate of the emissions was made. This estimate was based on a study of the degradation products (i.e., airborne emissions) of Nylon 6 when heating the polymer to temperatures above the melting point (Bockhorn et al., 2001). At such temperatures, $96 \%$ of the airborne emissions by weight are caprolactam, the monomer that makes up the polymer Nylon 6 (also known as polycaprolactam). The other $4 \%$ of emissions were neglected because of their small contribution. The environmental fate or the concentration of the emissions in a particular environmental compartment (e.g., air, soil, or water) where the chemicals would accumulate over time was calculated using the national version of the multimedia fate and transport model CHEMGL (Wright et al., 2008; Zhang et al., 2003), the same procedure used as in (Clarke-Sather et al., 2009c). The national version of CHEMGL breaks the U.S. into 9 ecoregions (Figure 6.5). Each of the 11 potential locations resided in a particular ecoregion (Figure 6.5 and Table 6.1). 


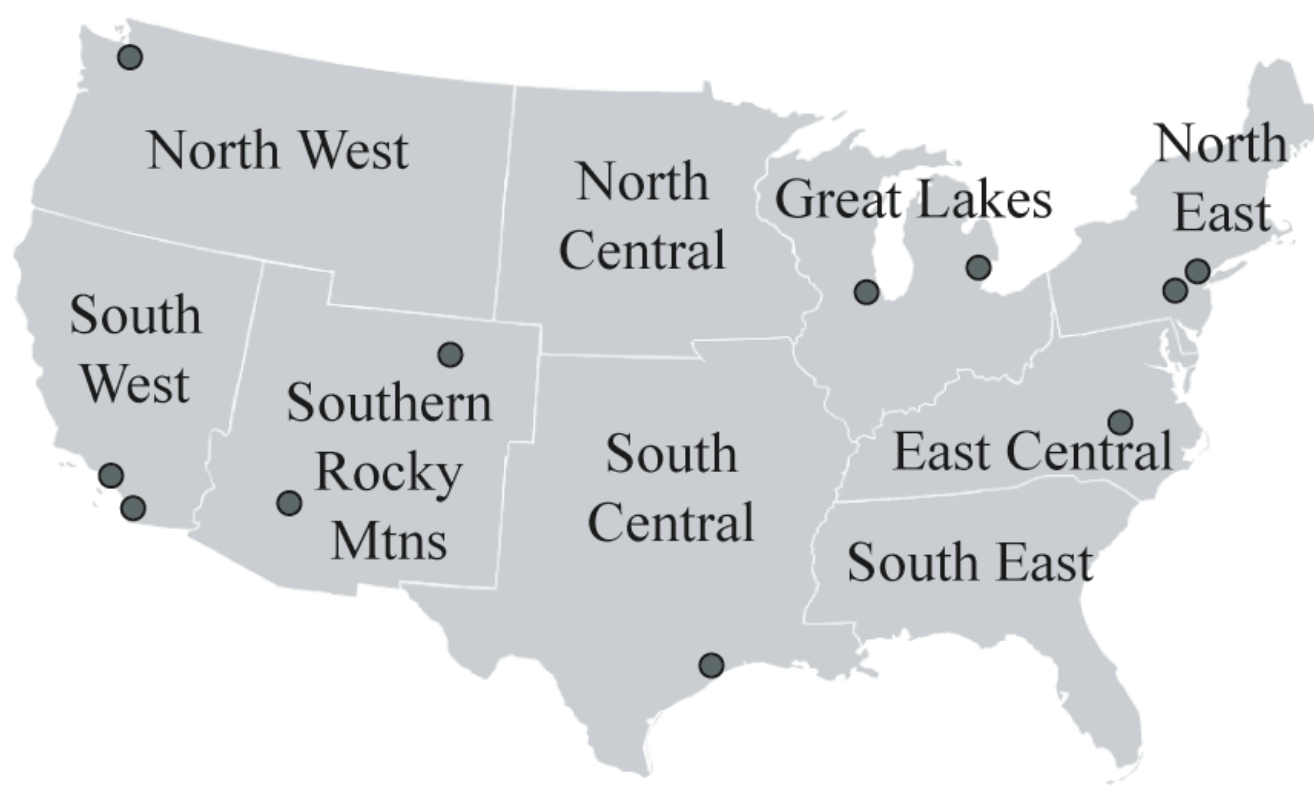

Figure 6.5: The potential locations of operations shown relative to the CHEMGL ecoregions

A specific chemical will have a different concentration within each environmental compartment (e.g., air) due to environmental factors (e.g., average temperature or rainfall) that differ between ecoregions (Zhang et al., 2003). Thus, ecoregions have different sensitivities to chemicals. Therefore, the toxicity potential indicator is affected by: the total amounts of emissions; both the environmental compartments into which the emissions are released and into which the emissions concentrate (these compartments are not necessarily the same), and the U.S. ecoregion into which the emissions are released.

The concentrations of chemicals in different environmental compartments were used to calculate specific toxicity indicators. Fish toxicity (Equation 6.1), ingestion toxicity (Equation 6.2), and inhalation toxicity (Equation 6.3) indicators were the indicators considered using the same approach as (Clarke et al., 2008) and (Clarke-Sather et al., 2009c). These indicators were combined into a single index, the toxicity potential. 


$$
\begin{aligned}
& I_{F T}=\sum_{\text {chem }}\left(\sum_{r c} \frac{C_{c h e m, r c, s w} / L C_{50_{\text {chem }}}}{C_{\text {Reference }, r c, s w} / L C_{50_{\text {Recternec }}}}\right) \\
& I_{I N G}=\sum_{c h e m}\left(\sum_{r c} \frac{\sum_{e c}\left(C_{c h e m, r c, e c} \times E F_{e c} / R f D_{c h e m}\right)}{\sum_{e c}\left(C_{\text {Reference, }, r c, a} \times E F_{e c} / R f D_{\text {Reference }}\right)}\right) \\
& I_{I N H}=\sum_{\text {chem }}\left(\sum_{r c} \frac{C_{c h e m, r c, a} / R f C_{\text {chem }}}{C_{\text {Reference }, r c, a} / R f C_{\text {Reference }}}\right)
\end{aligned}
$$

\section{Variables}

FT

ING

INH

chem

rc

C

sw

Reference

$L C_{50}$

ec

$E F_{e c}$

$R f D$

$a$

$R f C$
Fish toxicity

Ingestion

Inhalation

chemical of interest

release compartment, environmental compartment where chemicals were released

concentration of chemical

surface water environmental compartment

reference chemical

lethal concentration were $50 \%$ of population of fish exposed die

environmental compartment, where chemicals concentrate

exposure factor for a particular environmental compartment, e.g. how much water on average a person ingests per day

reference dose, amount of chemical that can be ingested per day without harmful effects per kilogram body weight

air boundary layer environmental compartment

reference concentration, amount of chemical that can be inhaled constantly without harmful effects per day

These indicators always compare the toxicity of the chemicals of interest (caprolactam in this case) to a reference chemical (Shonnard and Hiew, 2000). Toluene was the reference chemical used. In general, values for the $L C_{50}$ (amount of a chemical released that will kill off half of the studied population, for fish this is chemical released into the water) reference dose, $R f D$, (amount of a chemical that can be ingested per day 
with no ill effects over a lifetime), and reference concentration, $R f C$, (amount of a chemical that can be inhaled constantly with no ill effects over a lifetime) for the chemical of interest and the reference chemical came from the U.S. EPA IRIS database (U.S. Environmental Protection Agency, 2009b). The EPA does not currently have an agreed upon value for an $R f C$ for caprolactam so it was considered to be zero (U.S. Environmental Protection Agency, 2009b). There is no $L C_{50}$ available for fish for caprolactam, so the $L C_{50}$ value for caprolactam was estimated using ECOSAR software as 786.534 milligrams/liter or parts per million (U.S. Environmental Protection Agency, 2009a). The toxicity indicators were normalized and weighted equally before being combined into a toxicity potential for meeting a specific demand, $i$, at a particular location, $j$, (Equation 6.4). This specific toxicity potential is summed over all markets' demand and all sited facilities (all $i$ and $j$ ), to calculate the toxicity potential for a particular solution, which is the same approach used in (Clarke-Sather et al., 2009c).

$$
T P_{i j}=W_{F T} \hat{I}_{F T}+W_{I N G} \hat{I}_{I N G}+W_{I N H} \hat{I}_{I N H}
$$

\section{Variables}

market (location of demand)

$j$ metro area

$T P_{i j}$ the toxicity potential for a facility at $j$ satisfying demand at $i$

$W_{F T}, W_{I N G}, W_{I N H}$ the weights for fish toxicity, ingestion toxicity, and inhalation toxicity respectively

For the availability of alternative transportation systems indicator, the different transportation options (e.g., ferry, bus, or lightrail) for a metropolitan area were found within the National Transit Database (Federal Transit Administration, 2009). The National Transit Database considers only the transit industry and thus does not have 
information on the availability of facilities needed for bicycle commuting (e.g., bicycle lanes, paths, and routes). The number of bicycle lanes in a metro area correlates with the numbers of bicycle commuters in a metro area (Dill and Carr, 2003); thus, for this research the existence of bicycle lanes in a metro area was used to measure the availability of bicycle commuting within a metro area. Metro area government sponsored bicycle maps and bicycle transportation departments were used to determine if bicycle lanes existed or not within a metro area.

Proximity to reclaimed materials was measured as the distance between the most populous metro area where Ecologic sold products in a market, according to 2008 U.S. Census data (U.S. Census Bureau - Population Division, 2009), and the potential locations. Because Ecologic tends to sell more products in urban areas, this seems to be a reasonable assumption. Most of the retailers and B2B clients Ecologic has are located in urban areas; this makes sense since economic activity is more densely concentrated in urban areas in the U.S.

\subsubsection{Problem details}

Before starting this analysis, Ecologic assumed that they would maintain their operations in Denver at current level of operation. In the growth scenario considered, product demand outstrips the reclaimed material supply in Denver. Thus, in order to meet this new product demand other facilities must be sited in addition to the Denver facility to at least reclaim materials and to potentially perform all level of operations. Specifically, this problem found the optimal number of facilities to site, where to site those facilities, and which operations to perform at those facilities. 
The number of facilities was varied from adding $p=1$ to $p=7$ facility locations. Varying the numbers of facilities sited in this research was used to explore the degree of centralization issue (Clarke et al., 2008; Clarke-Sather et al., 2009c). Siting only 1 additional facility $(p=1)$ besides Denver creates a very centralized production network. Whereas, siting one facility for every market, a 1 to 1 ratio of facilities to markets, creates a very decentralized or localized production network.

It was assumed that the demand of 1 market could only be satisfied by 1 facility location and that the demand of all markets had to be satisfied. These are the same assumptions made for a typical $p$-median problem and for the examples considered in Chapter 4 and (Clarke et al., 2008) and (Clarke-Sather et al., 2009c). Given the relative cohesiveness in the geography of each of Ecologic's markets, this assumption is plausible. In addition, these assumptions were made to reduce computation time. This facility location problem is a discrete problem like many real world facility location problems (Ehrgott and Gandibleux, 2000). The computational resources needed to solve such a discrete problem increase rapidly as a function of the number of potential facilities sited when a facility can service partial instead of all the demand within a given market.

There are many ways that the 11 potential facilities can satisfy the demand of the 7 markets considered. Thus, the problem was solved to find the minimum objective function value for each specific number of facilities sited, $p$, where the particular facilities sited satisfied specific markets' demands. Furthermore each of the facilities sited only performed specific level of operations. Then values for $p$ from 1 to 7 were considered. 


\subsubsection{Solution method}

The solution method used to address the Ecologic problem was enumeration. The solution method had to answer 3 distinct questions - (1) which operations to site at a potential location?, (2) which locations to site for a specific number of facilities?, and (3) what is the best number of facilities to site? The solution procedure for this three-step problem began by selecting $p$ facility locations to site. Then, for this set of locations, demands for the 7 market regions were assigned to the locations. With this information, the first question (what level of operations to use at each site?) could be answered for that set of locations and demand allocated to those locations since the answer depends upon both the total demand met and which location meets that demand. The decision concerning level of operation is discussed further in the next section.

After determining the level of operations for a set of locations, all of the indicators could be calculated, normalized, weighted, and summed to calculate the objective function. All possible demand allocations to the set of site locations were enumerated, and thus a solution was obtained for each set of locations and set of demand allocations. Then all combinations of facility locations (assuming $p$ sites to be located) were enumerated. The combination of locations sited and allocation of market demand to those locations with the minimum objective are the optimal facility sites for a given $p$. Finally, the minimum solution for $p$ ranging from 1 to 7 was found; this solution revealed the optimal degree of centralization for sited facilities, or in other words the optimal $p$, number of facilities to site. 


\section{Level of operation decision}

Ecologic currently manages all level of operations in the Denver metro area. There are 4 level of operations; (1) collection, storage, and shipping of reclaimed materials, (2) materials processing and shipping, (3) contracting garment workers or manufacturing facilities for production, and (4) manufacture of products at Ecologic facilities. For the growth scenario considered, the demand for reclaimed materials must outstrip the amount of materials available for reclamation in the Denver metro. Thus, a new facility of some type in a new region must at least satisfy unmet demand for reclaimed materials. There are several decisions to be made about the level of operations that a facility in a new location could perform, whether to;

1. collect reclaimed materials $O R$ reimburse reclamation partners for shipping,

2. process reclaimed materials OR ship materials to Denver for processing,

3. manufacture products in-house OR contract a manufacturer to create products, or

4. manufacture products in the new location OR in Denver.

This decision about which operations to site in different locations is solely based on costs. In order for Ecologic to make a new facility location decision, the decision must be cost effective. Each level has a measure of cost-effectiveness. If the measure of costeffectiveness is met the first option is chosen, and if not, the second option is chosen. All cost-effectiveness measures, and factors within the measures, are considered on an annual basis. The criteria for the level of operation are discussed further below.

Instead of an Ecologic employee collecting reclaimed materials and shipping those materials in bulk for processing for level 1, Ecologic could reimburse the shipping costs (to Denver) for a reclamation partner. For example, a bicycle repair shop could box 
up all of their bicycle inner tubes and ship them to Ecologic. The most cost-effective option is found by comparing the costs of Ecologic collecting materials to reimbursing shipping in the cost-effective measure (Equation 6.5).

$$
\text { cost }_{\text {materials pick up }}+\text { cost }_{\text {warehouse }}+\operatorname{cost}_{\text {ship bulk }}<\operatorname{cost}_{\text {ship from partners }}
$$

where materials pick up involves labor, vehicle, and fuel costs

For materials processing (operation level 2), general laborers process materials and managers oversee their work. For example, some parts of a bicycle inner tube (mainly the valve) cannot be used and hence are scrapped before being stored or cut into the right size for specific products. In order to expand to a level 2 facility, the savings in shipping processed materials (minus any scrap material removed during processing) must outweigh any additional costs for materials processing in the potential location, $j$, over simply processing materials at the existing facility in Denver (Equation 6.6).

$\operatorname{cost}_{\text {material processing.j }}+$ cost $_{\text {ship bulk less scrap }}<\operatorname{cost}_{\text {ship bulk }}+\operatorname{cost}_{\text {material processing, Denver }}$

where the cost of materials processing includes labor, space (additional square footage needs in a building), equipment, and energy costs

For production or manufacturing of products (operation level 3), workers prepare materials (general laborers), sew products (garment workers), and manage other workers (managers). Expanding to level 3 operations requires that in-house production be more cost effective than hiring a contract manufacturer (5.7). Many contract manufacturers possess more efficient and much more expensive cutting equipment than Ecologic needs on a regular basis. However, using more efficient cutting equipment allows contract manufacturers to finish cutting in $10 \%$ of the time Ecologic needs for cutting.

$$
\text { cost }_{\text {in-house production }}<\text { cost }_{\text {contract manufacturer }}
$$


where in-house production costs involve labor, space, equipment, and energy.

The last decision for level of operation considers whether to manufacture products in the potential location, $j$, (in addition to Denver) or to manufacture products in Denver. Ecologic will maintain existing operations in Denver; manufacturing products in another location besides Denver will only occur if the cost effective criterion is met. This decision depends on the outcome of the level 3 cost effectiveness measure. If in-house production is more cost-effective, Equation (6.8) is the cost effectiveness criterion that should be employed. Whereas if contracting a manufacturer is more cost effective, Equation (5.9) represents the cost-effectiveness criterion to use.

$$
\begin{aligned}
& \operatorname{cost}_{\text {in-house production }, j}<\operatorname{cost}_{\text {in-house production, Denver }}+\operatorname{cost}_{\text {ship bulk }} \\
& \operatorname{cost}_{\text {contract manufacturer }, j}<\operatorname{cost}_{\text {contract manufacturer, Denver }}+\operatorname{cost}_{\text {ship bulk }}
\end{aligned}
$$

These cost effectiveness measures simply determine the level of operations that a potential new location will have based on the total amount of demand that location satisfies. Next the remaining two decisions must be analyzed, namely: which facilities to site and whether siting many or few facilities is the optimal strategy.

\section{Solving the facility location problem}

This facility location problem considered was approached as a discrete $p$-median problem, where $p$ is the number of facilities to site (or locations with operations to site). The goal of the $p$-median problem is to minimize the total demand weighted distance between facilities in discrete locations that meet the demand of all markets (Daskin, 1995). In this case, the demand-weighted distance is the value of the sustainability indicators weighted together. Thus, the objective function is a weighted combination of the sustainability indicators or an index of sustainability, Sust (Equation 6.6). The goal of 
the optimization used in this research is to minimize this index of sustainability over all market demands, $i$, satisfied by $p$ number of facilities, $j$.

$$
\begin{aligned}
& \text { Minimize Sust }=\sum_{j} \sum_{i}\left(R_{E c o n} E_{c o n}+R_{E n v} E n v_{i j}+R_{S o c} \operatorname{Soc}_{i j}\right) \quad \forall i, j \\
& \text { where } E n v_{i j}=\sum_{1}^{n} R_{e n v} \hat{I}_{e n v_{i j}} \text { and } \hat{I}=\frac{I}{I_{\max }}
\end{aligned}
$$

\section{Variables}

$\begin{array}{ll}\text { Sust } & \text { the composite sustainability index } \\ \text { Econ, Env, and Soc } & \begin{array}{l}\text { the composite economic, environmental, and social sustainability } \\ \text { indices respectively }\end{array} \\ \text { env } & \text { subscript denotes an individual environmental indicator } \\ R & \text { weight } \\ n & \text { number of indicators } \\ I & \text { indicator value } \\ I_{\max } & \text { maximum indicator value } \\ \hat{I} & \text { normalized indicator value }\end{array}$

The values of the sustainability indicators are affected by the total demand met by a particular location. In other words, the scale or total volume of production affected costs and environmental impacts unequally. When considering only costs this effect would be called 'economies of scale.' To fully consider the effect of scale, all potential combinations of demand for the 7 U.S. markets were considered. For example, when siting 6 facilities, Table 6.5 shows how the locations were optimally assigned to meet the demand for 7 markets. 
Table 6.5: Allocation of markets' demand (rows) to locations (columns) for minimum solution for 6 facilities $(p=6)$ where 1 denotes allocation of demand

\begin{tabular}{|c|c|c|c|c|c|c|}
\hline & CHI & DTT & HOU & PHL & SAN & SEA \\
\hline Central & & & 1 & & & \\
\hline Great Lakes & 1 & & & & & \\
\hline Northeast & & & & 1 & & \\
\hline $\begin{array}{c}\text { Pacific } \\
\text { Northwest }\end{array}$ & & & & & & 1 \\
\hline $\begin{array}{c}\text { Rocky } \\
\text { Mountains }\end{array}$ & & & & & 1 & \\
\hline Southeast & & 1 & & & & \\
\hline West Coast & & & & & & 1 \\
\hline
\end{tabular}

Now consider the level of operation decision for Houston (HOU). Table 6.6 shows the values and outcomes from the cost effectiveness measures for HOU. The level of operation decisions are made in the same manner for all other facilities as shown in Table 6.6 for HOU when 5 facilities are sited.

Table 6.6: Level of operation decision when HOU satisfies CN market demand

\begin{tabular}{|c|c|c|c|}
\hline $\begin{array}{l}\text { Operation } \\
\text { Level }\end{array}$ & Left hand inequality & Right hand inequality & \\
\hline & Collect Materials & Reimburse Shipping & Best Option \\
\hline \multirow[t]{2}{*}{ Level 1} & $\$ 98,171$ & $\$ 339,708$ & $\begin{array}{l}\text { Collect } \\
\text { Materials }\end{array}$ \\
\hline & $\begin{array}{c}\text { Materials Processing - } \\
\text { HOU }\end{array}$ & $\begin{array}{c}\text { Materials Processing - } \\
\text { DEN }\end{array}$ & \\
\hline \multirow[t]{2}{*}{ Level 2} & $\$ 60,868$ & $\$ 68,354$ & $\begin{array}{c}\text { Materials } \\
\text { Processing - } \\
\text { HOU }\end{array}$ \\
\hline & Produce In-house & Contract Production & \\
\hline \multirow[t]{2}{*}{ Level 3} & $\$ 246,735$ & $\$ 137,374$ & $\begin{array}{c}\text { Contract } \\
\text { Production }\end{array}$ \\
\hline & $\begin{array}{c}\text { Contract Production - } \\
\text { HOU }\end{array}$ & $\begin{array}{c}\text { Contract Production - } \\
\text { DEN }\end{array}$ & \\
\hline Level 4 & $\$ 137,374$ & $\$ 160,211$ & $\begin{array}{c}\text { Contract } \\
\text { Production - } \\
\text { HOU }\end{array}$ \\
\hline
\end{tabular}


Once the level of operation are known, the indicator values can be calculated and normalized for each chosen facility location that satisfies certain demands (Table 6.7).

Table 6.7: Normalized environmental indicator values when HOU satisfies CN market demand

\begin{tabular}{|c|c|c|c|c|}
\hline Indicators & $\begin{array}{c}\# \text { of } \\
\text { Reclamation } \\
\text { Partners }\end{array}$ & Competition & $\begin{array}{c}\text { Amount of } \\
\text { Reclaimed } \\
\text { Materials }\end{array}$ & $\begin{array}{c}\text { Toxicity } \\
\text { Potential - } \\
\text { spatially } \\
\text { dependent }\end{array}$ \\
\hline & 0.00204775 & 0 & 0.001686849 & 0.001103089 \\
\hline Weights & $31 \%$ & $30 \%$ & $20 \%$ & $19 \%$ \\
\hline $\begin{array}{c}\text { Environmental } \\
\text { index }\end{array}$ & 0.001345433 & & & \\
\hline
\end{tabular}

These normalized indicator values are then weighted and summed into their respective category index (economic, environmental, or social). Finally all the category indices are weighted and summed together to create the sustainability index for that particular location satisfying those specific demands (Table 6.8).

Table 6.8: Index values for HOU meeting demand from Central Market

\begin{tabular}{|c|c|c|c|}
\hline Indices & Economic & Environmental & Social \\
\hline & 0.001384916 & 0.001345433 & 0.004680271 \\
\hline Weights & $35 \%$ & $25 \%$ & $40 \%$ \\
\hline Sustainability index & 0.002693187 & & \\
\hline
\end{tabular}

Table 6.9: Sustainability index values for all locations, $p=6$ minimum solution

\begin{tabular}{|c|c|}
\hline Location & Sustainability Index \\
\hline Houston & 0.004680999 \\
\hline Chicago & 0.002629589 \\
\hline Detroit & 0.002999434 \\
\hline Philadelphia & 0.00246318 \\
\hline Seattle & 0.002464004 \\
\hline San Diego & 0.002693187 \\
\hline Objective & $\mathbf{0 . 0 1 7 9 3 0 3 9 4}$ \\
\hline
\end{tabular}


The sum of all sustainability index values for $p=6$ locations that satisfy demand of all markets is the objective function value (Table 6.9). As has been noted, the indicator values were enumerated for each set of locations and all combinations of demand for those set of locations. The total minimum objective value was determined for every value of $p$ ranging from 1 to 7 .

\subsection{Results}

The overall minimum objective occurred when some level of operations was located in 6 metro areas in addition to Denver (Figure 6.6). The level of operations varied greatly amongst metro areas (Figure 6.7). In the solution, $\mathrm{CHI}$ and SEA only collected materials before shipping those materials to DEN for processing and manufacturing into products: the finished products were then shipped back to meet demand in the Pacific West and Great Lakes markets where CHI and SEA respectively are located (Figure 6.8). DEN acted as a materials processing hub for PHL. The processed materials were then shipped to PHL for in-house manufacturing of products that satisfied demand in the North East region. DTT, HOU, and SAN collected and processed materials as well as manufactured products. Contracted manufacturers were optimal for DTT and HOU, whereas in-house production was best for SAN. 


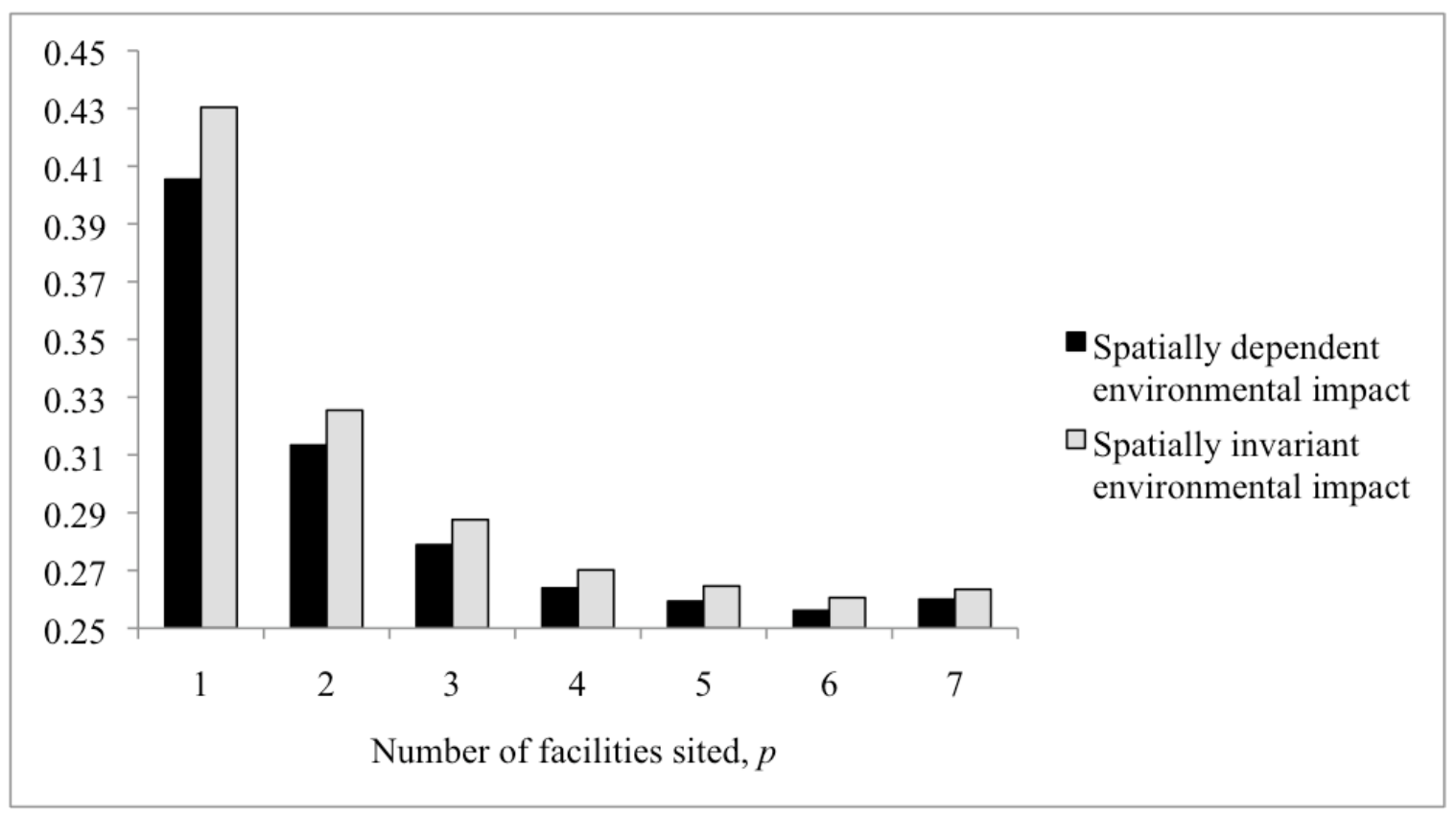

Figure 6.6: Minimum objective function values for spatially dependent and spatially invariant environmental impact by number of facilities sited, $p$

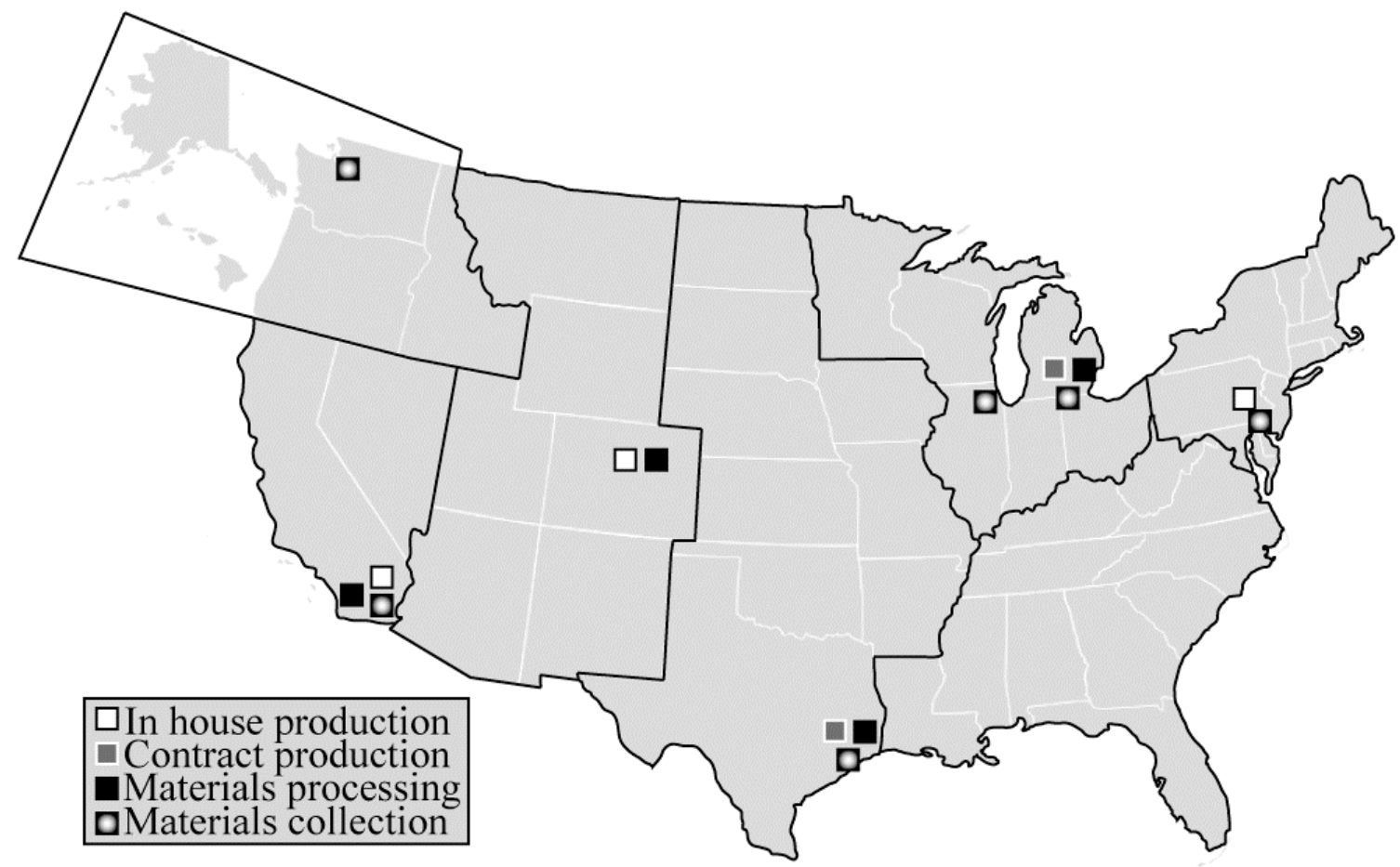

Figure 6.7: Locations and level of operation for minimum objective $(p=6)$ solution considering the spatial dependence of environmental impact 
In summary, 6 different locations added level of operation. Production occurred in 5 metro areas that covered the entirety of the U.S. North to South and the Atlantic, Pacific, and Gulf coasts. Production was almost evenly split between being accomplished in-house or through contracted manufacturers, with in-house production slightly favored. Only 1 facility sited, SAN, was completely vertically integrated. The SAN facility collected and processed materials as well as manufactured products. The DTT, HOU, and PHL facilities show some level of integration. DTT and HOU both collected and processed materials before sending them within the metro area to contractors for manufacturing. PHL acted in concert with the materials processing hub in Denver, in that materials were collected and products manufactured at the PHL facility, but materials were processed in Denver. Materials processing was always paired with the existence of production in a city. This did not mean that manufacturing products in a city necessitated materials processing (as PHL clearly exhibits). Materials processing took place in just 4 of the 5 metro areas that manufactured products. Rather, as both CHI and SEA show, processing materials in a metro area is unnecessary without production also located in that same metro area.

In addition to the locations and level of operations, note-worthy material and product flow patterns emerged in the optimal solution. As mentioned, DEN acted as hub for materials processing and manufacturing. $\mathrm{CHI}, \mathrm{HOU}$, and PHL satisfied demand in the geographical markets where those metro areas are located - the Great Lakes, Central, and Northeast markets respectively. In the optimal solution, SEA used its materials to meet demand in its own market, the Pacific Northwest, and an adjacent market, the West 
Coast, by routing all materials processing and product manufacturing through the DEN hub. DTT and SAN collected materials, processed materials, and manufactured products for demand in adjacent markets, the Southeast and Rocky Mountains markets respectively. This behavior is shown in Figure 6.8.

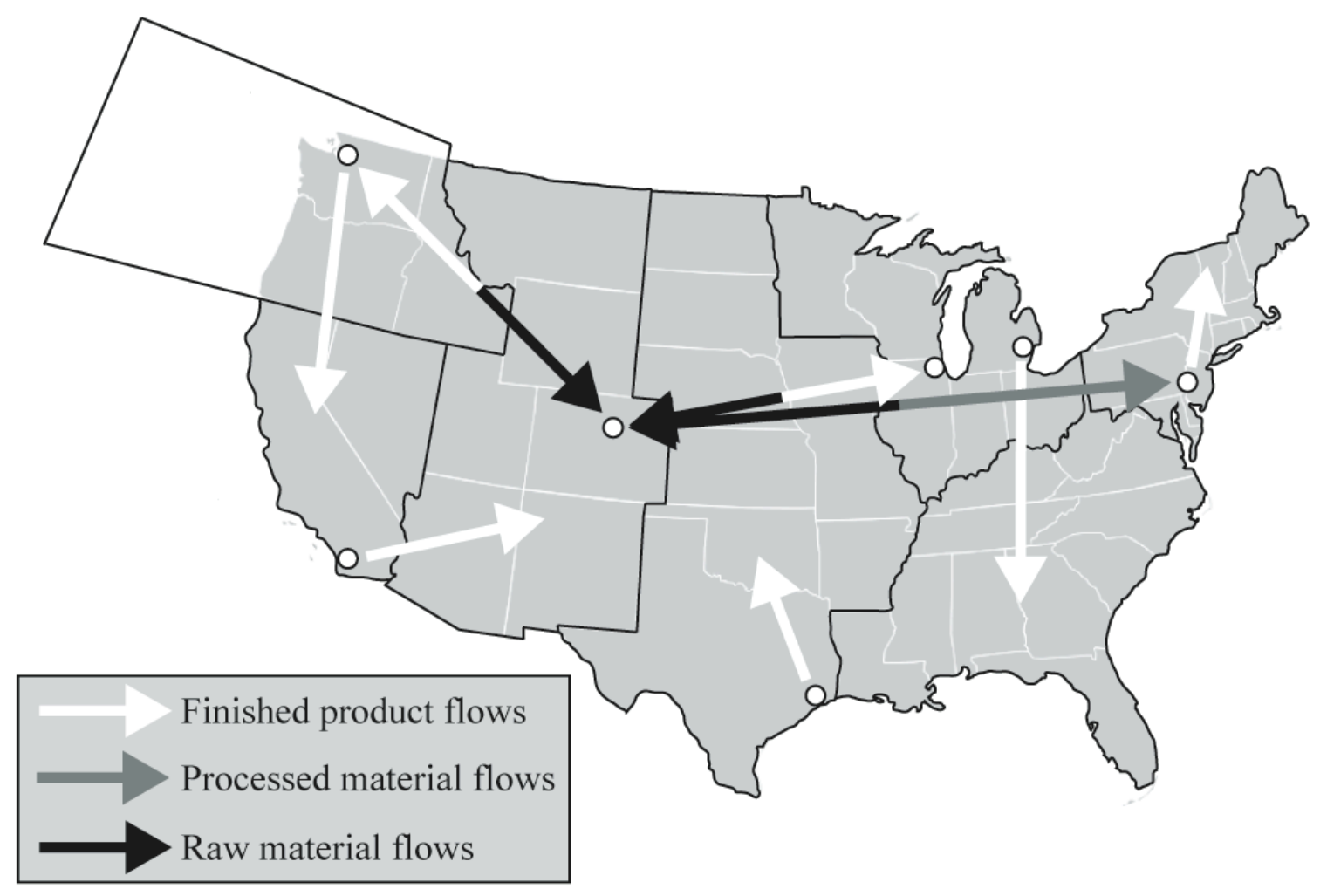

Figure 6.8: Flows of materials and product for minimum objective $(p=6)$ solution considering the spatial dependence of environmental impact

\subsubsection{Dependence on scale}

As $p$ increases, the minimum value of the final objective generally decreases (Figure 6.6). However the savings from decentralizing operations eventually bottoms out. Siting 7 facilities is the most decentralized or localized production strategy considered, where there is one facility assigned to satisfy demand for each market (a 1 to 1 correlation between facilities and markets). When 7 facilities are sited, the minimum 
value of the objective increases over the $p=6$ value instead of decreasing. After 1 operation is already located and servicing demand in a market, another great jump in demand would need to occur to set up a second set of operations. This situation is likely to happen in a more developed market for a further established company. At this point, Ecologic, like many startups, is only planning for that first growth spurt due to a surge in demand.

Interesting trends emerged among the numbers of facilities sited. In general the same locations were chosen amongst all numbers of facilities sited, $p$. For example SEA was always chosen, regardless of $p$. If considering only the demand (Figures 6.3 and 6.4) for products within the market where SEA is located, the Pacific Northwest, SEA would be the last place to locate operations. However, for the $p=1$ solution, when shipping collected materials from SEA to DEN for processing and production, a compromise emerged that had low costs and environmental impacts and moderate social impacts relative to other locations. SEA has the second highest toxicity potential whereas DEN has the lowest. Thus when only materials collection occurs in SEA, SEA becomes a very attractive place to locate.

This combination of material collection in SEA and processing and production in DEN for the $p=1$ solution (referred to SEA throughout the rest of this paragraph) was never the location with the minimum value for an index, but when all indices were combined it came out as the best choice overall. Specifically, SEA had the second smallest value for economic index and third smallest for environmental index. PHX had the minimum value in both categories, yet had the highest value in the social index category whereas SEA had the fifth least value. Similarly JRC had the minimum social 
index category value but in terms of environmental and economic indices had the highest and second highest value. Thus siting at SEA emerged as the best compromise among the economic, environmental, and social indices.

Even more obvious were the locations that were not chosen. JRC, LAX, and PHX were never selected. Their combined sustainability indices were always much higher than the other locations. LAX had the worst (maximum) economic index value for the minimum solutions found for any $p$. JRC had the maximum environmental index and PHX had the maximum social index. Additionally LAX was consistently the second highest for the environmental index and JRC was second highest for the economic index. The poor performance of JRC, LAX, and PHX on one or several of the indices guaranteed that these locations would never be sited.

\subsubsection{Level of operations}

In general, specific locations that were selected had the same level of operation each time (Table 6.10). There were two exceptions. As more facilities were sited, PHL moved materials processing from its own location to the DEN hub. When the greatest number of locations was selected, SEA moved from an in-house facility to contracting. Likely this has to do with the total volume of demand being handled through SEA. There tends to be an advantage at higher volumes for in-house production, which makes sense because of economies of scale. As there became a one-to-one ratio of operations to markets or in other words highly localized operations, the volume of demand was lower, making it cheaper to simply send it to a contractor for production. Thus manufacturing of products is achieved with contract manufacturers more often than through in-house production as greater numbers of facilities are sited, i.e. $p$, increases (Table 6.10). In 
addition, certain locations tend to favor production either in-house (PHL, SAN, DEN) or contract (DTT, HOU). The favoring of either in-house or contract production reflects the relative cost of labor in an area to the cost of contractors as well as the total production volume. 
Table 6.10: Level of operation by number of facilities sited, $p$, and location selected, when spatially dependent and invariant solutions differ, solutions with spatial dependence in light grey and without in black

\begin{tabular}{|c|c|c|c|c|c|}
\hline$p$ & $\begin{array}{c}\text { Materials } \\
\text { collection } \\
\text { location }\end{array}$ & $\begin{array}{l}\text { Materials } \\
\text { collection }\end{array}$ & $\begin{array}{c}\text { Materials } \\
\text { processing } \\
\text { location }\end{array}$ & $\begin{array}{l}\text { Production } \\
\text { location }\end{array}$ & Production \\
\hline 1 & SEA & Pick up & DEN & $\mathrm{DEN}$ & In house \\
\hline 2 & PHL & Pick up & PHL & PHL & In house \\
\hline 2 & $S E A$ & Pick up & $D E N$ & $D E N$ & In house \\
\hline 2 & $S A N$ & Pick up & $S A N$ & $S A N$ & In house \\
\hline 2 & $S E A$ & Pick up & $D E N$ & $D E N$ & In house \\
\hline 3 & PHL & Pick up & PHL & PHL & In house \\
\hline 3 & SAN & Pick up & SAN & SAN & In house \\
\hline 3 & SEA & Pick up & DEN & DEN & In house \\
\hline 4 & $\mathrm{CHI}$ & Pick up & $\mathrm{DEN}$ & $\mathrm{DEN}$ & In house \\
\hline 4 & PHL & Pick up & DEN & PHL & In house \\
\hline 4 & SAN & Pick up & SAN & SAN & In house \\
\hline 4 & SEA & Pick up & DEN & $\mathrm{DEN}$ & In house \\
\hline 5 & $\mathrm{CHI}$ & Pick up & DEN & $\mathrm{DEN}$ & In house \\
\hline 5 & DTT & Pick up & DTT & DTT & Contract \\
\hline 5 & PHL & Pick up & DEN & PHL & In house \\
\hline 5 & SAN & Pick up & SAN & SAN & In house \\
\hline 5 & SEA & Pick up & DEN & DEN & In house \\
\hline 6 & $\mathrm{CHI}$ & Pick up & DEN & DEN & In house \\
\hline 6 & DTT & Pick up & DTT & DTT & Contract \\
\hline 6 & $\mathrm{HOU}$ & Pick up & $\mathrm{HOU}$ & $\mathrm{HOU}$ & Contract \\
\hline 6 & PHL & Pick up & $\mathrm{DEN}$ & PHL & In house \\
\hline 6 & SAN & Pick up & SAN & SAN & In house \\
\hline 6 & SEA & Pick up & DEN & $\mathrm{DEN}$ & In house \\
\hline 7 & $\mathrm{CHI}$ & Pick up & DEN & $\mathrm{DEN}$ & In house \\
\hline 7 & DTT & Pick up & DTT & DTT & Contract \\
\hline 7 & GSO & Pick up & DEN & GSO & Contract \\
\hline 7 & $\mathrm{HOU}$ & Pick up & $\mathrm{HOU}$ & $\mathrm{HOU}$ & Contract \\
\hline 7 & PHL & Pick up & DEN & PHL & In house \\
\hline 7 & SAN & Pick up & SAN & SAN & In house \\
\hline 7 & SEA & Pick up & DEN & DEN & Contract \\
\hline
\end{tabular}


Table 6.11: The locations that satisfies all markets' demands by number of facilities sited, $p$, when spatially dependent and invariant environmental impact solutions differ, solutions with spatial dependence in light grey and without in black

\begin{tabular}{|c|c|c|c|c|c|c|c|c|c|}
\hline$p$ & Production & Production & \multicolumn{7}{|c|}{ Market demand satisfied by location } \\
\hline 1 & $\mathrm{DEN}$ & In house & $\mathrm{CN}$ & GL & $\mathrm{NE}$ & $\mathrm{PW}$ & $\mathrm{RM}$ & $\mathrm{SE}$ & $\mathrm{WC}$ \\
\hline 2 & PHL & In house & $C N$ & $G L$ & $N E$ & & & $S E$ & \\
\hline 2 & $D E N$ & In house & & & & $P W$ & $R M$ & & $W C$ \\
\hline 2 & $S A N$ & In house & & & & & $R M$ & & $W C$ \\
\hline 2 & $D E N$ & In house & $C N$ & $G L$ & $N E$ & $P W$ & & $S E$ & \\
\hline 3 & PHL & In house & & $G L$ & $N E$ & & & $S E$ & \\
\hline 3 & $S A N$ & In house & & & & & $R M$ & & \\
\hline 3 & $D E N$ & In house & $C N$ & & & $P W$ & & & $W C$ \\
\hline 3 & PHL & In house & & & $N E$ & & & $S E$ & \\
\hline 3 & $S A N$ & In house & & & & & $R M$ & & $W C$ \\
\hline 3 & $D E N$ & In house & $C N$ & $G L$ & & $P W$ & & & \\
\hline 4 & DEN & In house & $\mathrm{CN}$ & GL & & & & & \\
\hline 4 & PHL & In house & & & $\mathrm{NE}$ & & & $\mathrm{SE}$ & \\
\hline 4 & SAN & In house & & & & & $\mathrm{RM}$ & & \\
\hline 4 & DEN & In house & & & & $\mathrm{PW}$ & & & $\mathrm{WC}$ \\
\hline 5 & DEN & In house & $\mathrm{CN}$ & GL & & & & & \\
\hline 5 & DTT & Contract & & & & & & SE & \\
\hline 5 & PHL & In house & & & $\mathrm{NE}$ & & & & \\
\hline 5 & SAN & In house & & & & & $\mathrm{RM}$ & & \\
\hline 5 & DEN & In house & & & & PW & & & WC \\
\hline 6 & DEN & In house & & GL & & & & & \\
\hline 6 & DTT & Contract & & & & & & $\mathrm{SE}$ & \\
\hline 6 & $\mathrm{HOU}$ & Contract & $\mathrm{CN}$ & & & & & & \\
\hline 6 & PHL & In house & & & $\mathrm{NE}$ & & & & \\
\hline 6 & SAN & In house & & & & & $\mathrm{RM}$ & & \\
\hline 6 & DEN & In house & & & & $\mathrm{PW}$ & & & WC \\
\hline 7 & DEN & In house & & GL & & & & & \\
\hline 7 & DTT & Contract & & & & & $\mathrm{RM}$ & & \\
\hline 7 & GSO & Contract & & & & & & $\mathrm{SE}$ & \\
\hline 7 & $\mathrm{HOU}$ & Contract & $\mathrm{CN}$ & & & & & & \\
\hline 7 & PHL & In house & & & $\mathrm{NE}$ & & & & \\
\hline 7 & SAN & In house & & & & & & & WC \\
\hline 7 & DEN & Contract & & & & $\mathrm{PW}$ & & & \\
\hline
\end{tabular}




\subsubsection{Building or renting facilities}

At most potential facility sites it is cheaper to rent than build. There were a few exceptions - PHX, SEA, and SAN. The combined annualized costs for land and construction were lower than rental costs in those metro areas. Still, this analysis of whether to rent or build is only comparing a single type of cost. There are other important reasons, in addition to other costs, that favor renting or building facilities such as flexibility in location (which would likely favor renting) or ability to power facilities with renewable energy (which would likely favor owning and/or building a facility). Choosing to build or rent a facility is a more complicated decision that requires investigating the details of both options while considering additional factors not considered in this assessment. Yet comparing the average rental costs to average land and construction costs for a metropolitan area can provide an idea of whether it is even worth asking the question of whether to rent or build a facility

\subsubsection{Spatial dependence of environmental impact}

For most of the solutions the locations chosen and level of operations chosen were the same regardless of whether the spatial dependence of environmental impact was considered (see Table 6.10). A notable exception was the siting of two facilities, PHL and SEA for the spatially dependent solution and SAN and SEA for the spatially invariant solution. Since most of the time the spatially dependent and invariant solutions selected the same locations, in general the optimal solutions that are spatially dependent and spatially invariant calculated the same environmental indicators besides toxicity, i.e., the same availability of reclamation partners, competition for reclaimed materials, and amount of reclaimed materials indicators (Figure 6.9a and b). 


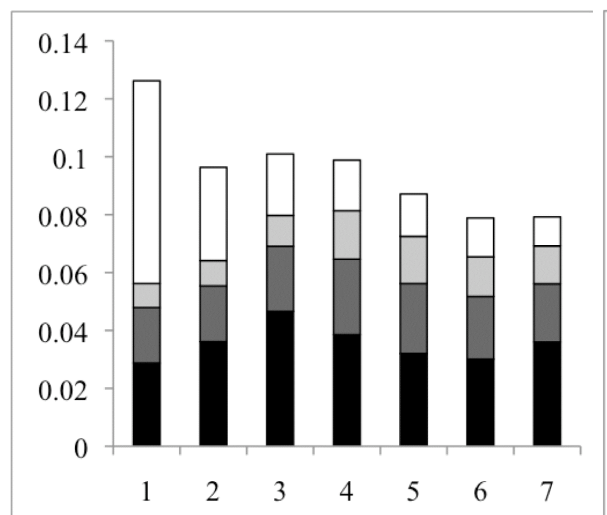

(a)

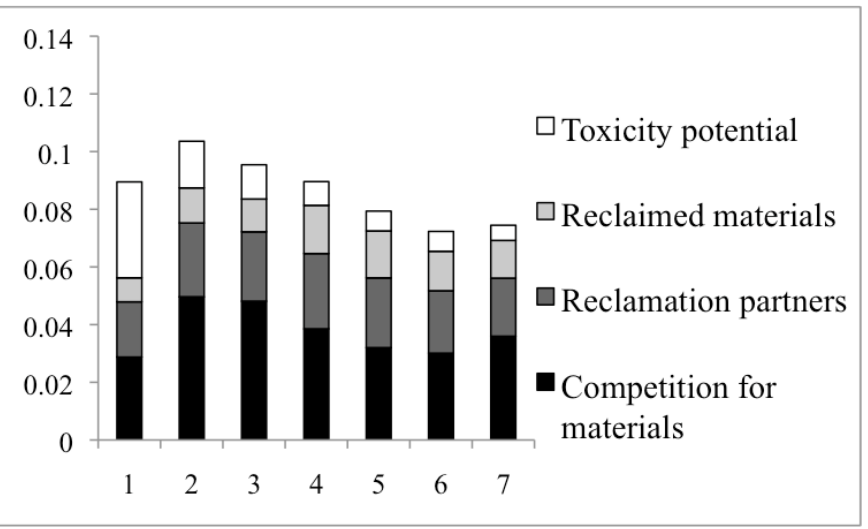

(b)

Figure 6.9: Weighted and normalized environmental indicators by $p$ for (a) spatially invariant (b) and spatially dependent toxicity potential

Toxicity potential for the spatially invariant solution was based on a national average, which is most often higher than the toxicity potential for a chosen location. Thus the toxicity potential differed in all cases between the spatially dependent and invariant solutions. The allocation of the markets' demand to locations was dissimilar for the spatially dependent and invariant solutions when 2 and 3 facilities were sited. Thus, for $p$ values ranging from 4 to 7 , the toxicity potential followed the same trend, with the spatially dependent solution always less than the invariant value. The $p=1$ case looks strikingly different in toxicity between the solutions - this occurs because the spatially invariant toxicity potential value is the maximum value for all combinations of demand.

\subsection{Discussion}

Ecologic is deeply rooted in the Denver metro area and interested in maintaining operations there. That the optimal solution to their facility location problem suggested that DEN would continue to serve as a hub for materials processing and product manufacturing confirms the satisfaction the management at Ecologic has with their current location. This optimal solution also confirms a feasible course of action for 
expansion. Even if a decentralized approach is the most optimal way to expand their supply chain, it is unlikely that Ecologic will expand in 6 different directions at once. However, Ecologic can turn their current location into the processing hub and headquarters. On some level Ecologic already envisions their current location in DEN as the root from which to start branching their operations. Over time, Ecologic can start by collecting materials in other strategic metro areas. Then, production can be slowly added to those areas that are already collecting materials.

A valuable insight that came from this analysis is that the processing of materials should be the last operation level to be added in an expansion of Ecologic's supply chain. This is not an obvious finding. One might think that a company would add operations to a new location in the sequence those operations occur for the manufacture of the product. However, for Ecologic materials processing requires more labor and the same or more capital than production itself. Thus, economies of scale have much more influence over materials processing and much less sway over production. Production, instead of materials processing, can more easily locate to a new area to obtain advantages, such as reduced shipping costs, cheaper and more abundant supply of skilled labor, and reduced contracted manufacturing costs.

On one hand, materials processing can be quite specialized for any industry. This specialization can justify locating most of the materials processing in 1 or 2 locations. However, this relationship between materials processing and production seems to perhaps embody the challenges of companies involved in product take back in any from. Transportation of products, i.e., reverse logistics, pose a significant concern to companies involved in the reverse supply chain (Fleischmann et al., 2001; Guide et al., 2000; 
Jayaraman et al., 1999; Krikke et al., 1999). Unsurprisingly, the great need for transportation, and the costs involved, can push take back companies to decentralize operations. Yet the concentration of expertise and skill in processing and production combined with often high capital costs make centralized production with fewer satellite locations more appealing. Overall the optimal solution for Ecologic appears to be a highly decentralized solution - especially for materials collection and production. Yet a balance of sorts is achieved between these competing aims, centralization and decentralization, in this solution. The centralization of 1 level of operation, materials processing is urged, while the decentralization of the other 2 levels of production is promoted. Thus, the positive aspects of each aim are incorporated, without the consequences of only choosing a single strategy.

Most of the time the same locations for siting operations were chosen by both the spatially dependent and spatially invariant solutions. Although when differences arose in either the facilities sited or the allocation of the demand from markets to facilities, these differences were due to differences in the toxicity potential between solutions. As more facilities were sited, the toxicity potentials involved more greatly resembled the national average toxicity potential. The manufacturing process considered has, relative to many other types of manufacturing processes, very few emissions in total amount as well as different types of chemicals released. Also, toxicity potential was weighted the lowest of all environmental indicators. Yet even with this simple process and downplayed indicator of toxicity, differences between a spatially dependent and invariant solution could be found. Thus, this research provides further credence to the need for facility location analysis to include the spatial dependence of environmental impact. 


\subsection{Conclusions}

The idea that bigger is better, or that centralization is the way to manufacture products is deeply rooted in the sensibility of many manufacturers. And often reducing overhead costs is possible when manufacturing larger volumes of products. Yet Ecologic has a set of operations unique to a business involved in the take back of products or materials reclamation in their case. One of the greatest challenges to the success of recycling is the amount of labor and/or equipment involved (Royte, 2005). Similar to a recycler, Ecologic needs great amounts of labor to process the materials it uses in its products. This part of their business is improved by centralizing production.

However transportation costs are also important to a business that takes back products (Krikke et al., 1999), and clearly, transportation is an important part of Ecologic's business. Transportation concerns arose directly in the economic and social categories (e.g., transportation cost and proximity to hubs) and indirectly in the environmental indicators category (availability of materials captures the distances involved in collection of reclaimed materials). A company that takes back products is benefited by decentralizing production to lower the time (thus labor) and cost of collecting items.

This research finds a middle ground between these two strategies. The advantages of scaling up from centralization are maintained for materials processing. While the benefits of decentralization or localization, dispersion throughout a national market, are achieved for materials collection and production. Thus a compromise between two strategies to facility location and supply chain operation can work together as the best approach for this company involved with product recovery. 


\section{Chapter 7}

\section{Summary and Conclusions}

This dissertation has explored the trade-offs between strategies of centralization and decentralization for siting supply chain facilities when considering more than just costs. Centralization has often been promoted as a smart strategy for businesses. But when considering businesses that take back products, this strategy can fail. Transportation costs and impacts can be significant for product recovery, promoting a more decentralized approach to facility siting. In addition, how to incorporate concerns such as environmental impact and social sustainability were also explored through this research

\subsection{Summary of the Dissertation}

Considering costs alone to decide between strategies of centralization and decentralization for siting facilities can be difficult. However, including other factors such as environmental impact simply increases the complexity of the analysis. Rarely are the environmental impacts of facility siting decisions included into facility location analysis. This dissertation demonstrated that the spatial dependence of environmental impact could be used in conjunction with costs to find optimal facility locations. The spatial dependence of environmental impact is often neglected in environmental impact assessment methods such as life cycle assessment (Graedel, 1998). How to incorporate 
the spatial dimension of environmental impact into a facility location optimization problem was explored. Specifically, a multimedia fate and transport model, CHEMGL, was used to calculate the concentrations of released chemicals in specific parts of the environment or environmental compartments (e.g., air, water, and soil). These concentrations of chemicals in specific environmental compartments were then assessed for toxicity. The author has found no other research that utilizes multimedia fate and transport analysis to help assess environmental impact within facility location analysis. A theoretical example (Chapter 4) and a real world example (Chapter 6) of facility location analysis incorporating the spatial dependence of environmental impact were examined.

The examples considered in this dissertation formulated the facility location problem as a discrete $p$-median problem. In a $p$-median problem, the demand weighted distance from $p$ facilities to $m$ demand locations or markets is minimized (Daskin, 1995). Enumeration was used to solve the facility location problems considered. Discrete facility location problems pose their own array of challenges, since this set of problems is $\mathrm{NP}-$ hard and thus as the number of facilities or demand locations increases, the computation time to solve these problems increases rapidly. Therefore a heuristic, based on a Lagrangian relaxation approach, was used to demonstrate that incorporating spatially dependent environmental impact into facility location analysis could be achieved for problems with larger numbers of facilities or locations.

In addition to environmental impact, costs were addressed in this research. Costs and environmental impacts are rarely considered jointly to optimize facility locations. The examples mentioned all considered costs in addition to environmental impacts. Also, economies of scale are rarely considered in determining the costs used in the objective 
functions used to optimize for facility locations. Economies of scale get at the heart of the centralization or decentralization quandary. For some operations, centralizing these operations into a single or a small number of locations can reduce capital and labor costs significantly. In the examples of both Chapters 4 and 6, cost advantages from aggregating demand or centralizing operations in the form of economies of scale were considered.

In addition, the theoretical example (Chapter 4) considered how weighting costs and environmental impacts in the objective function affected the optimal solutions. Also, the affect of product return rate was considered. Often the product return rate is not known before setting up a reverse supply chain. The theoretical example found that when only costs were considered (or only environmental impact) the optimal solution was different than when both costs and environmental impact were considered together and weighted equally. For this theoretical example, costs and environmental impacts considered together were minimized with a centralized strategy to facility location.

Along with environmental impacts and cost, social sustainability concerns of an SME were included. The sustainability concerns of Ecologic Designs, a sustainable manufacturer of bags and accessories from reclaimed materials such as climbing rope, were investigated. Most often the sustainability concerns of SMEs are unexplored or unknown because the concerns of larger companies dominate corporate sustainability efforts (Luetkenhorst, 2004). Also SMEs do not have the same resources to devote to sustainability efforts as do larger companies (Tsai and Chou, 2009).

Additionally, social sustainability indicators are still largely undefined. The author created an approach for developing and weighting sustainability indicators that utilized pairwise comparison analysis (Saaty, 1980). Weights were revised using the 
method of (Cao et al., 2008). The weights of multiple decision-makers were grouped using the geometric mean method (Leskinen and Kangas, 2005). Ecologic managers developed and weighted sustainability indicators for use in a facility location decision how to expand their existing supply chain as demand for products grew - using this process. The managers organized the developed indicators into 3 categories they brainstormed encompassing economic, environmental, and social sustainability. The 3 indicator categories were weighted and combined together into an index of sustainability.

Through this process information regarding an SME's perspective on sustainability, especially what aspects of social sustainability an SME are concerned about, was gathered. Additionally, indicators and weights were developed for a specific corporate strategic decision - supply chain expansion and thereby the location of operations and facilities. Many existing systems of indicators, such as the GRI (GRI, 2008), are generic in nature and do not necessarily consider impacts relevant to decisions of strategic instead of operational importance. Also, this demonstrated that with relatively little time invested, company managers could create a set of useful and usable indicators. Not very many methods to develop and weight indicators exist that are feasible, both in terms of time and knowledge required, and are appropriate for SMEs.

These developed indicators and weights were then applied to the question of how Ecologic could best meet its sustainability goals while expanding its supply chain and operations into new locations. The developed and weighted indicators were used to answer a three fold question; (1) what level of operation (including materials collection, materials processing, and product manufacture) are cost-effective to operate at which locations and when satisfying which markets' demands?, (2) at which locations to site 
operations to minimize total sustainability impact?, and (3) how many facilities should be sited to minimize overall impact? A decentralized solution with many facilities sited was found to minimize sustainability impacts. However, the optimal solution included some centralization of materials processing operations. Whereas materials collection and product manufacture operations were decentralized throughout the markets considered.

\subsection{Conclusions from this Research}

Many conclusions come out of this research. First of all, considering more than just costs in the objective for facility location analysis results in different optimal solutions. Cost is not the only factor that is important to business success. Ecologic weighted social sustainability concerns as more important than both costs and environmental impacts under their criteria of relevance to day-to-day operation of their business. Ecologic defined social sustainability as maintaining healthy external relations with business partners such as suppliers and reclamation partners and good internal relations with employees. Considering what potential business partnerships exist within in a community and if the kind of employees a business wants to attract would want to live at a location are concerns that many businesses besides Ecologic, already possess. Strategies that businesses currently use to help make decisions, such as cost-benefit analysis, ignore other important concerns that influence the viability of a business. The inclusion of other factors, such as environmental and social sustainability impacts, into facility location decision-making is important for finding the best places for businesses to expand operations.

Following from that, different optimal solutions can and do result when considering or ignoring the spatial dependence of environmental impact. These solutions 
can differ in terms of where facilities are sited, which operations occur at those sited facilities, and how demand is allocated to those facilities. Environmental impacts affect distinct locations at different severities. Including spatial dependence of environmental impact is necessary to fully describe the entire impact of potential facility locations. Even with much larger problems that consider more potential facilities, markets, or locations the spatial dependence of environmental impact can still be incorporated and minimized in the objective. Heuristics can incorporate spatially dependent environmental impact and come to solution with acceptable accuracy.

In addition, considering a combination of factors, such as costs and environmental impacts, results in different optimal solutions as well as considering the spatial dependence of environmental impact. Specific indicators may influence a solution more than others. The weights for indicators also influence solution outcomes. Regardless of how great or small an indicator is weighted, it may still influence the optimal solution. An indicator's range of values may differ more than other indicator values in an objective. This variation in an indicator between options can strongly influence the final solution, despite an indicator being weighted relatively low. Therefore every indicator could be the linchpin to an optimal solution.

Since each indicator matters, it is important that the indicators developed are the aspects of sustainability decision-makers in a company agree are important for their business. Especially for SMEs, indicators need to have a clearly defined application. Deciding on a specific purpose for utilizing sustainability indicators allows decisionmakers to come up with the relevant criteria an indicator must meet to be useful. This can slim down the number of indicators created and divert less time and fewer resources for 
the entire indicator development process. SMEs can more easily develop and apply a simpler focused set of sustainability indicators to a decision than a larger, more generic set of indicators.

\subsubsection{Centralization and decentralization}

Perhaps the most interesting conclusion involves centralization and decentralization. This dissertation considered 2 examples of production systems that take back products. For one system a centralized strategy was preferred. For the other system a decentralized strategy was optimal. Many factors influence whether a strategy is optimal for a company that takes back products including the spatial dependence of environmental impact, economies of scale, product return rates, the indicators chosen, and indicator weights. That said, including the factors that push either centralization or decentralization strategies, such as economies of scale or transportation environmental impact respectively, into facility location analysis illuminates the trade-offs between the strategies.

Great economies of scale tend to promote a highly centralized system of facilities. High need for transportation can decentralize either facilities or certain operations. When less product recovery is needed, centralization is optimal; the opposite is true for high product recovery rates where more transport is needed.

A reassuring finding from both studies of take back systems is that amongst many numbers of facilities sited, and thus many degrees of centralization, the same facilities are sited. In the theoretical example, amongst different product return rates the same facilities or facility clusters were sited. This seems to indicate that regardless of how some of the factors may vary, some locations are better for locating a facility. Therefore, if a 
company does not predict product return rate accurately, the facility locations it finds through optimization are likely to be the optimal (or at least close, such as within a nearby cluster of cities) regardless of the actual return rate. For Ecologic, regardless of how many facilities were sited, Seattle (SEA) was always an optimal location for materials collection.

Realistically there is likely no optimal degree of centralization for businesses that take back products. Companies have specialized operations. Businesses involved with product take back are tied to their particular resource stream. As unique as that recovered resource stream is, so too is the degree of centralization and optimal facility locations.

\subsection{Recommendations for Future Work}

This dissertation explored several types of quantitative and qualitative approaches to decision-making through the lens of facility location analysis and indicator development and weighting. In general, translating facility location analysis methods and techniques into off-the-shelf tools for use by SMEs lacking time, knowledge, and resources would be quite useful. However, before this can happen specific concerns within facility location analysis research need improvement, such as simplifying current multi-objective discrete optimization methods (also called multi-objective combinatorial optimization or MOCO) and creating more methods that incorporate 3 or more objectives instead of just 2. The research in the entire field of MOCO may need to progress further before specific tools can be developed.

In general there are too many systems of sustainability indicators and too little guidance for organizations on how to use the sustainability indicators to make better decisions. Organizations do not know what to do with all of the sustainability information 
that they collect. Investigating the most effective ways for organizations to utilize sustainability indicators seems important. Exploring what other types of decision-making processes (besides deciding how to expand operations) companies engage in and how sustainability concerns can be incorporated into those decisions seems to be the most fruitful area for future work.

\subsection{Broader Impacts of this Work}

Currently, there are too few methods available for businesses, and for SMEs in particular, to incorporate anything but cost concerns into decision-making processes. This dissertation offers a method for SMEs to use to begin to incorporate the multiple objectives of sustainability into strategic decision-making. Also, this dissertation documents the thoughts of a SME on sustainability. From this single case study, it can be seen that SMEs do not necessarily have the same concerns for sustainability as large companies. Nor do SMEs have the same concerns about sustainability that external organizations, such as sustainability reporting standardization systems, may have about sustainability for SMEs. SMEs make up a large percentage of business, and in many industries, the majority of the businesses. Obtaining buy-in from many small businesses for improving sustainability seems difficult. However, the social sustainability concerns raised in this case study may provide more openings for sustainability experts in academia, government, and non-governmental organizations to consider how to interest and engage SMEs in improving sustainability. 


\section{References}

1. Abram, S., 2005. The Smell of Money. In: Boholm, A. and Löfstedt, R. E., eds. Facility Siting: Risk, Power and Identity in Land Use Planning London: Earthscan Publications Ltd., 73-89.

2. AccountAbility, 2008. AA1000 Overview [online]. Available from: http://www.accountability21.net [Accessed February 6 2009].

3. Aczèl, J. and Saaty, T. L., 1983. Procedures for synthesizing ratio judgements. Journal of Mathematical Psychology, 27 (1), 93-102.

4. Alliance for Sustainability, 2006. Sustainable Chequamegon Initiative Strategic Plan: 2006-2011 [online]. Available from: http://www.allianceforsustainability.org [Accessed February 28 2009].

5. $\quad$ Anonymous, 2006, "North America's hump yards", Trains, July 8. http://www.trains.com/trn/default.aspx?c=a\&id=537

6. Anonymous, 2008. KPMG 2008 Sustainability Report Study. Business and the Environment, 19 (12), 6-7.

7. Ashley, S., 1993. Designing for the environment. Mechanical Engineering, 115 (3), 52-55.

8. Association of American Port Authorities, 2009. North America: Container Port Traffic in TEUs (1990-2008) [online]. Available from: http://aapa.files.cmsplus.com/Statistics/CONTAINERTRAFFICNORTHAMERICA1990\%2D2008.xl s [Accessed July 1 2009].

9. AtKisson, A., 1996. Developing Indicators of Sustainable Community: Lessons From Sustainable Seattle. Environmental Impact Assessment Review, 16 (337$350)$,

10. Azapagic, A., 2004. Developing a framework for sustainable development indicators for the mining and minerals industry. Journal of Cleaner Production, 12 (6), 639-662. 
11. Bakker, J., Brandes, L. J., den Hollander, H. A., van de Meent, D. and Struijs, J., 2003, "Validating SimpleBox-Computed Steady-state Concentration Ratios," 607220010, Netherlands Environmental Assessment Agency (RIVM), Bilthoven. http://www.rivm.nl/bibliotheek/rapporten/607220010.pdf

12. Barnes, G. and Langworthy, P., 2003, "The Per-mile Costs of Operating Automobiles and Trucks," Minnesota Department of Transportation, St. Paul, Minnesota. www.lrrb.org/pdf/200319.pdf

13. Barros, A. I., Dekker, R. and Scholten, V., 1998. Two-level network for recycling sand: A case study. European Journal of Operational Research, 110 (2), 199-214.

14. Barzilai, J. and Golany, B., 1994. Deriving weights from pairwise comparison matrices. INFOR, 32 (2), 57-63.

15. BASF, 2009. BASF at a glance [online]. Available from: http://www.basf.com/group/corporate/en/about-basf/profile/index [Accessed May 26 2009].

16. Beamon, B. M., 1998. Supply chain design and analysis: Models and methods. International Journal of Production Economics, 55 (3), 281-294.

17. Beamon, B. M., 1999. Measuring Supply Chain Performance. International Journal of Operations and Production Management, 19 (3), 275-292.

18. Beamon, B. M., 2005. Environmental and Sustainability Ethics in Supply Chain Management. Science and Engineering Ethics 11 (2), 221-234.

19. Beamon, B. M. and Fernandes, C., 2004. Supply-chain network configuration for product recovery. Production Planning and Control, 15 (3), 270-281.

20. Beatley, T., 1994. Ethical land use: principles of policy and planning Baltimore: Johns Hopkins University Press.

21. Bell, M. L., Hobbs, B. F., Elliot, E. M., Ellis, H. and Robinson, Z., 2001. An Evaluation of Multi-Criteria Methods in Integrated Assessment of Climate Policy. Journal of Multi-Criteria Decision Analysis, 10 (5), 229-256.

22. Bell, S. and Morse, S., 2008. Sustainability indicators : measuring the immeasurable? London: Earthscan.

23. Bennett, D. H., Scheringer, M., McKone, T. E. and Hungerbuhler, K., 2001. Predicting long-range transport: A systematic evaluation of two multimedia transport models. Environmental Science and Technology, 35 (6), 1181-1189. 
24. Berner, C., Bauer, B. and Dahl, J., 2005, "New tools for the design of green products," 16, Danish Environmental Protection Agency, http://www.mst.dk/publica/projects/2003/87-7972-585-6.htm

25. Birkenstock USA, 2008. Store Locator [online]. Birkenstock. Available from: http://www.birkenstockusa.com/store-locator/list [Accessed February 5 2008].

26. Bloemhof-Ruwaard, J. M., Salomon, M. and Van Wassenhove, L. N., 1996a. The Capacitated distribution and waste disposal problem. European Journal of Operational Research, 88 (3), 490-503.

27. Bloemhof-Ruwaard, J. M., van Beek, P., Hordijk, L. and Van Wassenhove, L. N., 1995. Interactions between operational research and environmental management. European Journal of Operational Research, 85 (2), 229-243.

28. Bloemhof-Ruwaard, J. M., Van Wassenhove, L. N., Gabel, H. L. and Weaver, P. M., 1996b. An Environmental Life Cycle Optimization Model for the European Pulp and Paper Industry. Omega, 24 (6), 615-629.

29. Blumberg, D. F., 2005. Introduction to Management of Reverse Logistics and Closed Loop Supply Chain Processes. Boca Raton: CRC Press.

30. Bockhorn, H., Donner, S., Gernsbeck, M., Hornung, A. and Hornung, U., 2001. Pyrolysis of polyamide 6 under catalytic conditions and its application to reutilization of carpets. Journal of Analytical and Applied Pyrolysis, 58-59 (April 1), 79-94.

31. Bogatin, R. and Clarke, A., 2008, "ECOLOGIC DESIGNS, INC. 2007 SUSTAINABILITY REPORT," Boulder, Colorado. http://ecologicdesigns.com/ecofileshare/Ecologic_GRI_Report.pdf

32. Boholm, A. and Löfstedt, R. E., 2005. Introduction. In: Boholm, A. and Löfstedt, R. E., eds. Facility Siting: Risk, Power and Identity in Land Use Planning London: Earthscan Publications Ltd., xii-xxv.

33. Borland, N. and Wallace, D., 1999. Environmentally Conscious Product Design: A Collaborative Internet - based Modeling Approach. Journal of Industrial Ecology, 3 (2\&3), 33-46.

34. Bras, B., 1997. Incorporating environmental issues in product design and realization. Industry and Environment, 20 (1-2), 7-13.

35. Brezet, H. and van Hemel, C., 1997. Ecodesign: a promising approach to sustainable production and consumption. Paris: United Nations Environment Programme. 
36. Bruntland Commission, 1987. Our Common Future. Oxford: Oxford University Press.

37. Burgess, A. A. and Brennan, D. J., 2001. Application of life cycle assessment to chemical processes. Chemical Engineering Science, 56 (8), 2589-2604.

38. Buss, T. F., 2001. The Effect of State Tax Incentives on Economic Growth and Firm Location Decisions: An Overview of the Literature. Economic Development Quarterly, 15 (1), 90-105.

39. Canavate-Bernal, R., Landete-Ruiz, M. and Marin-Perez, A., 2000. On the resolution of the single product capacitated machine siting problem. Journal of the Operational Research Society, 51 (8), 982-992.

40. Cao, D., Leung, L. C. and Law, J. S., 2008. Modifying inconsistent comparison matrix in analytic hierarchy process: A heuristic approach. Decision Support Systems, 44 (4), 944-953.

41. Chaco Inc., 2007. repair your sandals [online]. Available from: https://chacousa.com/Portal.aspx?CN=26AD6CEBF909\&MN=E81374EAC464 [Accessed April 14 2008].

42. Chamaret, A., O'Connor, M. and Recoche, G., 2007. Top-down/bottom-up approach for developing sustainable development indicators for mining: application to the Arlit uranium mines (Niger). International Journal of Sustainable Development, 10 (1/2), 161-174.

43. Chambers, N., Simmons, C. and Wackernagel, M., 2000. Sharing in nature's interest: Ecological footprints as an indicator of sustainability London: Earthscan Publications Ltd.

44. Chavda, R. K., 2004. Public Sector Incentive Programs and Locational Characteristics: Do Preferences Differ by Industry? Thesis (Ph.D.). Rutgers.

45. Choo, E. U. and Wedley, W. C., 2004. A common framework for deriving preference values from pairwise comparison matrices. Computers \& Operations Research, 31 (6), 893-908.

46. Clarke, A. and Gershenson, J. K., 2006. Design for the Life-Cycle. In: Kutz, M., ed. Handbook of Environmentally Conscious Mechanical Design. John Wiley \& Sons, Inc., (in press).

47. Clarke, A. and Gershenson, J. K., 2007. Design for the Life-Cycle. In: Kutz, M., ed. Handbook of Environmentally Conscious Mechanical Design. Hoboken, New Jersey: John Wiley \& Sons, Inc., 67-125. 
48. Clarke, A. R., Zhang, Q., Gershenson, J. K. and Sutherland, J. W., 2008. Selection of Remanufacturing Facility Locations to Minimize Cost and Environmental Impact. The 15th CIRP International Conference on Life Cycle Engineering, Sydney, Australia.

49. Clarke-Sather, A. R., Hutchins, M. J., Zhang, Q., Gershenson, J. K. and J. W. Sutherland, 2009a. Development and weighting of social, environmental, and economic indicators for a sustainable enterprise. Journal of Environmental Management, submitted.

50. Clarke-Sather, A. R., Hutchins, M. J., Zhang, Q., Gershenson, J. K. and Sutherland, J. W., 2009b. Development and weighting of social, environmental, and economic indicators for a sustainable enterprise. Journal of Environmental Management,(submitted).

51. Clarke-Sather, A. R., Jenkins, T. L., Haapala, K. R. and Sutherland, J. W., 2010. Sustainable Production. Encyclopedia of Geography, Warf, B., Thousand Oaks, CA, SAGE Publications, Inc., (in press).

52. Clarke-Sather, A. R., Zhang, Q., Gershenson, J. K. and J. W. Sutherland, 2009c. Integrating spatially specific environmental impacts into facility location problems. International Journal of Production Research, submitted.

53. Cohen, M. A. and Moon, S., 1991. An integrated plant loading model with economies of scale and scope. European Journal of Operational Research, 50 (3), 266-279.

54. Cole, L. W. and Foster, S. R., 2001. From the Ground Up: Environmental Racism and the Rise of the Environmental Justice Movement. New York: New York University Press.

55. Conner, M., 2007. Cherokee International: Where in the world are design and manufacturing?, EDN, January 18, 32,

56. Cornuejols, G., Fisher, M. L. and Nemhauser, G. L., 1977. Location of Bank Accounts to Optimize Float: An Analytic Study of Exact and Approximate Algorithms. Management Science, 23 (8), 789-810.

57. CorporateRegister.com, 2009. CorporateRegister.com [online]. Available from: http://www.corporateregister.com/ [Accessed May 21 2009].

58. Crawford, G. and Williams, C., 1985. A note on the analysis of subjective judgment matrices. Journal of Mathematical Psychology, 29 (4), 387-405. 
59. Creighton, J. L., 2005. The Public Participation Handbook: Making Better Decisions Through Citizen Involvement. 1st, San Francisco: John Wiley \& Sons.

60. Daskin, M. S., 1995. Network and Discrete Location: Models Algorithms and Applications. New York: John Wiley and Sons, Inc.

61. Davies, A. R., 1999. Where Do We Go from Here? Environmental focus groups and planning policy formation. Local Environment, 4 (3), 295-316.

62. Dill, J. and Carr, T., 2003. Bicycle Commuting and Facilities in Major U.S. Cities: If You Build Them, Commuters Will Use Them - Another Look. Journal of the Transportation Research Board, 1828116-123.

63. Dolan, A. and Aldous, J., 1993. Networks and Algorithms: An Introductory Approach. Chichester, United Kingdom: John Wiley \& Sons.

64. Dong, Y., Xu, Y., Li, H. and Dai, M., 2008. A comparative study of the numerical scales and the prioritization methods in AHP. European Journal of Operational Research, 186 (1), 229-242.

65. Dowlatshahi, S., 2005. A strategic framework for the design and implementation of remanufacturing operations in reverse logistics. International Journal of Production Research, 43 (16), 3455-3480.

66. Ehrenfeld, J. and Gertler, N., 1997. Industrial Ecology in Practice: The Evolution of Interdependence at Kalundborg. Journal of Industrial Ecology, 1 (1), 67-79.

67. Ehrgott, M. and Gandibleux, X., 2000. A survey and annotated bibliography of multiobjective combinatorial optimization. OR Spectrum, 22 (2), 425-460.

68. Elkington, J., 1994. Towards the suitable corporation: Win-win-win business strategies for sustainable development. California Management Review, 36 (2), 90-101.

69. Escobar, M. T. and Moreno-jiménez, J. M., 2007. Aggregation of Individual Preference Structures in Ahp-Group Decision Making. Group Decision and Negotiation, 16 (4), 287-301.

70. Esty, D. C., Levy, M., Srebotnjak, T. and de Sherbinin, A., 2005, "2005 Environmental Sustainability Index: Benchmarking National Environmental Stewardship," Yale Center for Environmental Law \& Policy, New Haven. www.yale.edu/esi/ESI2005_Main_Report.pdf

71. Fairtrade Labelling Organizations International (FLO), 2009. Fairtrade Standards [online]. Available from: http://www.fairtrade.net/ [Accessed February 6 2009]. 
72. Federal Transit Administration, 2009. National Transit Database [online]. Federal Transit Administration. Available from: http://204.68.195.57/ntdprogram/ [Accessed July 6 2009].

73. FedEx, 2009. FedEx Facts [online]. Available from: http://about.fedex.designcdt.com/our_company/company_information/fedex_expr ess [Accessed June 15 2009].

74. Fenner, K., Scheringer, M., Macleod, M., Matthies, M., McKone, T., Stroebe, M., Beyer, A., Bonnell, M., Le Gall, A. C., Klasmeier, J., Mackay, D., Van De Meent, D., Pennington, D., Scharenberg, B., Suzuki, N. and Wania, F., 2005. Comparing estimates of persistence and long-range transport potential among multimedia models. Environmental Science and Technology, 39 (7), 1932-1942.

75. Fleischmann, M., Beullens, P., Bloemhof-Ruwaard, J. M. and van Wassenhove, L. N., 2001. The Impact of Product Recovery on Logistics Network Design. Production and Operations Management, 10 (2), 156-173.

76. Fleischmann, M., Bloemhof-Ruwaard, J. M., Dekker, R., van der Laan, E., van Nunen, J. A. E. E. and Van Wassenhove, L. N., 1997. Quantitative models for reverse logistics: a review. European Journal of Operational Research, 103 (1), 117.

77. Fleischmann, M., Krikke, H. R., Dekker, R. and Flapper, S. D. P., 2000. A characterisation of logistics networks for product recovery. Omega, 28 (6), 653666.

78. Forman, E. and Peniwati, K., 1998. Aggregating individual judgments and priorities with the analytic hierarchy process. European Journal of Operational Research, 108 (1), 165-169.

79. Fraser, E. D. G., Dougill, A. J., Mabee, W. E., Reed, M. and McAlpine, P., 2006. Bottom up and top down: Analysis of participatory processes for sustainability indicator identification as a pathway to community empowerment and sustainable environmental management. Journal of Environmental Management, 78 (2), 114127.

80. Gambale, G., Cranmer, L. J., Wegfahrt, A. M., Canup, B. and Schneider, P., 2007. 21st Annual Corporate Survey. Area Development Site and Facility Planning, 41 (7), 33-51.

81. Gass, S. I. and Rapcsák, T., 1998. A note on synthesizing group decisions. Decision Support Systems, 22 (1), 59-63. 
82. Global Reporting Initiative, 2008. G3 Guidelines [online]. Available from: http://www.globalreporting.org/ [Accessed April 10 2008].

83. Goedkoop, M. and Spriensma, R., 2000, "A damage oriented method for Life Cycle Impact Assessment," 90-72130-80-4, Pré Consultants, Amersfoort, the Netherlands. http://www.pre.nl/download/EI99_methodology_v3.pdf

84. González-Pachón, J. and Romero, C., 2004. A method for dealing with inconsistencies in pairwise comparisons. European Journal of Operational Research, 158 (2), 351-361.

85. Google Inc., 2009a. Google Maps [online]. Available from: http://maps.google.com/ [Accessed October 15 2007].

86. Google Inc., 2009b. Google Maps category:"Bicycle Shop" [online]. Available from: http://maps.google.com/ [Accessed June 15 2009].

87. Google Inc., 2009c. Google Maps category:"Mountain \& Rock Climbing Equip" [online]. Available from: http://maps.google.com/ [Accessed June 15 2009].

88. Google Inc., 2009d. Google Maps category:"Scuba Diving Equip \& Instruction" [online]. Available from: http://maps.google.com/ [Accessed June 15 2009].

89. Gottinger, H. W., 1988. A computational model for solid waste management with application. European Journal of Operational Research, 35 (3), 350-365.

90. Graedel, T. E., 1998. Streamlined Life-Cycle Assessment. Upper Saddle River, New Jersey: Prentice Hall.

91. Graedel, T. E. and Allenby, B. R., 2003. Industrial Ecology. Upper Saddle River, New Jersey: Prentice Hall.

92. GRI, 2008. G3 Guidelines [online]. Available from: http://www.globalreporting.org/ [Accessed April 10 2008].

93. Guide, V. D. R., Jayaraman, V., Srivastava, R. and Benton, W. C., 2000. SupplyChain Management for Recoverable Manufacturing Systems. Interfaces, 30 (3), 125-142.

94. Guinée, J. B., ed., 2002, Handbook on Life Cycle Assessment, Kluwer Academic Publishers, Dordrecht, The Netherlands.

95. Gunter, K. L., 2004. Inventory and value management in demanufacturing facilites. Thesis (Ph.D.). Michigan Technological University. 
96. Harker, P. T., 1987. Derivatives of the Perron root of a positive reciprocal matrix: with application to the analytic hierarchy process. Applied Mathematics and Computation, 22 (2-3), 217-232.

97. Harker, P. T. and Vargas, L. G., 1987. THE THEORY OF RATIO SCALE ESTIMATION - SAATY ANALYTIC HIERARCHY PROCESS. Management Science, 33 (11), 1383-1403.

98. Hawken, P., Lovins, A. B. and Lovins, L. H., 1999. Natural capitalism: creating the next industrial revolution. 1st, Boston: Little, Brown and Co.

99. Herman, M. W. and Koczkodaj, W. W., 1996. A Monte Carlo study of pairwise comparison. Information Processing Letters, 57 (1), 25-29.

100. Hertwich, E. G., Pease, W. S. and Koshland, C. P., 1997. Evaluating the environmental impact of products and production processes: A comparison of six methods. The Science of the Environment, 196 (1), 13-29.

101. Hillary, R., 2004. Environmental management systems and the smaller enterprise. Journal of Cleaner Production, 12 (6), 561-569.

102. Holmberg, K. and Ling, J., 1997. Lagrangean heuristic for the facility location problem with staircase costs. European Journal of Operational Research, 97 (1), 63-74.

103. Houghton, J. T., Ding, Y., Griggs, D. J., Noguer, M., van der Linden, P. J., Dai, X., Maskell, K., Johnson, C. A. and Trenberth, K., ed., 2001, Climate Change 2001: The Scientific Basis, IPCC Third Assessment Report, Intergovernmental Panel on Climate Change, Geneva, Switzerland.

104. Huijbregts, M. A. J., Geelen, L. M. J., Hertwich, E. G., McKone, T. E. and van de Meent, D., 2005. A comparison between the mutlimedia fate and exposure models CalTOX and Uniform System for Evaluation of Substances adapted for life-cycle assessment based on the popoulation intake fraction of toxic pollutants. Environmental Toxicology and Chemistry, 24 (2), 486-493.

105. Huijbregts, M. A. J., Lundi, S., McKone, T. E. and Van de Meent, D., 2003. Geographical scenario uncertainty in generic fate and exposure factors of toxic pollutants for life-cycle impact assessment. Chemosphere, 51 (6), 501-508.

106. Hutton, D., 2008. Dirty greasy money; The value of restaurant grease has doubled in the last year. , The Globe and Mail, August 2, 1,

107. International Labour Organization (ILO), 2009. International Labour Standards [online]. Available from: www.ilo.org [Accessed February 11 2009]. 
108. International Organization for Standardization (ISO), 1998, "ISO 14041:

Environmental management -- Life cycle assessment -- Goal and scope definition and inventory analysis," International Organization for Standardization (ISO), Geneva, Switzerland.

109. International Organization for Standardization (ISO), 2000a, "ISO 14042: Environmental management -- Life cycle assessment -- Life cycle impact assessment," International Organization for Standardization (ISO), Geneva, Switzerland.

110. International Organization for Standardization (ISO), 2000b, "ISO 14043: Environmental management -- Life cycle assessment -- Life cycle interpretation," International Organization for Standardization (ISO), Geneva, Switzerland.

111. International Organization for Standardization (ISO), 2006a, "ISO 14040:

Environmental management -- Life cycle assessment -- Principles and framework," International Organization for Standardization (ISO), Geneva, Switzerland.

112. International Organization for Standardization (ISO), 2006b, "ISO 14044: Environmental management -- Life cycle assessment -- Requirements and guidelines," International Organization for Standardization (ISO), Geneva, Switzerland.

113. Ishizaka, A. and Lusti, M., 2006. How to derive priorities in AHP: a comparative study. Central European Journal of Operations Research, 14 (4), 387-400.

114. Jansen, B. and Vercalsteren, A., 2001, December, "Eco-KIT: web based EcoDesign Toolbox for SMEs " 2nd International Symposium on Environmentally Conscious Design and Inverse Manufacturing (EcoDesign'01), Tokyo, Japan, pp. 234-239.

115. Jarrell, S. L., Shoesmith, G. and Robbins, J. N., 2006. Law and Economics of Regulating Local Economic Development Incentives. Wake Forest Law Review, 41 (3), 805-835.

116. Jayaraman, V., Guide, V. D. R., Jr. and Srivastava, R., 1999. A closed-loop logistics model for remanufacturing. Journal of the Operational Research Society, 50 (5), 497-508.

117. Jelavich, M., 2001. Manufacturing and Rural Economies in the United States: The Role of Nondurable Producers, Labor Costs and State Taxes. American Journal of Economics and Sociology, 60 (1), 185-192. 
118. Jolliet, O., Margni, M., Charles, R., Humbert, S., Payet, J., Rebitzer, G. and Rosenbaum, R., 2003. IMPACT 2002+: A New Life Cycle Impact Assessment Methodology. International Journal of Life Cycle Assessment, 8 (6), 324-330.

119. Jung, E. J., Kim, J. S. and Rhee, S. K., 2001. The measurement of corporate environmental performance and its application to the analysis of efficiency in oil industry. Journal of Cleaner Production, 9 (6), 551-563.

120. Kates, R. W., Clark, W. C., Corell, R., Hall, J. M., Jaeger, C. C., Lowe, I., McCarthy, J. J., Schellnhuber, H. J., Bolin, B., Dickson, N. M., Faucheux, S., Gallopin, G. C., Grubler, A., Huntley, B., Jager, J., Jodha, N. S., Kasperson, R. E., Mabogunje, A., Matson, P., Mooney, H., Moore, I. B., O'Riordan, T. and Svedin, U., 2001. Environment and development: Sustainability science. Science, 292 (5517), 641-642.

121. Kates, R. W., Parris, T. M. and Leiserowitz, A. A., 2005. What is sustainable development? Goals, indicators, values, and practice. . Environment, 47 (3), 9-21.

122. Kawamoto, K., MacLeod, M. and Mackay, D., 2001. Evaluation and comparison of multimedia mass balance models of chemical fate: Application of EUSES and ChemCAN to 68 chemicals in Japan. Chemosphere, 44 (4), 599-612.

123. Keoleian, G. A. and Menery, D., 1993. Life cycle design guidance manual. EPA, Washington, D.C., U.S. Government Publishing Office.

124. Kodali, R. and Routroy, S., 2006. Decison Framework for Selection of Facilites Location in Competitive Supply Chain. Journal of Advanced Manufacturing Systems, 5 (1), 89-110.

125. Kolsch, D., Saling, P., Kicherer, A., Grosse-Sommer, A. and Schmidt, I., 2008. How to measure social impacts? A socio-eco-efficiency analysis by the SEEBALANCE [registered trademark] method. International Journal of Sustainable Development, 11 (1), 1-23.

126. Kowalski, K., Stagl, S., Madlener, R. and Omann, I., 2009. Sustainable energy futures: Methodological challenges in combining scenarios and participatory multi-criteria analysis. European Journal of Operational Research, 197 (3), 10631074.

127. Krajnc, D. and Glavic, P., 2005. A model for integrated assessment of sustainable development. Resources, Conservation and Recycling, 43 (2), 189-208.

128. Krikke, H., Bloemhof-Ruwaard, J. and Van Wassenhove, L. N., 2003. Concurrent product and closed-loop supply chain design with an application to refrigerators. International Journal of Production Research, 41 (16), 3689-3719. 
129. Krikke, H., van Harten, A. and Schuur, P. C., 1999a. Business case Océ: reverse logistic network re-design of copiers. OR Spektrum, 21 (3), 381-409.

130. Krikke, H., van Harten, A. and Schuur, P. C., 1999b. Business case Océ: reverse logistic network re-design of copiers. OR Spectrum, 21 (3), 381-409.

131. Kumar, V., Shirodkar, P. S., Camelio, J. A. and Sutherland, J. W., 2007. Value flow characterization during product lifecycle to assist in recovery decisions. International Journal of Production Research, 45 (18-19), 4555-4572.

132. Lane, E. F. and Verdini, W. A., 1989. A Consistency Test for AHP Decision Makers. Decision Sciences, 20 (3), 575-590.

133. Leskinen, P. and Kangas, J., 2005. Rank reversals in multi-criteria decision analysis with statistical modelling of ratio-scale pairwise comparisons. The Journal of the Operational Research Society, 56 (7), 855-861.

134. Lewis, H. and Gertsakis, J., 2001. Design + environment: A global guide to designing greener goods. Sheffield: Greenleaf.

135. Li, F., Liu, X., Hu, D., Wang, R., Yang, W., Li, D. and Zhao, D., 2009. Measurement indicators and an evaluation approach for assessing urban sustainable development: A case study for China's Jining City. Landscape and Urban Planning, 90 (3-4), 134-142.

136. Life Cycle Systems Group, 2005. The LCIA toxicity model IMPACT 2002 [online]. EPFL-GECOS (Ecosystem Management Laboratory). Available from: http://gecos.epfl.ch/lcsystems/Fichiers_communs/Recherche/IMPACT2002.html [Accessed October 17 2006].

137. Lin, R., Lin, J. S.-J., Chang, J., Tang, D., Chao, H. and Julian, P. C., 2008. Note on group consistency in analytic hierarchy process. European Journal of Operational Research, 190 (3), 672-678.

138. LoopNet, 2009. Find a Property for Sale or For Lease [online]. Available from: http://www.loopnet.com/ [Accessed July 11, 2009].

139. Louwers, D., Kip, B. J., Peters, E., Souren, F. and Flapper, S. D. P., 1999. Facility location allocation model for reusing carpet materials. Computers and Industrial Engineering, 36 (4), 855-869.

140. Luetkenhorst, W., 2004. Corporate social responsibility and the development agenda. Intereconomics, 39 (3), 157-166. 
141. Lyons, D. I., 2007. A Spatial Analysis of Loop Closing Among Recycling, Remanufacturing, and Waste Treatment Firms in Texas. Journal of Industrial Ecology, 11 (1), 43-54.

142. Mackay, D., Paterson, S., Di Guardo, A. and Cowan, C. E., 1996. Evaluating the Environmental Fate of a Variety of Types of Chemicals Using the EQC Model. Environmental Toxicology and Chemistry, 15 (9), 1627- 1637.

143. Mackay, D., Paterson, S. and Shiu, W. Y., 1992. Generic models for evaluating the regional fate of chemicals. Chemosphere, 24 (6), 695-717

144. MacLeod, M., Bennett, D. H., Perem, M., Maddalena, R. L., McKone, T. E. and Mackay, D., 2004. Dependence of intake fraction on release location in a multimedia framework: A case study of four contaminants in North America. Journal of Industrial Ecology, 8 (3), 89-102.

145. MacLeod, M. and Mackay, D., 1999. An Assessment of the environmental fate and exposure of benzene and the chlorobenzenes in Canada. Chemosphere, 38 (8), 1777-1796.

146. MacLeod, M. and MacKay, D., 2004. Modeling transport and deposition of contaminants to ecosystems of concern: A case study for the Laurentian Great Lakes. Environmental Pollution, 128 (1-2), 241-250.

147. Matthies, M., Berding, V. and Beyer, A., 2004. Probabilistic uncertainty analysis of the European Union System for the Evaluation of Substances multimedia regional distribution model. Environmental Toxicology and Chemistry, 23 (10), 2494-2502.

148. McCool, S. F. and Stankey, G. H., 2004. Indicators of Sustainability: Challenges and Opportunities at the Interface of Science and Policy Environmental Management, 33 (3), 294-305.

149. McDonough, W. and Braungart, M., 2002. Cradle to cradle: Remaking the way we make things. New York: North Point Press.

150. McKone, T. E., 1993a, "CalTOX, a multimedia total-exposure model for hazardous-waste sites part I: executive summary," UCRL-CR-111456PtI, Lawrence Livermore National Laboratory, Livermore, CA. http://www.dtsc.ca.gov/AssessingRisk/upload/techman1-2.pdf

151. McKone, T. E., 1993b, "CalTOX, a multimedia total-exposure model for hazardous-waste sites part II: the dynamic multimedia transport and transformation model," UCRL-CR-111456PtII, Lawrence Livermore National 
Laboratory, Livermore, CA.

http://www.dtsc.ca.gov/AssessingRisk/upload/techman2.pdf

152. McKone, T. E., 1993c, "CalTOX, a multimedia total-exposure model for hazardous-waste sites part III: the multi-pathway exposure model," UCRL-CR111456PtIII, Lawrence Livermore National Laboratory, Livermore, CA. http://www.dtsc.ca.gov/AssessingRisk/upload/techman3.pdf

153. McKone, T. E., 1994, June 19-24, "CAirTOX, An Inter-Media Transfer Model for Assesssing Indirect Exposures to Hazardous Air Contaminants," Air \& Waste Management Association 87th Annual Meeting and Exhibition, Cincinatti, pp. 1-16.

154. McKone, T. E. and MacLeod, M., 2003a. Tracking multiple pathways of human exposure to persistent multimedia pollutants: Regional, continental, and globalscale models. Annual Review of Environment and Resources, 28463-492.

155. McKone, T. E. and MacLeod, M., 2003b. Tracking Multiple Pathways of Human Exposure to Persistent Multimedia Pollutants: Regional, Continental, and GlobalScale Models. In: Annual Review of Environment and Resources. 463-492.

156. McKone, T. E. and Small, M. J., 2007. Integrated Environmental Assessment Part III: Exposure Assessment. Journal of Industrial Ecology, 11 (1), 4-7.

157. Mikhailov, L., 2004. Group prioritization in the AHP by fuzzy preference programming method. Computers \& Operations Research, 31 (2), 293-301.

158. Morana, R. and Seuring, S., 2007. End-of-life returns of long-lived products from end customer - insights from an ideally set up closed-loop supply chain. International Journal of Production Research, 45 (18), 4423-4437.

159. Moreno-Jiménez, J. M., Aguar ón, J. and Escobar, M. T., 2008. The core of consistency in AHP-group decision making. Group Decision and Negotiation, 17 (3), 249-265.

160. Muñoz, M. J., Rivera, J. M. and Moneva, J. M., 2008. Evaluating sustainability in organisations with a fuzzy logic approach. Industrial Management \& Data Systems, 108 (6), 829-841.

161. Narula, S. C., Ogbu, U. I. and Haakon, M. S., 1977. An Algorithm for the pMedian Problem. Operations Research, 25 (4), 709-713.

162. National Center for Environmental Assessment, 1989. Exposure Factors Handbook. Washington, D.C.: U.S. Environmental Protection Agency. 
163. Nema, A. K. and Gupta, S. K., 2003. Multiobjective Risk Analysis and Optimization of Regional Hazardous Waste Management System. Practice Periodical of Hazardous, Toxic, and Radioactive Waste Management, 7 (2), 6977.

164. Nickel, S. and Puerto, J., 2005. Location theory: A unified approach. Berlin: Springer.

165. NJ Business, 2009. Job Creation \& Retention Incentive Programs [online]. State of New Jersey. Available from:

http://www.state.nj.us/njbusiness/financing/incentive/beip_brrag.shtml [Accessed July 1 2009].

166. O'Connor, M. and Spangenberg, J. H., 2008. A methodology for CSR reporting: assuring a representative diversity of indicators across stakeholders, scales, sites and performance issues. Journal of Cleaner Production, 16 (13), 1399-1415.

167. Occupational Safety \& Health Administration (OSHA), 2009. Regulations (Standards - 29 CFR) [online]. U.S. Department of Labor. Available from: www.osha.gov [Accessed February 10 2009].

168. Ostrom, E., 1990. Governing the Commons: The evolution of institutions for collective action. Cambridge: Cambridge University Press.

169. Pennington, D. W., Margni, M., Ammann, C. and Jolliet, O., 2005. Multimedia fate and human intake modeling: Spatial versus nonspatial insights for chemical emissions in Western Europe. Environmental Science and Technology, 39 (4), 1119-1128.

170. Pré Consultants, 2006a. Eco-Indicator 99 [online]. Available from: http://www.pre.nl/eco-indicator99/eco-indicator_99_introduction.htm [Accessed May 18 2006 ].

171. Pré Consultants, 2006b. SimaPro 7.1 Multi User [online]. Pré Consultants,. Available from: http://www.pre.nl/simapro/simapro_lca_software.htm [Accessed October 15, 2007].

172. Prevedouros, K., MacLeod, M., Jones, K. C. and Sweetman, A. J., 2004. Modelling the fate of persistent organic pollutants in Europe: Parameterisation of a gridded distribution model. Environmental Pollution, 128 (1-2), 251-261.

173. Quariguasi Frota Neto, J., Bloemhof-Ruwaard, J. M., van Nunen, J. A. E. E. and van Heck, E., 2007a. A methodology for assessing eco-efficiency in logistics networks. European Journal of Operational Research, 111 (2), 195-208. 
174. Quariguasi Frota Neto, J., Bloemhof-Ruwaard, J. M., van Nunen, J. A. E. E. and van Heck, E., 2007b. Designing and evaluating sustainable logistics networks. International Journal of Production Economics, 111 (2), 195-208.

175. Ramanathan, R. and Ganesh, L. S., 1994. Group preference aggregation methods employed in AHP: An evaluation and an intrinsic process for deriving members' weightages. European Journal of Operational Research, 79 (2), 249-265.

176. Realff, M. J., Ammons, J. C. and Newton, D., 1999. Carpet recycling: determining the reverse production system design. Polymer-Plastics Technology and Engineering, 38 (3), 547-567.

177. Realff, M. J., Ammons, J. C. and Newton, D., 2000. Strategic design of reverse production systems. Computers and Chemical Engineering, 24 (2), 991-996.

178. Reap, J., Bras, B., Newcomb, P. J. and Carmichael, C., 2003, September, "Improving life cycle assessment by including spatial, dynamic and place-based modeling," Proceedings of ASME 2003 Design Engineering Technical Conference, ASME 2003 Design Engineering Technical Conference, Chicago, Illinois, pp. 77-83.

179. Reap, J., Bras, B., Realff, M. J. and Carmichael, C., 2004, September, "Using ecosystem landscape models to investigate industrial environmental impacts," Proceedings of the ASME 2004 Design Engineering Technical Conference, ASME 2004 Design Engineering Technical Conference, Salt Lake City, Utah, pp. 965-970.

180. Redmond, J., Walker, E. and Wang, C., 2008. Issues for small businesses with waste management. Journal of Environmental Management, 88 (2), 275-285.

181. Renner, R., 1995. Predicting Chemical Risks with Multimedia Fate Models. Environmental Science \& Technology, 29 (12), 556-559.

182. Rigby, D. K. and Vishwanath, V., 2006. LOCALIZATION: THE REVOLUTION IN CONSUMER MARKETS. Harvard Business Review, 84 (4), 82-92.

183. Rosenbaum, R. and Margni, M., 2004, "Analysis and comparison of prioritised methods IMPACT 2002, CalTOX 4.0, USES-LCA and EDIP for generic organic chemicals," http://www.omniitox.net/Results/Deliverables/D28A\%20final.pdf

184. Royte, E., 2005. Garbage Land: On the Secret Trail of Trash. New York Little, Brown.

185. RSMeans, 2009. CostWorks [online]. Reed Construction Data. Available from: http://www.meanscostworks.com/ [Accessed July 9 2009]. 
186. Saaty, T. L., 1980. The Analytical Hierarchy Process. New York: McGraw-Hill.

187. Saaty, T. L., 1986. AXIOMATIC FOUNDATION OF THE ANALYTIC HIERARCHY PROCESS. Management Science, 32 (7), 841-855.

188. Saaty, T. L., 1990. AN EXPOSITION OF THE AHP IN REPLY TO THE PAPER REMARKS ON THE ANALYTIC HIERARCHY PROCESS. Management Science, 36 (3), 259-268.

189. Saaty, T. L., 1994a. Fundamentals of decision making and priority theory with the analytic hierarchy process. Pittsburgh, PA: RWS Publications.

190. Saaty, T. L., 1994b. HIGHLIGHTS AND CRITICAL-POINTS IN THE THEORY AND APPLICATION OF THE ANALYTIC HIERARCHY PROCESS. European Journal of Operational Research, 74 (3), 426-447.

191. Saaty, T. L., 1996. Decision making with dependence and feedback: The analytic network process : the organization and prioritization of complexity. Pittsburgh, PA: RWS Publications.

192. Saaty, T. L., 2003. Decision-making with the AHP: Why is the principal eigenvector necessary. European Journal of Operational Research, 145 (1), 85-91.

193. Saaty, T. L. and Hu, G., 1998. Ranking by eigenvector versus other methods in the analytic hierarchy process. Applied Mathematics Letters, 11 (4), 121-125.

194. Savaskan, R. C., Bhattacharya, S. and Van Wassenhove, L. N., 2004. ClosedLoop Supply Chain Models with Product Remanufacturing. Management Science, 50 (2), 239-252.

195. Schmidt-Bleek, F. and Klüting, R., 1994. viel Umwelt braucht der Mensch?: MIPS, das Mass für ökologisches Wirtschaften. Berlin: Birkhäuser Verlag.

196. Seid, D., 2007. Automaker-state partnership helped to cement deal, Knight Ridder Tribune Business News, February 28, 1,

197. Shonnard, D. R. and Hiew, D. S., 2000. Comparative Environmental Assessments of VOC Recovery and Recycle Design Alternatives for a Gaseous Waste Stream. Environmental Science \& Technology, 34 (24), 5222-5228.

198. Shonnard, D. R., Kicherer, A. and Saling, P., 2003. Industrial Applications Using BASF Eco-Efficiency Analysis: Perspectives on Green Engineering Principles. Environmental Science and Technology, 37 (23), 5340-5348.

199. Shuman, M. H., 1998. Going Local: Creating Self-Reliant Communities in a Global Age. New York: The Free Press. 
200. Sikdar, S. K., 2003. Sustainable development and sustainability metrics. AIChE Journal, 49 (8), 1928-1932.

201. Simmons, P. and Walker, G., 2005. Living with Technological Risk: Industrial Encroachment on Sense of Place. In: Boholm, A. and Löfstedt, R. E., eds. Facility Siting: Risk, Power and Identity in Land Use Planning London: Earthscan Publications Ltd., 90-106.

202. Singh, R. K., Murty, H. R., Gupta, S. K. and Dikshit, A. K., 2007. Development of composite sustainability performance index for steel industry. Ecological Indicators, 7 (3), 565-588.

203. Singh, R. K., Murty, H. R., Gupta, S. K. and Dikshit, A. K., 2009. An overview of sustainability assessment methodologies. Ecological Indicators, 9 (2), 189-212.

204. Snyder, L. V., Daskin, M. S. and Teo, C.-P., 2007. The stochastic location model with risk pooling. European Journal of Operational Research, 179 (3), 1221-1238.

205. Social Accountability International, 2001. Social Accountability 8000 (SA8000) Standard [online]. Available from: http://www.sa-intl.org [Accessed February 6 2009].

206. Sonnemann, G., Schuhmacher, M. and Castells, F., 2002. Integrated Life-Cycle and Risk Assessment for Industrial Processes. Boca Raton, Florida: CRC Press.

207. Spangenberg, J. H., 2008. Second order governance: learning processes to identify indicators. Corporate Social Responsibility and Environmental Management, 15 (3), 125-139.

208. Spangenberg, J. H. and Bonniot, O., 1998. Sustainability indicators - A Compass on the road towards Sustainability. Wuppertal, Germany, Wuppertal Institute for Climate, Environment, Energy. http://www.ulb.ac.be/ceese/STAFF/Tom/spangenberg.pdf

209. Spengler, T., Puchert, H., Penkuhn, T. and Rentz, O., 1997. Environmental integrated production and recycling management. European Journal of Operational Research, 97 (2), 308-326.

210. Srdjevic, B., 2005. Combining different prioritization methods in the analytic hierarchy process synthesis. Computers \& Operations Research, 32 (7), 18971919.

211. Staikos, T. and Rahimifard, S., 2007. A decision-making model for waste management in the footwear industry International Journal of Production Research, 45 (18), 4403-4422. 
212. Struijs, J. and Peijnenburg, W., 2002, "Predictions by the multimedia environmental fate model SimpleBox compared to field data: Intermedia concentration ratios of two phthalate esters," 607220008, Netherlands Environmental Assessment Agency (RIVM), Bilthoven. http://www.rivm.nl/bibliotheek/rapporten/607220008.pdf

213. Su, Y. and Wania, F., 2005. Does the forest filter effect prevent semivolatile organic compounds from reaching the arctic? Environmental Science and Technology, 39 (18), 7185-7193.

214. Sun, J. and Gu, Y., 2002. A Parametric Approach for a Nonlinear Discrete Location Problem. Journal of Combinatorial Optimization, 6 (2), 119-132.

215. SustainLane, 2009. 2008 US City Rankings [online]. SustainableCircles Corporation. Available from: http://www.sustainlane.com/us-city-rankings/ [Accessed February 23 2009].

216. Sutherland, J. W., Adler, D. P., Haapala, K. R. and Kumar, V., 2008. A comparison of manufacturing and remanufacturing energy intensities with application to diesel engine production. CIRP Annals - Manufacturing Technology, 57 (1), 5-8.

217. Sutherland, J. W., Gunter, K. L. and Weinmann, K. J., 2002. A model for improving economic performance of a demanufacturing system for reduced product end-of-life environmental impact. Annals of CIRP, 51 (1), 45-48.

218. Swisher, M. E., Rezola, S. and Sterns, J., 2006, "Sustainable Community Development Step 4: Develop Sustainability Indicators to Measure Progress," \#FCS7217-Eng, Family Youth and Community Sciences Department, Florida Cooperative Extension Service, Institute of Food and Agricultural Sciences, University of Florida, Tallahassee, FL. http://edis.ifas.ufl.edu/CD029

219. Tadei, R., Ricciardi, N. and Perboli, G., 2009. The stochastic p-median problem with unknown cost probability distribution. Operations Research Letters, 37 (2), 135-141.

220. Teitz, M. B. and Bart, P., 1968. Heuristic Methods for Estimating the Generalized Vertex Median of a Weighted Graph. Operations Research, 16 (5), 955-961.

221. ten Berge, W. F., 1994, "HAZCHEM: A Mathematical Model for Use in Risk Assessment of Substances," 8, European Centre for Ecotoxicology and Toxicology of Chemicals, Brussels.

222. The Timberland Company, 2007, "2006 Corporate Social Responsibility Report," http://www.timberland.com/corp/index.jsp?page=csroverview 
223. Thierry, M., Salomon, M., van Nunen, J. and van Wassenhove, L. N., 1995. Strategic Issues in Product Recovery Management. California Management Review, 37 (2), 114-135.

224. Toose, L., Woodfine, D. G., MacLeod, M., Mackay, D. and Gouina, J., 2004. BETR-World: a geographically explicit model of chemical fate: application to transport of a-HCH to the Arctic. Environmental Pollution, 128 (1), 223-240.

225. Tsai, W.-H. and Chou, W.-C., 2009. Selecting management systems for sustainable development in SMEs: A novel hybrid model based on DEMATEL, ANP, and ZOGP. Expert Systems with Applications, 36 (2 PART 1), 1444-1458.

226. U.S. Bureau of Labor Statistics, 2009. May 2008 Metropolitan and Nonmetropolitan Area Occupational Employment and Wage Estimates [online]. Occupational Employment Statistics. Available from: [Accessed July 1, 2009].

227. U.S. Census Bureau, 2007a. 2007 Economic Census [online]. Available from: http:/www.census.gov/econ/census07/ [Accessed May 20 2009].

228. U.S. Census Bureau, 2008. 2005-2007 American Community Survey 3-Year Estimates B08135. Aggregate Travel Time to Work (in Minutes) of Workers by Travel Time to Work. American FactFinder, http://factfinder.census.gov/, Washington DC, U.S. Census Bureau.

229. U.S. Census Bureau, 2009. 2007 MSA Business Patterns (NAICS) [online]. U.S. Census Bureau. Available from: http://censtats.census.gov/cgibin/msanaic/msasel.pl [Accessed July 1, 2009].

230. U.S. Census Bureau - Population Division, 2009. Table 2. Annual Estimates of the Population of Combined Statistical Areas: April 1, 2000 to July 1, 2008. Excel, CBSA-EST2008-02.xls, Washington, DC, U.S. Census Bureau.

231. U.S. Census Bureau, P. D., 2007b. Table 1. Annual Estimates of the Population of Metropolitan and Micropolitan Statistical Areas: April 1, 2000 to July 1, 2006. . Washington, D.C., U.S. Census Bureau. http:/www.census.gov/population/www/estimates/CBSA-est2006-annual.html

232. U.S. Economic Census, 2009a. Sector 42: Wholesale Trade: NAICS 42313: Tire $\&$ tube merchant wholesalers: Geographic Area Series: Summary Statistics: 2002 [online]. U.S. Census Bureau in American FactFinder. Available from: http://factfinder.census.gov [Accessed June 1, 2009].

233. U.S. Economic Census, 2009b. Sector 54: Professional, Scientific, and Technical Services: NAICS 541850: Display Advertising: Geographic Area Series: 
Summary Statistics: 2002 [online]. U.S. Census Bureau in American FactFinder. Available from: http://factfinder.census.gov [Accessed June 1, 2009].

234. U.S. Environmental Protection Agency, 2007a. Toxics Release Inventory (TRI) Program [online]. U.S. Environmental Protection Agency. Available from: http://www.epa.gov/tri/ [Accessed April 11 2007].

235. U.S. Environmental Protection Agency, 2007b. TRI Explorer [online]. U.S. Environmental Protection Agency. Available from: http://www.epa.gov/triexplorer/ [Accessed October 15 2007].

236. U.S. Environmental Protection Agency, 2009a. Ecological Structure Activity Relationships (ECOSAR) [online]. U.S. Environmental Protection Agency. Available from: http://www.epa.gov/oppt/newchems/tools/21 ecosar.htm [Accessed July 18 2009].

237. U.S. Environmental Protection Agency, 2009b. Integrated Risk Information System (IRIS) [online]. U.S. Environmental Protection Agency. Available from: http://www.epa.gov/iris/index.html [Accessed July 18 2009].

238. U.S. Environmental Protection Agency (EPA), 2009. EPI Suite (TM) http://www.epa.gov/oppt/exposure/pubs/episuitedl.htm

239. U.S. National Library of Medicine, 2009. TOXNET: Toxicology Data Network [online]. National Institute of Health. Available from: http://toxnet.nlm.nih.gov/ [Accessed January 15 2009].

240. Ugwu, O. O. and Haupt, T. C., 2007. Key performance indicators and assessment methods for infrastructure sustainability--a South African construction industry perspective. Building and Environment, 42 (2), 665-680.

241. Ugwu, O. O., Kumaraswamy, M. M., Wong, A. and Ng, S. T., 2006. Sustainability appraisal in infrastructure projects (SUSAIP): Part 1. Development of indicators and computational methods. Automation in Construction, 15 (2), 239-251.

242. UN, 2003. Johannesburg Declaration on Sustainable Development and Plan of Implementation of the World Summit on Sustainable Development. Johannesburg, South Africa: United Nations Department of Public Information.

243. UN DSD, 2009. Expert Group Meeting on Indicators of Sustainable Development [online]. Available from: http://www.un.org/esa/dsd/dsd_aofw_ind/ind_meetwork.shtml [Accessed February 18 2009]. 
244. UNCSD, 2001, " Indicators of Sustainable Development: Guidelines and Methodologies.," New York.

http://www.un.org/esa/sustdev/natlinfo/indicators/indisd/indisd-mg2001.pdf

245. UNEP DTIE Production and Consumption Unit, 2003, "Evaluation of environmental impacts in life cycle assessment," United Nations Environment Programme Division of Technology, Industry and Economics Paris.

246. United Nations (UN), 1948. The Universal Declaration of Human Rights [online]. United Nations (UN),. Available from: http://www.un.org/Overview/rights.html [Accessed February 10 2009].

247. United Nations Division for Sustainable Development (UN DSD), 2009. Expert Group Meeting on Indicators of Sustainable Development [online]. Available from: http://www.un.org/esa/dsd/dsd_aofw_ind/ind_meetwork.shtml [Accessed February 18 2009].

248. United Parcel Service of America, 2009. Worldwide Facts [online]. Available from: http://www.ups.com/content/us/en/about/facts/worldwide.html [Accessed June 15 2009].

249. van de Meent, D., 1993, "Simplebox: a generic multimedia fate evaluation model," 672720 001, RIVM, Biltohoven, The Netherlands.

250. Van Den Honert, R. C. and Lootsma, F. A., 1996. Group preference aggregation in the multiplicative AHP. The model of the group decision process and Pareto optimality. European Journal of Operational Research, 96 (2), 363-370.

251. Vanclay, F., 2006. Principles for social impact assessment: A critical comparison between the international and US documents. Environmental Impact Assessment Review, 26 (1), 3-14.

252. Vargas, L. G., 1990. AN OVERVIEW OF THE ANALYTIC HIERARCHY PROCESS AND ITS APPLICATIONS. European Journal of Operational Research, 48 (1), 2-8.

253. Vargas, L. G., 1994. Reply to Schenkerman's avoiding rank reversal in AHP decision support models. European Journal of Operational Research, 74 (3), 420425.

254. Veleva, V. and Ellenbecker, M., 2001. Indicators of sustainable production: framework and methodology. Journal of Cleaner Production, 9 (6), 519-549. 
255. Wackernagel, M., 1994. Ecological footprint and appropriated carrying capacity: a tool for planning toward sustainability. Thesis (Doctoral). University of British Columbia.

256. Whelan, G., Buck, J. W., Strenge, D. L., Droppo Jr., J. G., Hoopes, B. L. and Aiken, R. J., 1992. Overview of the multimedia environmental pollutant assessment system (MEPAS). Hazardous Waste \& Hazardous Materials, 9 (2), 191-208.

257. Whitehouse, M., 2007. For Some Manufacturers, There Are Benefits to Keeping Production at Home, The Wall Street Journal, January 22, 2,

258. Woodfine, D., MacLeod, M. and Mackay, D., 2002. A regionally segmented national scale multimedia contaminant fate model for Canada with GIS data input and display. Environmental Pollution, 119 (3), 341-355.

259. World Bank, 1996. The World Bank participation sourcebook. Washington, D.C.: World Bank.

260. World Commission on Environment and Development, 1987. Our Common Future. Oxford: Oxford University Press.

261. Wright, H. E., Zhang, Q. and Mihelcic, J. R., 2008. Integrating economic inputoutput life cycle assessment with risk assessment for a screening-level analysis. International Journal of Life Cycle Assessment, 13 (5), 412-420.

262. Xu, Z. and Wei, C., 1999. Consistency improving method in the analytic hierarchy process. European Journal of Operational Research, 116 (2), 443-449.

263. Zhang, Q., Crittenden, J. C. and Mihelcic, J. R., 2001. Does Simplifying Transport and Exposure Yield Reliable Results? An Analysis of Four Risk Assessment Methods. Environmental Science and Technology, 35 (6), 1282-1288.

264. Zhang, Q., Crittenden, J. C., Shonnard, D. and Mihelcic, J. R., 2003. Development and evaluation of an environmental multimedia fate model CHEMGL for the Great Lakes region. Chemosphere, 50 (10), 1377-1397.

265. Zhou, P., Ang, B. W. and Poh, K. L., 2007. A mathematical programming approach to constructing composite indicators. Ecological Economics, 62 (2), 291-297. 


\section{Vita}

Abigail R. Clarke-Sather (nee Clarke) was born to Sandra S. and Roger C. Clarke on May 1, 1982 in Minneapolis, Minnesota. She graduated from Earlham College in Richmond, Indiana with College Honors for her B.A. in Physics (2004) and completed her M.S.M.E. (2006) at Michigan Technological University. Her doctoral research as an NSF IGERT Trainee in the Michigan Tech and Southern University Sustainable Futures IGERT addressed the sustainability of facility location analysis and decision-making. As a Trainee, she was a doctoral exchange student in the Ph.D. program in Public Policy at Southern (2007). Clarke-Sather was an intern and then Sustainability Project Manager at the International Center for Appropriate \& Sustainable Technology in Lakewood, Colorado (2007-2008). She also served as Sustainability Engineer at Ecologic Designs in Boulder, Colorado (2008-2009). Clarke-Sather has published a book chapter, an encyclopedia entry, 2 articles in conference proceedings, and helped co-author 2 other conference proceedings. She has presented at conferences in the U.S. and abroad. ClarkeSather has been recognized for her achievements with several awards, including the 2007 Best Small/Medium Enterprise Sustainability Report from Corporate Register and an American Association of University Women's Selected Professionals Engineering Dissertation Fellowship. 